\title{
Pesticide-Induced Environmental Risks: \\ A field study in Ghana
}

Michael Onwona-Kwakye 


\section{Thesis committee}

\section{Promotor}

Prof. Dr Paul J. van den Brink

Personal chair, Aquatic Ecology and Water Quality Management

Wageningen University \& Research

\section{Co-promotor}

Dr Jonathan Hogarh

Environmental Scientist

Kwame Nkrumah University of Science and Technology

Kumasi, Ghana

\section{Other Members}

Prof. Dr Peter Oosterveer

Wageningen University \& Research

Dr Joost Lahr

National Institute for Public Health and the Environment (RIVM), Bilthoven

Prof. Dr Martina Vijver Leiden University

Dr Michiel Daam

New University of Lisbon, Portugal

This research was conducted under the auspices of the Graduate School for Socio-Economic and Natural Sciences of the Environment (SENSE). 


\title{
Pesticide-Induced Environmental Risks: \\ A field study in Ghana
}

\author{
Michael Onwona-Kwakye
}

Thesis

Submitted in fulfilment of the requirements for the degree of doctor at Wageningen University

by the authority of the Rector Magnificus

Prof. Dr A.P.J. Mol,

in the presence of the

Thesis Committee appointed by the Academic Board

to be defended in public

on Thursday 11 June 2020

at 11.00 a.m. in the Aula. 
Michael Onwona-Kwakye

Pesticide-Induced Environmental Risks: A field study in Ghana 172 pages.

PhD thesis, Wageningen University, Wageningen, NL (2020) With references, with summary in English

ISBN: 978-94-6395-362-7

DOI: https://doi.org/10.18174/518456 
The author Michael Onwona-Kwakye was sponsored by a PhD grant from the Ghana Education Trust Fund (GETFund). Financial support from NIH R01 Grant number R01Al116914, the Molecular Basis of Infectious Diseases Training Grant from the NIH Institute of Allergy and Infectious Diseases (T32AI055449), and the Gillson-Longenbaugh Foundation for working on chapter 5 is extremely indebted. 
Dedicated to my beloved late parents,

Benson Onwona and

Faustina Asomaning

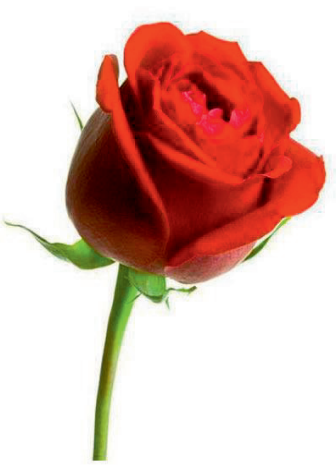




\section{Contents}

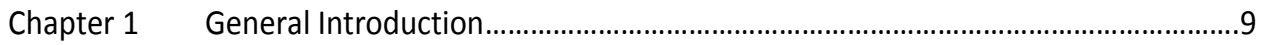

Chapter 2 Pesticide registration, distribution and use practices in Ghana.............................17

Chapter 3 Environmental risk assessment of pesticides currently applied in Ghana.............49

Chapter 4 Linking macroinvertebrates and physico-chemical parameters for water quality assessment in the lower basin of the Volta River in Ghana........................89

Chapter 5 Pesticides decrease bacterial diversity and abundance of irrigated rice fields...117

Chapter 6 General discussion and concluding remarks.........................................................137

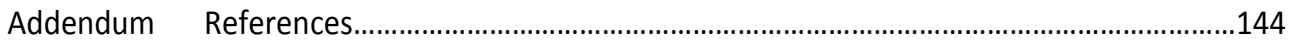

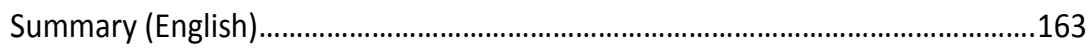

Acknowledgement........................................................................................166

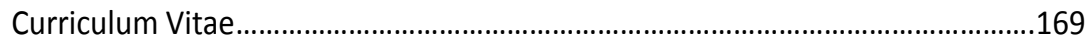

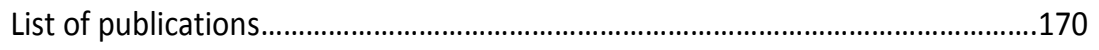

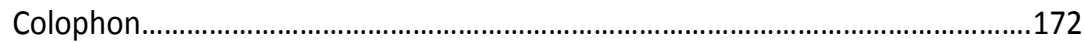




\section{Chapter 1}

General Introduction 


\section{Pesticides}

Increase in demand for food throughout the world has made farmers to increase their production base as it is expected that human population can reach about 10 billion by 2050 (UN DESA, 2017). This intensification of agriculture has resulted in the use of pesticides to grow more food on less land by protecting crops from pests, diseases and weeds as well as raising productivity per hectare. Technological advances particularly in the form of chemical products led to the creation of high efficiency pesticides and fertilizers enabling a large increase in crop yield (Carvalho, 2017). Without pesticides, more than half of our crops would be lost to pests and diseases. Between 26 and 40 percent of the world's potential crop production is lost annually because of weeds, pests and diseases (Cai, 2008; Zhang et al. 2011; OECD-FAO, 2012).

In Ghana, agriculture is one of the most important sectors of the economy contributing $30 \%$ to Gross Domestic Product (GDP) and employing more than half of its workforce who are mainly small landholders. Production of major crops has been increasing in recent years, mainly as a result of extensive cultivation in a bid to meet this challenge (MOFA, 2011). Pesticide use among farmers in Ghana has reached its peak in recent years especially for controlling weeds, pests, and preservation of harvested crops (Horna et al. 2008; Imoro et al. 2019).

Presently, throughout the globe approximately 2 million tonnes of pesticides are utilized, out of which $47.5 \%$ are herbicides, $29.5 \%$ are insecticides, $17.5 \%$ are fungicides and 5.5\% are other pesticides (De et al. 2014). Moreover, it has been estimated that by this year (2020), the global pesticide usage will increase up to 3.5 million tonnes (Zhang, 2018). In Ghana, pesticides use is similar to the global trend and there is a steady increase in importation and consumption of pesticides (Fig. 1.1).

\section{Pesticide law of Ghana}

Ghana has a legal procedure for pesticide registration, as prescribed by Part II (Pesticides Control and Management) of the Environmental Protection Agency Act, 1994 (Act 490). With this Act, a number of pesticide products have been registered for use in both agriculture and public health sectors (GEPA, CCMC 2012). The EPA has the mandate to regulate all pesticides that are sold, distributed and used in Ghana. The Act defines pesticides 
as (a) a substance or mixture of substances intended for preventing, destroying, repelling or reducing the destructive effects of pests, or (b) a substance or mixture of substances intended for use as a plant regulator, desiccant or wood preservative. It includes all of the following: herbicide, insecticide (which may include insect growth regulators, termiticides, etc.) nematicide, molluscicide, piscicide, avicide, rodenticide, bactericide, insect repellent, animal repellent, antimicrobial, and fungicide. The objective of regulating pesticides is to protect society from the adverse effects of pesticides without denying access to the benefits of their use. Registration of pesticides enables authorities to exercise control over quality, use levels, claims, labelling, packaging, advertising, and disposal of pesticides, thus ensuring that the interests of end-users are properly protected. Apart from the registration of pesticides, the Act provides requirements for pesticide dealership and safeguards for the safe use of pesticides. Registration of pesticides started in 2003 , and opened a new economic boom with a resultant increase in registration and importation of pesticide products for use in Ghana (Fig. 1.1).

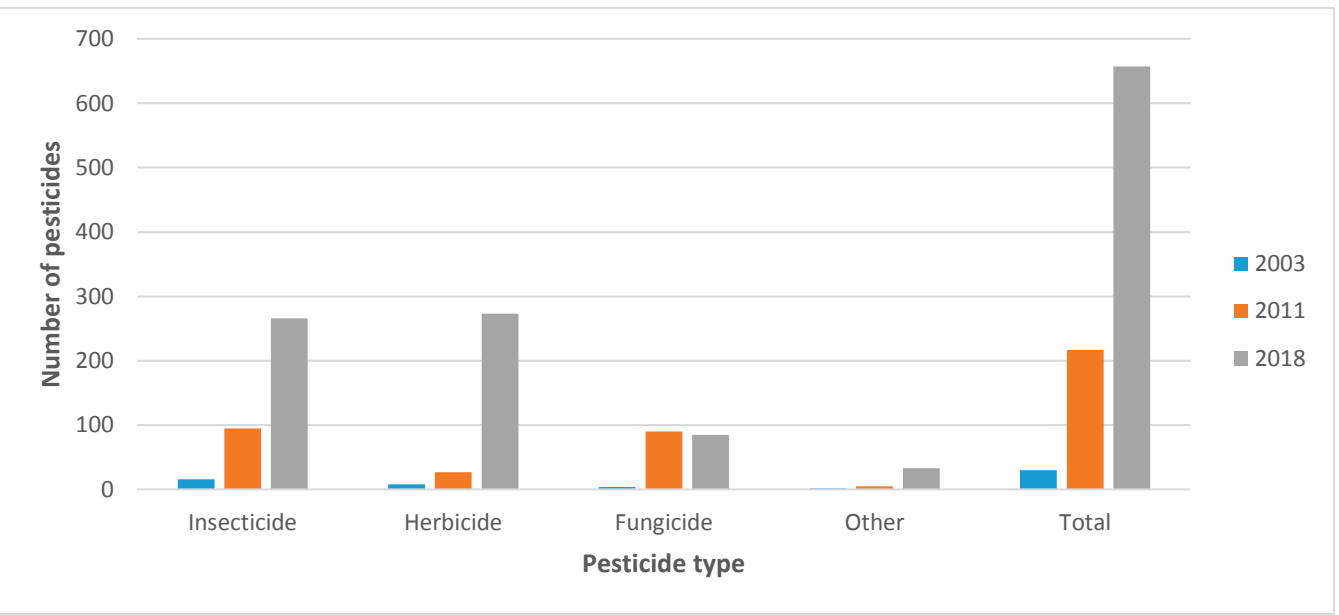

Figure 1.1: Number of formulated pesticide products registered/provisionally cleared in Ghana (2003-2018).

"Other" includes rodenticides, nematicides, fumigants and other conventional pesticides, and other chemicals used as pesticides such as sulphur, petroleum oil and sulphuric acid.

\section{Pesticide evaluation procedure of Ghana}

Basic scientific data requirements include: mammalian toxicity, ecotoxicology, environmental fate, physical and chemical properties, five batch analysis, residue chemistry if 
used on food or feed crop, fish and wildlife, if applicable, phytotoxicity, if applicable and bio efficacy. Evaluation of pesticides is conducted on their environmental toxicology (ecotoxicology), human toxicology, bio-efficacy, labels and advertisement. Complete data provided for pesticide product is assessed and evaluated based on acceptability criteria (GEPA, CCMC 2012).

Pesticide registration in Ghana is based on international data and prospective risk assessments (GEPA, CCMC 2012). Since the operationalization of the Act over a decade ago, no study has been conducted to establish how protective the pesticide legal procedure is to the environment and occupational health. No environmental risk assessment has been conducted in the fields of use. The Act prescribes controls on import and use under sections 28 and 40 as well as safeguards for use of pesticides with regards to occupational health under section 44. This notwithstanding, the Act provides an opportunity under section $62(\mathrm{a}-\mathrm{f})$ to establish regulations that can monitor effect of pesticide use in the field where the use of ecological risk assessment becomes key.

\section{Environmental impacts of pesticides}

Pesticides generally are manufactured to be very toxic for their intended targets and once they spread in the environment may have effects on other related and non-related, nontarget organisms. Pesticides may end up in the environment via a couple of routes like spray drift, run-off, leaching through the soil once applied in the field and may reach water bodies adjacent to the agricultural fields where they can pose risk to non-target aquatic biota (PerezLuca, 2015; Bonmatin et al. 2018). Pesticide usage in most developing countries including Ghana are characterised by risk to humans and other life forms and unwanted side effects to the aquatic and terrestrial environment and safe management is usually not prominent (Ecobichon, 2001; Aktar, 2009; NPASP, 2012; Onwona-Kwakye et al. 2019). In Europe for example, to safeguard the adverse effects of pesticides, extensive risk assessment is conducted to ensure that negative effects on the environment during pesticide registration are factored into the recommended use (eg. EFSA, 2013a, b). With this, the field of Ecological Risk Assessment (ERA) is very important in Europe and aims at assessing the potential adverse effects resulting from various human activities like the impact of chemical compounds on the environment. Pesticides are regulated under Regulation No 1107/2009 (EC 2009) where 
protection goals, data requirements and risk characterisation are defined for the environmental compartment whereas in Ghana it is practically non-existent.

\section{Overall aim of thesis}

The aim of the thesis was to review the pesticide law and registration procedure of Ghana and to establish how effective it has been in protecting the environment and users in Ghana using post registration monitoring. Further, the study sought to use models such as PRIMET (Pesticides Risks in the Tropics to Man, Environment, and Trade), SSD (Species Sensitivity Distribution) and empirical data obtained from the field, to assess the risk of pesticides and determine the threshold levels protective of ecological communities. The thesis also investigated the effects of these pesticides on abundance and diversity of bacteria populations in the soil environment.

Based on this overall aim, the following research objectives were set:

1. To review relevant portions of the Ghanaian pesticide law, the registration procedure, in relation to actors perspective of its implementation to establish whether it has achieved its intended purpose, and indicate adjustments needed for further consideration and improvement;

2. To perform risk assessments using empirical data and models to establish the risks of pesticides to the aquatic and terrestrial environments of agricultural fields according to farmers' pesticide use regimes in Ghana; and

3. Determine the water quality of water bodies in Ghana using physico-chemical parameters, pesticide concentrations, and biological indicators.

\section{Outline of thesis}

Chapter 2 reviews Ghana's pesticide policy (pesticide law) which was adopted to achieve safe use of such products. This chapter provides a brief overview of the pesticide regulatory policy framework (pesticide law), the pesticide registration and licensing procedure as well as the theoretical framework (evaluation model) for the study. The main part of the study deals with how the policy has developed over time. The study also discusses the farmers' pesticide use in day-to-day farm practices and distribution in the country, in relation to the policy and also the interactions of state (regulators) and non-state actors (pesticide 
distributors, dealers and farmers). To conclude, the study discusses a number of initiatives that need to be initiated to overcome problems encountered.

Chapter 3 describes the use of the PRIMET model (Van den Brink et al. 2005) (1 $1^{\text {st }}$ Tier) to assess the risks of pesticides to the aquatic and terrestrial environments. To this end, empirical data obtained from farmers in their application of pesticides and other aquatic waterway parameters realistic for a tropical scenario, see e.g., (Van den Bosch et al. 2006) were used. Results from $1^{\text {st }}$ tier showing risk were then further refined using SSD model (Maltby et al. 2005; Van den Brink et al. 2006; Maltby et al. 2009) (2 ${ }^{\text {nd }}$ Tier) to estimate pesticide concentration levels protective of the aquatic environment.

Chapter $\mathbf{4}$ describes a monitoring approach using a variety of techniques to assess the water quality of Volta River to chemicals and pesticides. This involved the sampling and analysis of water samples from selected locations and the analysis of the concentrations of pesticides used in the areas as obtained from an earlier survey (chapter $\mathbf{3}$ ). This was then linked to the physicochemical characteristics of the sampling locations as well as the macroinvertebrate species identified. Finally an explanation is given and inferences made on the health of the water body and presented as a water quality assessment tool for use in Ghana.

In Chapter 5, the study investigated the effect of pesticides used in irrigation farms on bacterial abundance and diversity relative to agriculture. The study also focuses on bacteria capable of degrading diverse classes of pesticides used in these farms. They are envisaged to be isolated for future works and could be utilized in a variety of environmental clean-up scenarios as a multi-purpose remediation for pollution and decontamination of heavily polluted sites such as oil fields, landfills, and sewage collectors as has been possible in other jurisdictions (Rupa et al. 2013).

Chapter 6 provides a general discussion of the results and conclusions of this thesis. The findings of the thesis and an overall discussion and conclusion on how the pesticide law could be enhanced to effectively protect the environment from their negative effects, the real effect of the pesticides in use on the environment and the possibility of isolating a variety of bacteria which can metabolize pesticides are discussed. 
General Introduction 


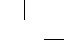




\title{
Chapter 2
}

\section{Pesticide registration, distribution and use practices in Ghana}

\author{
Onwona Kwakye, Michael ${ }^{1,2}$, Belay Mengistie ${ }^{3}$, John Ofosu-Anim ${ }^{4}$, Alexander Tetteh K. Nuer ${ }^{5}$,
} Paul J. Van den Brink ${ }^{1,6}$

${ }^{1}$ Aquatic Ecology and Water Quality Management Group, Wageningen University, Wageningen University and Research, P.O. Box 47, 6700 AA, Wageningen, The Netherlands.

2 Environmental Protection Agency, P. O. Box M326, Accra, Ghana.

${ }^{3}$ Plant Health Regulatory Directorate, Ministry of Agriculture and Natural Resources, P.O. Box 62347, Addis Ababa, Ethiopia.

${ }^{4}$ College of Basic and Applied Sciences, School of Agriculture, University of Ghana, P. O. Box LG 25 Legon, Ghana.

${ }^{5}$ Institute of Tropical Agriculture (KITA) Box 293, UST, Kumasi, Ghana.

${ }^{6}$ Wageningen Environmental Research (Alterra), Wageningen University and Research, P.O. Box 47, 6700 AA, Wageningen, The Netherlands.

This chapter has been published in Environment, Development and Sustainability (2019), 21: 26672691. 


\section{Chapter 2}

\section{Abstract}

Ghana has implemented regulation on the registration, distribution and usage of pesticides in order to evaluate their environmental and human health effects. However, environmental monitoring and certified laboratories for pesticide analysis are lacking. Pesticide misuse, misapplication, contamination of the environment and human exposure still continue and little is known to what extent pesticide registration, distribution and use is properly implemented in Ghana. This study aimed at investigating how the pesticide policy operates in Ghana, how state (policy; national/local) and non-state (importers, dealers' and farmers) stakeholders function, what their challenges are, and to which extend the policy objectives are achieved.

A conceptual framework based on the contextual interaction theory (CIT) was developed and a review of Ghana's pesticide policy implementation with two empirical field studies on state policy and non-state policy actors was conducted, supplemented with secondary data and a number of interviews conducted with stakeholders and informants. Results indicate that pesticides are registered in compliance with the law. Non-state actors scored low with respect to their mandate which likely results in environmental and human health risks. Significant association existed between educational level attained and knowledge $\left(X^{2}=3.614 ; P \leq 0.05\right)$. Work experience or duration of farming also significantly influenced the knowledge of respondents $(P<0.001)$, as well as attitude $\left(X^{2}=15.328 ; P<0.05\right)$. Work experience/ duration of farming also significantly influenced attitude at $95 \%$ confidence level $(P<0.001)$ and duration of farming was significantly associated with farm management practices at $5 \%$ level of significance $(P \leq 0.05)$ while state actors are not motivated and resourced. It is recommended to perform a preliminary risk assessment to the aquatic environment, to derive threshold levels which are protective of communities, to screen farmers for pesticide exposure and poisoning, to develop well-targeted training programmes for pesticide retailers and farmers on pesticide use, personal protective equipment (PPE) use, as well as pesticide management and law. Additionally, pesticide policy implementers have to be motivated and resourced to carry out their mandate, i.e. to execute the pesticide legislation. 


\section{Introduction}

Pesticides use in agriculture in Ghana has resulted in reduced crop loss (Clarke et al. 1997). There has been a continuous increase in the importation and use of pesticides (MOFA, 2011). This includes both the number of chemicals and quantities registered as well as recorded by the competent authorities and regulators such as the Food and Drugs Authority (FDA), Environmental Protection Agency (EPA) of Ghana, Ghana Standards Authority (GSA) and the Ministry of Food and Agriculture (MOFA). This increase is prevalent due to expansion of cultivation areas for food and cash crops in a bid to meet the increasing demand for food (MOFA, 2003). The increase can also be attributed to the liberalization of the economy and the government's aim of attaining a middle income economy as enshrined in the country's Vision 2020 agenda. Further, the regulation and the registration of pesticides opened a new economic boom with the resultant increase in the registration of pesticide products for use in Ghana. The use of pesticides, however, has not been without deleterious effects on people, such as farmers, traders and consumers, which are involved in the food supply chain. Poor knowledge of farmers on the types of pesticides, their use and associated risks, ineffective governmental enforcement of pesticides' regulations and strong incentives among pesticide traders and users to make profits, have been reported to leading to an increased use of cheap, mislabelled and adulterated pesticides in Ghana (NPASP, 2012; GNA, 2012). Instances of over use and misuse on crops have been reported with the accompanying negative effects on productivity, environment and human health (Gerken et al. 2001; Dunham et al. 2003; Amoako et al. 2012). Williamson et al. (2008) described chlorpyifos, endosulfan and lambdacyhalothrin being associated with instances of ill health among Ghanaian farmers. Ntow (2001) detected endosulfan and lindane in water and sediment of streams in areas of intensive tomato farming, while other organochlorine pesticide residues were also found in sediment. Similar results were recorded by Ntow (2005) for the Volta Lake in Ghana.

With these problems, there has been a shift to the use of relatively "safer" pesticide alternatives which gave birth to the implementation of the pesticide registration process of Ghana in 2003. The pesticide law at the time was the Pesticide Control and Management Act, Act 528 of 1996. The law has been consolidated to become Part II of the main Ghana Environmental Protection Agency (EPA) Act, Act 490 of 1994. This law includes the whole 
pesticide life cycle, so the registration and procurement of pesticides, their import, distribution and retail to farmers, their monitoring for quality control and waste management.

Since the implementation of the pesticide registration process, a number of interventions such as training courses on pesticide storage and handling and their proper use have been organized for importers, distributors, retailers and farmers by the state and a number of non-state organisations (NSOs). However, little is known regarding how and to what extent the registration, distribution and use of pesticides is properly implemented in Ghana. It is also not clear whether these actions by the registration authorities have yielded the necessary improvements in pesticide management and their use. This is so because the operationalization of the pesticide law lacks extensive and reliable information that could be available to experts, scholars, researchers and practitioners in this field of enquiry. The main objective of this study was to examine how pesticides are registered, distributed and used and to assess how different state (policy implementers) and non-state (distributors and the farmers) pesticide actors can improve the pesticides management in order to increase their environmental sustainability as well as workers' health in Ghana.

\section{Pesticide law in Ghana: registration, distribution and use (regulatory framework)}

Ghana has a pesticide legislation, part II of the Environmental Protection Agency (EPA) Act (Act 490), which governs the whole pesticide life cycle. The legislation helps to ensure that pesticides are used in a safe and responsible manner in the country. The Ghana EPA is responsible for the registration of pesticides as well as their management. They do this to ensure that the pesticides are properly labelled, distributed, stored, transported, used and applied by following accepted procedures and processes. The Ghana EPA further monitors pesticide use and, if needed, reacts against illegal use, and issues pesticides importation and use licences. The registration of pesticides is headed by a Pesticides Registrar (PR) who works with a Pesticides Technical Committee (PTC) which is drawn from a wide background of expertise and institutions (section 53 of the Act) who advises the Ghana EPA Board on whether pesticides should be registered or not.

The Plant Protection and Regulatory Services Directorate (PPRSD), of the Ministry of Agriculture through the Pesticide and Fertilizer Regulatory Division Act 803 (2010) 
compliments the Ghana EPA. They supervise and train pesticide inspectors, register and inspect pesticide dealers and provide information materials and training on pesticides, among others, for retailers and farmers.

To tackle illegal trade in pesticides, the Customs Division of the Ghana Revenue Authority regulates all imports into Ghana including chemicals under Act 791 (2009). Under the auspices of the Ghana EPA, the customs division examines documents and certificates issued by the Ghana EPA. The aim is to validate the claims regarding pesticide importation. The law (Act 791) gives customs officers the jurisdiction to search certain persons, premises and baggage and seize prohibited items, including pesticides.

Ghana, in the exercise of its duty on pesticides, recognises international legal agreements relating to pesticides. These include the International Code of Conduct on the Distribution and Use of Pesticides (i.e. the FAO Code of Conduct). Ghana is also a signatory to the Rotterdam Convention on Prior Informed Consent (ratified in 2003), which facilitates the sharing of information between countries and thus prevents banned or severely restricted pesticides are exported and imported. Furthermore, the Stockholm Convention on Persistent Organic Pollutants, which aims at safeguarding human health and the environment from effects of persistent organic pollutants (POPs), is subscribed to by the country (ratified in 2003).

\section{Pesticides registration procedure in Ghana}

Ghana's pesticide registration is a stepwise process (Fig. 2.1), which assesses available and submitted data and results in a final decision to grant or deny registration. The process aims to identify potential risks that may arise from the sale and use of pesticides under Ghana's conditions and culture (GEPA, 2012).

The process includes: 1) the application for registration, 2) data on chemical and physical properties, toxicology, efficacy, residues and fate in the environment of the active ingredient and formulated product, 3) several specific requirements like an agency agreement between the agent and the manufacturer, a batch certificate of analysis, 4) locally generated efficacy data form, 5) samples of the pesticide, 6) a manufacturing licence in the country of origin and 7) the package label in English (GEPA, 2012). 


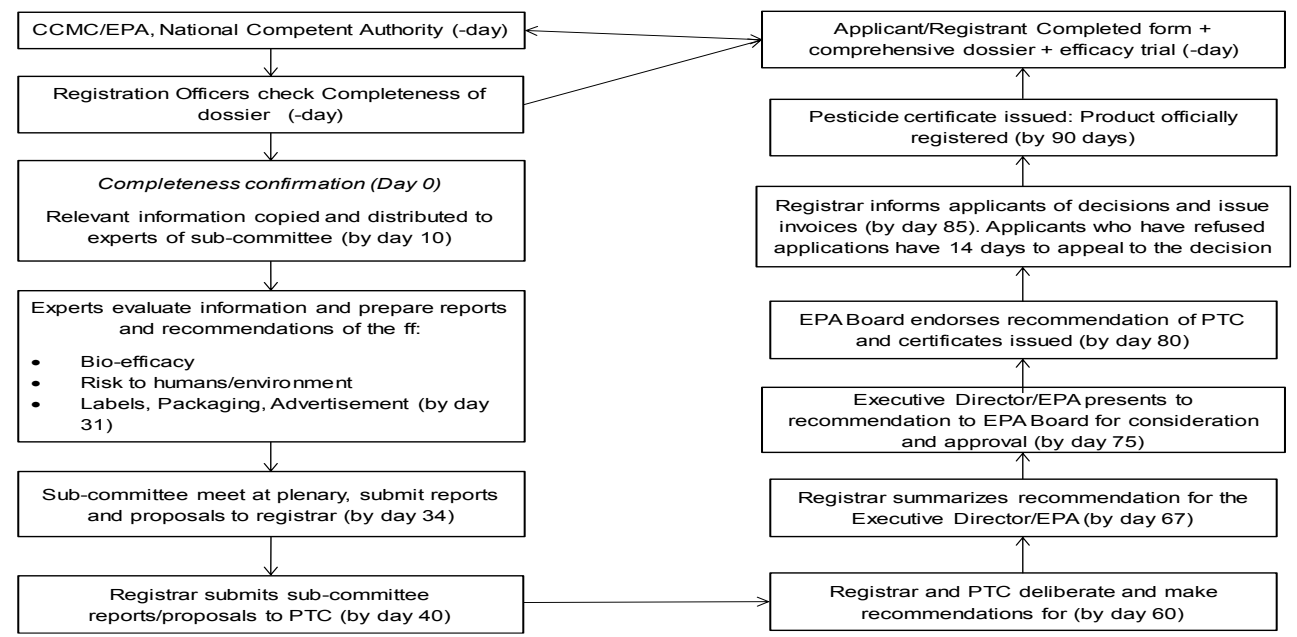

Figure 2. 1: Pesticide application and registration stepwise process (GEPA, 2012)

Application for the registration of a pesticide involves the submission of a product dossier with the necessary annexures to the registrar (GEPA, 2012). The complete application is scientifically scrutinized by technical sub-committees on environmental and human toxicology, bio-efficacy, labelling and advertisements. An evaluation report and recommendations on the application are then submitted to the Pesticide Technical Committee (PTC).

The PTC evaluates the report and proposes a registration decision for deliberation by the Ghana EPA Board. The decisions could be full registration valid for three years and can be renewed. A provisional clearance permit lasts between six months to one year, in which case the applicant is supposed to submit additional information for further consideration. An experimental permit can also be issued for the purposes of research. Decision on banned products (banned for use locally or internationally) or suspension of the registration (inability of the Board to reach a decision) can also be reached (GEPA, 2012). These permits can also be renewed upon expiry. Registered pesticides are subsequently gazetted into public communication channels, as the media.

The Ghana EPA is responsible for verifying the registration and the import of pesticides by issuing a clearance permit, after the importer submitted an application which includes the 
data as requested by the Ghana EPA. Under the Ghana EPA Act, "a person shall not import, export, manufacture, distribute, advertise or sell a pesticide except in accordance with a licence issued under this Act" (GEPA, 2012). For the storage of pesticide products, a pesticide licence is required. Pesticide licences are issued based on the presence of a satisfactory location of the storage facility upon inspection by the Ghana EPA.

Pesticide clearance permits are required for an importer to clear consignments from the port based on availability of pesticide licence and if the imported pesticide product is registered.

\section{Theoretical framework for analysing policy implementation}

A conceptual framework based on the contextual interaction theory (CIT) was developed for the study from the review of policy implementation literature (Van Horn and Van Meter, 1977; Sabatier, 1991; Fimyar, 2014). The theory as described by Bressers (2007) indicates that implementing a policy is a social process where the output and outcome are defined by interactions of its actors. The framework evaluates how a policy operates in practice, how state (registration authorities) and non-state (pesticide dealers and farmers) actors are functioning and whether the policy objectives are achieved. Outputs are the tangible results of a measure or the noticeable effects shortly after or even during implementation (Bressers, 2007). The Ghana pesticide registration offers a number of outputs that are supposed to be implemented by state actors and the outputs are supposed to yield certain desired outcomes by the non-state actors. The CIT thus offers an opportunity to evaluate whether the desired outcome has been achieved or not. The CIT brings to the fore a couple of actor characteristics including information, motivation and resources. These were selected for the purpose of this study to better understand their impact on the likelihood to implement a policy. The governance approach focuses on the interaction taking place between governing actors with information, motivation and resources (Mengistie et al. 2014). The interaction shapes actors and actors shape interaction patterns. The three variables information, motivation and resources may mutually influence each other as well (Locke and Letham, 2004; Karwai, 2005; Bressers, 2007; Harder, 2008; Logan, 2010). 


\section{Chapter 2}

Many research efforts have shown that the characteristics of a policy network may be a useful base for elucidating the functioning of a policy instrument and its design (e.g. de Bruijn and Hufen, 1998). The concept of policy networks generally contains the assumption that there are both links and actors (Carlsson, 2000b). The implementation process of the policy gets its particular shape through such networks. This conceptual framework (evaluation model) is used to link the registration and policy on the one hand and use practices at farm level on the other hand.

This policy evaluation framework is realized by the different governance approaches focusing on the interaction between governing actors; so the output depends on actor performance. These actors are brought into perspective in the three key ingredients of this study:

1. Policy input and objective. What is the pesticides policy and what are its objectives which are used by the administration to produce outputs? Such resources would include personnel, finance, pesticides registration documents (international chemical conventions, regulation, dossier for pesticides registration, among others) and what the policy says about state and non-state actors of pesticides regarding environment and human health safety and sustainability.

2. Policy implementation process. This refers to the roles of authorities, companies, nongovernmental organizations and individuals. Information on how, why and under what circumstances these actors are involved in the course of policy implementation is important. There is the need to identify who are important actors and stakeholders and what they are doing related to safe pesticides registration, distribution and use. There is the need to focus on agricultural and environmental offices from national to local level. This should involve the importers in the country, pesticides inspectors, extension workers, wholesalers, retailers (since they are important source of pesticides for farmers) and farmers' associations.

3. Policy output. This entails the issues and challenges listed by the target groups (farmers) who are faced with, e.g. selection and use of certain products. This is the group where the noticeable effects occurring shortly after or even during implementation can be observed. 
This study aims to evaluate 1 ) how the pesticides policy functions, how state (national and local policy) and non-state (importers, dealers' and farmers) actors are functioning, 2) the extent by which the policy is implemented and enforced including the challenges encountered, and 3) whether the enacted policy achieves its objectives.

\section{Study area and methodology}

This study was based on Ghana's pesticides law and two empirical field studies on state policy and non-state policy actors were conducted. Data for this study were supplemented with secondary data and a number of interviews conducted with stakeholders and informants.

\section{Study area and actors}

Two empirical surveys were conducted. For the first survey, purposeful sampling was used to select the locations to interview non-state actors (distributors, retailers and farmers). This was done to select those distributors and retailers who had interactions with the regulatory bodies. Farmers were chosen if they applied pesticides themselves, interacted with the pesticides dealers and extension staff. Interviews and inspections were conducted with 13 pesticides importing companies made up of nine national and four foreign companies selected in Accra and Kumasi. These companies had been selected based on their preparedness to respond to questionnaires of the team and to allow their outfits to be inspected. Their simple task was to indicate and show to the team whether their outfits had been inspected by the EPA during the year of the study, whether they had valid pesticides dealers licence to operate as described in section $40(1-2)$ of the Act, whether they were selling registered pesticides (section 28 of Act) and whether the attendants were provided with PPE which were in-line with section 44 (4 - 5).

Fieldwork was conducted on 30 randomly selected pesticides' retailers in KumasiKejetia, which is the main commercial market in Ghana where most of the import, distribution and retail of pesticides occur. A list of licensed pesticides importers, retailer shops and commercial applicators for the country was used to identify their locations for the interview. Since pesticides are special products under the pesticides law, having the license or not was considered vital for accessing the actors, but the status of licences was noted. The survey was 
conducted from May 2013 to January 2014 at seven sites comprising of six irrigation sites from five regions and one plantation area for the farmers. These were the Okyereko (OK) irrigation site (25 respondents) in the Central region, the Weija (WJ) and the Ashaiman (AS) irrigation sites (25 respondents) each in the Greater Accra Region, the Akuse (AK) irrigation site (25 respondents) and cocoa plantations in New Tafo Akim/Tontro (TN) (31 respondents), the Eastern region, the Akomadan ( $A D)$ irrigation site (14 respondents) in the Ashanti region and the Tono (TO) irrigation site (11 respondents) in the Upper East region. The study sites were chosen to reflect the increasing importance of farming in the country and where pesticides are used intensively. These regions were selected as representative of Ghana in terms of economic prosperity, agricultural advancement, crops grown, geography and climate among others (Dickson and Benneh, 1998; MOFA, 2011). Crops grown in OK and AS included vegetables (tomato, pepper, onion, okro, garden eggs, cabbage, cucumber, tinda, cowpea, soybean, lettuce, and groundnut) and rice, while vegetables were grown in WJ, AD and TO, rice in AK and cocoa in TN.

A questionnaire was pre-tested in the field on some farmers. The focus was on farmers' understanding of agricultural pesticides used, and possible risks for human beings and the environment when pesticides are used. This allowed for corrections and adjustments to the questionnaire before the final survey. Other information required included the pesticides used, their purity and use dosages, time of application and poisoning symptoms. Information on the use of PPE by farmers whilst applying pesticides was also obtained. The source of information for farmers on new and banned pesticides was noted. Farmers were also asked whether they have been screened for pesticide poisoning. Data were subsequently collected by completing the questionnaire during semi-structured (personal and group) interviews and discussions (in English and local dialects) with local farmers. At least one agrochemical dealer in each site was also interviewed concerning pesticides usage and safety. The registration status of the identified pesticides used by farmers in Ghana was determined from the registration authorities (Environmental Protection Agency, Ghana).

Prior informed consent from each respondent was gained and permission to carry out research at the sites was obtained from the scheme managers of the irrigation sites and from the owners of cocoa farms. A total of 156 farmers voluntarily responded to the questionnaire in the survey. We also observed farmers' practices as they work to validate some of the 
questionnaire-based data because most interviews were conducted when farmers were working in the field. Further interviews were conducted with a total of 15 extension staff (local state actors) in the course of data collection with the farmers. These interviews centred on the problems they encounter in the running of their daily activities with respect to their access to information, the available resources and their motivation whilst working with the farmers. It involved 18 questions (10 questions on motivation, three on resource and five on information).

A second survey included a total of 17 extensive interviews with national state actors (policy implementers). They included nine pesticides registration experts from the Ghana EPA, and five persons from the PPRSD. The interview focused on the pesticides policy implementation, the registration process, pesticides inspections and pesticides quality control and available observation in terms of information, motivation and resources. Discussions were also held with the Poison Control Center (PCC) of the Ministry of Health (MoH) on pesticides poisoning related issues. Two officers of the Customs Division of the Ghana Revenue Authority (GRA) were interviewed on import and export controls, access to information, resources, and their motivation. For this, a questionnaire containing 21 questions (motivation 10, resource 5 and information 6 questions) regarding available observation in the implementation process was used. In addition, results of secondary data collected from the registration authority in Ghana were used to verify the authenticity of the findings of the pesticides law (Part II of Act 490, 1994).

The response for the non-state policy actors were mostly "yes" or "no" and the results were presented as percentages. Bivariate analysis using the chi square was used to determine statistically significant associations between the demographic characteristic and farmers' knowledge, attitude and practices. In addition, multi-criteria statistical cluster analyses was used for responses of the national state policy actors' (Ghana EPA and PPRSD on pesticide governance). The respondents had the task of assigning a grade between 1 and 5 (1: insignificant, 2: quite insignificant, 3: significant, 4: very significant, 5: most significant) to a particular question. Analysis of the data accepts the general knowledge that state policy actors responded to the same questions regarding implementation of the policy. The answers to the questions provides ordinal qualitative variables, yielding a classic multidimensional matrix consisting of objects (policy implementer) and questions which has attributes referred to as 


\section{Chapter 2}

observations in the form of either a motivation, information or resource question. Responses obtained for particular question form clusters which are mutually-interdependent. The clusters are formed using a hierarchical agglomeration procedure, which progressively clusters groups of elements, starting with the grouping of the most similar ones and, in the following steps, group less similar clusters.

The analysis identifies groups with similar compositions of needs to defined possible solution options (remediations) based on similarities between the responses to the main question. SPSS statistical software (version 21.0) was used for all the analyses.

\section{Results and discussion}

\section{Non-state policy actors of pesticides}

\section{Farmers' pesticides use practices}

Table 2.1 shows the summary statistics of the demographic characteristics of the respondents. Out of the total of 156 farmers that were given a questionnaire, all questionnaires were filled and returned, given a response rate of $100 \%$. Almost all of the farmers interviewed were males and those aged more than 50 years formed the majority among the respondents. The majority had worked for a period between 10-20 years representing $42.7 \%$ of the respondents and $58.3 \%$ had some form of basic education.

Table 2.1: Demographic characteristics of respondents

\begin{tabular}{lll}
\hline Variable & Frequency(N=156) & Percentage \\
\hline Age (years) & 50 & 32.1 \\
$18-35$ & 48 & 30.8 \\
$36-50$ & 58 & 37.2 \\
$>50$ & & \\
Educational level & 49 & 31.4 \\
No formal education & 91 & 58.3 \\
Basic & 13 & 8.3 \\
Secondary & 3 & 1.9 \\
College & & \\
Duration of work (years) & 34 & 21.8 \\
$<10$ & 67 & 42.9 \\
10-20 & 20 & 12.8 \\
$21-30$ &
\end{tabular}


$>30$

Stagger planting
10

25
6.4

16.0

All interviewed farmers sprayed their crops with a pesticide to control pests and diseases, an observation that is shared by Ntow et al. (2006). Dinham (2003) estimated that $87 \%$ of Ghana vegetable farmers use chemical pesticides for pest and disease control. Thirtythree different pesticide products made up different active ingredients from the combined study sites were recorded. Table 2.2 shows the products with their applied doses, recommended doses, active ingredient concentration and their groupings. These included $36 \%$ insecticides, $30 \%$ fungicides, $30 \%$ herbicides and $4 \%$ nematicides. All the used pesticides had been registered for use (Table 2.2) in compliance with section 28 (1) of the Act. This is an improvement from a decade ago, since Ntow et al. (2006) found in a similar study that $47 \%$ of the used pesticides were not registered. Our findings are in line with Ngowi et al. (2007) who reported that insecticides are predominantly used for vegetables in Tanzania. However, a pesticide registered to control fungi pest on cocoa, i.e. Kocide (Copper hydroxide), was found in Weija being used for fungi pest on vegetables. This finding is consistent with a study by Amoako et al. (2012) who mentioned kocide as a product used for the cultivation of vegetables (cabbage) in Ghana and in violation of section 44 (1) of the Act. Figure 2.2 presents a summary of the origin of pesticides imports encountered at the study sites per the label information during the field study. These were subsequently verified on Ghana's pesticides register of the Environmental Protection Agency. The verification confirmed the products as registered and derived from authentic sources satisfying section 38 of the pesticides Act. The identified products are therefore not likely to pose problems with regards to faking and adulteration.

Table 2.2: Synthetic pesticides recorded in the study and approved by the Environmental Protection Agency of Ghana to control the most important pests in agriculture including their active ingredients, purity, applied and recommended dosages

\begin{tabular}{l|llll}
\hline $\begin{array}{l}\text { Active } \\
\text { Ingredient }\end{array}$ & $\begin{array}{l}\text { Active } \\
\text { Ingredient } \\
\text { Conc. }\end{array}$ & Group & $\begin{array}{l}\text { Applied dose, } \\
\text { L/ha, kg/ha }\end{array}$ & $\begin{array}{l}\text { Recommended dose } \\
\text { on label, L/ha, kg/ha }\end{array}$ \\
\hline Herbicide & & Phosphonate & $1.2-9.8 \mathrm{~L}$ & $0.5-2.5 \mathrm{~L}$ \\
${ }^{*}$ Glyphosate & $360 \mathrm{~g} / \mathrm{L}$ & & & \\
& $480 \mathrm{~g} / \mathrm{L}$ & Bipiridillium & $1.5-8.33 \mathrm{~L}$ & $1.5-3.0 \mathrm{~L}$ \\
*Paraquat & $200 \mathrm{~g} / \mathrm{L}$ & Acetanilide & $6.67 \mathrm{~L}$ & $4.0 \mathrm{~L}$ \\
\end{tabular}




\begin{tabular}{|c|c|c|c|c|}
\hline${ }^{*}$ Pendimethalin & $400 \mathrm{~g} / \mathrm{L}$ & Dinitroaniline & $3.0-9.8 \mathrm{~L}$ & $2.5-3.0 \mathrm{~L}$ \\
\hline Propanil & $360 \mathrm{~g} / \mathrm{L}$ & Acetanilide & $2.0-3.7 \mathrm{~L}$ & $8.0-10 \mathrm{~L}$ \\
\hline $\begin{array}{l}\text { *Bensulfuron } \\
\text { methyl }\end{array}$ & $30 \%$ & Sulfonylurea & $0.42 \mathrm{~kg}$ & $0.003-0.10 \mathrm{~kg}$ \\
\hline $\begin{array}{l}\text { *Bispyribac } \\
\text { sodium }\end{array}$ & $400 \mathrm{~g} / \mathrm{L}$ & Pyrimidinyl oxybenzoic acid & $0.10 \mathrm{~L}$ & $0.015-0.05 \mathrm{~L}$ \\
\hline Propanil + & $360 \mathrm{~g} / \mathrm{L}+$ & Acetanilide & $2.0-3.7 \mathrm{~L}$ & $4.0 \mathrm{~L}$ \\
\hline $2,4-D$ & $200 \mathrm{~g} / \mathrm{L}$ & Phenoxy acid & & \\
\hline $\begin{array}{l}\text { *Pretilachlor + } \\
\text { Pyribenzoxim }\end{array}$ & $\begin{array}{l}30 \%+ \\
2 \%\end{array}$ & $\begin{array}{l}\text { Chloroacetamide } \\
\text { Pyrimidinyl(thio)benzoate }\end{array}$ & $2.0 \mathrm{~L}$ & $1.0-1.5 \mathrm{~L}$ \\
\hline $\begin{array}{l}\text { *Oxyfluorfen + } \\
\text { Glyphosate }\end{array}$ & $\begin{array}{l}300 \mathrm{~g} / \mathrm{L}+ \\
360 \mathrm{~g} / \mathrm{L}\end{array}$ & Phosphonate & $1.5-2.0 \mathrm{~L}$ & $0.75-0.90 \mathrm{~L}$ \\
\hline Insecticide & & & & \\
\hline $\begin{array}{l}\text { *Lambda- } \\
\text { Cyhalothrin }\end{array}$ & $\begin{array}{l}25 \mathrm{~g} / \mathrm{L} \\
50 \mathrm{~g} / \mathrm{L}\end{array}$ & Pyrethroid & $1.0-14.8 \mathrm{~L}$ & $\begin{array}{l}0.6 \mathrm{~L} \\
0.4 \mathrm{~L}\end{array}$ \\
\hline${ }^{*}$ Chlorpyrifos & $480 \mathrm{~g} / \mathrm{L}$ & Organophosphate & $1.0-1.67 \mathrm{~L}$ & $0.6-1.0 \mathrm{~L}$ \\
\hline $\begin{array}{l}{ }^{*} \text { Emamectin } \\
\text { benzoate }\end{array}$ & $1.9 \%$ & Avermectin & $0.62-1.85 \mathrm{~L}$ & $0.25-0.30 \mathrm{~L}$ \\
\hline Imidacloprid & $200 \mathrm{~g} / \mathrm{L}$ & Neonicotinoid & $0.15 \mathrm{~L}$ & $0.6 \mathrm{~L}$ \\
\hline $\begin{array}{l}\text { *Lambda- } \\
\text { cyhalothrin + } \\
\text { Acetamiprid }\end{array}$ & $\begin{array}{l}16 \mathrm{~g} / \mathrm{L}+ \\
20 \mathrm{~g} / \mathrm{L}\end{array}$ & Pyrethroid & $1.5 \mathrm{~L}$ & $1.0 \mathrm{~L}$ \\
\hline & & Neonicotinoid & & \\
\hline Acetamiprid & $200 \mathrm{~g} / \mathrm{L}$ & Neonicotinoid & $0.37 \mathrm{~L}$ & - \\
\hline Novaluron & $35 \mathrm{~g} / \mathrm{L}$ & Insect growth regulator & $0.45 \mathrm{~L}$ & - \\
\hline Thiamethoxam & $240 \mathrm{~g} / \mathrm{L}$ & Neonicotinoid & $0.125-0.150 \mathrm{~L}$ & $0.125-0.150 \mathrm{~L}$ \\
\hline Bifenthrin & $27 \mathrm{~g} / \mathrm{L}$ & Pyrethroid & $0.50 \mathrm{~L}$ & \\
\hline $\begin{array}{l}{ }^{*} \text { Cypermethrin + } \\
\text { Dimethoate }\end{array}$ & $36 \mathrm{~g} / \mathrm{L}+400 \mathrm{~g} / \mathrm{L}$ & $\begin{array}{l}\text { Pyrethroid } \\
\text { Carbamate }\end{array}$ & $2.5-9.8 \mathrm{~L}$ & $0.5 \mathrm{~L}$ \\
\hline $\begin{array}{l}\text { Bifenthrin + } \\
\text { Novaluron }\end{array}$ & $\begin{array}{l}30 \mathrm{~g} / \mathrm{L} \\
35 \mathrm{~g} / \mathrm{L}\end{array}$ & $\begin{array}{l}\text { Pyrethroid } \\
\text { IGR }\end{array}$ & $0.45 \mathrm{~L}$ & - \\
\hline $\begin{array}{l}\text { Bifenthrin + } \\
\text { Acetamiprid }\end{array}$ & $\begin{array}{l}30 \mathrm{~g} / \mathrm{L} \\
16 \mathrm{~g} / \mathrm{L}\end{array}$ & $\begin{array}{l}\text { Pyrethroid } \\
\text { Neonicotinoid }\end{array}$ & $0.055-0.075 \mathrm{~L}$ & - \\
\hline Nematicide & & & & \\
\hline Carbofuran & $3 \%$ & Carbamate & $0.6 \mathrm{~kg}$ & $20-25 \mathrm{~kg}$ \\
\hline Fungicide & & & & \\
\hline${ }^{*}$ Mancozeb & $800 \mathrm{~g} / \mathrm{Kg}$ & Dithiocarbamate & $5.93-9.88 \mathrm{~kg}$ & $0.8-2.0 \mathrm{~kg}$ \\
\hline${ }^{*}$ Carbendazim & $500 \mathrm{~g} / \mathrm{Kg}$ & Benzimidazole carbamate & $0.8-1.6 \mathrm{~kg}$ & $0.13-0.26 \mathrm{~kg}$ \\
\hline *Sulphur & $800 \mathrm{~g} / \mathrm{Kg}$ & & $0.8-0.988 \mathrm{~kg}$ & $0.67 \mathrm{~kg}$ \\
\hline${ }^{*}$ Maneb & $800 \mathrm{~g} / \mathrm{Kg}$ & $\begin{array}{l}\text { ethylene } \\
\text { bisdithiocarbamate }\end{array}$ & $9.88 \mathrm{~kg}$ & $2.0-4.0 \mathrm{~kg}$ \\
\hline $\begin{array}{l}\text { Copper } \\
\text { Hydroxide }\end{array}$ & $77 \%$ & & $0.74-1.5 \mathrm{~kg}$ & $2.0-4.0 \mathrm{~kg}$ \\
\hline
\end{tabular}




$\begin{array}{lllll}\text { Metalaxyl }+ & 8 \%+ & \text { Phenylamide } & 1.0 \mathrm{~kg} & 2.0-2.5 \mathrm{~kg} \\ \text { Mancozeb } & 64 \% & & & \\ \text { Metalaxyl-M }+ & 12 \%+ & \text { Phenylamide } & 0.25-4.94 \mathrm{~kg} & 1.0 \mathrm{~kg} \\ \begin{array}{l}\text { Cuprous Oxide } \\ \text { Cuprous Oxide }\end{array} & 80 \% & & & \\ \begin{array}{l}\text { nordox } \\ \text { Cupric hydroxide }\end{array} & 53.8 \% & - & 0.15 \mathrm{~kg} & - \\ \begin{array}{l}\text { Copper }+ \\ \text { Metalaxyl }\end{array} & 35 \%+15 \% & - & 0.8 \mathrm{~kg} & - \\ & & & 0.75 \mathrm{~kg} & -\end{array}$

$\left(^{*}\right)$ Pesticide Products that showed over dosing in their application

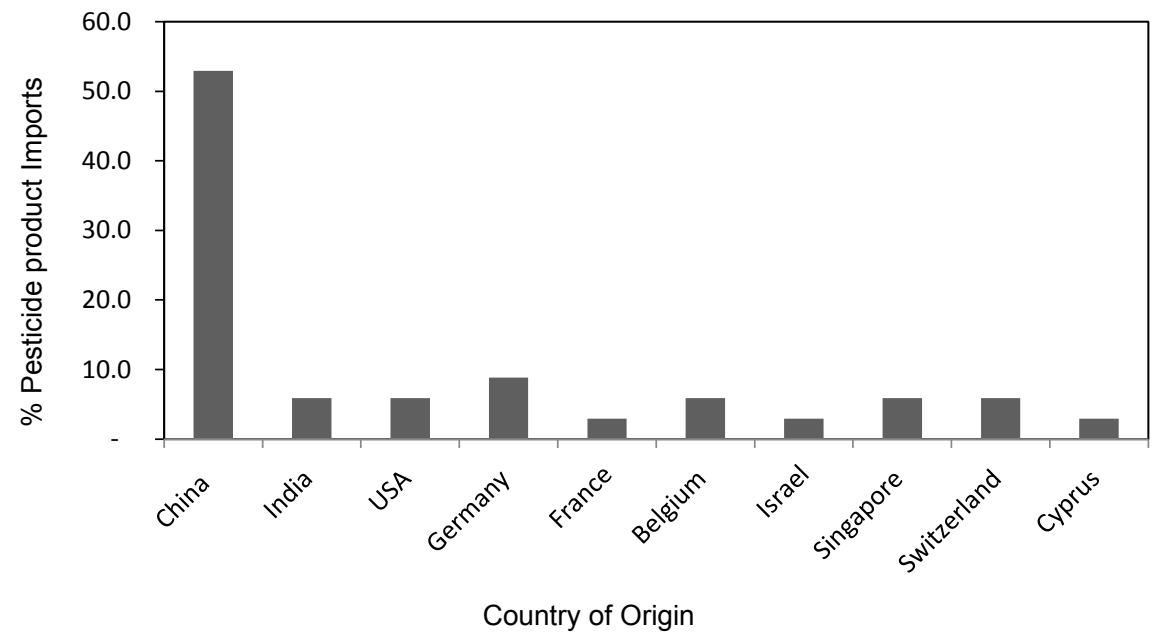

Figure 2.2: Origin of pesticide imports at the study sites

From the first empirical survey, information on the safe handling and use of pesticides appeared to be limited to the farmers. Seventeen pesticides were overdosed (Table 2.3), an assertion described by several other earlier studies (Clarke et al. 1997; Ntow et al. 1998; Mensah et al. 2002) but recent studies are missing. Our results show that pesticides use by this category of respondents contravenes section 44 (1) of the Act. Some of the farmers attributed the reason to overdose to the presence of dew on the leaves of plants especially during the mornings. As a result they usually increase the volume of pesticides product to apply. In their estimation, this could compensate for the excess water on the leaves, and this 
is likely to contribute to the overdosing. This assertion needs attention and the necessary corrective intervention by state policy implementers.

Table 2.3: Synthetic pesticides recorded in the study, which were overdosed pesticides as well as the sites where the overdosing took place.

\begin{tabular}{|c|c|c|c|c|c|c|}
\hline \multirow[t]{2}{*}{$\begin{array}{l}\text { Pesticide } \\
\text { Class }\end{array}$} & \multirow[t]{2}{*}{ Active Ingredient(s) } & \multicolumn{2}{|c|}{ Applied dose, L/ha, kg/ha } & \multicolumn{2}{|c|}{$\begin{array}{l}\text { Recommended dose on label, } \\
\mathrm{L} / \mathrm{ha}, \mathrm{kg} / \mathrm{ha}\end{array}$} & \multirow[t]{2}{*}{ Site(s) } \\
\hline & & Range & Median & Range & Median & \\
\hline \multirow[t]{8}{*}{ Herbicide } & Glyphosate & $1.2-9.8 \mathrm{~L}$ & $5.5 \mathrm{~L}$ & $0.5-2.5 \mathrm{~L}$ & $3.0 \mathrm{~L}$ & AS \\
\hline & Paraquat & $1.5-8.33 \mathrm{~L}$ & $4.9 \mathrm{~L}$ & $1.5-3.0 \mathrm{~L}$ & $2.25 \mathrm{~L}$ & AS \\
\hline & Bensulfuron methyl & $0.42 \mathrm{~kg}$ & - & $0.003-0.10 \mathrm{~kg}$ & $0.05 \mathrm{~kg}$ & AS, OK, AK \\
\hline & $\begin{array}{l}\text { Pretilachlor } \\
\text { Pyribenzoxim }\end{array}$ & $2.0 \mathrm{~L}$ & - & $1.0-1.5 \mathrm{~L}$ & $1.25 \mathrm{~L}$ & AK \\
\hline & $\begin{array}{l}\text { Oxyfluorfen } \\
\text { Glyphosate }\end{array}$ & $1.5-2.0 \mathrm{~L}$ & $1.75 \mathrm{~L}$ & $0.75-0.90 \mathrm{~L}$ & $0.83 \mathrm{~L}$ & WJ \\
\hline & Pendimethalin & $3.0-9.8 \mathrm{~L}$ & $6.4 \mathrm{~L}$ & $2.5-3.0 \mathrm{~L}$ & $4.0 \mathrm{~L}$ & AS, AK \\
\hline & Bispyribac sodium & $0.10 \mathrm{~L}$ & - & $0.015-0.05 \mathrm{~L}$ & $0.03 \mathrm{~L}$ & $A K$ \\
\hline & Butachlor & $6.67 \mathrm{~L}$ & - & $4.0 \mathrm{~L}$ & - & OK \\
\hline \multirow[t]{5}{*}{ Insecticide } & Lambda-cyhalothrin & $1.0-14.8 \mathrm{~L}$ & $7.9 \mathrm{~L}$ & $0.4-0.6 \mathrm{~L}$ & $0.5 \mathrm{~L}$ & $\begin{array}{l}\text { AS, OK, WJ, } \\
\text { AK }\end{array}$ \\
\hline & Emamectin benzoate & $0.62-1.85 \mathrm{~L}$ & $1.24 \mathrm{~L}$ & $0.25-0.30 \mathrm{~L}$ & $0.28 \mathrm{~L}$ & AS, OK, WJ \\
\hline & $\begin{array}{l}\text { Lambda Cyhalothrin } \\
+ \text { Acetamiprid }\end{array}$ & $1.5 \mathrm{~L}$ & - & $1.0 \mathrm{~L}$ & - & OK \\
\hline & $\begin{array}{l}\text { Cypermethrin } \\
\text { Dimethoate }\end{array}$ & $2.5-9.8 \mathrm{~L}$ & $6.15 \mathrm{~L}$ & $0.5 \mathrm{~L}$ & - & AS, OK \\
\hline & Chlorpyrifos & $1.0-1.67 \mathrm{~L}$ & $1.33 \mathrm{~L}$ & $0.6-1.0 \mathrm{~L}$ & $1.1 \mathrm{~L}$ & $\begin{array}{l}\text { AS, OK, WJ, } \\
\text { AK }\end{array}$ \\
\hline \multirow[t]{4}{*}{ Fungicide } & Mancozeb & $5.93-9.88 \mathrm{~kg}$ & $7.9 \mathrm{~kg}$ & $0.8-2.0 \mathrm{~kg}$ & $1.4 \mathrm{~kg}$ & AS, WJ, OK \\
\hline & Carbendazim & $0.8-1.6 \mathrm{~kg}$ & $1.2 \mathrm{~kg}$ & $0.130-0.260 \mathrm{~kg}$ & $0.2 \mathrm{~kg}$ & WJ \\
\hline & Sulphur & $0.8-0.988 \mathrm{~kg}$ & $0.89 \mathrm{~kg}$ & $0.67 \mathrm{~kg}$ & - & AS, AK \\
\hline & Maneb & $9.88 \mathrm{~kg}$ & - & $2.0-4.0 \mathrm{~kg}$ & $2.0 \mathrm{~kg}$ & WJ, AS \\
\hline
\end{tabular}

NB: AS Ashaiman, AK Akuse, WJ Weija, OK Okyereko, TN Tontro

Farmers indicated that they mix the pesticides close to the rivers, streams and canals (Table 2.4). All the interviewed farmers indicated that they cleaned their spraying equipment after pesticides use by rinsing with water, and that canals and drains have sometimes been compromised by emptying the rinse water into nearby water bodies. Practices of mixing pesticides and washing tanks near and in the river as well as throwing pesticide containers after use in the river or forests could pose environmental risks to aquatic environment. 
Table 2.4: Questions on farmers and sprayers knowledge, attitude, practices during pesticide use and occurrence of recent spills ( $n=156)$

\begin{tabular}{|c|c|c|c|}
\hline \multicolumn{2}{|l|}{ Question } & \multirow[t]{2}{*}{ Yes } & \multirow[t]{2}{*}{ Percentage } \\
\hline a) & Have you ever spilt pesticide mix on your body whilst working & & \\
\hline i. & Because of improper fitted lid & 142 & 91 \\
\hline ii. & During Pouring, loading & 141 & 90 \\
\hline iii. & Wrong wind direction & 156 & 100 \\
\hline iv. & Leaking equipment & 156 & 100 \\
\hline v. & Falling in the field & 156 & 100 \\
\hline vi. & Wrong movement with the sprayer & 156 & 100 \\
\hline vii. & Spray above the body & 156 & 100 \\
\hline b) & \multicolumn{3}{|l|}{ How can you help a colleague during pesticide splash } \\
\hline i. & Advice washing & 156 & 100 \\
\hline ii. & Go to health center & 156 & 100 \\
\hline iii. & Advice drink water & 0 & 0 \\
\hline iv. & Advice drink red palm oil & 0 & 0 \\
\hline v. & No problem, no idea & 0 & 0 \\
\hline c) & \multicolumn{3}{|l|}{ What protective measure did you take to protect yourself at your last spray operation } \\
\hline i. & Wore overall & 0 & 0 \\
\hline ii. & Wore safety shoe & 25 & 16 \\
\hline iii. & Used respirator & 4 & 3 \\
\hline iv. & Used gloves & 0 & 0 \\
\hline v. & Used goggles & 0 & 0 \\
\hline vi. & Used apron & 0 & 0 \\
\hline vii. & Used a hat & 0 & 0 \\
\hline viii. & Practiced careful working & 156 & 100 \\
\hline ix. & Timed the spraying e.g. early morning & 156 & 100 \\
\hline d) & \multicolumn{3}{|l|}{ What did you do during and after spraying the pesticide } \\
\hline i. & Wash your hands after spraying? & 156 & 100 \\
\hline ii. & Eat/drink/smoke during work with pesticides & 12 & 8 \\
\hline iii. & Keep meals near pesticides? & 0 & 0 \\
\hline iv. & Drink water near pesticide treated fields & 0 & 0 \\
\hline v. & Shower after pesticide exposure & 24 & 15 \\
\hline vi. & Change clothing before and after pesticide exposure & 7 & 5 \\
\hline e) & \multicolumn{3}{|l|}{ Where do you prepare pesticide mix for application } \\
\hline i. & Chemical store & 0 & 0 \\
\hline ii. & Outdoors & 0 & 0 \\
\hline iii. & Close to dam/river/stream & 156 & 100 \\
\hline iv. & In the house & 0 & 0 \\
\hline v. & Wherever & 0 & 0 \\
\hline f) & How did the most recent accidental spill that you experienced take place? & & \\
\hline
\end{tabular}




\section{Chapter 2}

$\begin{array}{llll}\text { i. } & \text { Whilst mixing (Accidental) } & 1 & 1 \\ \text { ii. } & \text { During preparation for spraying } & 0 & 0 \\ \text { iii. } & \text { Inferior equipment } & 128 & 82 \\ \text { iv. } \quad \text { While storing } & 0 & 0 \\ \text { v. } & \text { Other (strong wind) } & 27 & 17 \\ \text { g) } \quad \text { Have you ever been screened for pesticide poisoning before? } & 0 & 0\end{array}$

The possible environmental risks have been demonstrated in other studies by Ramo et al. (2016) and Teklu et al. (2016) in Costa Rica and Ethiopia, respectively. There is, therefore, a need to perform environmental risk assessments of current pesticides use in Ghana to identify pesticides that pose the highest risks to the aquatic environment and to determine threshold levels of the pesticides that are protective of the environment.

The data indicated that accidental spills took place in the field during pesticides application as a result of inferior equipment (82\%), when removing pressurized tubes and nozzles due to strong winds (together $17 \%$ ), while one farmer reported an accidental spill during mixing (Table 2.4). Farmers are probably the actors having the greatest risk of pesticides poisoning due to their intimate contact with pesticides. Ntow et al. (2006) found that knapsack sprayer is prone to leakage, especially when it is getting old. Matthews et al. (2003) emphasises the need to provide better-quality, affordable and comfortable equipment.

A couple of farmers (15\%) wash themselves after accidentally being exposed to pesticides while others (5\%) changed clothing before and after pesticides exposure, while the remaining farmers did not do anything (Table 2.4). This lack of adherence to strict safety measures under section 44 (4) of the Act could lead to different health problems.

Interviewed farmers indicated that they got most information and updates regarding pesticides usage and safety, banned pesticides including new methods of pesticide application, through extension staff (Table 2.5). Interactions with the farmers revealed that information from the registration authorities is not disseminated easily to the farmers and information on the status of pesticides is not regularly published. It is expected that the registration authorities would seriously engage the services and expertise of the agricultural extension staff to disseminate information to the farmers a view shared by Ngowi et al. (2007). 
Table 2.5: Questions on information on pesticide usage and safety, banned pesticides and new methods of application $(n=156)$

\begin{tabular}{lll}
\hline Item & Yes & Percentage \\
\hline Pesticides Usage and Safety & 120 & 77 \\
$\quad$ Extension staff & 17 & 11 \\
Labels & 19 & 12 \\
$\quad$ Consultants & & \\
Banned Pesticides & 115 & 74 \\
Extension Staff & 19 & 12 \\
Consultants & 13 & 8 \\
Meetings & 9 & 6 \\
$\quad$ Farmer's Association & & \\
New Methods of Pesticide Application & 115 & 74 \\
Extension Staff & 19 & 12 \\
Consultants & 11 & 7 \\
Meetings & 11 & 7 \\
Farmers' Association & & \\
\hline
\end{tabular}

The survey showed that the interviewed farmers had gained some form of expertise on pesticide application and safety. Most of the knowledge and expertise acquired was from formal advice (90\%) and through training on the job. Additionally, extension staff and consultants who promote their pesticides also engaged them (Table 2.5).

Generally, none of the farmers had recorded any pesticide spill on their body as a result of wrong wind direction, leaking equipment, as a result of falling in the field, wrong movement with the sprayer or spraying above the body. However, $90 \%$ of farmers admitted spill during pouring and loading of spray equipment, suggesting the need for special attention on the correct and appropriate means of pouring and loading spray equipment in subsequent training sections. Farmers had ample knowledge on how to help a colleague in the event of pesticide splash, and apart from safety shoes and respirators, no respondent had used protective measures, i.e. PPE, to protect themselves during their spray operations (Table 2.4). Other studies have also shown that protective actions using PPEs are rarely taken while handling and applying pesticides (Berg, 2001; Perry et al. 2002; Matthews et al. 2003). Wilson and Tisdell (2001) reports that protective clothing have not been used enough particularly in less developed countries. A lack of money to buy them and the absence of (enforcement of) 
regulations on their use are posed as the most important reasons for this. However in Ghana, this is a clear violation of section 44 (1, 2 and 4$)$ of the pesticides Act. In the survey farmers complained of the cost of PPEs and the fact that it is uncomfortable to use. Ntow et al. (2006) reported similar findings that the PPEs are hardly used by Ghanaian farmers because of discomfort associated with the hot and humid weather and their costs. However, there is the urgent need for farmers' attention to be drawn to the usefulness of the PPEs through practical demonstrations by extension staff. Okoffo et al. (2016) reported that the influence of extension service on the use of PPE is significant enough to strengthen it in order to increase farmers' knowledge and awareness of the consequences of applying pesticides without PPE. The study showed that the age of farmers had a significant influence on their knowledge about the use of pesticides. A bivariate analysis using the chi square revealed statistically significant associations between age and knowledge variables such as: the use of improper fitted lid, identification of wrong wind direction during spraying, knowledge during pouring and loading of pesticides as well as wrong movement during spraying of pesticides $\left(X^{2}=32.236, P<0.001\right)$. There was also significant association between educational level attained and knowledge $\left(X^{2}=3.614 ; P \leq 0.05\right)$. Work experience or duration of farming also significantly influenced the knowledge of respondents $(P<0.001)$.

The study further revealed statistically significant associations between age and practice such as: the washing of hands after spraying, eat/drink or smoke during working with pesticides, keep meals near pesticides, drinking water near pesticides treated fields, shower after pesticides exposure and changing of clothing immediately after pesticide exposure $(\mathrm{P}<$ 0.001). There was a significant association between educational level attained and farm management practices $(P<0.05)$. Work experience or duration of farming was significantly associated with farm management practices at $5 \%$ level of significance $(P \leq 0.05)$.

Interactions with the farmers revealed that they are not conversant with the pesticides law and the provisions in it to safeguard them and the environment. The registration authorities in collaboration with the extension services have to educate the farmers at their meetings of their roles and responsibilities regarding the pesticides law, its provisions and penalties especially sections 44, 56-62. The behaviour and action of farmers has been motivated by certain factors that pertain to their setting and circumstances. Interviewing the farmers indicated that $76 \%$ of them use products immediately, whilst $24 \%$ use the products 
within a month. Storage is limited since sales outlets are within reach of the communities, the farms are small and finances are limited. The decrease in the time of storage for the use of the products is encouraging, as the likelihood of exposure to the pesticides and related health effects are reduced, since most farmers store pesticides in their house but not in bedrooms (89\%). Five percent of the respondents keep it somewhere on the farm for later use. Two percent and $4 \%$ of the farmers stored the pesticides in their general stores and bedrooms, respectively. Storing pesticides in the homes and bedrooms for long durations can lead to exposure and risk of intoxication (Clarke et al. 1997). Kimani and Mwanthi (1995), Ngowi et al. (2001) and Murphy et al. (2002) report that it is very common in many developing countries to store pesticides at unguarded places in their homes. In the upper East region of Ghana 15 farmers died in 2010 which was attributed to pesticides poisoning, mostly related to poor storage of pesticides (NPASP, 2012). Seventy percent of the farmers purchase pesticides from local dealers/retailers, while $6 \%$ obtained the products from importers/local agents in the cities. Those who purchased them from consultants of the importing companies were $4 \%$ and remaining were those involved in the governments mass spraying exercise in Tontro site (20\%).

Seventy percent of the farmers used rate of applications recommended by the supplier, retailer or dealer. This was followed by the recommended application rate or frequency on the packaging label, and those who used their own application rate and frequency (Table 2.6). This may be a result of the direct contact between the suppliers and the farmers and the resulting ease to convince them. Ntow et al. (2006), however, reports that agricultural extension officers and/or pesticide labels as main source of information on pesticides application rates.

Table 2.6: Questions on skills and knowledge for storage of pesticide and use of recommended application of pesticides $(n=156)$

\begin{tabular}{lll}
\hline Item & Yes & Percentage \\
\hline Skills and knowledge of storage & & \\
Stored in the house, not bedroom & 138 & 89 \\
Somewhere on the farm for later use & 9 & 5 \\
Store pesticides in general stores & 3 & 2 \\
Store in the house, bedroom & 6 & 4
\end{tabular}




\section{Chapter 2}

Recommended application

Label recommendation

Supplier recommendation

41

26

Own recommendation

109

70

6

4

With regards to choice of using a pesticide (Table 2.7), seasonal occurrence of pest (45\%) especially during land preparation (weed control) was the most important factor followed by preventive reasons (15\%), pest density control $(8 \%)$, curative factors $(4 \%)$, weather factors and defensive related use (3\%) and routine application (22\%). Amoako et al. (2012) conducted a similar study in Ashanti region of Ghana and reported a contrary observation, i.e. that choice for a particular pesticide was based on its availability on the market in their area of operation, its price and its efficacy for insect pests. From the result, it is important to encourage farmers to use pesticides only when necessary as anticipated pest occurrence and pesticides application may lead to problems of pest resistance, environmental pollution, and occupational exposure, among others (Metcalf, 1980; Ngowi et al. 2007; Ramo et al. 2016). The pesticides use and frequency by farmers are provided in Table 2.7.

Table 2.7: Decision for selection of pesticide for use $(n=156)$

\begin{tabular}{lll}
\hline Item & Yes & Percentage \\
\hline Seasonal occurrence of pest & 70 & 45 \\
Preventive reasons & 23 & 15 \\
Pest density control & 12 & 8 \\
Curative factors & 6 & 4 \\
Weather factors, & 5 & 3 \\
Defensive related use & 5 & 3 \\
Routine application & 34 & 22 \\
\hline
\end{tabular}

Most farmers mentioned during the discussion that pesticides are necessary, but are open and willing to use appropriate alternative methods of pest control if they became available, effective and affordable. Farmers mentioned health problems like headaches, burning sensation in the eyes, itching and skin irritation, among others (Table 2.8). Pesticides exposure may result in physical and mental illnesses such as dermatitis, anxiety, irritability, 
loss of memory and depression, which ultimately may result in suicide (Kishi et al. 1995; Koh and Jeyaratnam, 1996; Harris, 2000). It is estimated that worldwide 3 million people are affected by pesticides poisoning annually, resulting in 220,000 deaths (Konradsen et al. 2003). The situation calls for immediate attention for necessary solution options from the authorities. The farmers also remarked that they had not been screened specifically for pesticides poisoning before (Table 2.4), and therefore were prepared to subject themselves to be screened for pesticides exposure/poisoning if the opportunity is made available.

Table 2.8: Have you experienced any of the listed symptoms following pesticide application? $(n=156)$

\begin{tabular}{lll}
\hline Symptom & Yes & Percentage \\
\hline Headache & 156 & 100 \\
Burning sensation in eyes/face & 156 & 100 \\
Fever & 146 & 94 \\
Watering eye & 156 & 100 \\
Skin rash & 142 & 91 \\
Itching and skin irritation & 156 & 100 \\
Dizziness & 154 & 99 \\
Cold, breathlessness and/or chest pain & 122 & 78 \\
Forgetfulness & 136 & 87 \\
Loss of libido & 83 & 53 \\
Salivation and vomiting & 110 & 71 \\
Abdominal pain/diarrhoea & 117 & 75 \\
Weakness & 156 & 100 \\
\hline
\end{tabular}

\section{Pesticides import, distribution and retail}

The involvement of private actors in importation, distribution and retailing of pesticide products in Ghana has been increasing since the introduction of the pesticides registration. Currently the pesticides distribution in Ghana is performed by many small-scale private businesses and their number increased from 515 in 2010 to 916 in 2011 (Personal communication, Office of the Pesticides Registrar, Ghana EPA). Following the implementation of the law, 441 pesticides had been registered in December 2014 for agricultural and household uses by the EPA. The registered pesticides included $47 \%$ insecticides, $12 \%$ fungicides, $37 \%$ herbicides, $1 \%$ plant growth regulators, and $1 \%$ (molluscicides, rodenticides, 


\section{Chapter 2}

nematicides and adjuvants). It is on record that the number of registered pesticides increased from 2003 to 2011 (Fig. 2.3), whilst the volume of imported pesticide products was on average of 9,216 tons of insecticides, 8,986 tons of herbicides and 2,545 tons of fungicides from 2004 to 2015 (Personal communication, Office of the Pesticides Registrar, Ghana EPA).

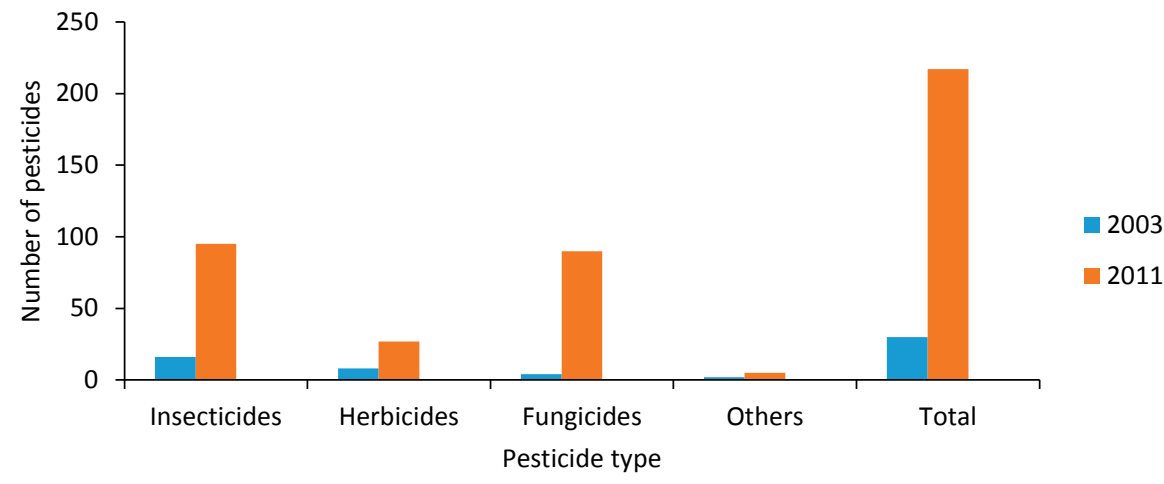

Figure 2.3: Number of formulated pesticide products registered or provisionally cleared in 2003 and 2011. Source: Environmental Protection Agency-Ghana, Annual Reports, Accra. "Other" includes rodenticides, nematicides, fumigants and other conventional pesticides, and other chemicals used as pesticides such as petroleum oil

It is worth mentioning that currently there are no pesticides manufacturing and formulation plants in Ghana, so all pesticide products are imported (Fig. 2.2). The rapid increase in the amount of pesticide companies and retailers shows the lucrative nature of the pesticides business in Ghana. The motivation is the profit on sales as the interaction revealed. Empirical findings of this study showed that all the visited distributors had valid licences to operate and pesticides registration permits for the displayed pesticide products (Table 2.9).

Table 2.9: Compliance to Pesticide Registration Licence by pesticide dealers

\begin{tabular}{lll}
\hline Question & Yes & Percentage \\
\hline a) Has this place been inspected by the EPA/PPRSD (2014/15)? & 13 & 100 \\
Importer/Distributor $(n=13)$ & 30 & 100 \\
Pesticide Retailer $(n=30)$ &
\end{tabular}




\begin{tabular}{|c|c|c|c|}
\hline Impo & Distributor $(n=13)$ & 13 & 100 \\
\hline Pestic & Retailer $(n=30)$ & 23 & 77 \\
\hline Tec & Know-how/Use of PPEs & & \\
\hline Impo & Distributor & & \\
\hline i. & Know the Pesticide Law & 13 & 100 \\
\hline ii. & Do you have the current pesticide registration list (Dec. 2014)? & 7 & 54 \\
\hline iii. & Knowledge/skill to identify symptoms of pest attack? & 13 & 100 \\
\hline iv. & Technical Knowledge on field diagnosis of pest? & 13 & 100 \\
\hline v. & Know the different pesticide application methods? & 13 & 100 \\
\hline vi. & Use of PPE & 3 & 23 \\
\hline Retai & & & \\
\hline i. & Know the Pesticide Law & 30 & 100 \\
\hline ii. & Do you have the current pesticide registration list (Dec. 2014)? & 0 & 0 \\
\hline iii. & Knowledge/skill to identify symptoms of pest attack? & 5 & 17 \\
\hline iv. & Technical Knowledge on field diagnosis of pest? & 6 & 20 \\
\hline v. & Know the different pesticide application methods? & 26 & 87 \\
\hline vi. & Use of PPE & 11 & 37 \\
\hline
\end{tabular}

The displayed products were not expired (Table 2.9). This was to be expected as their ability to import pesticide products are tied in to the renewal of licenses. However, $23 \%$ of the retail outlets had their licenses expired or in the process of being renewed in violation of section 40 (1) of the Act. Similar observations were made regarding their knowledge of the pesticides law, as their appreciation of it was generally inadequate. The distributors and retailers violated section 44 ( 4 and 5 ) of the Act. The provision and use of PPEs as well as the technical knowledge on the handling of pesticides by retailers was low (Table 2.9).

The observation suggests the probable shortage of expert advice and technical support on pesticides for farmers who may patronise these shops. This could lead to problems of indiscriminate use, high frequency of application and application of pesticides with the same mode of action, resulting in pest resistance and resurgence and associated indirect costs. Gill and Garg (2014) discussed other potential management options including cultural and physical control, host plant resistance, biocontrol, and the use of biopesticides. Although having limited knowledge, many farmers still prefer to contact a pesticides retailer instead of an extension official when problems arise, because of their close proximity. Mengistie et al. (2014) reported a similar trend whilst seeking information by farmers in Ethiopia. Discussion 


\section{Chapter 2}

with owners of the shops indicated that most of their recruited staff upon successful training in pesticides management resign to either establish their own businesses or join companies with better remuneration. However, since the level of know-how of the retailers needs further improvement, rigorous information dissemination by the extension service is required.

\section{State policy actors of pesticides}

The state policy actors of pesticides was considered at national (Ghana EPA and PPRSD) and local (extension staff) levels. The state actors are important to transfer knowledge to importers, distributors/retailers and farmers and to increase the implementation of policy at both the national and the local (farm) level.

\section{National state actors}

The ranked score gave an indication of how the issues questioned on (motivation, information and resources) had performed and showed those that had been achieved, those in-between and those that had underperformed and needed attention. This defines the strong and weak aspects of the implementation process. It is clear that "salary is encouraging" and "transport facilities are adequate to access pesticides dealers and users" are the least scored. This indicates the need of state policy implementers for improvements in salaries and means to reach pesticides distributors, retailers and farmers. Among the most strong aspects in the implementation process investigated were "knowledge of the pesticides law", "current pesticides register", "pesticides registration process", "different pesticide application methods" and "work being interesting" (Table 2.10).

Table 2.10: Ranking of responses to questions and related observation $(n=17)$

\begin{tabular}{llll}
\hline Rank & Motivation(M)/Resource(R)/Information(I) & Observation & Sum of responses \\
\hline 1 & Know the Pesticide Law & I & 85 \\
1 & Do you have the current pesticide registration list (Dec. 2014) & I & 85 \\
1 & Familiar with the pesticide registration process? & I & 85 \\
4 & Know the different pesticide application methods? & I & 79 \\
4 & Work itself interesting & $\mathrm{M}$ & 79 \\
6 & Current Job is satisfactory & $\mathrm{M}$ & 77
\end{tabular}




\begin{tabular}{|c|c|c|}
\hline 7 & Knowledge/skill to identify symptoms of pest attack? & I \\
\hline 7 & Technical Knowledge on field diagnosis of pest? & I \\
\hline 9 & Job security & M \\
\hline 10 & The relation between management and employees & M \\
\hline 11 & $\begin{array}{l}\text { Technical staff for risk assessment of submitted pesticide } \\
\text { dossiers? }\end{array}$ & $\mathrm{R}$ \\
\hline 12 & $\begin{array}{l}\text { In-service training and skills development on current job } \\
\text { satisfaction }\end{array}$ & M \\
\hline 13 & Sufficient space to work & M \\
\hline 14 & $\begin{array}{l}\text { Pesticide user manuals are available to be effectively used by } \\
\text { pesticide dealers }\end{array}$ & $\mathrm{R}$ \\
\hline 15 & Accredited laboratory to test pesticide products? & $\mathrm{R}$ \\
\hline 16 & Carrier structure and promotion on current job satisfactory & M \\
\hline 17 & Recognition, rewards, praise by supervisors & M \\
\hline 18 & Financial benefits and bonuses & M \\
\hline 18 & $\begin{array}{l}\text { No. of pesticide inspectors assigned to dealers and users of } \\
\text { pesticides proportional? }\end{array}$ & $\mathrm{R}$ \\
\hline 21 & Salary is encouraging & M \\
\hline 21 & $\begin{array}{l}\text { Transport facilities are adequate to access pesticide dealers and } \\
\text { users? }\end{array}$ & $\mathrm{R}$ \\
\hline
\end{tabular}

Motivation=M); Resource=R; Information=I

Figure 2.4 shows the available observation criteria for state policy implementers in policy implementation hierarchical cluster. The tree-diagram depicts the result of the cluster analyses of 21 mutually dependent questions and attributes (referred to as observation motivation (M), information (I) and resource (R) shown in Table 2.10) and responses for the cluster represents people who share similar concerns and characteristics.

The first cluster (most left) are state policy actors who know the pesticides law, have the current pesticides registration list, are familiar with the pesticides registration process, know the different pesticides application methods, have knowledge/skill to identify symptoms of pest attack, have technical knowledge on the diagnosis of pest in the field, find the work itself interesting, and are satisfied with their current job. 


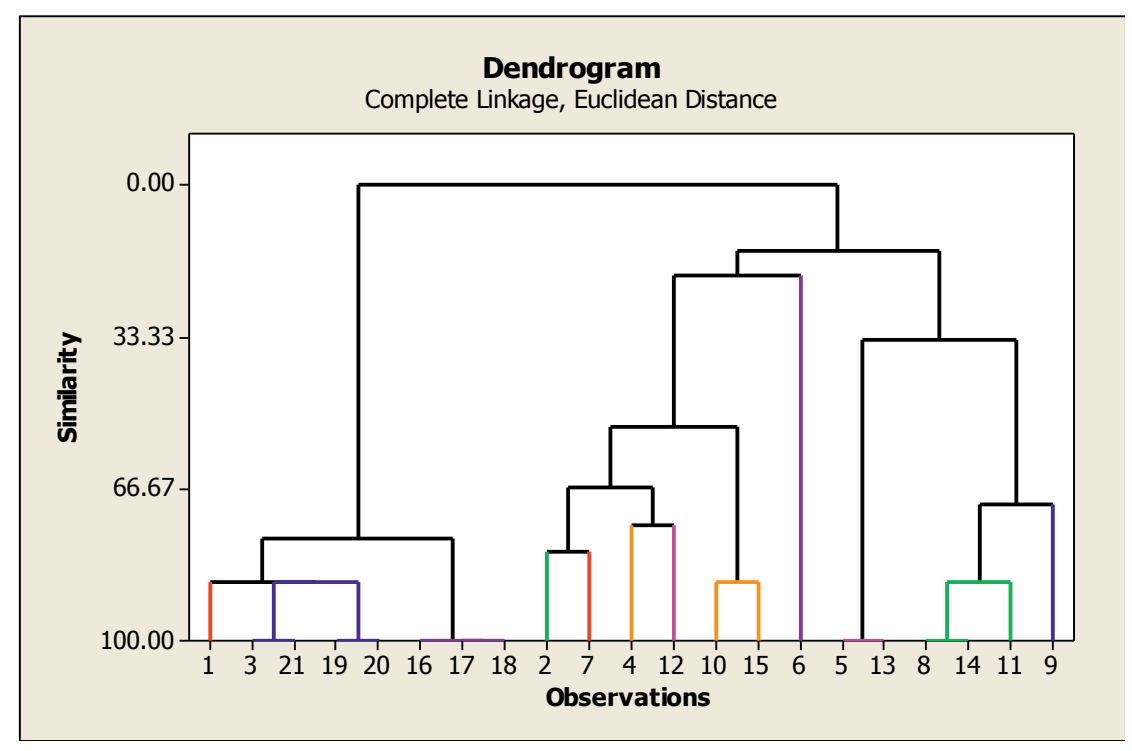

Figure 2.4: Diagram showing hierarchical cluster of observation (motivation (1-10), resources (11-15) and information (16-21)) by policy implementers.

These people find their work to be the most significant contributor to their motivation. Motivation, resources and information are significant to achieving their required job. This cluster can be described as the work result recognition group (Zámečník, 2014).

The second cluster (middle) concerns the relation between management and employees, technical staff for risk assessment of submitted pesticide dossiers, in-service training and skills development on current job satisfaction, sufficient space to work, pesticide user manuals are available to be effectively used by pesticide dealers, and carrier structure and promotion on current job satisfaction. To a large extent, the second cluster is linked to the first cluster -motivation and resources are significant to achieving this required job.

The third cluster (most right) is composed of accredited laboratory to test pesticide products, recognition of actors input to achieving results by management, rewards and praise by supervisors for success, financial benefits and bonuses, number of pesticide inspectors assigned to dealers and users of pesticides proportional, unattractive salary, lack of transport facilities to adequately access pesticide dealers and users. In a similar study by Mengistie et al. (2014) in Ethiopia, the majority of the actors indicated that they were underpaid given their 
workload. This cluster can be called the materialistic cluster since motivation and resources are significant to achieving their required job, and these are the main factors undermining the proper implementation of the pesticide registration policy (Zámečník, 2014).

\section{Local state actors}

Respondents were motivated with high scores regarding security of job (100\%), interested in what they do, and that the job was satisfactory (Table 2.11). Salary, financial benefits, bonuses and recognition for work done by supervisors, however, was low. Access to information was considered adequate with respect to the pesticide law, knowledge and skills to identify symptoms of pest attack, diagnosis and the different pesticide application methods. Lessons drawn from Ntow et al. 2006 points to the importance of agricultural extension officer's involvement in farmers' knowledge of insecticide application. The exception recorded in the study is the unavailability of the pesticides register for 2014. All respondents were of the opinion that the proportion of extension officers to dealers and users of pesticides was low and that there is a lack of transport to easily access the pesticide dealers and users (Table 2.11).

Table 2.11: Responses of state actors at local level $(n=15)$

\begin{tabular}{|c|c|c|c|}
\hline \multicolumn{2}{|l|}{ Item } & Yes & Percentage \\
\hline \multicolumn{4}{|c|}{ A) Motivation } \\
\hline i. & Current job is satisfactory & 12 & 80 \\
\hline ii. & In service training and skills development on current job satisfaction & 9 & 60 \\
\hline iii. & Work itself interesting & 13 & 86 \\
\hline iv. & Carrier structure and promotion on current job satisfaction & 11 & 73 \\
\hline v. & Salary is encouraging & 3 & 20 \\
\hline vi. & Job security & 15 & 100 \\
\hline vii. & The relation between management and employees & 9 & 60 \\
\hline viii. & Financial benefits and bonuses & 3 & 20 \\
\hline ix. & Recognition, rewards, praise by supervisors & 3 & 20 \\
\hline $\mathrm{x}$. & Sufficient space to work & 10 & 66 \\
\hline \multicolumn{4}{|c|}{ B) Resource } \\
\hline vii. & Transport facilities are adequate to access pesticide dealers and users? & 5 & 33 \\
\hline viii. & $\begin{array}{l}\text { No. of pesticide inspectors/extension assigned to dealers and users of pesticides } \\
\text { proportional? }\end{array}$ & 0 & 0 \\
\hline ix. & $\begin{array}{l}\text { Pesticide user manuals are available to be effectively used by pesticide dealers } \\
\text { and farmers? }\end{array}$ & 11 & 73 \\
\hline
\end{tabular}




\section{Chapter 2}

C) Information

$\begin{array}{llll}\text { vii. } & \text { Know the Pesticide Law } & 15 & 100 \\ \text { viii. } & \text { Do you have the current pesticide registration list (Dec. 2014)? } & 8 & 53 \\ \text { ix. } & \text { Knowledge/skill to identify symptoms of pest attack? } & 15 & 100 \\ \text { x. } & \text { Technical Knowledge on field diagnosis of pest? } & 15 & 100 \\ \text { xi. } & \text { Know the different pesticide application methods? } & 15 & 100\end{array}$

\section{Conclusions}

Pesticides legislation on registration and licensing is relatively well-developed in Ghana. The study shows a couple of challenges in the policy implementation. These findings have a number of effects on pesticides implementation policy and agricultural sustainability in general. The focus of this study was that policy implementation processes are interaction processes between state actors (policy implementers) and non-state actors (farmers and pesticide dealers, importers etc.) in relation to attributes as information, motivation and resources. The pesticides policy implementation in Ghana has not been able to adequately deal with the non-state actors such as pesticide dealers with respect to the choice of particular pesticides for a given problem and technical knowledge on field diagnosis of pests and diseases. This thus make it difficult to professionally dispense pesticides to farmers including advice on the use of PPEs. Although some farmers are aware of the risks associated with pesticide use, adequate protection provided by PPEs is hardly used. Adequate training on the pesticide handling, use and diagnosis of disease symptoms in the field is required more of state actors and suppliers to train farmers to rotate the use of chemical pesticide thus reducing the risk of pest resistance. Also, farmers should be encouraged to use their old clothes during preparation and spray operations instead of buying special clothes for spraying, which may be expensive for them. Farmers with a combination of a bit of education and extensive experience identified in study could be used to promote best knowledge, attitude and practices to other farmers. Farmers should also be trained on acute and chronic symptoms of pesticide poisoning and for them to better appreciate the necessary remediative steps to take once they experience such symptoms.

Most importantly, our study reflects the stronger involvement of state actors with the responsibilities to make available to non-state actors various sources of information with regards to pesticides use, management of pesticides and the pesticides law as well as friendly 
PPE alternatives for farmers through government intervention at subsidised prices. Finally, the pesticides regulations should be passed and implementers (Ghana EPA/PPRSD) should also be motivated and resourced enough to carry out their mandate in Ghana. 


\section{Chapter 3}

\section{Environmental risk assessment of pesticides currently applied in Ghana}

${ }^{a}$ Aquatic Ecology and Water Quality Management Group, Wageningen University, P.O. Box 47, 6700 AA, Wageningen, The Netherlands

${ }^{\mathrm{b}}$ Environmental Protection Agency, P. O. Box M326, Accra, Ghana

${ }^{c}$ Department of Environmental Science, College of Science, Kwame Nkrumah University of Science and Technology, PMB University Post Office, Kumasi, Ghana

${ }^{d}$ Wageningen Environmental Research, P.O. Box 47, 6700 AA, Wageningen, The Netherlands

This chapter has been revised and published in Chemosphere (2020), 254: 126845. 


\section{Chapter 3}

\section{Abstract}

Registration of pesticides for use in Ghana is based on prospective environmental risk assessment (ERA) to assess the risks of future pesticide use on the environment. The present study evaluated whether pesticides currently used by Ghanaian farmers may harm the aquatic and terrestrial environment under day-to-day farm practice by performing a $1^{\text {st }}$ tier ERA for terrestrial and aquatic environment and a $2^{\text {nd }}$ tier ERA for the aquatic environment using existing scenarios and models. The evaluation applied the $1^{\text {st }}$ tier PRIMET (Pesticides RIsks in the Tropics to Man, Environment, and Trade) model, as well as the Species Sensitivity Distribution (SSD) concept to determine environmental exposure concentrations and ecological threshold levels of the pesticides protective to aquatic and terrestrial communities. Results of the $1^{\text {st }}$ tier risk assessment indicated that in the investigated regions in south Ghana, many pesticides might pose an acute risk to aquatic ecosystems adjacent to the treated fields while lambda cyhalothrin, chlorpyrifos, cypermethrin, dimethoate, mancozeb, carbendazim, sulphur, maneb, copper hydroxide and cuprous oxide may pose the highest chronic risks. Butachlor, dimethoate and carbendazim may pose acute risks to the terrestrial soil ecosystem, while glyphosate, chlorpyrifos, imidacloprid, dimethoate, mancozeb, carbendazim, maneb, copper hydroxide and cuprous oxide may pose the highest chronic risks. Paraquat, lambda cyhalothrin, chlorpyrifos, emamectin benzoate, imidacloprid, thiamethoxam, bifenthrin, cypermethrin, dimethoate, carbofuran, mancozeb and maneb may pose acute risks to bees and propanil, lambda cyhalothrin, chlorpyrifos imidacloprid, carbofuran, sulphur, copper hydroxide and cuprous oxide to the terrestrial non-target arthropods. The $2^{\text {nd }}$ tier acute aquatic risk assessment showed that the risks of pendimethalin, propanil, oxyfluorfen, lambda cyhalothrin, chlorpyrifos, cypermethrin, dimethoate carbofuran, mancozeb, carbendazim, maneb and copper hydroxide could be substantiated using species sensitivity distribution (SSD). Actual pesticide use was a factor of 1.3 to 13 times higher than the recommended label instructions, indicating a general practice of overdosing. The case study shows that the PRIMET model in combination with the SSD concept may offer pesticide registration authorities in Ghana a means to assess environmental risks associated with pesticide usage in a user-friendly and cost-effective manner. 


\section{Introduction}

Agriculture makes a big contribution to the economy of Ghana ranking second to the services sector in terms of gross domestic product (GSS, 2015). Inputs such as pesticides, fertilizers and improved planting materials are increasingly used (WAAPP, 2014). The use of pesticides is important to protect crops from pests which has significantly reduced losses and improved the yield of crops such as cereals, vegetables and fruits (MOFA, 2003). Information from the Environmental Protection Agency of Ghana indicated that 540 pesticides have been registered and are available for use in agriculture and public health as of December 2015 (Ghana EPA, 2015). Pesticides applied to the field are of concern because of the risk of pollution, especially to vulnerable aquatic and terrestrial ecosystems (Aktar et al. 2009). The need to monitor the environmental risks of pesticides has been highlighted (Vijver et al. 2017), but Ghana's pesticide law does not have the necessary regulation to adequately address this issue (NPASP, 2012). Although pesticide use is high in Ghana, regulatory infrastructure is underdeveloped or not adequately enforced and capacity for routine monitoring programmes is lacking (NPASP, 2012; Onwona Kwakye et al. 2019).

The registration of pesticides for use in Ghana is based on prospective risk assessment, while the development of the underpinning field of sciences, i.e. environmental chemistry and ecotoxicology, is in its early stages in Ghana. Local studies on pesticides regarding environmental risk assessment and particularly assessments of pesticides toxic effects on aquatic and terrestrial organisms have not been widely undertaken. A few studies that have been conducted involved pesticides exposure in rivers in the intensive cocoa growing areas of the Ashanti and Eastern Regions of Ghana. In Oda, Kowire and Atwetwe rivers, for example, mean pesticide concentrations found in water samples for lindane and endosulfan were 19.4 and $12.4 \mu \mathrm{g} / \mathrm{L}$ (Oda), 16.4 and $17.9 \mu \mathrm{g} / \mathrm{L}$ (Kowire), 20.5 and $21.4 \mu \mathrm{g} / \mathrm{L}$ (Atwetwe), respectively (Acquaah, 1997). A study published by Ntow in 2001 on organochlorine pesticide levels in water samples collected from streams near the city of Akumadan, a prominent vegetablefarming area in Ghana, showed that endosulfan sulfate was the most frequently occurring pesticide, detected in $78 \%$ of the sampled waters with a mean concentration of $30.8 \mu \mathrm{g} / \mathrm{L}$. In a similar study on the Volta Lake, lindane was detected in 38 samples, comprising of $76 \%$ of the analysed samples. Lindane and endosulfan were identified in relatively low mean concentrations of $\leq 0.008$ and $0.036 \mu \mathrm{g} / \mathrm{L}$, respectively (Ntow, 2005). 


\section{Chapter 3}

The current study evaluated whether current pesticide use by Ghanaian farmers may harm the environment under day-to-day farm practice by:

1. performing a $1^{\text {st }}$ tier environmental risk assessment to identify pesticides that may pose a risk to the aquatic and terrestrial environment using the PRIMET (Pesticides Risks in the Tropics to Man, Environment, and Trade) model (Peeters et al. 2008);

2. determining $2^{\text {nd }}$ tier threshold levels that are protective of aquatic communities in the study site(s) using the Species Sensitivity Distribution (SSD) concept (Maltby et al. 2005);

3. evaluating the use of banned products and the overuse of pesticides, i.e. higher use than recommended dose.

The findings of this paper will contribute in filling the pesticide risk assessment gap with respect to available tools and procedures for especially the aquatic environment in Ghana. If risks are indicated, it is expected that the pesticide registration authority (Ghana Environmental Protection Agency; EPA) will use the information to initiate the necessary changes of farmers' pesticide use and that of other stakeholders to improve the quality of the aquatic and terrestrial environment.

\section{Materials and methods}

\section{Study sites}

A survey was conducted between May 2013 to January 2014 in four selected irrigation sites and a cocoa farming community involving 131 farmers. The sites were in the Central (Okyereko), Greater Accra (Weija and Ashaiman) and Eastern (Tontro/New Tafo and Akuse) regions of Ghana (Fig. 3.1). The study sites were chosen to reflect i) the steady increase of crop farming in the country, ii) the regions which uses pesticides intensively and iii) the regions being representative of Ghana in terms of agricultural advancement, crops grown, geography, and climate, among others (Dickson and Benneh, 1998; MOFA, 2011). The system of farming was mainly mono-cropping for each of the sites. 


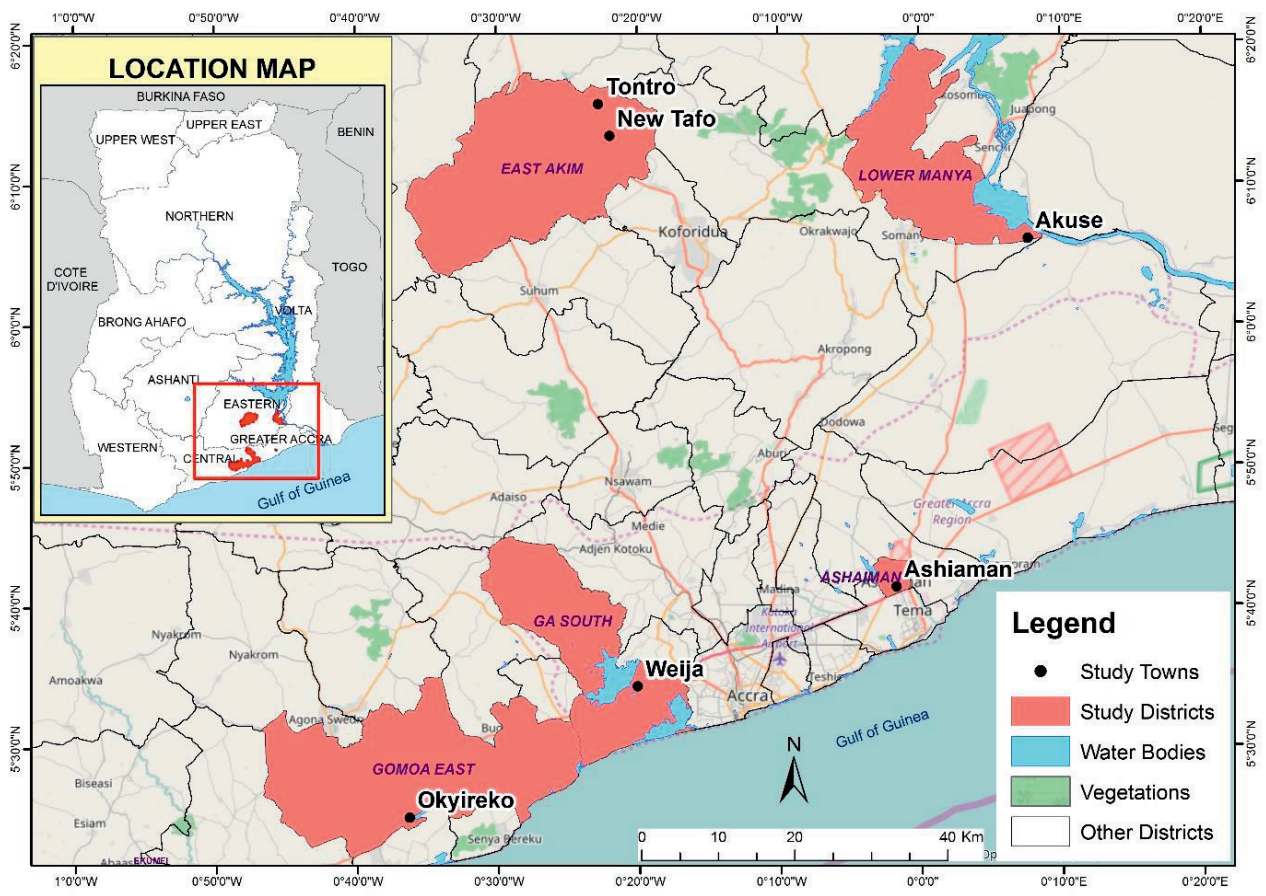

Figure 3.1: Geographical location of the study sites in Ghana.

Prior informed consent was obtained from each respondent and permission to carry out research at the sites was obtained from the scheme managers of the irrigation sites and from the owners of the cocoa farms. Information on pesticides used, application dose, and frequency were obtained from the farmers by way of questionnaire administration and records of observations of farmers whilst working in the field. The application rate of the pesticides being applied was particularly noted and compared to the recommended rates on the pesticide label (see Table SI 3.1; supplementary information for questionnaire used).

\section{The PRIMET model}

The $1^{\text {st }}$ tier risk assessment of the pesticides to the aquatic and terrestrial environment was performed by applying the risk assessment model PRIMET (Pesticide Risks in the Tropics to Man, Environment and Trade; version 2.0) using hypothetical exposure scenarios (Peeters et al. 2008). To perform a risk assessment in PRIMET, a scenario describing the physical properties of the environmental compartment must be provided as well as data on the 


\section{Chapter 3}

physico-chemical properties of the pesticides and the sensitivity of the organisms under evaluation. Scenarios of actual pesticide use were limited to application method, dosages (g active ingredient (a.i.)/ha), application interval (d) and frequency of use reported by the farmers. Pesticide formulations that had been made of more than one active ingredient were separated into the different active ingredient concentrations (Table SI 3.2). For each environmental compartment (aquatic, soil, bee and non-target arthropods), PRIMET calculates an exposure concentration (Predicted Environmental Concentration, PEC) and a threshold concentration for effects (Predicted No Effect Concentration, PNEC), from which the Exposure Toxicity Ratio (ETR) can be calculated by dividing the PEC by the PNEC. An ETR lower than 1 indicates that no serious risks are expected, an ETR between 1 and 100 indicates that risks may be present, while an ETR of higher than 100 indicates that risks are very likely to occur. The PRIMET DSS (Decision Support System) is freely available on www.primet.wur.nl and incorporated in a Graphical User Interface.

\section{Physico-chemical data}

In order to calculate the exposure concentration using the PRIMET model, data on each of the pesticides' intrinsic physico-chemical properties were mostly already available in the model and, if not, taken from literature sources. Most available data were collected for the temperate regions of Europe and North America, but were temperature corrected within the PRIMET model. Table SI 3.3 shows the pesticide physico-chemical characteristics required for the PRIMET model. The pesticide products and active ingredients evaluated are the most used pesticides in the study area. The variables in Table SI 3.3 were obtained from either the PPDB: Pesticide Properties DataBase (PPDB, 2020) or already given in the PRIMET database.

\section{First tier acute and chronic aquatic risk assessment}

In this $1^{\text {st }}$ tier risk assessment for the aquatic risk assessment only entry via spray drift was taken into consideration. An irrigation channel with an aquatic waterway of $1 \mathrm{~m}$ wide at the bottom, a slope of 0.5 and a water depth of $0.5 \mathrm{~m}$ was used for the aquatic scenario. The length from which the channel received spray drift following the applications was $100 \mathrm{~m}$ with a flow velocity of $100 \mathrm{~m} /$ day. The water phase was assumed to contain $1 \mathrm{~g} / \mathrm{L}$ of suspended 
solids with an organic matter content of $50 \%$, while the water temperature was taken to be $30{ }^{\circ} \mathrm{C}$. The climate of Akuse, Okyereko, Ashaiman and Weija is of the tropical savannah type and characterized by a bimodal rainfall pattern. Average annual rainfall ranges from 625 to $1000 \mathrm{~mm}$. Mean annual temperature is $\left(29^{\circ} \mathrm{C}\right)$ and decreases to $26^{\circ} \mathrm{C}$ in July and August (http://mofa.gov.gh/site/?page_id=2985; GSS, 2014). New Tafo/Tontro lies in the moist semideciduous forest which is also characterized by two main rainfall seasons. The mean annual rainfall is between 125 and $175 \mathrm{~mm}$. Temperatures are found to be fairly uniform ranging between $26{ }^{\circ} \mathrm{C}$ in August and $30{ }^{\circ} \mathrm{C}$ in March and characteristic of a typical tropical climate (GSS, 2014; Abban et al. 2018).

Pesticides were applied using hand-pressured backpack knapsack (Matabi 15L). The spraying was done with the lance positioned in front of the applicators while they walked through the crops, also directly next to water courses. It was assumed that on the average $10 \%$ of the amount of pesticide applied per ha on the crops would reach the water surface by spray drift based on empirical drift data from knapsack sprayers shown by Snelder et al. (2008).

The data was entered into the PRIMET model to calculate an acute and chronic PEC. To calculate the $1^{\text {st }}$ tier acute Exposure Toxicity Ratio (ETR), this PEC was then divided by acute or chronic PNEC. An acute and chronic PNECs are based on toxicity data in the form of EC50 and NOEC data for selected standard test species from different trophic levels, namely algae (primary producers), Daphnia (invertebrates) and fish (vertebrates). The toxicity data extracted from these databases were for the acute static tests for freshwater invertebrates (48 h), vertebrates ( $96 \mathrm{~h}$ ) and primary producers (72 $\mathrm{h}$ and $96 \mathrm{~h}$ ) and for the chronic the extracted toxicity data were Daphnia (21 days) and fish (28 days). The relevant EC50 and NOEC data were extracted from the USEPA ECOTOX (USEPA, 2020a), the RIVM database (De Zwart, 2002) and the Pesticide Manual (Tomlin, 2000). The toxicity values used to calculate the $1^{\text {st }}$ tier PNECs are provided in Table SI 3.2.

These acute PNEC also incorporated an assessment factor (100 for fish and Daphnia and 10 for algae) and the lowest resulting PNEC was used as the threshold concentration of effects (Table SI 3.2). These assessment factors were used to extrapolate from the EC50 level to a concentration at which no effects on the organisms were expected and to account for interspecies variation (EU, 1997; Van den Brink et al. 2005). To calculate the chronic Exposure 


\section{Chapter 3}

Toxicity Ratio $\left(E^{n} R^{n}\right.$ ), a time weighted average PECs for fish (default period of 28 days) and daphnia (default period of 21 days) were calculated. These PECs were divided by their respective chronic PNEC for Daphnia (invertebrates) and fish (vertebrates), using an assessment factor of 0.1. When the resulting chronic PNEC was higher than the acute one, the acute PNEC was used for the chronic risk assessment. The assessment factors used in the PRIMET model are regarded as conservative for most of the chemicals evaluated in this study (Brock and Van Wijngaarden, 2012; Van Wijngaarden et al. 2015; Brock et al. 2016; Van Wijngaarden and Arts, 2018; Rico et al. 2019).

\section{First tier acute and chronic terrestrial risk assessment}

For the terrestrial risk assessments the toxicity values already incorporated in the PRIMET model were used. The terrestrial soil (earthworms) scenario included an acute 14 day LC50 and chronic NOEC for reproduction as effect endpoints using a default extrapolation factor of 0.1 and 0.2 for acute and chronic effect assessment of earthworm, respectively to calculate the PNEC. The exposure scenario included a bulk density of $1.0 \mathrm{~g} / \mathrm{cm}^{3}$ (Sally and Abernethy, 2002) of the soil, a depth of $0.05 \mathrm{~m}$ and the individual pesticide dose applied ( $\mathrm{g}$ a.i/ha), number of applications and application interval as obtained from the field survey.

The scenario for the bees included the acute LD50 ( $24 \mathrm{~h}$ and $48 \mathrm{~h}$ ) and the individual dose (g a.i./ha) of the pesticides applied. Likewise, for the non-target arthropod (NTA), an acute median lethal body residue (LR50), a vegetation scenario with a default distribution factor of 10, an extrapolation factor for effect assessment of NTA with a default value of 2 and a default drift factor value of 0.0277 as well as the number of pesticide applications (g a.i/ha) were used. The climatic conditions for the $1^{\text {st }}$ tier terrestrial risk assessment were the same as that described under the aquatic risk assessment.

Subsequently, the calculated acute and chronic soil PEC was then divided by the $1^{\text {st }}$ tier acute and chronic PNEC to calculate the acute and chronic ETR respectively. For NTAs and bees only an acute risk assessment was performed due to a lack of toxicity data. For NTAs an infield and off-field ETR was calculated with the latter being a factor of 100 lower (Peeters et al. 2008). 


\section{Second tier acute pesticide threshold levels for aquatic communities}

To refine the threshold values protective for ecological risk of insecticides, fungicides and herbicides to freshwater ecosystems in the study area, the species sensitivity distribution (SSD) concept was used to calculate the $2^{\text {nd }}$ tier acute PNEC for the chemicals indicated to pose an acute risk to aquatic ecosystems in the $1^{\text {st }}$ tier. This PNEC was compared to the $1^{\text {st }}$ tier acute PEC as calculated by PRIMET in order to calculate the $2^{\text {nd }}$ tier ETR.

When available, the SSD derived HC5 (Hazardous Concentrations 5\%) values present in Van den Brink et al. (2006) and Maltby et al. $(2005 ; 2009)$ were used as $2^{\text {nd }}$ tier acute PNECs (Table 3.3). In order to construct the SSDs for the remaining compounds, acute aquatic singlespecies were collated from the EPA ECOTOX database (USEPA, 2020a). Data selection criteria followed those of Maltby et al. $(2005 ; 2009)$ and Van den Brink et al. (2006), where the selected endpoints were median lethal concentration (LC50) or median effect concentration (EC50) regarding immobility for animals and EC50 regarding biomass or growth for plants. The test durations selected were 2 to $21 \mathrm{~d}$ for vertebrates, 1 to $7 \mathrm{~d}$ for invertebrates, 2 to $28 \mathrm{~d}$ for macrophytes, and 1 to $7 \mathrm{~d}$ for algae. Genera data were only used if no species data were reported for a genus. Each species was represented only once per compound in the analysis. The following data manipulations were performed where there were multiple toxicity values for a taxon:

1. The lowest value was selected where several duration times, temperatures, life stages, water types, etc., were studied in the same experiment.

2. The geometric mean was taken for data for the same species (and endpoint), but from different experiments.

The SSD generator developed by US EPA (USEPA, 2020b) was used to generate SSDs and median HC5 values (Hazardous Concentration 5\%) and their 95\% confidence interval. A log-normal distribution model by Aldenberg and Jaworska (2000) was fitted to a minimum of six data points, with model fit being evaluated using the Anderson- Darling goodness-of-fit test.

All arthropod data (crustaceans and insects) was included to construct SSD for insecticides, all aquatic data (vertebrates; invertebrates; and primary producers) for 


\section{Chapter 3}

fungicides and all data for primary producers (algae and macrophytes) for herbicides (Maltby et al. 2005; 2009; Van den Brink et al. 2006). The analysis was applied to the pesticide crop combination for which only a potential or likely acute risk was indicated in the $1^{\text {st }}$ tier calculation (i.e. ETR > 1). The analysis however focused on 19 pesticide compounds being 7 herbicides, 5 insecticides and 7 fungicides (Table 3.3).

\section{Overuse of pesticides}

The third aim was to evaluate whether the farmers overdose pesticides during normal day-to-day use and if products being used had been banned for use or not. The status of pesticides identified to be in use was cross-checked as well as application rate compared to the recommended rate provided by the registration authorities (GEPA, 2015) and as indicated on the label instructions.

\section{Results}

\section{First tier risk assessment}

The data set included 33\% insecticides, 30\% fungicides and 37\% herbicides as obtained from the individual active ingredient concentration (Table SI 3.3). For the risk assessment, the $1^{\text {st }}$ tier ETRs, the ranges of the ETRs and percentage of ETRs $>1$ were calculated (Table 3.1 and 3.2) using use patterns for 32 different active ingredients and their physico-chemical properties (Table SI 3.3). The application rate per hectare, application interval, number of applications per season, and crops applied to at the study sites are given in Table SI 3.2 together with their tier-1 acute L(E/D/R)C50 (Table SI 3.4) and tier-1 chronic NOEC (Table SI 3.5) data were included in the model to generate the PRIMET output. Three categories of risk were identified: 'no risk' (ETR < 1), 'possible risk' $(1<$ ETR < 100) and 'definite risk' $(E T R>100)$ for the pesticides studied within the environment. Some active ingredients showed ranges in ETRs spanning multiple categories due to differences with regards to the amount of active ingredient applied per hectare (Table 3.1 and 3.2).

Only for the insecticide emmamectin benzoate no acute and chronic aquatic risk assessment could be performed due to a lack of data, while this was not possible for pyribenzoxim and emmamectin benzoate for the acute soil risk assessment. Only for $53 \%$ of 


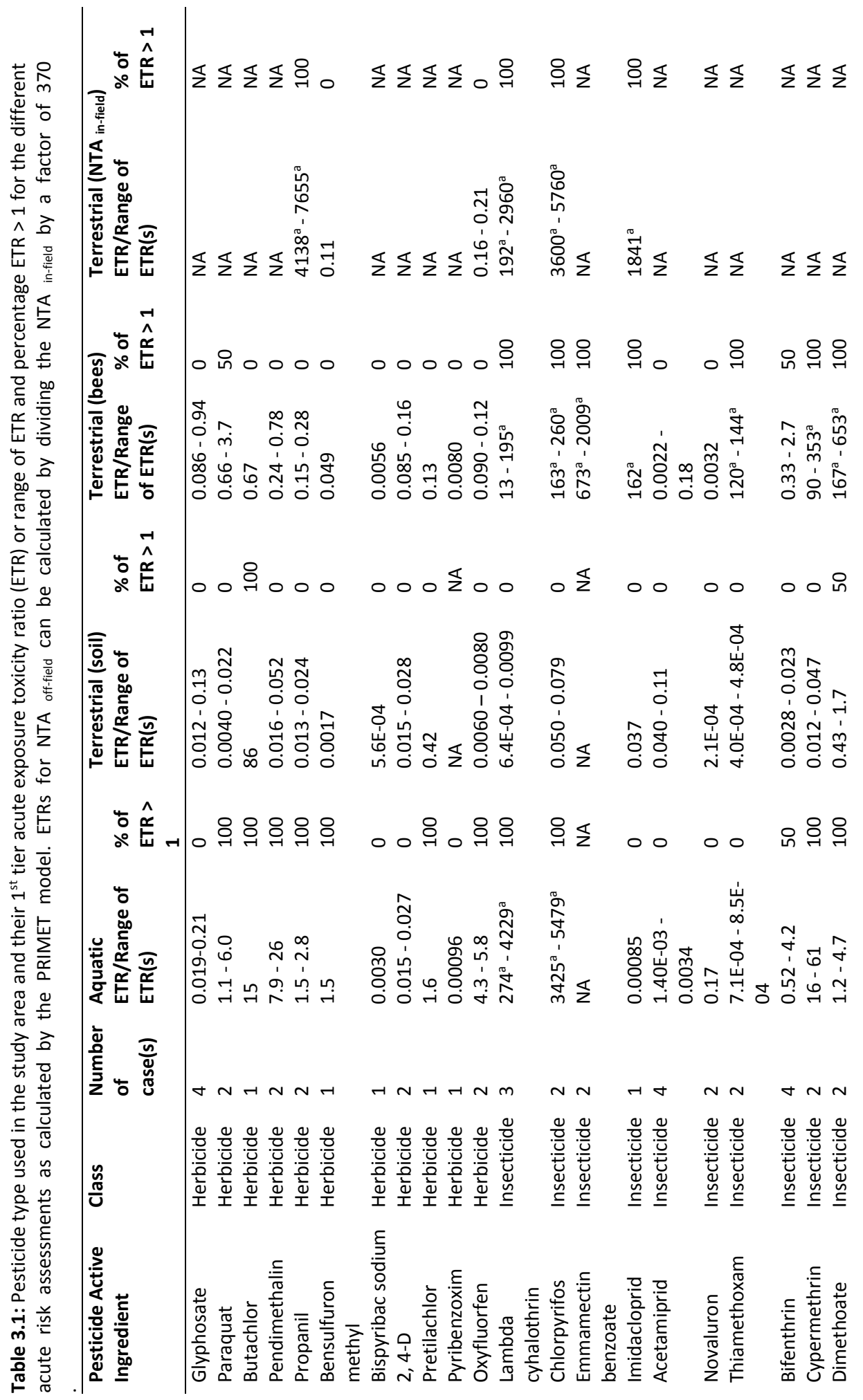




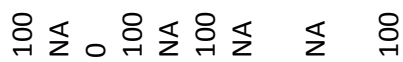

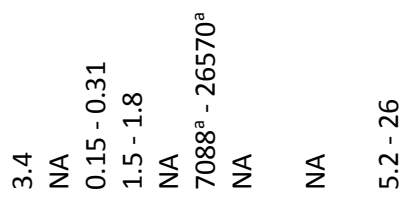

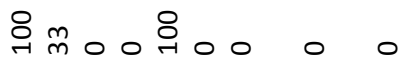

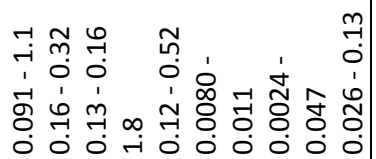
00 in 000000

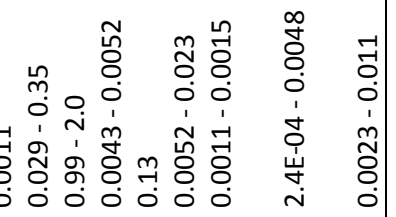

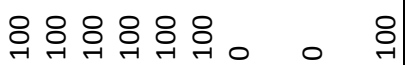
放

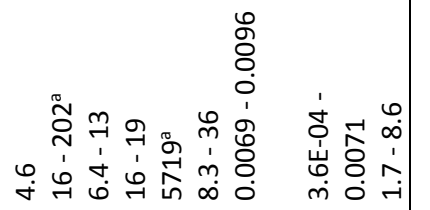


Table 3.2: Pesticide type used in the study area and their $1^{\text {st }}$ tier chronic exposure toxicity ratio (ETR) or range of ETR and percentage ETR for the different chronic risk assessments as calculated by the PRIMET model.

\begin{tabular}{|c|c|c|c|c|c|c|}
\hline \multirow{2}{*}{$\begin{array}{l}\text { Pesticide Active } \\
\text { Ingredient }\end{array}$} & \multirow[t]{2}{*}{ Class } & \multirow{2}{*}{$\begin{array}{l}\text { Number } \\
\text { of } \\
\text { case(s) }\end{array}$} & \multirow{2}{*}{$\begin{array}{l}\text { Aquatic } \\
\text { ETR/Range of } \\
\text { ETR(s) }\end{array}$} & \multirow[b]{2}{*}{$\begin{array}{l}\% \text { of } \\
\text { ETR }>1\end{array}$} & \multicolumn{2}{|c|}{ Terrestrial (soil) } \\
\hline & & & & & $\begin{array}{l}\text { ETR/Range } \\
\text { of ETR(s) }\end{array}$ & $\begin{array}{l}\% \text { of } \\
\text { ETR }>1\end{array}$ \\
\hline Glyphosate & Herbicide & 4 & $9.0 \mathrm{E}-04-0.0098$ & 0 & $0.10-1.1$ & 25 \\
\hline Paraquat & Herbicide & 2 & $0.051-0.28$ & 0 & NA & NA \\
\hline Butachlor & Herbicide & 1 & 0.72 & 0 & NA & NA \\
\hline Pendimethalin & Herbicide & 2 & $0.22-0.72$ & 0 & $0.24-0.78$ & 0 \\
\hline Propanil & Herbicide & 2 & $0.069-0.13$ & 0 & NA & NA \\
\hline $\begin{array}{l}\text { Bensulfuron } \\
\text { methyl }\end{array}$ & Herbicide & 1 & 0.070 & 0 & NA & NA \\
\hline Bispyribac sodium & Herbicide & 1 & $1.4 \mathrm{E}-04$ & 0 & NA & NA \\
\hline $2,4-D$ & Herbicide & 2 & $6.7 \mathrm{E}-04-0.0012$ & 0 & NA & NA \\
\hline Pretilachlor & Herbicide & 1 & 0.076 & 0 & NA & NA \\
\hline Pyribenzoxim & Herbicide & 1 & $4.3 \mathrm{E}-05$ & 0 & NA & NA \\
\hline Oxyfluorfen & Herbicide & 2 & $0.38-0.51$ & 0 & $0.12-0.17$ & 0 \\
\hline $\begin{array}{l}\text { Lambda } \\
\text { cyhalothrin }\end{array}$ & Insecticide & 3 & $31-479$ & 100 & NA & NA \\
\hline Chlorpyrifos & Insecticide & 2 & $401-642$ & 50 & $1.0-1.6$ & 100 \\
\hline $\begin{array}{l}\text { Emmamectin } \\
\text { benzoate }\end{array}$ & Insecticide & 2 & NA & 0 & NA & NA \\
\hline Imidacloprid & Insecticide & 1 & $1.9 \mathrm{E}-04$ & 0 & 4.0 & 100 \\
\hline Acetamiprid & Insecticide & 4 & $\begin{array}{l}1.7 \mathrm{E}-04-4.2 \mathrm{E}- \\
04\end{array}$ & 0 & 0.00470 .43 & 0 \\
\hline Novaluron & Insecticide & 2 & 0.89 & 0 & 0.11 & 0 \\
\hline Thiamethoxam & Insecticide & 2 & $4.9 \mathrm{E}-05-5.9 \mathrm{E}-05$ & 0 & $0.10-0.12$ & 0 \\
\hline Bifenthrin & Insecticide & 4 & $0.081-0.66$ & 0 & $0.022-0.18$ & 0 \\
\hline Cypermethrin & Insecticide & 2 & $1.8-7.1$ & 100 & NA & NA \\
\hline Dimethoate & Insecticide & 2 & $0.70-2.7$ & 50 & $2.5-9.7$ & 100 \\
\hline Carbofuran & Fungicide & 1 & 0.19 & 0 & 0.14 & 0 \\
\hline Mancozeb & Fungicide & 3 & $3.8-70$ & 100 & $0.21-2.6$ & 66 \\
\hline Carbendazim & Fungicide & 2 & $7.7-15$ & 100 & $6.7-13$ & 100 \\
\hline Sulphur & Fungicide & 2 & $1.4-1.7$ & 100 & NA & NA \\
\hline Maneb & Fungicide & 1 & $159^{a}$ & 100 & 6.6 & 100 \\
\hline Copper hydroxide & Fungicide & 4 & $0.59-4.6$ & 50 & $0.47-1.5$ & 25 \\
\hline Metalaxyl & Fungicide & 2 & $\begin{array}{l}6.4 \mathrm{E}-04-6.7 \mathrm{E}- \\
04\end{array}$ & 0 & NA & NA \\
\hline Metalaxyl-M & Fungicide & 2 & $1.4 \mathrm{E}-04-0.0072$ & 0 & NA & NA \\
\hline Cuprous oxide & Fungicide & 2 & $0.12-1.07$ & 50 & $0.25-1.3$ & 50 \\
\hline
\end{tabular}

ETR values below 1 indicate no risk, between 1 and 100 a potential risk and above 100 a definite risk.

NA indicates that the ETR was not determined because toxicity data were not available.

a- Represents a definite risk. 


\section{Chapter 3}

the compounds a chronic soil risk assessment could be performed while for all compounds an acute risk assessment for bees could be performed. For $37 \%$ of the compounds an acute risk assessment could be performed for NTAs (Table 3.1 and 3.2).

\section{'No risk'}

For the following pesticides 'no acute risk' were indicated based on the calculated highest acute ETRs for the aquatic environment: the herbicides glyphosate, bispyribacsodium, 2, 4-D and pyribenzoxim, the insecticides imidacloprid, acetamiprid, novaluron and thiamethoxam and the fungicides metalaxyl and metalaxyl-M (Table 3.1). There were also no chronic ETRs greater than 1 indicating no chronic risk to the aquatic environment with respect to the same pesticides as well as many others (Table 3.2).

With the exception of butachlor, dimethoate and carbendazim all active ingredients showed no acute risk for terrestrial (soil) organisms while the chronic terrestrial (soil) ETRs ranged from 0.0047 to 0.78 for pendimethalin, oxyfluorfen, acetamiprid, novaluron, thiamethoxam, bifenthrin and carbofuran (Table 3.2).

No acute risk to bees were calculated for herbicides, with the exception of paraquat, for insecticides with the exception of lambda cyhalothrin, chlorpyrifos, emmamectin benzoate, imidacloprid, thiamethoxam, bifenthrin, cypermethrin, dimethoate, and for fungicides with the exception of carbofuran, mancozeb, and maneb. The other active ingredients showed no acute risk to bees with $\mathrm{ETR}_{\text {Terrestrial acute Bees }}=0.0022-0.94$ (Table 3.1).

No acute ETRs $>1$ to terrestrial non-target arthropods (NTA) were calculated for the herbicide bensulfuron methyl and oxyfluorfen and the fungicide carbendazim while for all other pesticides for which data were available a (possible) risk was calculated. The chronic ETRs could only be calculated for $37 \%$ of the compounds. The ETRs of the herbicide bensulfuron methyl and oxyfluorfen, the insecticide carbofuran and the fungicides carbendazim, sulphur and cuprous oxide were lower than 1 (Table 3.1 and 3.2). It is clear that the chronic risk assessment for these organisms suffer from a lack of data as chronic, and even acute, toxicity data were not available for most compounds (Table 3.1 and 3.2). 


\section{'Possible risk'}

The predicted PRIMET highest acute ETR values were between 1 and 100 for most of the herbicides (i.e. paraquat, butachlor, pendimethalin, propanil, bensulfuron methyl, pretilachlor and oxyfluorfen), some insecticides (bifenthrin, cypermethrin and dimethoate) and almost half of the fungicides (carbofuran, carbendazim, sulphur, copper hydroxide and cuprous oxide). All highest chronic ETR values predicted by PRIMET for cypermethrin, dimethoate, mancozeb, carbendazim, sulphur, copper hydroxide and cuprous oxide were between 1 and 100, indicating possible risks with respect to the aquatic environment (Table 3.1 and 3.2).

The highest acute ETR predicted by PRIMET for the terrestrial soil environment were only larger than 1 for the herbicide butachlor, the insecticide dimethoate and fungicide carbendazim. They were also smaller than 100 and this indicating possible effects (Table 3.1). Chronic highest ETR between 1 and 100 were calculated for the herbicide glyphosate, the insecticides chlorpyrifos, imidacloprid and dimethoate and the fungicides mancozeb, carbendazim, maneb, copper hydroxide and cuprous oxide (Tables 3.1 and 3.2).

Acute highest ETRs between 1 and 100 for bees were calculated for the herbicide paraquat, the insecticide bifenthrin, and the fungicides carbofuran, mancozeb and maneb (Table 3.1).

Possible acute risks (highest ETR values between 1 and 100) for in-field NTAs were calculated for the fungicides carbofuran, sulphur and cuprous oxide (Table 3.1).

\section{'Definite risk'}

The PRIMET predicted definite acute risk (highest ETR values $>100$ ) values for the aquatic environment for the insecticides lambda cyhalothrin and chlorpyrifos and the fungicides mancozeb and maneb, while chronic definite risks were calculated for the insecticides lambda cyhalothrin and chlorpyrifos and the fungicide maneb (Table 3.1 and 3.2).

No definite acute or chronic risks (highest ETR values $>100$ ) were calculated for the soil compartment while definite acute risks values for bees included those for the insecticides lambda cyhalothrin, chlorpyrifos, emmamectin benzoate, imidacloprid, thiamethoxam, cypermethrin and dimethoate (Tables 3.1 and 3.2). For the non-target arthropods, PRIMET 


\section{Chapter 3}

calculated highest acute ETR values $>100$ for the herbicide propanil, the insecticides lambda cyhalothrin, chlorpyrifos and imidacloprid and the fungicide; copper hydroxide (Table 3.1).

\section{Second tier aquatic risk assessment}

For 15 of the 19 pesticides an HC5 could be calculated, however in the case of cuprous oxide only based on 7 data points instead of the required 8 ones (Table 3.3). The median factor at which the PNEC went up between the $1^{\text {st }}$ and $2^{\text {nd }}$ tier was 4.6. The highest increase in PNEC was observed for maneb (from $0.021 \mu \mathrm{g} / \mathrm{L}$ to $48 \mu \mathrm{g} / \mathrm{L}$, while a decrease was observed for 3 compounds (propanil, oxyfluorfen and dimethoate).

Paraquat, bifenthrin and cuprous oxide moved from the possible risk category to the no risk category, while 7 pesticides stayed in the possible risk category (Table 3.3). Only oxyfluorfen moved up in its risk category, i.e. from possible risk to definite risk. Chlorpyrifos, mancozeb and maneb moved from the definite risk category to the possible risk category, while lambda cyhalothrin was the only chemical staying in the definite risk category (Table 3.3). 


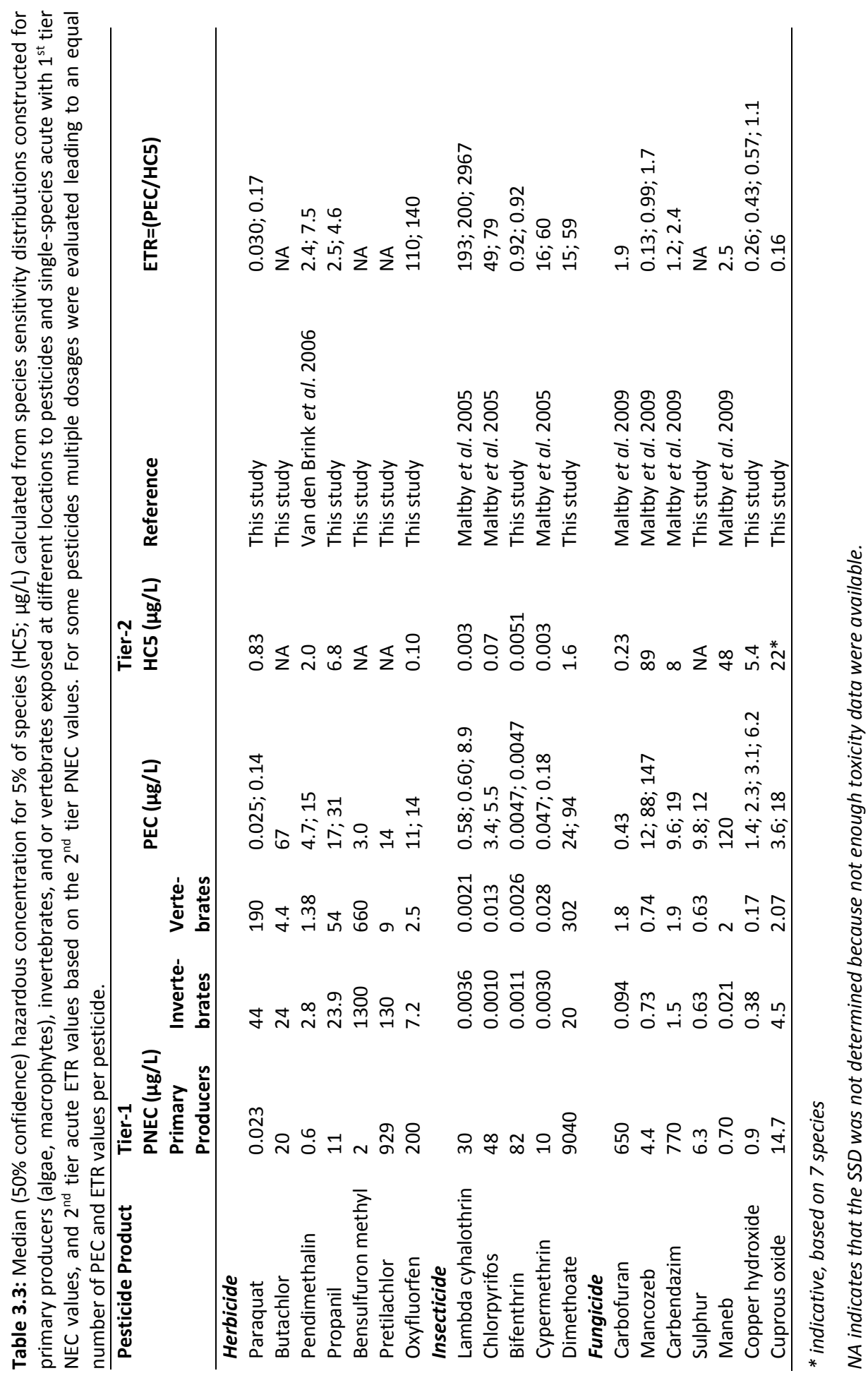




\section{Chapter 3}

\section{Overdosing of pesticides}

Table 3.4 shows that a number of pesticides have been applied in excess by farmers at the study sites as compared to the recommended dosages on the approved pesticide labels by Ghana pesticide registration authorities. Based on the mean of the minimum and maximum applied and recommended dosages, the average overdose factor was 4.5 with the highest values for the insecticides lambda cyhalothrin (applied as Karate, Conti-Halothrin, Pawa and Stricker) and cypermethrin and dimethoate mixture (applied as Cymethoate and Cydim Super) formulations. The lowest overdose factor values were observed for the fungicides sulphur (applied as Sulfa 80 WP), the insecticide mixture lambda cyhalothrin and acetamiprid (applied as K-Optimal), the herbicide mixture pretilachlor and pyribenzoxim (Solito formulation) and the herbicide butachlor (applied as Ceres Butachlor). No formulation was underdosed (Table 3.4). 


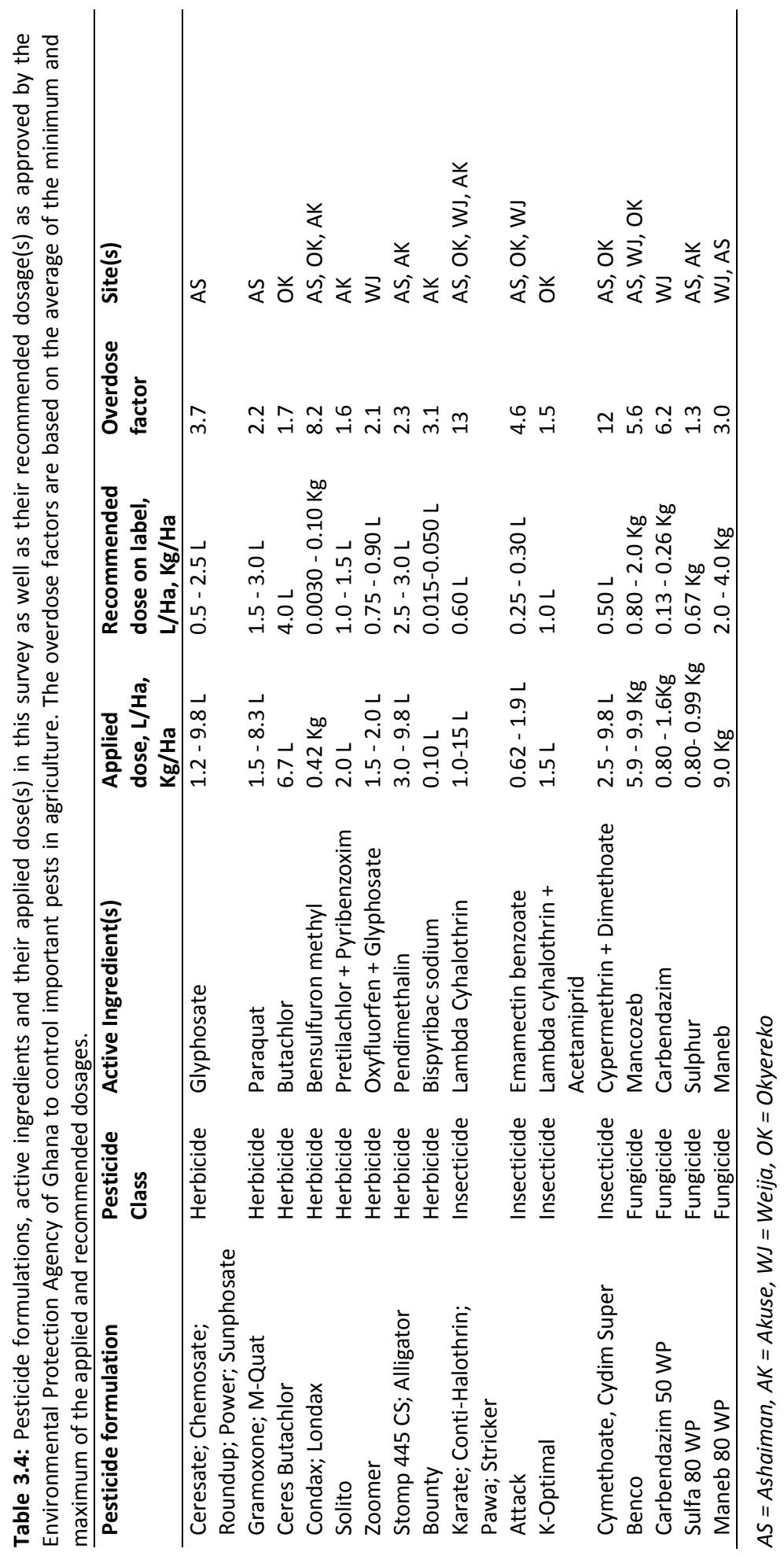




\section{Discussion}

This study reveals that environmental risks may be expected with regards to the use of pesticides in the case study areas of Ghana judging from the results of the environmental risk assessment in terms of ETRs for the aquatic (algae, daphnia and fish) and terrestrial (worms, bees and NTAs) compartments (Table 3.1, 3.2 and 3.3). This included the overdosing of pesticides applied by farmers, in comparison to the recommended dosages (Table 3.4). There was, however, no record of farmers using banned pesticide products in the study area.

\section{Aquatic risk assessment}

Aquatic ecosystems provide direct goods and services like clean drinking water, fish and aquatic macrophytes for consumption and indirect services like water purification, water retention and climate regulation (Grizzetti et al. 2016). It is, therefore, of most importance that aquatic ecosystems are of good ecological status and not impaired by chemicals such as pesticides. Among others, that was the reason for us to perform the aquatic risk assessment of the pesticide use dosages collected within this paper to evaluate the agricultural practices in the Central, Greater Accra and Eastern regions of Ghana.

Firstly, this study applied the PRIMET model for calculating environmental impact of pesticide use, and demonstrated that pesticide use poses serious potential acute and chronic risks to the aquatic environment, if aquatic ecosystems are present adjacent to the treated fields (Table 3.1 and 3.2). Malherbe et al. (2013) reported ETR values of 0.01, 0.2, 0.2-0.5 and 73 for dimethoate, glyphosate, carbendazim and paraquat respectively while Ansara-Ross et al. (2008) reported an ETR of 0.3 for pendimethalin for aquatic ecosystems in South Africa. In this study the calculated acute $1^{\text {st }}$ tier ETR for pendimethalin ranged between 7.9 and 26 (Table 3.1), indicating possible acute risk, which is substantiated by the $2^{\text {nd }}$ tier risk assessment (Table 3.3). These are much higher than the ETR reported by Ansara-Ross et al. (2008), partly because of higher applied dosages (up to a factor of 3). In this study no risk was indicated for glyphosate (ETR: 0.019-0.21), which is comparable to the study in South Africa (Malherbe et al. 2013). In this study possible risks were also calculated for paraquat, dimethoate and carbendazim as the $1^{\text {st }}$ tier ETRs ranged between 1.1-6.0, $1.2-4.7$ and $6.4-13$, respectively 
(Table 3.1). Paraquat showed possible acute risk based on a $1^{\text {st }}$ tier assessment for both this study and that of Malherbe et al. (2013) (Table 3.1). This risk, however, disappears when a $2^{\text {nd }}$ tier PNEC is used (Table 3.3). The calculated $1^{\text {st }}$ and $2^{\text {nd }}$ tier ETRs of dimethoate and carbendazim were much higher compared to the study of Malherbe et al. (2013), again a result of using much higher applied dosages (dimethoate up to a factor of 71 , carbendazim up to a factor of 55). This is partly a result of the overdosing recorded by this study of a factor $2.3,12$ and 6.2 (Table 3.4) for pendimethalin, dimethoate and carbendazim respectively. Chlorpyrifos use $\left(1^{\text {st }}\right.$ tier ETR $=3425,5479 ; 2^{\text {nd }}$ tier ETR $\left.=49,79\right)$ in this study show definite acute risk to the aquatic environment which was also recorded by Wiratno et al. $(2007)\left(1^{\text {st }}\right.$ tier ETR $\left.=1900\right)$. Lambda cyhalothrin showed a definite risk $\left(1^{\text {st }}\right.$ tier ETR = 274-4229; $2^{\text {nd }}$ tier ETR = 193-2967; Table 3.1 and 3.3) to the aquatic environment and cypermethrin showed an acute risk to the aquatic environment $\left(1^{\text {st }}\right.$ and $2^{\text {nd }}$ tier ETR $=16,60$; Table 3.1 and 3.3) and (ETR = 360; definite risk), while Wiratno et al. (2007) reported a lower value for lambda-cyhalothrin (ETR = 3) and higher one for cypermethrin (ETR = 360), but both predicting a (possible) risk. Van den Bosch et al. (2006) provided quite similar results for China and Vietnam with extremely high first ETR values (>1000) for cypermethrin, chlorpyrifos, lambda cyhalothrin and dimethoate, high ones (> 100) for carbendazim and lower ones for mancozeb and, especially metalaxyl and metalaxyl-M. These results match the results of the $2^{\text {nd }}$ tier risk assessment in our study although the highest ETR values are generally lower (Table 3.3). This points to the fact that the environmental side-effects of pesticide in countries with a weak pesticide registration system and enforcement needs more attention (Onwona Kwakye et al. 2019). This contamination of the aquatic ecosystem might not only harm the ecological integrity of the water, but also the ecosystem services for those who depend on such water sources for their livelihoods including reduced (drinking) water quality, reduced productivity (e.g., fish kills, effects on bees, cattle) and small ruminants that uses surface water as drinking water (Maltby et al. 2017).

PRIMET predicted no risk to the aquatic environment for the two neonicotinoid insecticides imidacloprid and thiamethoxam. It should be noted, however, that the standard test invertebrate Daphnia magna is relatively insensitive to imidacloprid with a geometric mean 96h LC50 value of 34,000 $\mu \mathrm{g} / \mathrm{L}$ (Morrissey et al. 2015), while insect taxa like mayflies are at least four orders of magnitude more sensitive in temperate regions ( $96 \mathrm{~h}$ EC50 for Cloeon dipterum $=1.0 \mu \mathrm{g} / \mathrm{L}$ in The Netherlands; (Roessink et al. 2013; Morrissey et al. 2015) and even 
seven orders of magnitude more sensitive in tropical regions ( $96 \mathrm{~h} \mathrm{EC50} \mathrm{for} \mathrm{Cloeon} \mathrm{sp.}=0.0055$ $\mu \mathrm{g} / \mathrm{L}$ in Bangladesh; Sumon et al. 2018). Thus, although the acute ETR for imidacloprid was low $(0.00085)$, in practice a risk may be present, as Ghana is also situated in the tropics. More research on the actual risks imidacloprid, and other neonicotinoid insecticides like thiamethoxam, poses to the aquatic ecosystem should be studied by testing local species. Thiamethoxam is also non-toxic to D. magna ( $96 \mathrm{~h} \mathrm{EC50} \mathrm{of} \mathrm{42,000} \mathrm{\mu g/L;} \mathrm{Morrissey} \mathrm{et} \mathrm{al.} \mathrm{2015)}$ and highly toxic to aquatic insects like mayflies (Van den Brink et al. 2016).

Of the pesticides for which the $2^{\text {nd }}$ tier risk assessment indicating a risk (ETR $>1$ ), no semi-field studies are available in the open literature for the herbicides pendimethalin, propanil and oxyfluorfen, the insecticide dimethoate and the fungicide carbofuran (Table 3.3; Van den Brink et al. 2006). Studies with the insecticide lambda cyhalothrin in experimental ecosystems have demonstrated that it is highly toxic to aquatic organisms (He et al. 2008). Reported effects of lambda cyhalothrin on arthropod invertebrates are likely to occur at concentrations at or above $0.01 \mu \mathrm{g} / \mathrm{L}$ (Van Wijngaarden et al. 2004, 2005b), while our $2^{\text {nd }}$ tier PNEC used was $0.003 \mu \mathrm{g} / \mathrm{L}$ (Table 3.3), making the second tier risks realistic. Lower-tier assessment of chlorpyrifos indicates risk for surface waters (Giesy et al. 1999; Giddings et al. 2014). Chlorpyrifos has also been studied extensively using microcosm and mesocosm (cosm) studies, single-species laboratory toxicity tests and used as a regulatory benchmarks across classes of insecticides (Brock et al. 2000b; 2006; Maltby et al. 2005; van Wijngaarden et al. 2005b). These cosm studies have also broadened the scope of conclusions about chlorpyrifos effects on aquatic communities to a wider range of locations and environmental conditions (van Wijngaarden et al. 2005a; Daam et al. 2008a, b; López-Mancisidor et al. 2008a, b; Zafar et al. 2011), all supporting the conclusion that concentrations of $0.1 \mu \mathrm{g} / \mathrm{L}$ chlorpyrifos or less cause no ecologically significant effects on aquatic communities (Brock et al. 2006; Giddings et al. 2014) which could be used as basis for control measures in this study. This threshold value of $0.1 \mu \mathrm{g} / \mathrm{L}$ is close to the PNEC of $0.7 \mu \mathrm{g} / \mathrm{L}$ used in the $2^{\text {nd }}$ tier risk assessment (Table 3.3). Van Wijngaarden et al. (2005) reports for cypermethrin a NOEC and LOEC based on a cosm experiment evaluating multiple applications of $<0.07$ and $0.07 \mu \mathrm{g} / \mathrm{L}$, respectively. The $2^{\text {nd }}$ tier PNEC of $0.003 \mu \mathrm{g} / \mathrm{L}$ is far below this value and is expected to be protective (Table 3.3). Several studies have indicated low $96 \mathrm{~h}$ LC50 value of mancozeb to fish, e.g. Oreochromis mossambicus $(12 \mu \mathrm{g} / \mathrm{L})$, Punctius ticto $(13 \mu \mathrm{g} / \mathrm{L})$ and Clarius batracus adult $(14 \mu \mathrm{g} / \mathrm{L})$ and 
fingerlings (14 $\mu \mathrm{g} / \mathrm{L}$ ) (Srivastava and Singh, 2013; Saha et al. 2016; Sharma et al. 2016). Maltby et al. (2009) report a NOEC and LOEC derived from a cosm study using multiple applications of 10 and $32 \mu \mathrm{g} / \mathrm{L}$, respectively. This means that the $2^{\text {nd }}$ tier PNEC of $89 \mu \mathrm{g} / \mathrm{L}$ is on the high side when evaluating effects on fish and aquatic ecosystems as a whole, meaning that the $2^{\text {nd }}$ tier risk assessment might even have underestimated the actual risks. For carbendazim, Maltby et al. (2009) reports a cosm based NOEC of $3 \mu \mathrm{g} / \mathrm{L}$ and a LOEC of $30 \mu \mathrm{g} / \mathrm{L}$ due to a single application, validating the $2^{\text {nd }}$ tier PNEC of $8 \mu \mathrm{g} / \mathrm{L}$ used in this study. In a cosm experiment performed with maneb only a treatment of $70 \mu \mathrm{g} / \mathrm{L}$ was evaluated, showing only clear effects on bivalves. This observation does not disqualify the PNEC of $48 \mu \mathrm{g} / \mathrm{L}$ used in this study. They also reported a cosm-based NOEC and LOEC of 12 and $24 \mu \mathrm{g} / \mathrm{L}$ for copper hydroxide, respectively, also supporting the $2^{\text {nd }}$ tier PNEC of $5.4 \mu \mathrm{g} / \mathrm{L}$ used in this study (Table 3.3).

Both the $1^{\text {st }}$ and the $2^{\text {nd }}$ tier ecological threshold values are mainly based on toxicity values from temperate species. So it is uncertain whether temperate sensitivity data can be used for a risk assessment in warmer, tropical regions (Daam and Van den Brink, 2010). It was, however, indicated by studies conducted by Maltby et al. (2005) and Kwok et al. (2007), that no systematic difference existed in toxicity and sensitivity between tropical and temperate species for some of the selected pesticides (chlorpyrifos, fenitrothion and carbofuran), although differences do exist (e.g. imidacloprid; Sumon et al. 2018).

The tiered approach scheme can be employed by the Ghana Pesticide registration Authorities to support the registration of pesticides as has been demonstrated in this study to determine the risks associated the use of pesticide products in Ghana, again it has successfully been used in Europe for pesticide registration (EFSA, 2013b).

\section{Terrestrial risk assessment}

There is a considerable concern about decline in biodiversity that would influence the delivery of various ecosystem services by terrestrial invertebrates (Hole et al. 2005; Hooper et al. 2005). In agricultural intensification, the most affected ecosystem services at severe risk are biological pest control (Tscharntke et al. 2005, Geiger et al. 2010), crop pollination (MEA, 2005; Biesmeijer et al. 2006; Zhang et al. 2007) and soil fertility maintenance (Hole et al. 2005; Hansen et al. 2006; Goh, 2011; Pandey and Singh, 2012). There should therefore be specific 
protection goals aimed at protecting important ecosystem services such as food web support, pest control and biodiversity (Maltby et al. 2018). Biodiversity and ecosystem services might be protected along with agro-ecosystems, where farmers get subsidies, partly to produce ecological benefits (Kleijn et al. 2001).

Earthworms are important in influencing organic matter dynamics, soil structure and microbial community (Edwards and Bohlen, 1996; Fragoso et al. 1997; Sims and Gerard, 1999). They actively participate in soil aeration, water infiltration and mixture of soil horizons, and they represent an important source of food for many other organisms like birds or moles (Edwards and Bohlen, 1996; Lavelle et al. 2006) so there is the need to protect them from pesticide exposure. The study demonstrated that earthworms were also under acute risk for three pesticides (butachlor, dimethoate and carbendazim) and under chronic risks for nine pesticides, of which more than half are fungicides (Table 3.1 and 3.2). The levels of risks were, however, much lower compared to the aquatic compartment (Table 3.1 and 3.2). Strangely, the highest acute risk is calculated for the herbicide butachlor. According to the PPDB data base, butachlor is acutely toxic to earthworms with a 14d LC50 of $515 \mu \mathrm{g} / \mathrm{kg}$ (PPDB, 2020). Chen et al. (2014), however, report a 14d LC50 of $1198 \mathrm{mg} / \mathrm{kg}$ for the same species, so its value in the PPDB data base might be an error. In another study by Gobi and Gunasekaran (2009), butachlor reduced the biomass and cocoon production and caused damage to epithelial tissue of earthworm (Eisenia fetida) leading to the reduction of nutrient absorption area from food. Their study is important as they used concentrations $(0.26-2.6 \mathrm{mg} / \mathrm{kg})$ relevant in this study. The concentrations of dimethoate and carbendazim only slightly exceeded the acute PNEC (factor of 2). Wiratno et al. (2007) provide similar results for Indonesia as found in our study where lambda cyhalothrin, chlorpyrifos and cypermethrin showed no acute risks to the terrestrial soil environment in both studies.

The chronic risk assessment indicated a small risk for all pesticides towards the terrestrial environment $(E T R<10$; Table 3.2), except for carbendazim $(E T R=13)$. Carbendazim is one of the few pesticides that has been extensively studied using terrestrial microcosms (Knacker et al. 2004). Jänsch et al. (2006) reported a NOEC and LOEC of 2.16 and $3.24 \mathrm{~kg}$ a.i./ha while in our study application rates of 1.2 and $2.4 \mathrm{~kg}$ a.i./ha, both probably not leading to large adverse effects, although the actual values of the soil parameters like organic matter content and dry bulk density will be important. 
As expected from the mode of action only for 1 out of 11 herbicides and 3 out of 9 fungicides a (possible) acute risk was indicated for bees, while for 8 out of 10 insecticides a (possible) acute risk was indicated (Table 3.1). Bees are most affected by lambda cyhalothrin, chlorpyrifos, emamectin benzoate, imidacloprid, thiametoxam, cypermethrin and dimethoate $(E T R>10)$. Some plants can produce guttation drops in the early hours of the morning (e.g. maize, strawberries), and systemic insecticides appear in such drops in elevated concentrations (Tapparo et al. 2011) that are capable of killing the bees (Johnson et al. 2006; Zhu et al. 2017). Again, pesticide residues in soil move and appear in streams, creeks and ponds of agricultural areas and beyond, which are thus contaminated with a mixture of agrochemicals (Belden et al. 2007), as pesticides enter surface waters through run-offs, seepage from groundwater and spray drift. Honey bees, bumblebees and wild bees drink from such puddles, irrigation ditches, ponds and streams, and if these waters are contaminated with pesticide residues may kill them (Schmaranzer, 2000; Samson-Robert et al. 2014). Since usage of these plant protection products cannot be stopped, chemical companies are obliged by law to state on the labels whether their products are dangerous to bees or not and must be enforced by the Ghana Registration Authority as well as communicating properly to applicators, farmers and beekeepers. More research is advocated for assessing the effects of chronic exposure of bees to pesticides taking into consideration recent approaches on how to improve the risk assessment of bees. (See e.g. EFSA, 2013a; 2018).

Possible or definite risks for NTAs were identified for almost all pesticides for which a risk assessment could be performed (Table 3.1). This is not surprising as, some of the pesticides are designed to eradicate species which are closely related to NTAs and an in-field risk assessment was performed. Peeters et al. (2008), therefore, recommend to perform an off-field risk assessment as well, taking drift percentage and vegetation distribution factor into account. When the default values proposed by Peeters et al. (2008) are used, the ETR in-field can be recalculated to an ETR off-field by dividing it by 0.0027 . In practice this means that all ETR in-field $_{\text {f }}$ values lower than 370 would lead to an acceptable ETR off-field value of $<1$. The ETR in-field value of 370 are exceeded by propanil, lambda cyhalothrin, chlorpyrifos, imidacloprid and copper hydroxide. Jänsch et al. (2006) reviewed the (semi-) field experiments performed with NTAs and presented data for all these pesticides, except propanil and copper hydroxide. For lambda cyhalothrin only one dosage (1.5 kg a.i./ha) has been evaluated, which showed clear effects 


\section{Chapter 3}

on some of the collembolan species (Jänsch et al. 2006). In our survey, we recorded use dosages of $0.14,0.15$ and $2.22 \mathrm{~kg}$ a.i./ha, in-crop effects are certainly expected the highest dosage. It is uncertain whether off-crop effects are to be expected as no field-based safe concentration could be derived. But since our $1^{\text {st }}$ tier ETRin-field was above 370 they cannot be excluded. The same applies for chlorpyrifos. The lowest concentration of chlorpyrifos tested under (semi) field circumstances was $0.48 \mathrm{~kg}$ a.i./ha, which already affected many species of collembolans (Jänsch et al. 2006). As the identified usage dosages of chlorpyrifos in our survey were 2.4 and $3.8 \mathrm{~kg}$ a.i./ha, in-crop effects are certainly to be expected. This is not the case for imidacloprid, which showed no field effects on collembolans at rates of $0.34 \mathrm{~kg}$ a.i./ha (Jänsch et al. 2006), while $0.12 \mathrm{~kg}$ a.i./ha was the use dosage recorded in our survey. Based on results from (semi-) field tests it is unclear whether in-field effects on NTAs are expected from the $0.018 \mathrm{~kg}$ a.i./ha carbofuran which was recorded in our survey, as the lowest dosage tested in (semi-)field experiments was $0.75 \mathrm{mg}$ a.i./ha and already had clear effects on collembolans (Jänsch et al. 2006). Based on the $1^{\text {st }}$ tier assessment presented in this study for in-field as offfield are predicted (Table 3.1).

\section{Overdosing of pesticides}

Finally, in this study farmers generally used a higher dosage of pesticides than recommended, a factor of 1.3 to 13 times above the recommended label instructions. Mengistie et al. (2017) reported similar observations for small holder vegetable farmers in the central rift valley, Ethiopia, but indicated that assessing the exact level of overdosing proved difficult, because of unlabelled units (such as tins) and different combinations of pesticides were used. Similarly, Kariathi et al. (2016) reported farmers overdosing pesticide in tomato treatment in Tanzania and claimed that this was partly due to the presence of resistant pests and diseases. The use of pesticide in higher dosage than recommended may lead to pest resistance and high accumulation of residues as reported with increased risk of exposure in Tanzania (Ngowi et al. 2007). Farmers at these sites and in general should be encouraged by the scheme managers, extension service providers and the Ghana registration authorities to limit the application of pesticides products to recommended rates to prevent acute risks to the aquatic environment. 
The implementation of alternative cropping systems that are less dependent on pesticides, the development of new pesticides with novel modes of action and improved safety profiles, and the improvement of the already used pesticide formulations towards safer formulations (e.g. microcapsule suspensions) have been suggested could reduce the adverse effects of farming and particularly the toxic effects of pesticides. In addition, the use of appropriate and well-maintained spraying equipment along with taking all precautions that are required in all stages of handling and applying pesticides to possibly minimize pesticides potential adverse effects on the environment (Damalas and Eleftherohorinos, 2011).

We recommend that the TRIAD approach (Chapman, 2000) is used to validate the true estimation of risks that the results from this preliminary ecological risk assessment using chemical measurements, bioassays and bio-monitoring.

\section{Acknowledgements}

The authors would like to thank the Ghana Education Trust Fund (GETFund) for the funding of this project. We would also like to thank Nana Domtie Onwona-Kwakye for all the help with this project. 
Chapter 3

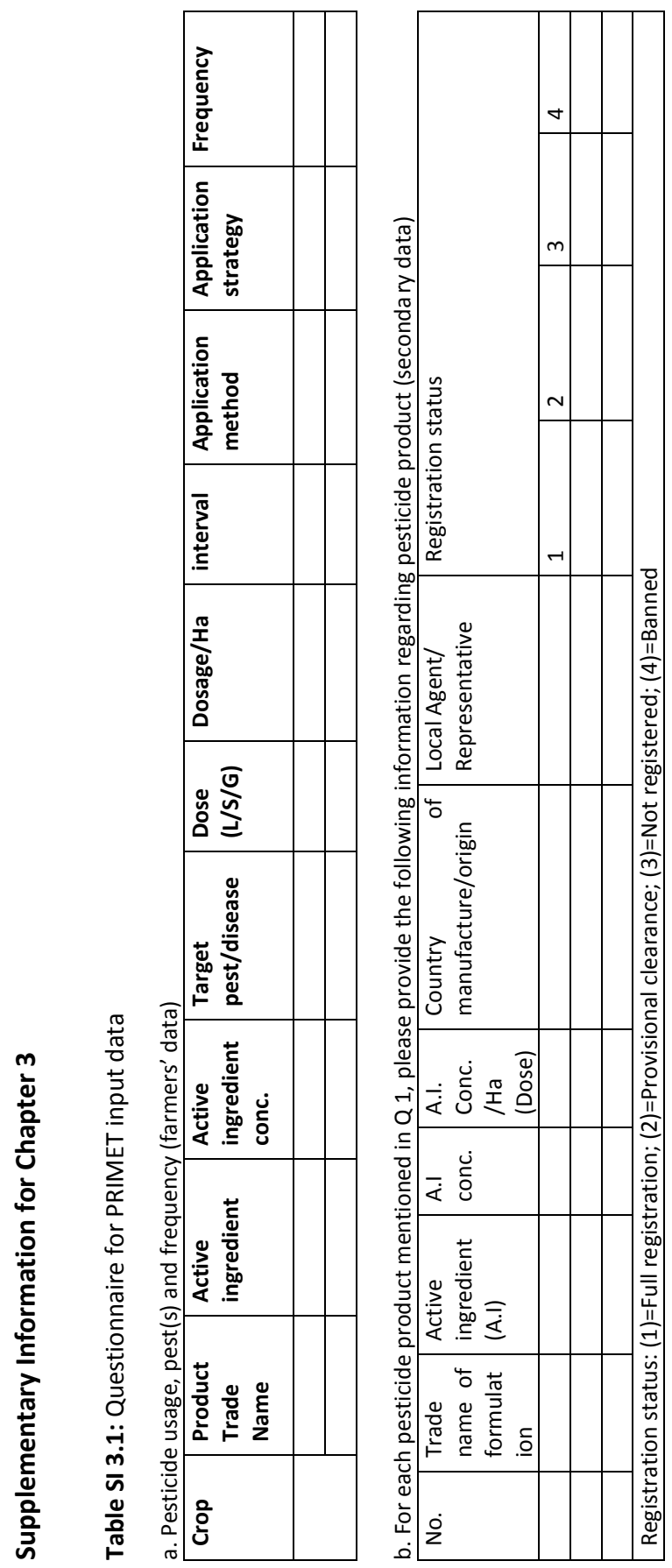




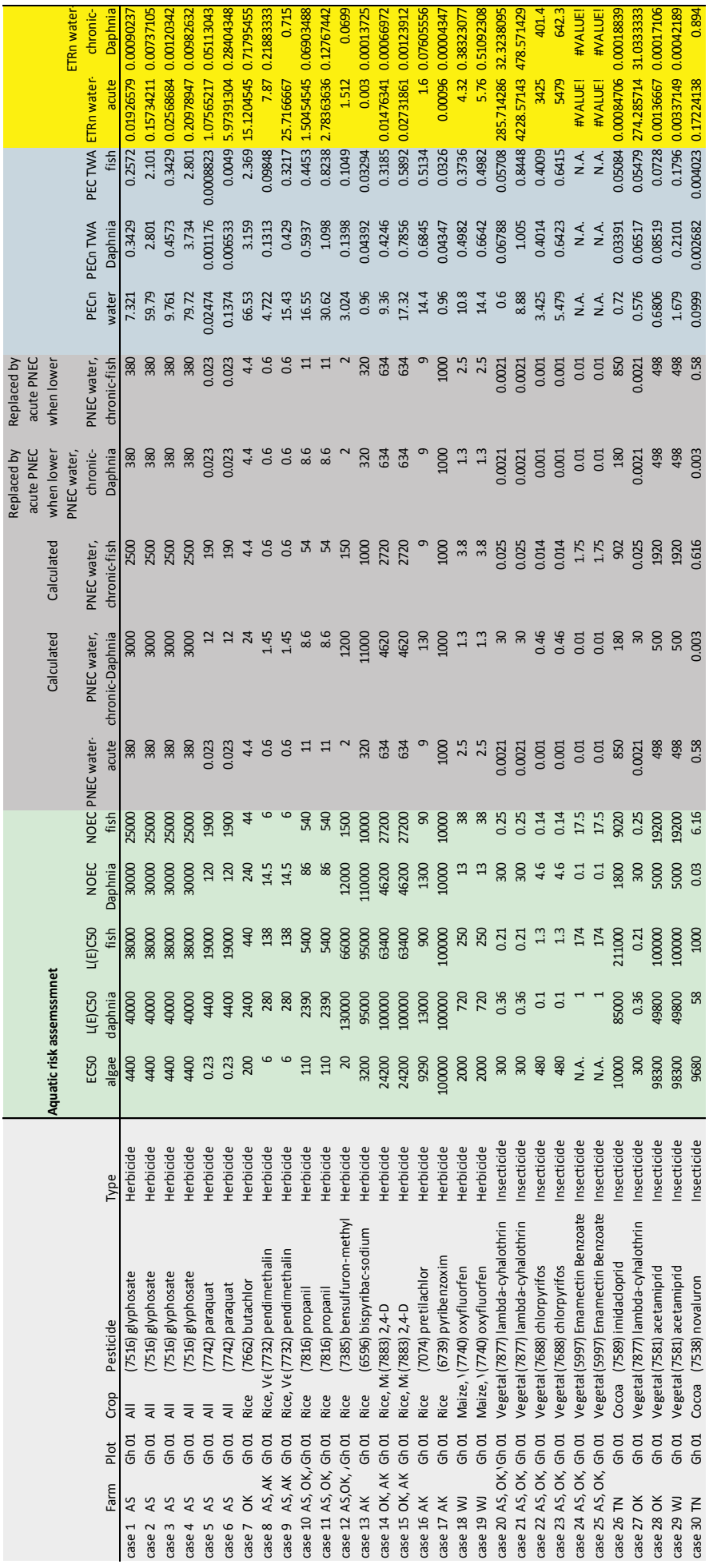




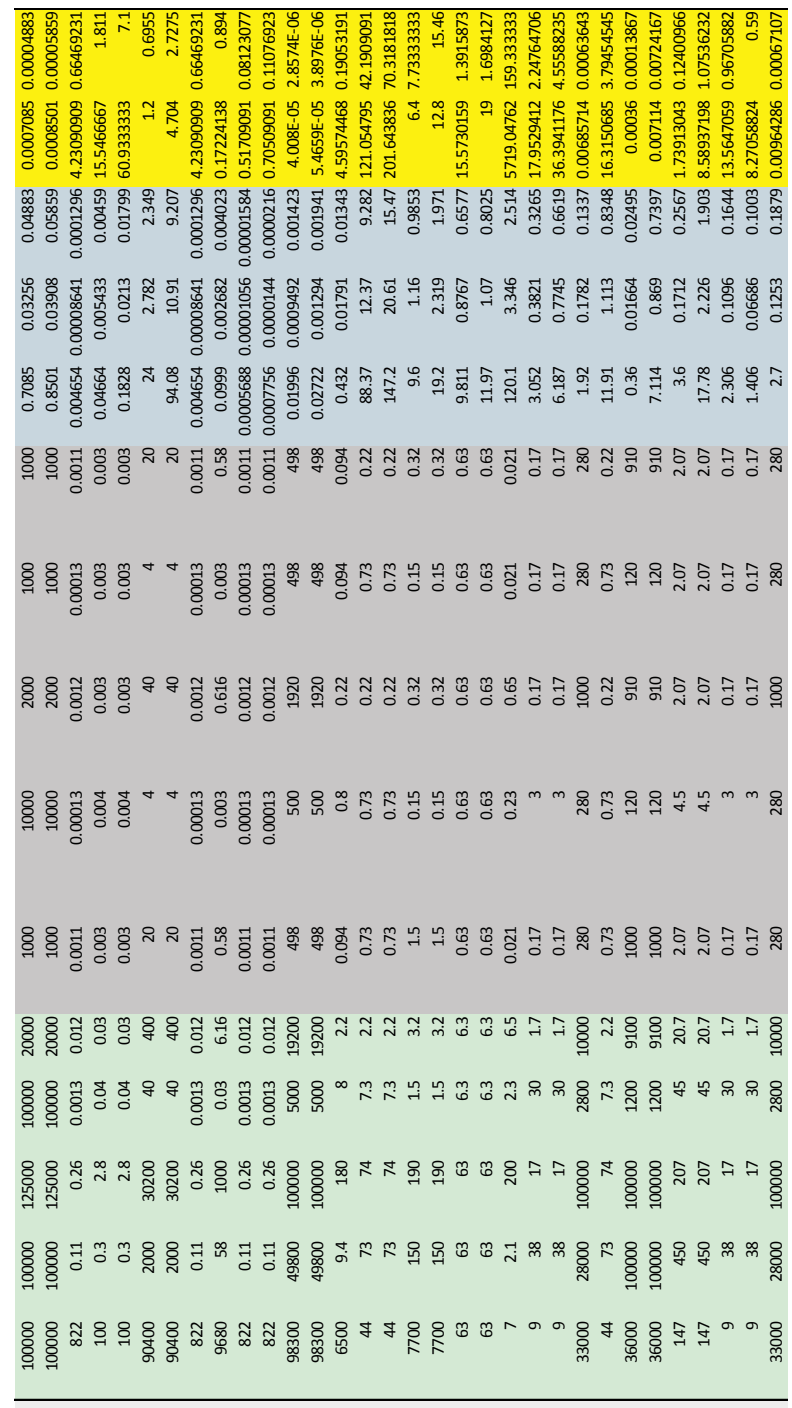

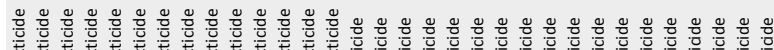
WIMIIIMmmmmm

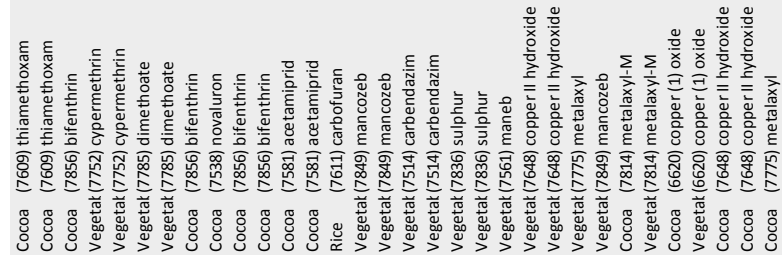

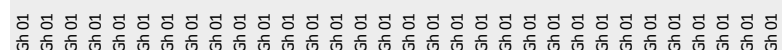

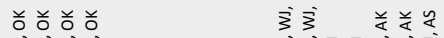

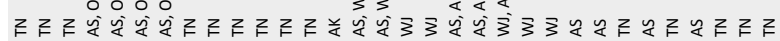

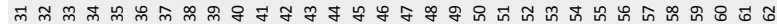

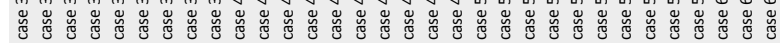




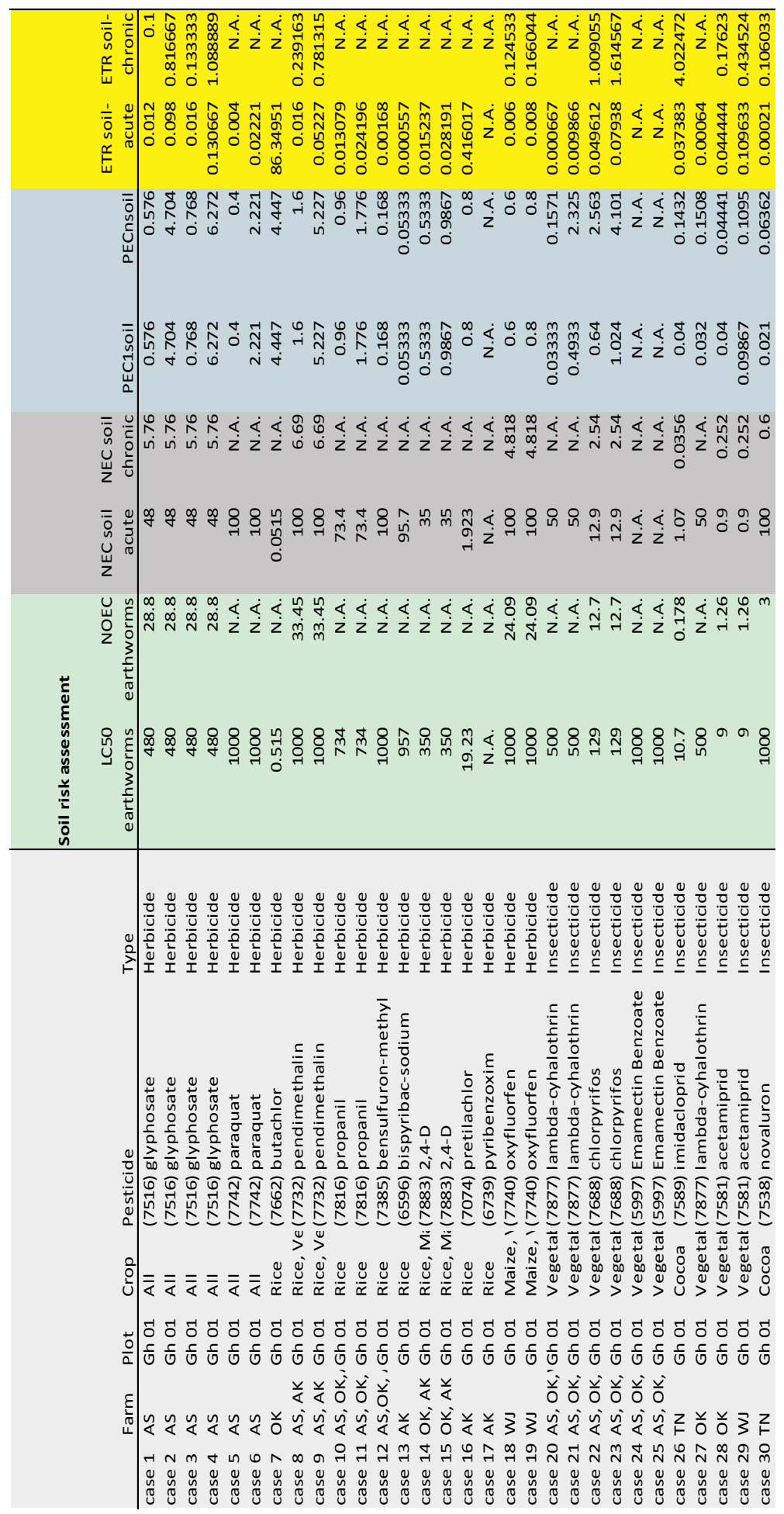




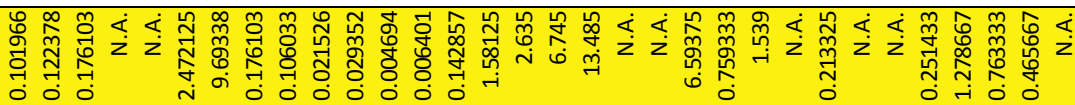

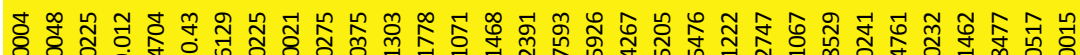

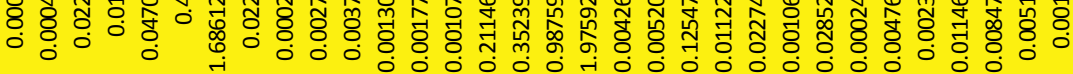

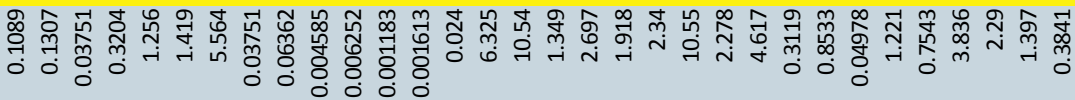

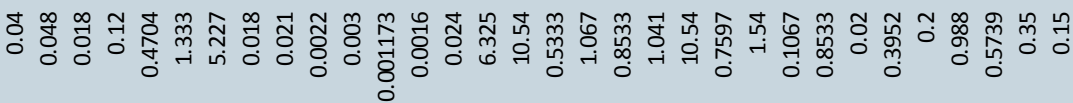

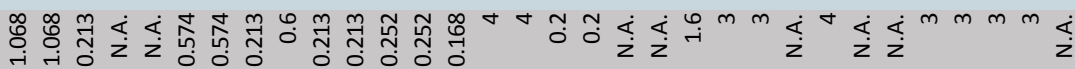
ర্] \&

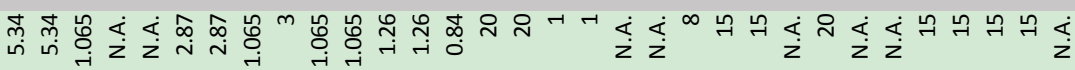

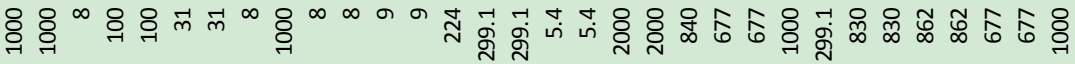

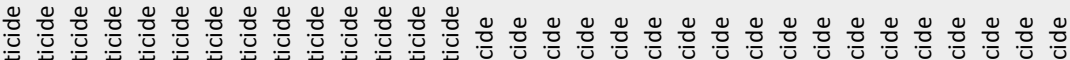

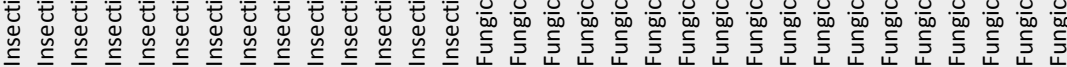

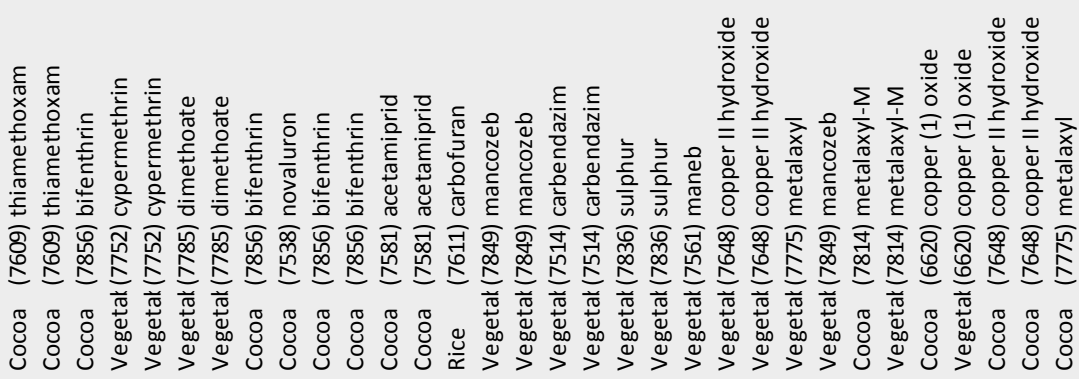

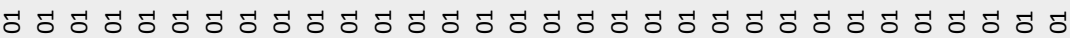

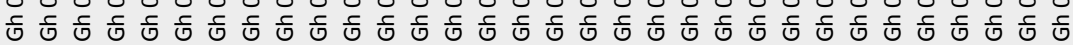
ö

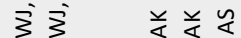

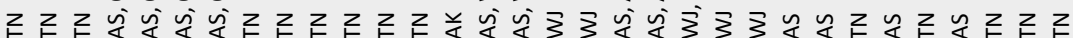

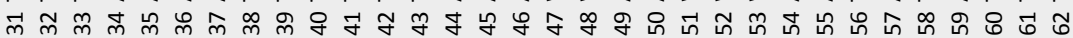

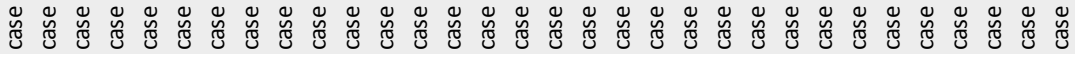




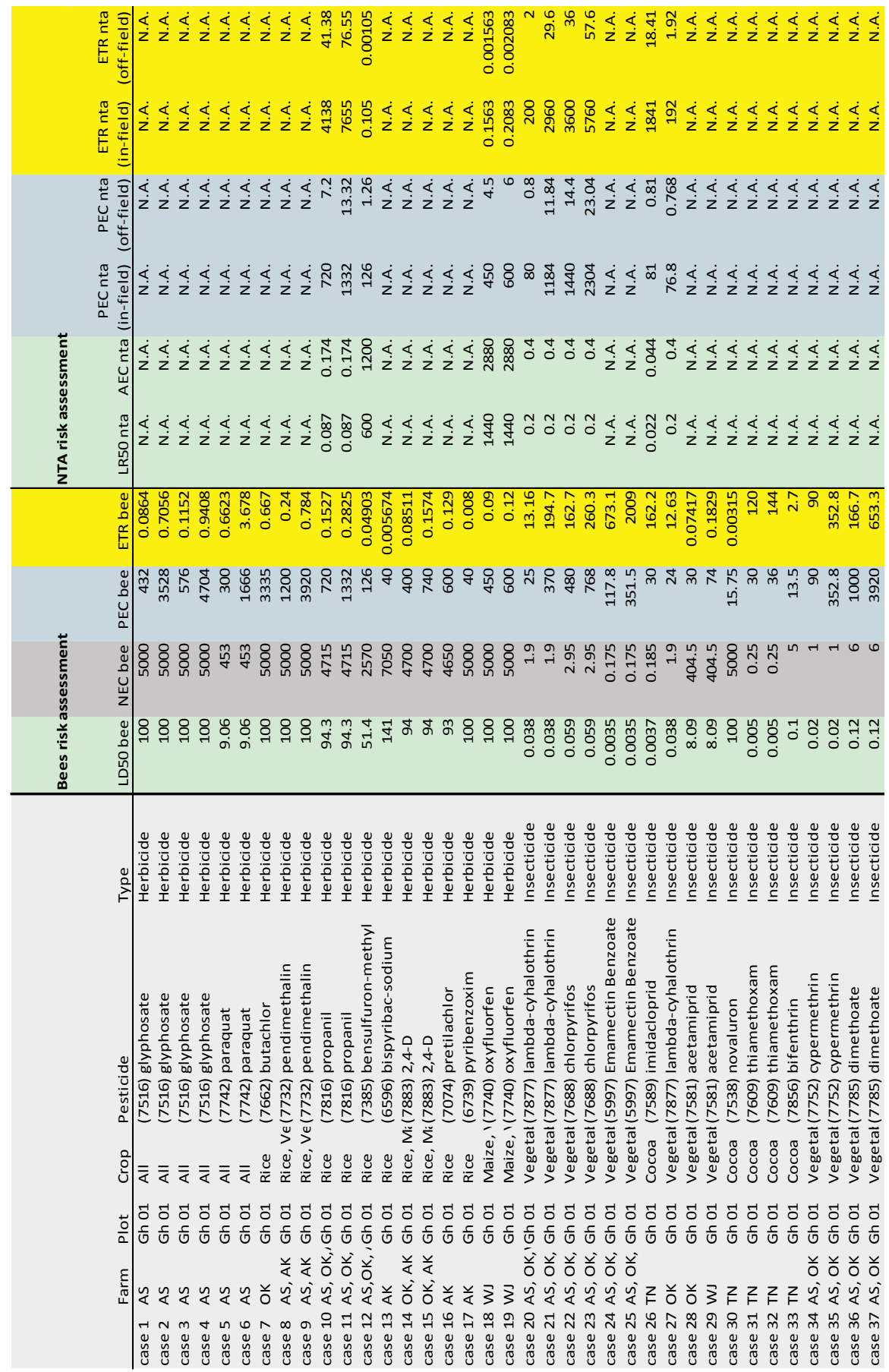




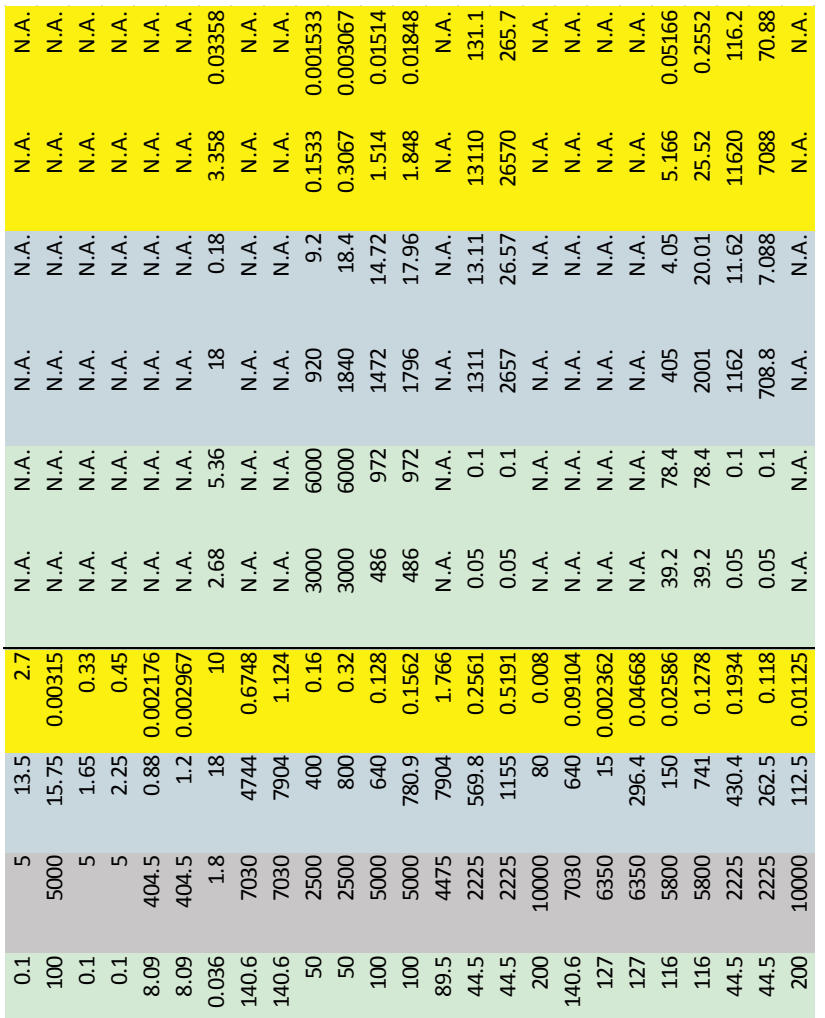

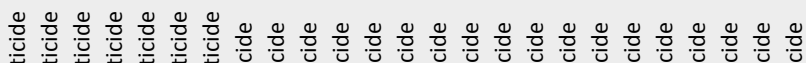

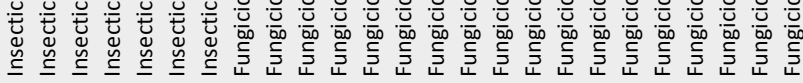

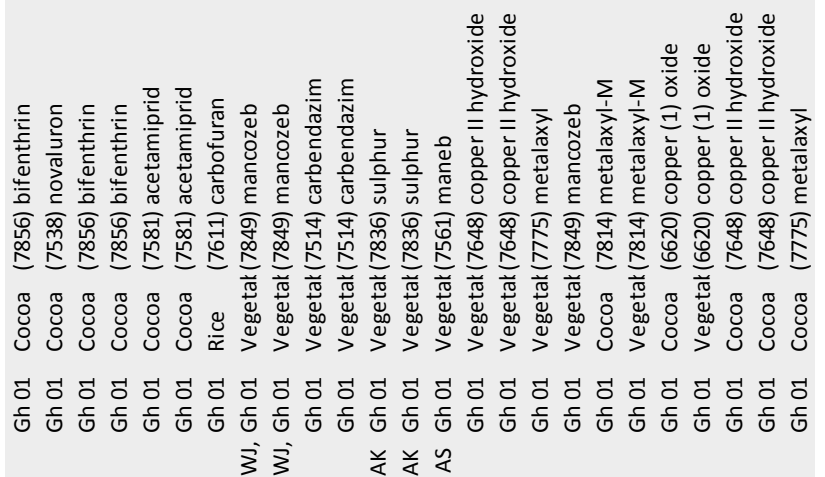

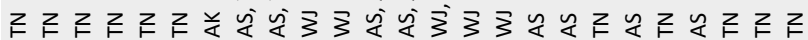

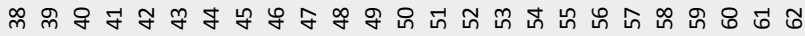

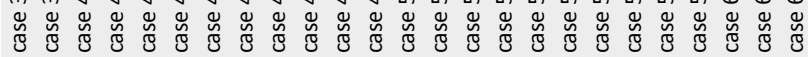




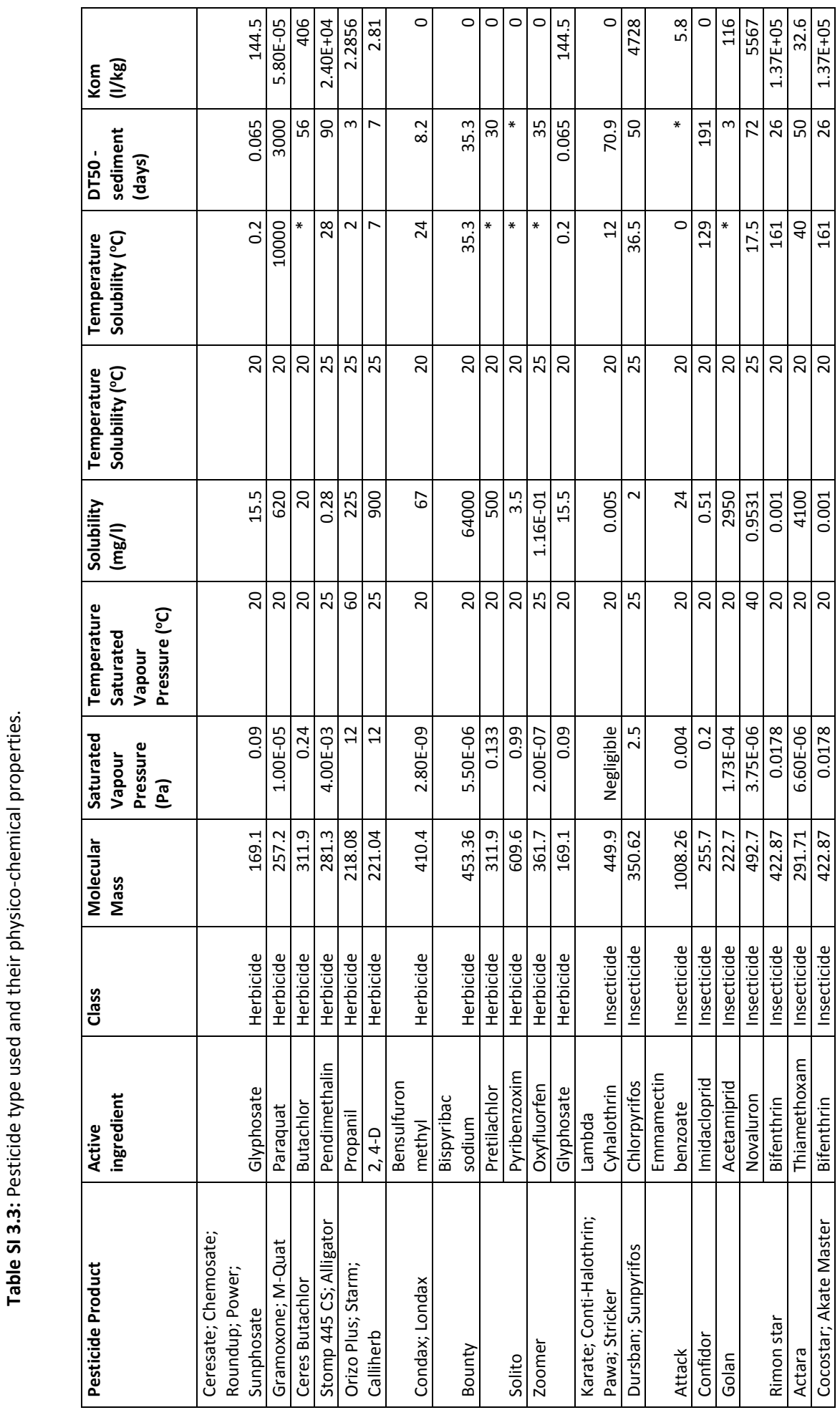


Chapter 3

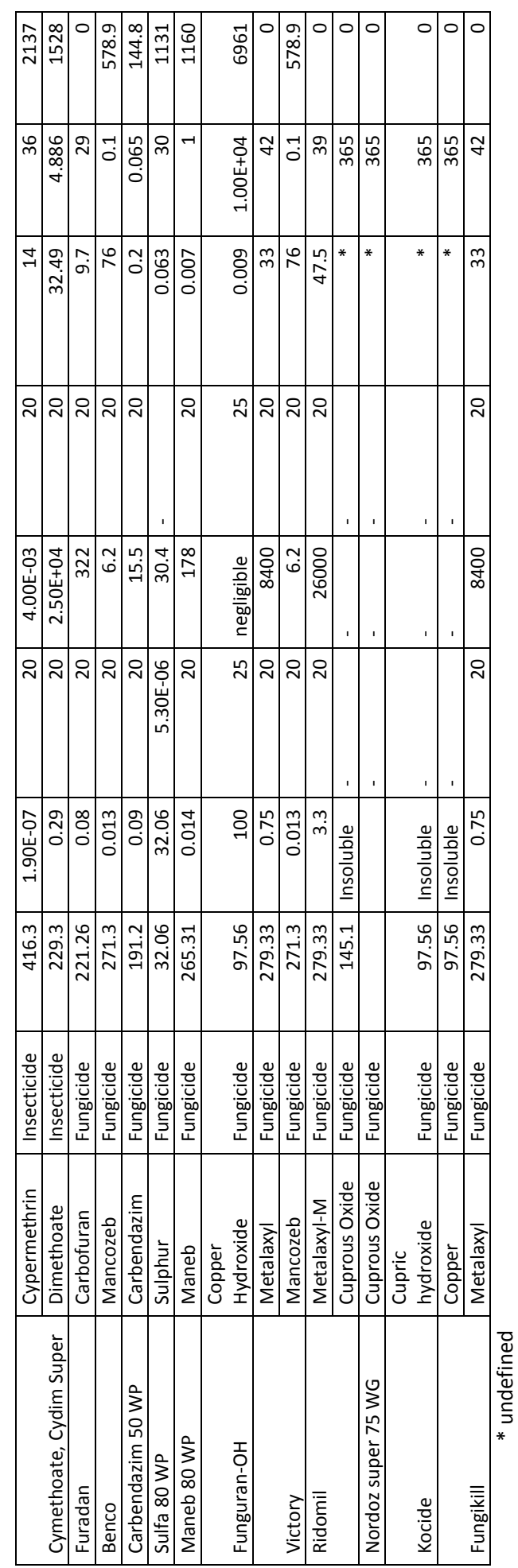




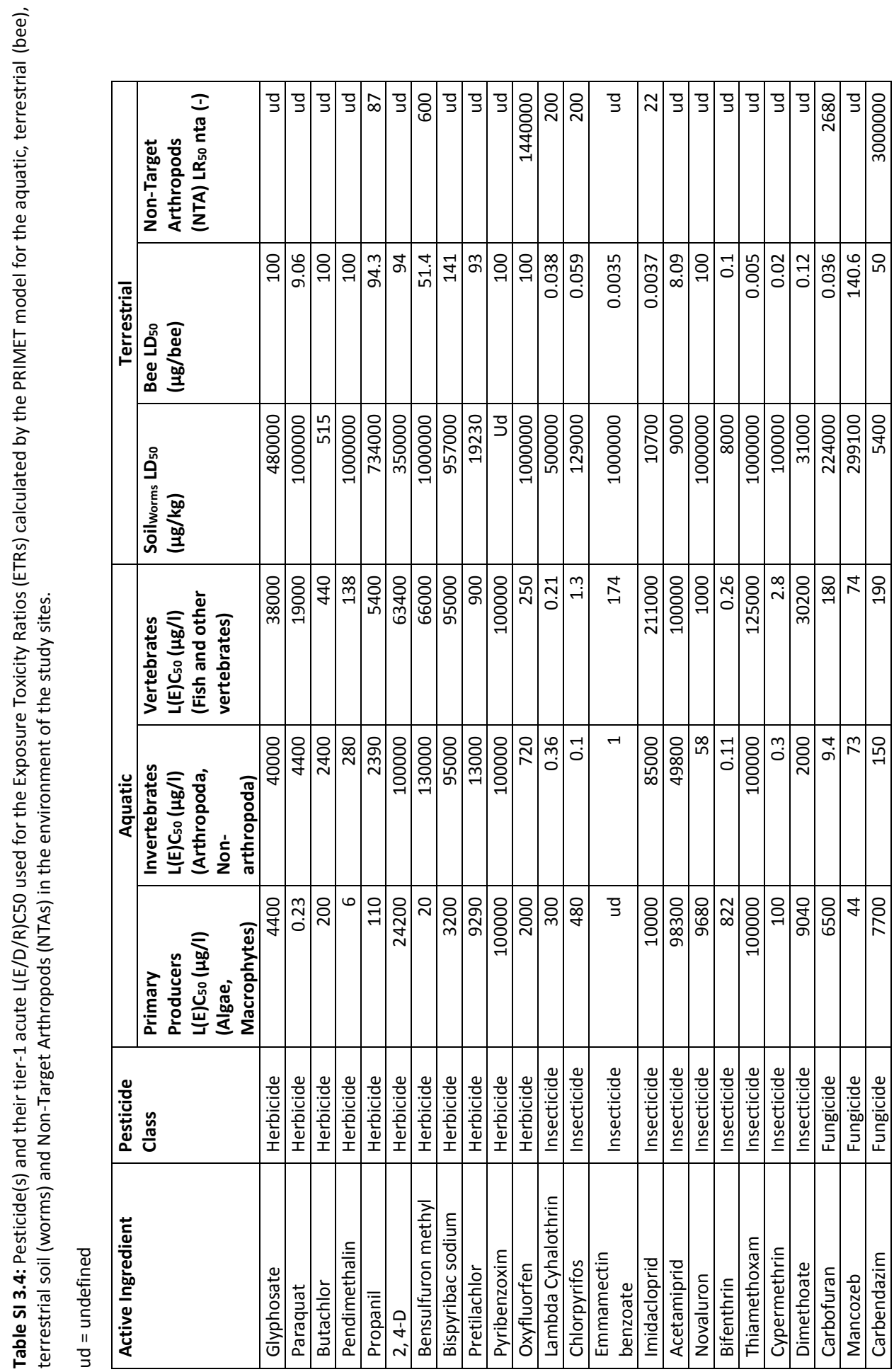




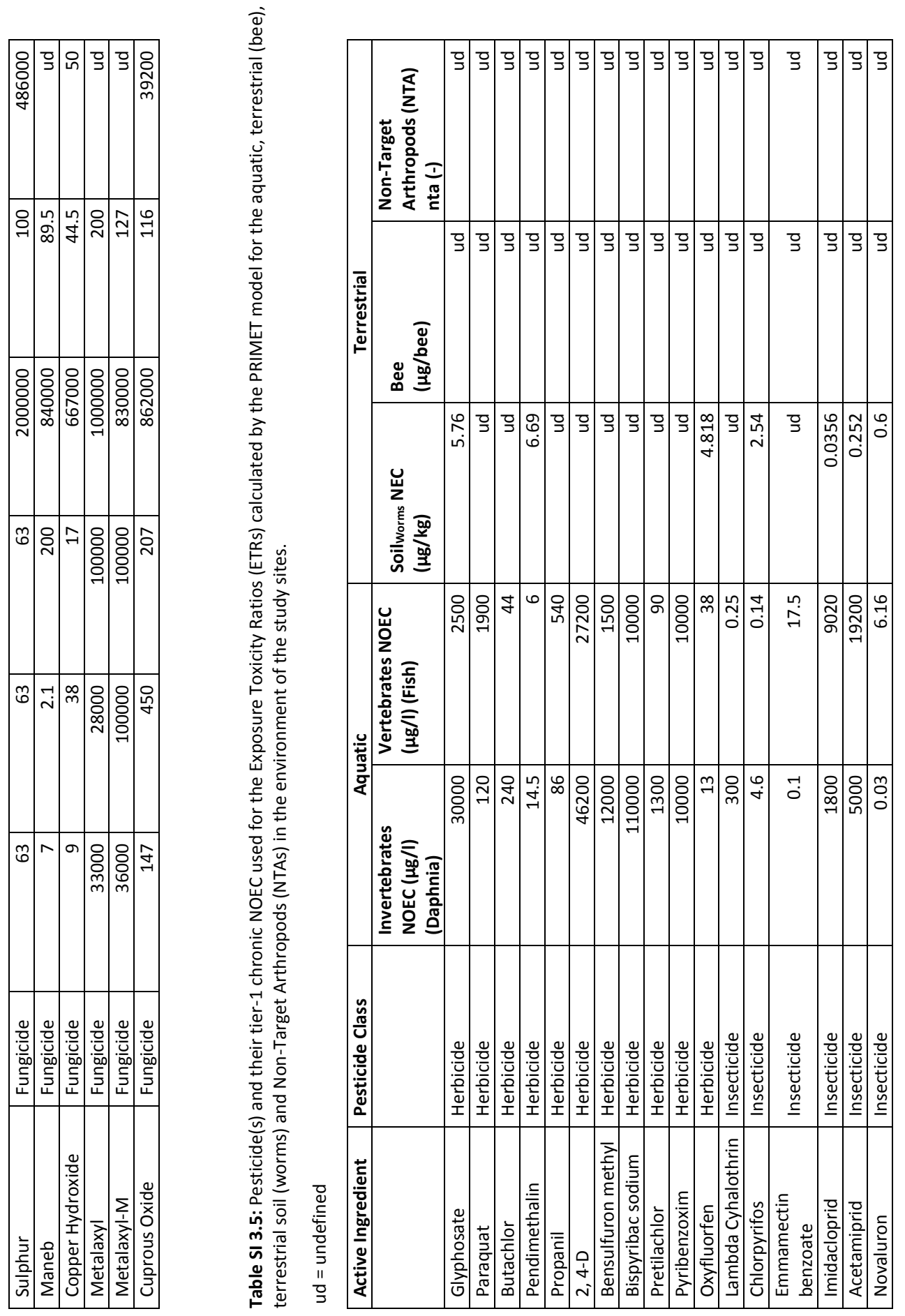




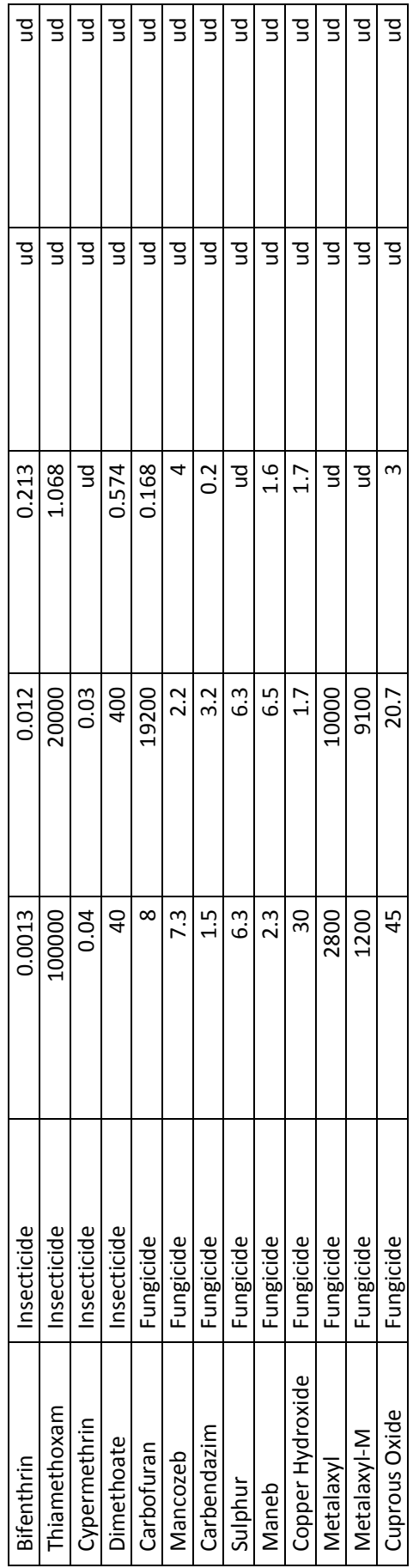




\section{Chapter 4}

\section{Linking macroinvertebrates and physico-chemical parameters for water quality assessment in the lower basin of the Volta River in Ghana.}

Onwona Kwakye, Michael ${ }^{\mathrm{a}, \mathrm{b}}$, Feng-Jiao, Peng ${ }^{\mathrm{a}, \mathrm{c}}$, Jonathan N. Hogarh ${ }^{\mathrm{d}}$ and Paul J. Van den Brink ${ }^{\mathrm{a}, \mathrm{e}}$

${ }^{a}$ Aquatic Ecology and Water Quality Management Group, Wageningen University, P.O. Box 47, 6700 AA, Wageningen, The Netherlands

${ }^{b}$ Ghana Environmental Protection Agency, P. O. Box M326, Accra, Ghana

${ }^{\mathrm{c}}$ Human Biomonitoring Research Unit, Department of Population Health, Luxembourg Institute of Health, 1 A-B rue Thomas Edison, 1445 Strassen, Luxembourg

${ }^{d}$ Department of Environmental Science, College of Science, Kwame Nkrumah University of Science and Technology, PMB University Post Office, Kumasi, Ghana

e Wageningen Environmental Research, P.O. Box 47, 6700 AA, Wageningen, The Netherlands 


\section{Chapter 4}

\section{Abstract}

The health of the lower basin of the Volta River in Ghana was evaluated in JanuaryFebruary and May-June 2016 using physico-chemical parameters and benthic macroinvertebrate species as indicators. The measured levels of selected environmental variables were compared to accepted environmental quality standard values where applicable. The association between the benthic macroinvertebrates and physico-chemical variables were analysed through benthic macroinvertebrate distribution and a principal component analysis (PCA) and redundancy analysis (RDA). Pesticide concentrations were generally below the limit of detection of $0.01 \mu \mathrm{g} / \mathrm{L}$ and $0.005 \mu \mathrm{g} / \mathrm{L}$ for organophosphate/synthetic pyrethroid and organochlorines, respectively, except isolated cases where $\lambda$-cyhalothrin was detected at Sedorm 1 (T1) and Akuse Canal (T8) with values of $0.6 \mu \mathrm{g} / \mathrm{L}$ and $8.8 \mu \mathrm{g} / \mathrm{L}$, respectively and cypermethrin detected with $1.7 \mu \mathrm{g} / \mathrm{L}$ at Marine (T3) during the January - February sampling period. Nutrient levels were also generally low, however significant differences existed between the values of physico-chemical parameters at the different sampling sites and seasons (Monte Carlo permutation test; $p=0.002$ ), as well as between the abundance of macroinvertebrates at the different sites and seasons (Monte Carlo permutation test; $p=0.002$ ). The environmental variables $\mathrm{DO}$, phosphate, $\mathrm{pH}$, substratum $(p<0.05)$, turbidity, electrical conductivity, total dissolved solids, total solids and nitrate $(0.05<p<0.10)$ significantly explained the variation in macroinvertebrate composition between sampling sites of the Volta river. Polypedilum fuscipenne, was significantly positively correlated with turbidity and DO concentrations; Physa sp., Centroptilum sp., Centroptiloides $\mathrm{sp}$. Phaon iridipennis and juvinile fish were positively correlated with nitrate concentration and $\mathrm{pH}$ and negatively correlated with turbidity and DO. Polluted sites were dominated by the snail Lymnaea glabra. This demonstrates that physicochemical parameters and macroinvertebrates could be applied to describe the water quality and improve the biomonitoring for water resources management and the environmental protection in the Lower Volta River system. 


\section{Introduction}

The Volta River is one of most important river systems in Ghana. It originates from Burkina Faso and runs mainly through Ghana and covers an estimated area of $400,000 \mathrm{~km}^{2}$ (Barry et al. 2005). The north-south extent of this transboundary basin stretches from approximately latitude $5^{\circ} 30^{\prime} \mathrm{N}$ in Ghana to $14^{\circ} 30^{\prime} \mathrm{N}$ in Mali, with the widest part stretching approximately from longitude $5^{\circ} 30^{\prime} \mathrm{W}$ to $2^{\circ} 00^{\prime} \mathrm{E}$ (Gordon et al. 2013). The lower part of the river basin promotes different uses including agriculture, aquaculture, fishing, hydroelectric power, water for domestic (drinking) and industrial purposes, water transport, sand mining and industrial activities (e.g. textile works) among others (Andah et al. 2003; Mul et al. 2015). The river receives domestic wastewater, industrial wastewater, municipal and rural wastes, and other human activities. High levels of organic pollutants may degrade the water quality in receiving waters and threaten the aquatic ecosystems (Corcoran et al. 2010; Wang et al. 2013; Asantewaa Owusu et al. 2016). For example, water may become polluted due to a range of contaminants originating from agricultural activities (Hooda et al. 2000; Lovell and Sullivan, 2006; Ansah Asare, 2006). Indeed, pesticides have been reported to affect water bodies in Ghana (Aquaah, 1997; Ntow, 2001; Ntow, 2005; Fianko et al. 2011). In addition, the statistics show that the water sources have been, and continued to be, exploited speedily (Asantewaa Owusu et al. 2016). To improve the water resources management and the water quality monitoring for the Volta River System and other water resources, monitoring of physiochemical parameters and aquatic macroinvertebrates have been applied (Thorne and Williams, 1997; Thorne et al. 2000; Baa-Poku et al. 2013).

Benthic macroinvertebrates are a ubiquitous and diverse group of long-lived species that react strongly and often predictable to human influences in aquatic ecosystems. In addition, they are sedentary, therefore body burdens reflects local conditions, allowing detection of a variety of perturbations in a range of aquatic habitats (Rosenberg and Resh, 1993). Benthic macroinvertebrates are an important and integral part of any aquatic ecosystem as they form the basis of the trophic cascade and any negative effects caused by pollution on the community structure can in turn affect higher trophic levels like fish and birds. In addition, aquatic invertebrates have the ability to clean waterways as they utilize the organic and detritus matter. According to Carlisle et al. (2007), macroinvertebrate populations 


\section{Chapter 4}

in streams and rivers can assist in the assessment of the overall health of the stream and monitoring of macroinvertebrates has been limited in Ghana.

The overall objectives of this study were to: 1) evaluate the values of the physicochemical parameters and pesticides, and benthic macroinvertebrate richness and composition in the Lower Volta River System, and 2) examine the relationships between the environmental variables and the macroinvertebrate community composition in the evaluated aquatic system of the Volta River.

\section{Materials and methods}

\section{Study area}

There are two distinct types of savannah in the basin: woodland savannah and grassy savannah. The woodland savannah, mostly found in the southern parts of the basin, is densely wooded with tall to medium tall grasses (Mul et al. 2015). The climate of the Volta basin is dominated by the rain-bearing south westerly tropical maritime air mass and the dry, north easterly tropical continental air mass (Dickson and Benneh, 1988). Normally, there is a bimodal rainfall from April to July and from September to November in Southern Ghana. The single wet season is from May to October in Northern Ghana, which is followed by dry season (Harmatan). The wettest area in Ghana is the extreme southwest where annual rainfall is about $2000 \mathrm{~mm}$, the annual rainfall generally decreases from south to north. The country has a high temperature with the average annual temperature ranging between $24{ }^{\circ} \mathrm{C}$ and $30{ }^{\circ} \mathrm{C}$ (GEPA, 2011). In the coastal area of Ghana the relative annual humidity is $95-100 \%$ in the morning and about $75 \%$ in the afternoon. In the north these values can be as low as $20-30 \%$ during the Harmatan period and $70-80 \%$ during the rainfall period (Andah et al. 2003).

The study area has an average rainfall of $1000 \mathrm{~mm}$ /year with distinct dry (October-May) and wet (May-October) seasons (van de Giesen et al. 2010). Temperatures vary between approximately $16^{\circ} \mathrm{C}$ and $40^{\circ} \mathrm{C}$ depending on season, time of day, and elevation (Bekoe and Logah, 2013) and falls within the Dahomeyan system which occurs at the southern part of the main Volta basin, and consists of mainly metamorphic rocks, including hornblende and biotite, gneisses, migmatites, granulites, and schist (Barry et al. 2005). 


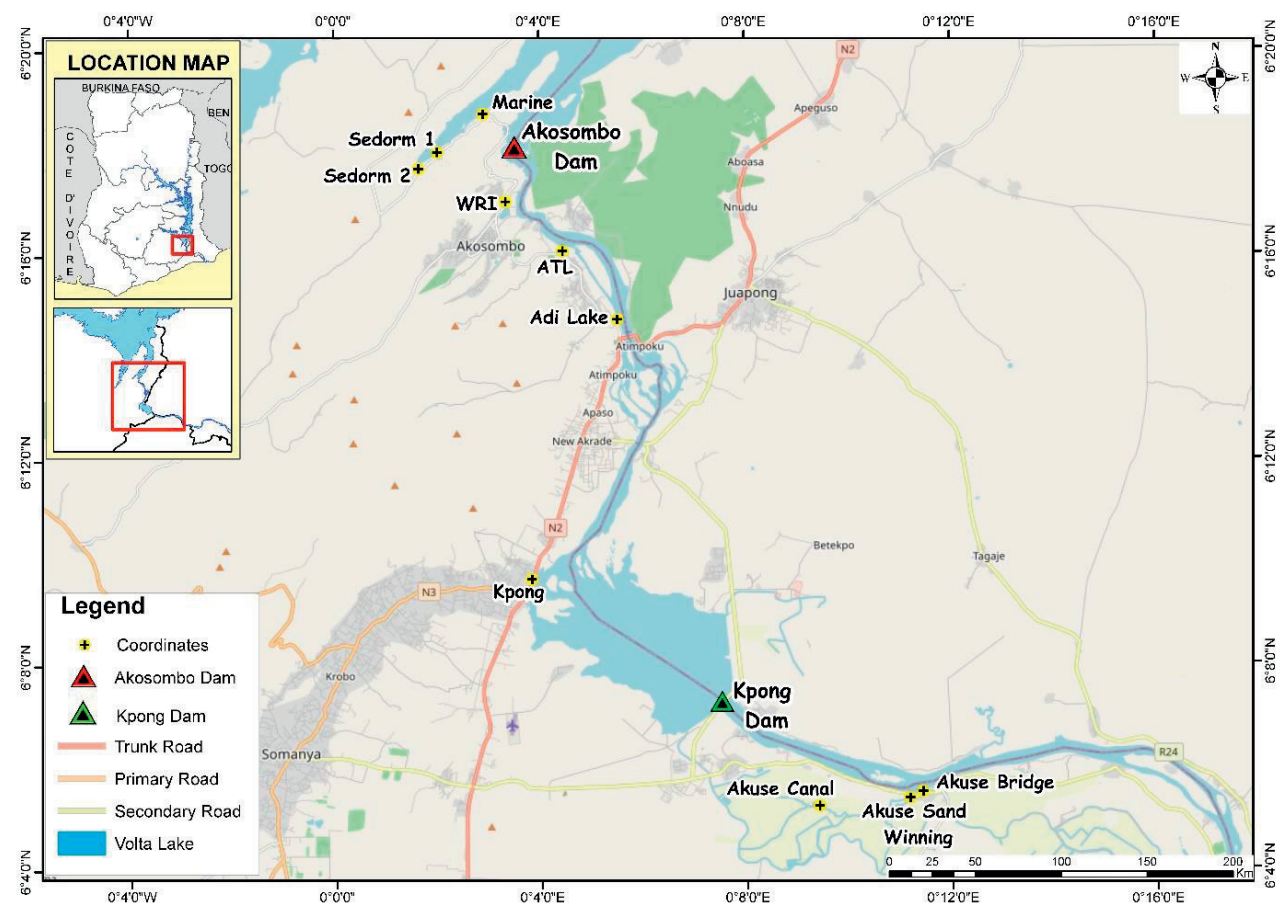

Figure 4.1: Map showing study area and sampling points.

\section{Site selection and sampling}

Site selection was based on land use, accessibility and anthropogenic activities using the Rapid Bioassessment Protocol (RBP) for streams and wadable rivers (Barbour et al. 1999). The stations were divided to three areas: up the Akosombo hydroelectric Dam (3 stations), in between the Akosombo hydroelectric Dam and Kpong hydroelectric Dam (4 stations) and down the Kpong hydroelectric Dam (3 stations) (Fig. 3.1). The water quality was evaluated in the river by sampling upstream, the disturbed areas themselves, and downstream of the waterways and the differences in macroinvertebrate abundance were used as main biological indicator of disturbance (Table SI 4.2, 4.3 and 4.4). Besides, we tried to have a good distribution of stations between land uses (Table SI 4.1) and stations were subjected to nonpoint influents (i.e. agricultural runoff) and point influents (i.e. fish pond). Also, one site was selected as reference site where there was no or slight pollution expected (Table SI 4.1; T6 (Adi Lake)). Each station was sampled three times with a two-week interval in the dry and wet 


\section{Chapter 4}

seasons namely: January - February 2016 and May - June 2016, respectively, for the investigation of physico-chemical parameters, pesticide concentrations and macroinvertebrate abundance. Sampling was mainly confined to a few meters ( $\sim 4)$ from the banks of the river courses except on a few occasions where a canoe was used due to unavailability of conducive bank. Surface water samples were taken from a depth of 20-30 $\mathrm{cm}$. Samples were collected into acid-cleaned high-density $1 \mathrm{~L}$ polyethylene bottles. The samples were carried in an ice cooler from the field and stored in a refrigerator at $4^{\circ} \mathrm{C}$ before analysis of physico-chemical parameters at the Ecological Laboratory of the University of Ghana, Legon. Water samples were again taken from each of the sites using pre-cleaned sterile glass amber bottles and kept at $4^{\circ} \mathrm{C}$ and subsequently used for pesticide analyses.

At each sampling location, a surber sampler (30x30 cm and 250 micron mesh) was used for collecting macroinvertebrates based on the RBP. On each site three replicates were collected and composited as one sample. Benthic macroinvertebrates were preserved in $4 \%$ formaldehyde solution. The macroinvertebrates were sorted, identified to the lowest possible taxonomic level (species, genus or families), and counted under a stereomicroscope.

\section{Physico-chemical analysis}

During sampling, water temperature $\left({ }^{\circ} \mathrm{C}\right), \mathrm{pH}(-)$, dissolved oxygen $(\mathrm{DO} \mathrm{mg} / \mathrm{L})$, total dissolved solids (TDS, $\mathrm{mg} / \mathrm{L}$ ), turbidity (NTU), and electrical conductivity $(\mu \mathrm{s} / \mathrm{cm}$ ) were measured on site using portable equipment (Horiba $U$-50 Series multi-parameter water quality meter). Total solids (TS) was determined by Gravimetric Method (APHA, 1998). 10mL of the samples were weighted into a pre-weighed evaporating dish which was then dried in an oven at a temperature of 103 to $105^{\circ} \mathrm{C}$ for two and a half hours. The dish was transferred into a desiccator and allowed to cool to room temperature and subsequently weighed. The TS was represented by the increase in the weight of the evaporating dish. The total suspended solids were easily obtained by simple calculation, i.e. total suspended solids $=$ total solids - TDS. BOD was determined according to standard methods for the examination of water and wastewater (APHA, 1998).

Othophosphate $\left(\mathrm{PO}_{4}-\mathrm{P}\right)$ was determined using ammonium molybdate and ascorbic acid method (Mackereth et al. 1978), ammonia-nitrogen $\left(\mathrm{NH}_{4}-\mathrm{N}\right)$ by the indophenol blue 
method (Franson, 1989), nitrate-nitrogen $\left(\mathrm{NO}_{3}-\mathrm{N}\right)$ by hydrazine reduction followed by diazotizing to form an azodye which was measured colorimetrically and nitrite-nitrogen $\left(\mathrm{NO}_{2}\right.$ -N) was determined by N-(1-2 naphthyl) ethylene di amine di -hydrochloride method. (APHA, 1998). All reagents used were of analytical grade, equipment was pre-calibrated appropriately before measurement and replicate analyses were carried out for each determination to ascertain reproducibility and quality assurance.

\section{Pesticide extraction and analysis}

The following pesticides were chosen as target compounds based on information of previous and current pesticide use: lindane, delta- $\mathrm{HCH}$, heptachlor, aldrin, gamma chlordane, alpha-endosulfan, DDE, endrin, dieldrin, DDD, DDT, endosulfan sulphate, methoxychlor, ethoprophos, diazinon, dimethoate, pirimiphos-methyl, fenitrothion, malathion, chlorfenvinphos, profenofos, allethrin, bifenthrin, $\lambda$-cyhalothrin, permethrin, cyfluthrin, cypermethrin, fenvalerate, deltamethrin and chlorpyrifos.

Pesticide samples (water) were analysed at the Pesticide Residue Laboratory of the Ghana Standards Authority. Liquid-liquid extraction method was used to extract pesticides from the water samples. The 1-L sample water was filtered (whatman binder-free glass microfiber filter (GF/D, pore size: $2.7 \mu \mathrm{m}$, Fisher Scientific, Pittsburgh, PA, USA)) and transferred into a $2 \mathrm{~L}$ capacity separatory funnel and $30 \mathrm{~mL}$ of saturated sodium chloride solution was added. The sample was partitioned with $100 \mathrm{ml}$ of dichloromethane (thrice), each time shaking the separatory funnel vigorously for 2-3 $\mathrm{min}$ and releasing the pressure intermittently. The layers were allowed to separate and the dichloromethane extract layer drained. The three extracts of dichloromethane layers were combined and concentrated to about $1 \mathrm{~mL}$ using a rotary vacuum evaporator for adsorption chromatography.

A Varian CP-3800 Gas Chromatograph (Varian Associates Inc. USA) equipped with an on-column injector and electron capture detector (ECD) was used to determine pesticide concentrations. $1 \mu \mathrm{L}$ aliquots of sample extract was injected and the separation was performed on a fused silica gel capillary column (VF- $5 \mathrm{~ms} 30 \mathrm{~m} \times 0.25 \mathrm{~mm}$ id, $0.25 \mu \mathrm{m}$ film thickness). The carrier gas was ultra-pure nitrogen at a flow rate of 1.0 to $29 \mathrm{~mL} \mathrm{~min}^{-1}$. The temperature of the injector operating in splitless mode and oven temperature were held at 


\section{Chapter 4}

$225^{\circ} \mathrm{C}$ while the detector temperature was $300^{\circ} \mathrm{C}$. The column oven temperature was programmed as follows: $60^{\circ} \mathrm{C}$ for $2 \mathrm{~min}, 180^{\circ} \mathrm{C} \mathrm{min}-1$ up to $300{ }^{\circ} \mathrm{C}$ which was held for 31.80 $\min$. The residues detected by the GC analysis were confirmed by the analysis of the extract on two other columns of different polarities. The first column was coated with ZB-1 (methyl polysiloxane) connected to ECD and the second column was coated with ZB-17 (58\% phenyl, methyl polysiloxane) and ECD. The residue of pesticide was identified based on comparison of the measured relative retention times to those of known standards. The residue levels of organochlorine and synthetic pyrethroid pesticides were quantitatively determined by the external standard method using peak area.

Chromatographic separations for organophosphates was performed with a capillary column coated with VF-1701ms ( $30 \mathrm{~m}, 0.25 \mathrm{~mm}, 0.25 \mathrm{~mm}$ film thickness). The carrier gas was nitrogen at a flow rate of $2.0 \mathrm{~mL} / \mathrm{min}$, while hydrogen $(14 \mathrm{~mL} / \mathrm{min})$, air $1(17 \mathrm{~mL} / \mathrm{min})$ and air 2 (10 ( $\mathrm{mL} / \mathrm{min})$ were used for the detector. The injector (splitless mode) and PFPD temperatures were held at $270^{\circ} \mathrm{C}$ and $300^{\circ} \mathrm{C}$, respectively. The column oven temperature was programmed as follows: $70^{\circ} \mathrm{C}$ for $2 \mathrm{~min}$, increased steadily at a rate of $25{ }^{\circ} \mathrm{C} / \mathrm{min}$ to $200{ }^{\circ} \mathrm{C}$, then at $20^{\circ} \mathrm{C} / \mathrm{min}$ up to $250^{\circ} \mathrm{C}$ and held for $4.3 \mathrm{~min}$. The injection volume was $2.0 \mu \mathrm{L}$ and the total run time for each sample was $15 \mathrm{~min}$. Measurement was carried out for the respective pesticides within the linear range of the detector. The peak areas whose retention times coincide with the standards were extrapolated on their corresponding calibration curves to obtain the concentration. The quantities of pesticide obtained were adjusted based on the recoveries of the spiked samples. The Limit of Detection (LOD) was determined using the formulae, $L O D=S \times t$, where, $\mathrm{S}$ is the standard deviation of the replicate analysis, and $\mathrm{t}$, the student's $t$ value for the $99 \%$ confidence interval with $n-1$ degrees of freedom (Wisconsin Department of Natural Resources, 1996; USEPA, 2012). The LOD was $0.005 \mu \mathrm{g} / \mathrm{L}$ for organophosphates/synthetic pyrethroids and $0.01 \mu \mathrm{g} / \mathrm{L}$ for organochlorines.

The quality of the measurements of the organochlorine, synthetic pyrethroid and organophosphate pesticide concentrations were assured through the analysis of solvent blanks, procedure blanks and duplicate samples. All reagents used during the analysis were exposed to same extraction procedures and subsequently run to check for interfering substances. In the blank for each extraction procedure no organochlorine, synthetic pyrethroid or organophosphate pesticide was detected. Sample of each series was analyzed 
in duplicates. The method was optimized and validated by spiking the water with $100 \mu \mathrm{L}$ of $100 \mathrm{ng} \mathrm{mL}^{-1}$ standard mixture before analysis to evaluate the recovery of compounds. The recoveries of internal standards ranged between $79 \%$ and $96 \%$ for all the pesticides.

\section{Data analysis}

Multivariate analyses were performed using CANOCO 5 to investigate the correlations among physicochemical characteristics of the sampling sites, the macroinvertebrate species and their relationships (Ter Braak and Šmilauer, 2012). For both the physico-chemical as the macroinvertebrate data set the significance of the differences between the dry and the wet season was evaluated using an RDA analysis including season as explanatory variable and sampling date and covariable. Within the Monte Carlo permutation test following the RDA analyses, the samples were only permuted within the covariables. The significance of the differences between sampling times was tested using season as covariables and permuting the samples only within the covariable. After that, a PCA was performed for both data sets including season and sites as passive explanatory variables

Redundancy analysis (RDA) testing the significance of each physico-chemical parameters, as well as the substrate composition (Table S1) in explaining the differences in community composition was used to examine the relationships between environmental variables (i.e., physico-chemical and habitat parameters) and abundance of macroinvertebrates. This analysis was followed by an RDA including the significant physicochemical and habitat parameters as explanatory variables and season and sampling site as passive explanatory variables. The abundance values of macroinvertebrates were $\log (2 x+1)$ transformed in the above multivariate analyse, where $\mathrm{x}$ represents the abundance data (Van den Brink et al. 2000).

\section{Results and discussion}

\section{Physico-chemical parameters}

The results of the habitat assessment during the study are summarised in Table S1 in the form of watershed features, riparian vegetation, in-stream features and substratum. Lower availability of the hard habitat like cobble substratum occurred at stations (Sedorm 1) 


\section{Chapter 4}

T1, (WRI) T4, ATL (T5), (Adi Lake Ref.) T6, (Kpong) T7 and (Akuse Sand Winning) T10. The rest of the stations had sand content ranging from $15-100 \%$.

There was a clear separation between physico-chemical parameters and their relative values in the different sites and seasons in the PCA ordination diagram (Fig. 4.2).

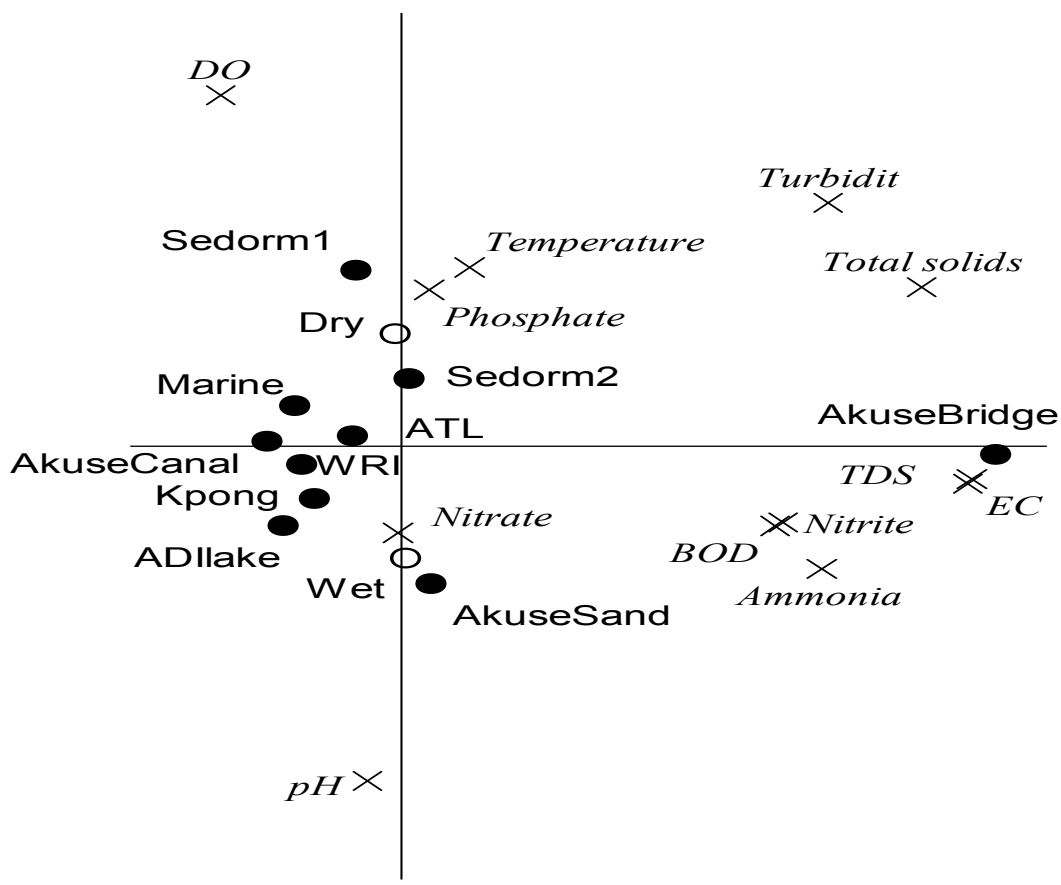

Figure 4.2: PCA plot showing the correlations between physico-chemical parameters and their relative values in the different sites and seasons. The horizontal and vertical axes display 34 and 19\% of the variation in physico-chemical parameter values, respectively. Monte Carlo permutation tests indicated that differences between seasons and sites are significant $(p=0.002)$, while the differences between sampling dates was not significant (see text for test conditions).

Additionally, there was a significant difference between seasons and sites whiles no significant difference existed between sampling dates (Monte Carlo permutation test; $p=0.002$ ). This is in contrast to the assertion by Gampson et al. (2014) that physico-chemical parameters do not vary much in terms of the sampling sites of the lower Volta basin. Thus the anthropogenic activities resulting from the adjoining land use characteristics, may have changed the physicochemical parameters. Again the rainy season is characterised with a lot of precipitation which can influence the physico-chemical parameters of the river. The PCA plot showed the largest difference in values between the stations for TDS, EC, turbidity, total 
solids, ammonia, pH and DO (Fig. 4.2). Akuse Bridge is clustered away from all other stations, with relatively high TDS and EC values. The vertical axis merely displays the differences between the seasons, which were significant. The dry season recorded lower $\mathrm{pH}$ values compared to the wet season (Table SI 4.2; Fig. 4.2). The lowest pH of 4.44 was recorded at the first sampling of Sedorm 1 during the dry season which could be described as acidic (Table SI 4.2). The highest (10.25) were also recorded at Sedorm 1 and Marine but during the wet season. All the $\mathrm{pH}$ values determined in the wet season were within the WHO recommended range for drinking water (6.5-9.5) (Table SI 4.2) except the first and third sampling of Sedorm 1 and the third sampling of Marine in the wet season. This could be due to photosynthetic activity and microbial respiration as well as decomposing activities at the sites affecting the $\mathrm{pH}$ value. Similar values have been reported in the Volta river by other studies (Amoah and Koranteng, 2006; Gampson et al. 2014). Overall, water temperature ranged from 28.1 to $32.8^{\circ} \mathrm{C}$ (ATL, Sedorm) and 28.5 to $31.5^{\circ} \mathrm{C}$ (Sedorm 2, Sedorm 1) in the dry and wet seasons, respectively (Table SI 4.2). The temperatures of the sampling sites were relatively constant and compares to the range $\left(27-30^{\circ} \mathrm{C}\right)$ reported by Amoah and Koranteng (2006).

Conductivity of the water samples ranged from 66 to $149 \mu \mathrm{S} / \mathrm{cm}$ (Akuse Canal, Akuse Bridge) and 68 to $165 \mu \mathrm{S} / \mathrm{cm}$ (WRI, Akuse Bridge) (Table SI 4.2) in the dry and wet seasons, respectively. The mean values obtained for both seasons were below the WHO recommended guideline limit of $1400 \mu \mathrm{S} / \mathrm{cm}$. Conductivity is related to the concentration of Total Dissolved Solids (TDS) (Bakhtiar et al. 2019). The TDS values obtained for both the dry and wet season were below recommended limit of 500-1000 (mg/L) permissible for drinking (Davis and De Wiest, 1966). The electrical conductivity and TDS values obtained here indicate relatively low salt contents in the study area. The mean total solids of the water in the study area ranged from 42-99 (mg/L) in the dry season and 44-106 ( $\mathrm{mg} / \mathrm{L})$ in the wet season, indicating good water quality as measured values were below the prescribed permissible limit of $500 \mathrm{mg} / \mathrm{L}$ according to the European Union (EPA, 2001). Turbidity values were comparatively higher in the dry season and ranged from 23 to 90 NTU, while the wet season recorded values of 3-26 NTU (Table SI 4.2). Except Adi lake, Kpong and Akuse canal in the wet season (Table SI 4.2), all the samples in both seasons had turbidity values exceeding $5 \mathrm{NTU}$, the WHO guideline value for turbidity in drinking water (WHO, 2004a, b). The high turbidity may be attributed to the larger particles such as organic matter, dissolved solids, agricultural runoff, leaching of soil 


\section{Chapter 4}

contaminant and point source water pollution discharged from industrial or sewage treatment plants. This causes problems with water purification processes, leading to increased treatment cost (DWAF, 1998).

Dissolved oxygen (DO) varied from $4.4-14.7 \mathrm{mg} / \mathrm{L}$ and $2.1-9.8 \mathrm{mg} / \mathrm{L}$ in the dry season and wet seasons, respectively (Tables SI 2). The highest value was measured during the dry season at sampling site Marine and the lowest value was measured at site Akuse Sand Winning in the wet season. The low DO at some sites may be caused by the decomposition of organic matter, dissolved gases, industrial waste, mineral waste and landfill leachate (Table SI 4.1). Acceptable range of BOD concentrations of $0.8-5 \mathrm{mg} / \mathrm{L}$ is set by WHO $(2004 \mathrm{a}, \mathrm{b})$ but our study revealed ranges of $2.18-5.82 \mathrm{mg} / \mathrm{L}$ and $1.0-18.7 \mathrm{mg} / \mathrm{L}$ in the dry season and wet season, respectively (Tables SI 2). The highest BOD value was recorded at the sampling site Akuse Sand Winning during the wet season (Table SI 4.2). The high levels obtained could possibly be attributed to domestic discharges which can increase the organic loads in the water (Table SI 4.1).

\section{Nutrients}

The WHO has adopted a standard of $50 \mathrm{mg} / \mathrm{L}$ for nitrate-nitrogen and $3 \mathrm{mg} / \mathrm{L}$ for nitrite-nitrogen as the maximum contaminant level (MCL) for drinking water (WHO, 2004a, b). Nitrate levels ranged between 0.1-1.7 mg/L in the dry season and 1.1-7.9 mg/L in the wet season. The ranges of nitrite were $0.01-0.03 \mathrm{mg} / \mathrm{L}$ (dry) and, $0.01-0.05 \mathrm{mg} / \mathrm{L}$ (wet) and of ammonium were $<0.0010 .65 \mathrm{mg} / \mathrm{L}$ (dry), 0.01-1.45 mg/L (wet) respectively (Table SI 4.2). These concentration levels were generally low and below the WHO standard. Criteria for total ammonia $\left(\mathrm{NH}_{3}\right)$ have been established, for example by the EPA, to reflect the varying toxicity of $\mathrm{NH}_{3}$ with $\mathrm{pH}$ (USEPA, 2013). Ammonium $\left(\mathrm{NH}_{4}{ }^{+}\right)$is less toxic than $\mathrm{NH}_{3}$. In other studies, water quality criteria for phosphorus compounds, such as phosphates, are set at a concentration that prevents excessive growth of algae. Phosphorous is a limiting nutrient for algal growth and therefore controls the primary productivity of a water body (Karikari et al. 2007). It is also an essential nutrient and indicator of anthropogenic pollution. In most natural waters, PO4-P concentration range from $0.005-0.020 \mathrm{mg} / \mathrm{L}$. In pristine waters, PO4-P concentrations may be as low as $0.001 \mathrm{mg} / \mathrm{L}$ (Karikari et al. 2007). Levels of PO4-P in this study varied between $0.16-4.97 \mathrm{mg} / \mathrm{L}$ in the dry season and $0.14-1.45 \mathrm{mg} / \mathrm{L}$ in the wet season. Digestive problems 
could occur in humans from drinking water with extremely high levels of phosphate (Morrison et al. 2001). None of the samples had values that exceeded the $5 \mathrm{mg} / \mathrm{L}$ set as standard in South Africa (Morrison et al. 2001).

\section{Pesticides}

The concentration of organochlorine pesticides were below the detection limit $(0.005$ $\mu \mathrm{g} / \mathrm{L}$ ) at all the sampling sites. Meanwhile, Ntow (2005) reported gamma-HCH levels of 0.008 $\mu \mathrm{g} / \mathrm{L}$ as well as alpha-endosulfan and endosulfan sulfate concentrations of 0.036 and 0.023 $\mu \mathrm{g} / \mathrm{L}$ respectively in the Volta Lake. The absence of detection of organochlorines could be due to the ban of the use of e.g. DDT (GEPA, 2008) in Ghana, over time leading to possible degradation and dilution in the water body. Recent use of such products may also have been stopped which might have contributed to the low organochlorine pesticide levels. However, $\lambda$-cyhalothrin was detected at Sedorm 1 and Akuse Canal in the dry season in concentrations of $0.6 \mu \mathrm{g} / \mathrm{L}$ and $8.8 \mu \mathrm{g} / \mathrm{L}$ respectively. Cypermethrin was detected at a concentration of 1.4 $\mu \mathrm{g} / \mathrm{L}$ at Marine during the January - February dry season sampling period. $\lambda$-cyhalothrin is highly lipophilic and tends to bind rapidly and strongly to organic materials (Maund et al. 1998; Leistra et al. 2003). Furthermore $\lambda$-cyhalothrin is highly toxic to some groups of aquatic organisms, particularly insects and crustaceans, with the midge Chaoborus obscuripes being sensitive (48- and 96-h EC50 = $0.0028 \mu \mathrm{g} / \mathrm{L}$ ). Other insect larvae (Hemiptera, Ephemeroptera) and macrocrustacea (Amphipoda, Isopoda) are also relatively sensitive, with 48-and 96-h EC50 values between 0.010 and $0.1 \mu \mathrm{g} / \mathrm{L}$ (Schroer et al. 2004). Reported LC50 are: bluegill sunfish, $0.21 \mu \mathrm{g} / \mathrm{L}$ and rainbow trout, $0.24 \mu \mathrm{g} / \mathrm{L}$ (Kidd and James, 1991). Cypermethrin likewise is very highly toxic to fish and aquatic invertebrates. The LC50 (96-hour) for cypermethrin in rainbow trout is $8.2 \mu \mathrm{g} / \mathrm{L}$, and for bluegill sunfish is $1.8 \mu \mathrm{g} / \mathrm{L}$ while the effect concentration for the total crustacean community and cladoceran and copepod subgroups in a study by Friberg-Jensen et al. (2003) ranged between 0.02-0.07 and 0.04-0.17 $\mu \mathrm{g} / \mathrm{L}$, respectively, with copepods being less sensitive than cladocerans. This raises concern as based on intrinsic sensitivity, biological traits, mode of action used for invertebrate vulnerability index rankings by Rico and Van den Brink (2015), Ephemeroptera, Plecoptera, Tricoptera, and Odonata genera were identified potentially most vulnerable to pyrethroids in aquatic ecosystems. The pesticide data were however not analysed further due to the low number of detections (Table SI 4.4). 


\section{Macroinvertebrate community}

A total of 14 and 16 macroinvertebrate fauna were identified in the dry and wet seasons, respectively, belonging to 2 major phyla viz: Arthropoda and Mollusca. Among these phyla, Arthropoda (Polypedilum fuscipenne, Stereo chironomus sp., Ictinogamphus sp., Laccophilus sp., Centroptiloides sp., Hagenius sp., Lethocerus sp., Phaon Iridipennis, Centroptiloides, Culicidae sp. and Eurymetra sp.) dominated (66.7\%) followed by Mollusca (Physa sp., Lymnae glabra, Mya arenaria, Bithynia sp. and Pomacea paludosa) (33.3\%) (Table SI 4.3). A significant difference existed between macroinvertebrate composition and sampling sites and seasons (Monte Carlo permutation tests; $p=0.002$; Fig. 4.3).

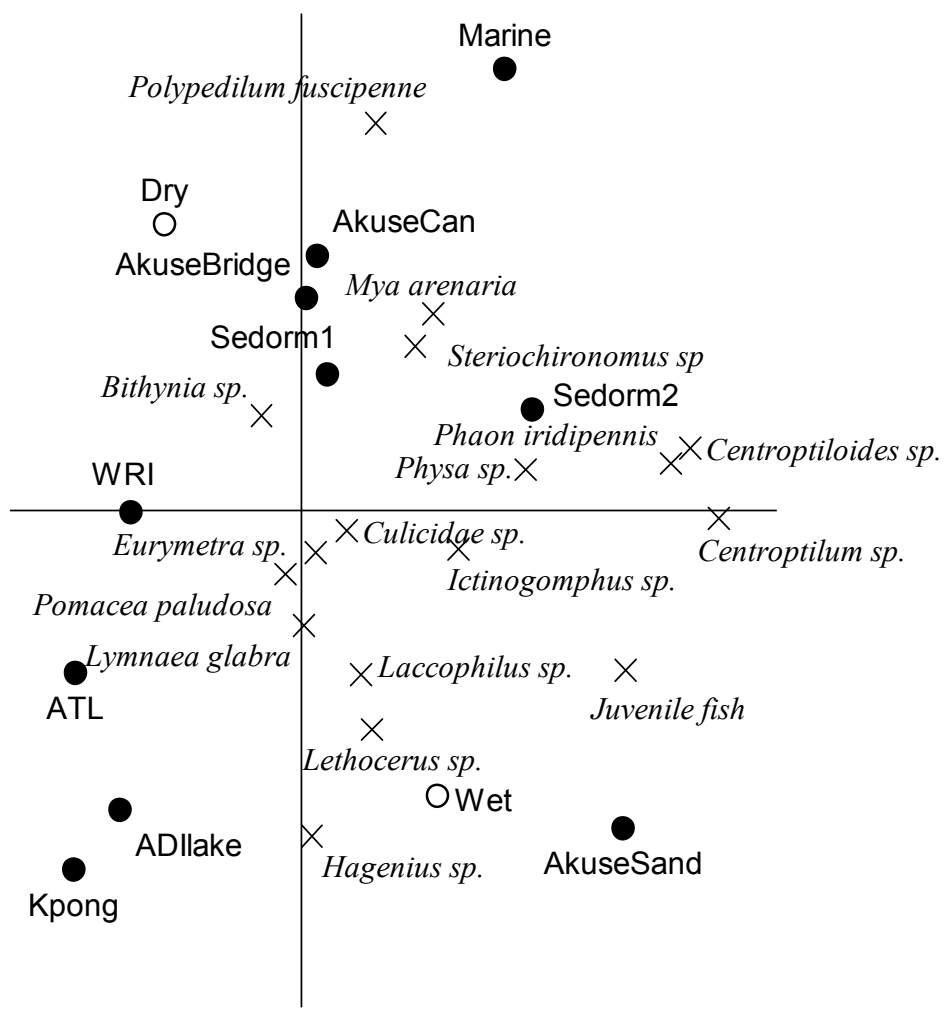

Figure 4.3: PCA plot showing the correlations between macroinvertebrate abundance values in the different sites and seasons. The horizontal and vertical axes display 27 and $16 \%$ of the variation in the abundance of macroinvertebrate species, respectively. Monte Carlo permutation tests indicated that differences between seasons and sites are significant $(p=0.002)$, while the differences between sampling dates was not significant (see text for test conditions). 
The macroinvertebrates were generally more abundant in the wet season than the dry season except Polypedilum fuscipenne and Bithynia sp. at Akuse Canal, Akuse Bridge and Marine (Fig. 4.3). The Akuse and Marine sites are however characterised by industrial, township and agricultural activities (Table SI 4.1). Similar results have been reported in the Porto-Novo lagoon in Benin (Adandedjan et al. 2011). Lymnae glabra was the predominant macroinvertebrate in both seasons (Fig. 4.3) because it can survive under polluted and unpolluted conditions (Rondelaud et al. 2009). The species with high frequency included Lymnaea glabra (Lymnaeidae; Gastropoda), Polypedilum fuscipenne (Chironomidae; Diptera), Centroptiloides sp (Baetidae; Ephemeroptera), Physa sp. (Physidae; Gastropoda) and Stereo chironomus sp. (Chironomidae; Diptera) (Fig. 4.3; Table SI 4.3). At the sites where human pressures were present (anthropogenic stress, agricultural waste and domestic waste, i.e. Akuse and Sedorm sites) taxa tolerant to pollution, such as Chironomidae increased in abundance, as well as even some non-tolerant ones increased (e.g. Ephemeroptera families) (Pham et al. 2015). Physa sp. for example has been used as a pollution indicator in Australia by Shield et al. (2014) and has also been found abundant in the study areas (Akuse, Sedorm, and WRI sites) where agricultural, aquaculture, waste, organic and sewage pollution is high. Also, in a study by Hynes, (1975a, b), Ephemeroptera (Centroptiloides sp. and Centroptilum) were mentioned as playing a major role in the recovery and recolonization of zoobenthos of dried up river (Pawmpawm River, Southern Ghana) showing their high recolonisation capacity.

\section{Correlation among the physico-chemical parameters and macroinvertebrates}

We found that $\mathrm{pH}, \mathrm{DO}, \mathrm{TDS}$, turbidity, EC nutrients and substratum together explained around $34 \%$ of the total variation in macroinvertebrate composition among sites (Fig. 4.4). Species on the left-hand side of the diagram, such as Polypedilum fuscipenne, were significantly positively correlated with turbidity and DO concentrations and occurred in Kpong and Akuse canal sampling sites during the dry season. Likewise, species on the right-hand side of the diagram, including Physa sp., Centroptilum sp., Centroptiloides sp., Phaon iridipennis and juvenile fish were positively correlated with nitrate concentration and $\mathrm{pH}$. 


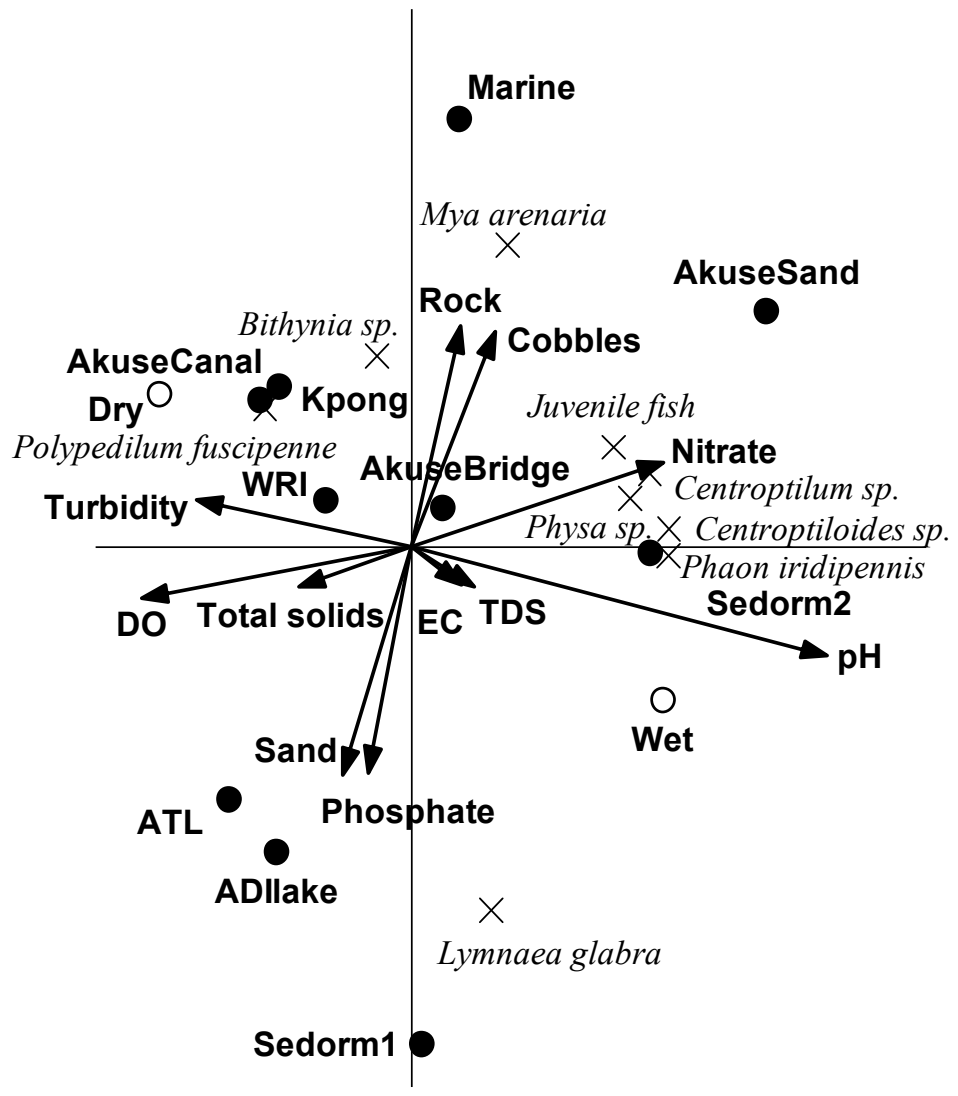

Figure 4.4: RDA biplot showing the environmental variables that significantly explained the variation in macroinvertebrate composition between stations as result of the Monte Carlo permutation tests $(\mathbf{p}<\mathbf{0 . 1 0})$. The environmental variables explained $34 \%$ of the variation in species composition of which $35 \%$ is displayed on the horizontal axis and another $27 \%$ on the vertical axis For clarity, only the 9 out of 17 species are shown, these are the species which best fitted the ordination space.

In contrast, these species also were negatively correlated with turbidity and DO, and occurred in higher abundance at Sedorm 2 sampling site during the wet season (Fig. 4.4). The molluscs (Mya arenaria and Bithynia sp.) were negatively correlated with the sand substratum and phosphate concentration, however, Lymnae glabra was positively correlated (Fig. 4.4). The results suggest that the nature of the substratum and organic contamination caused by anthropogenic activities might be a primary force in determining benthic community composition. For instance, absence of benthic macroinvertebrates was observed in samples from ATL where high levels of nutrients were detected (Tables S2 and S3). Overall, our results 
suggest that anthropogenic disturbance (i.e. environmental pollution) significantly contributed to the variation in benthic assemblages in rivers, even though we cannot rule out the influence of unmeasured ecological drivers.

\section{Conclusions}

The results of this study show that macroinvertebrate community composition shifted along the physicochemical parameters, site and season. There were significant correlations between macroinvertebrate communities and environmental variables (i.e., DO, turbidity, substratum, total solids, EC, TDS, $\mathrm{pH}$ and nutrients) in the Volta River. There was also a significant relationship between macroinvertebrate community composition and sampling sites. Absence of benthic macroinvertebrates was recorded at a few samples sites of the Volta River where high levels of nutrients were determined. Our results suggest that anthropogenic activities (e.g., aquaculture, agriculture effluent discharges) altered the macroinvertebrate community composition directly or indirectly in the exposed sampling sites. 


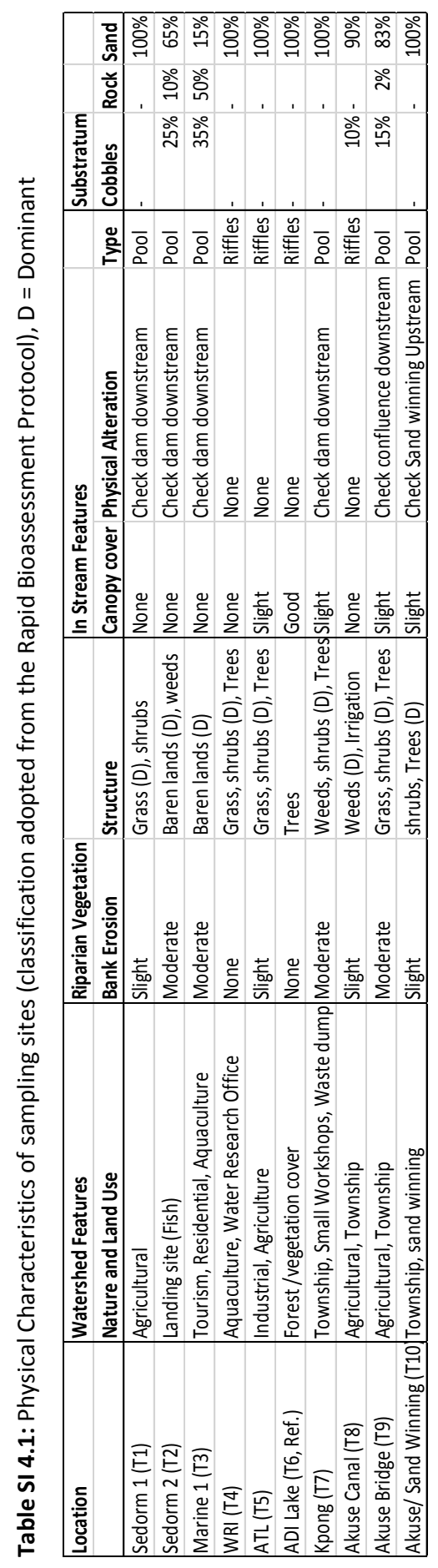




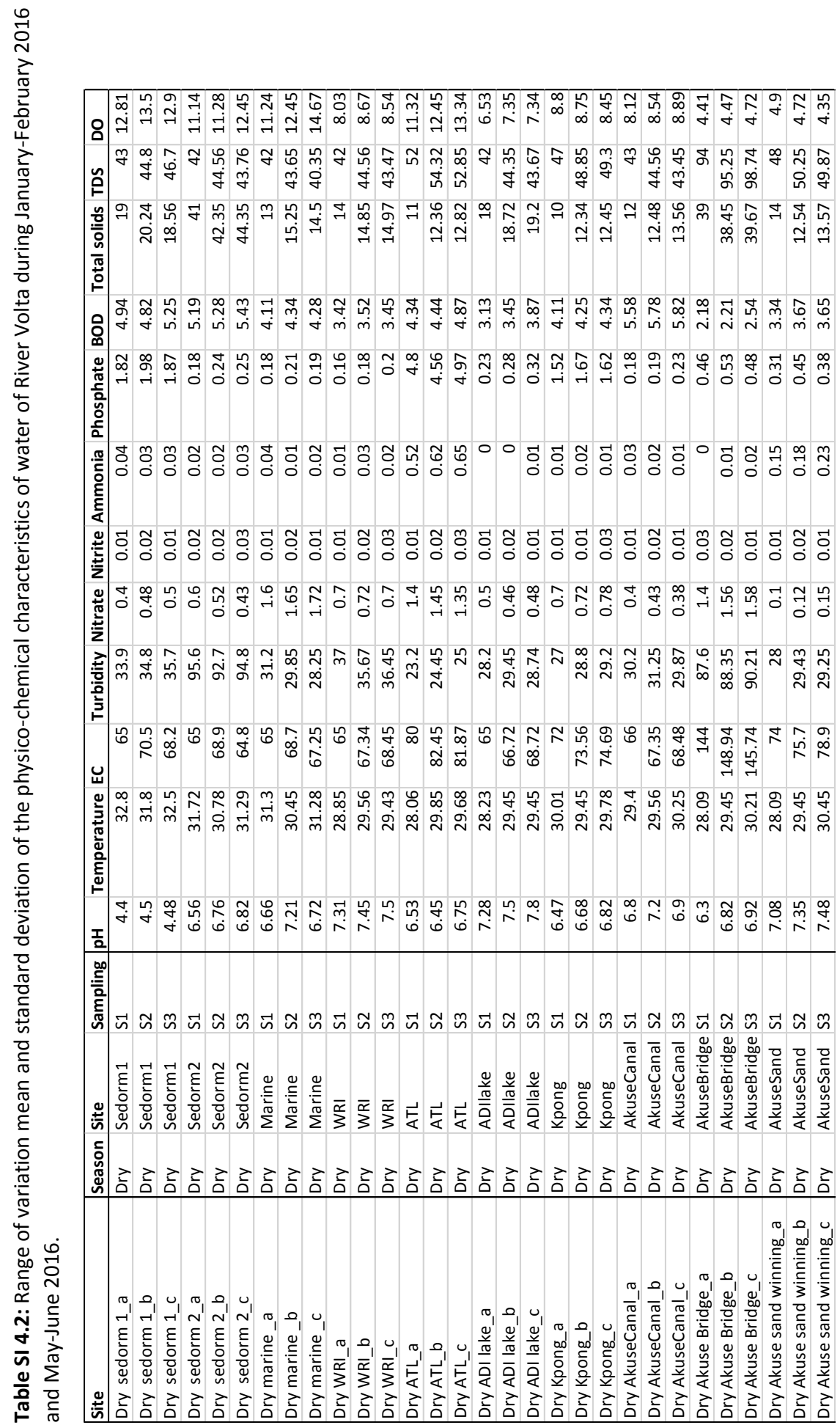




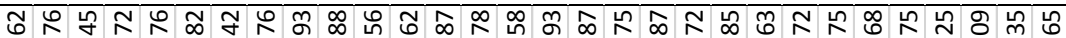

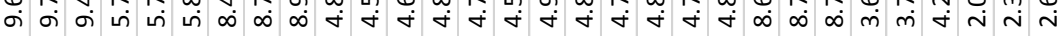

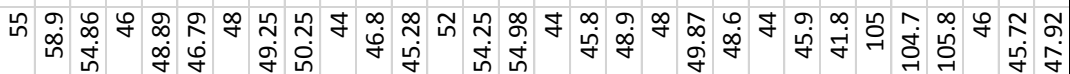

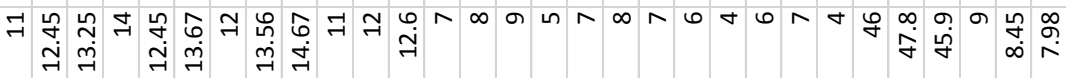

ชิ

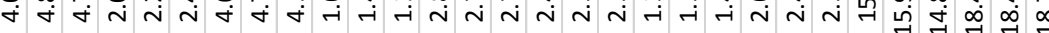

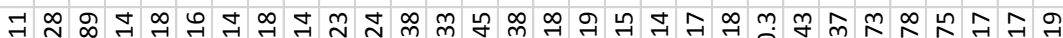
m $m$ m

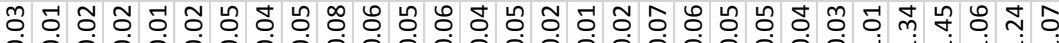

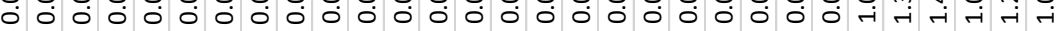

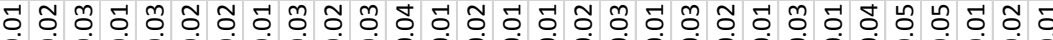

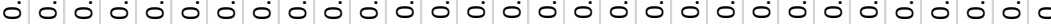

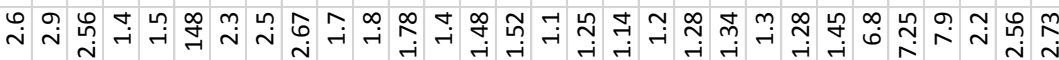

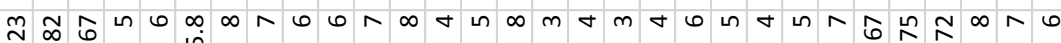
岀

崩 एं

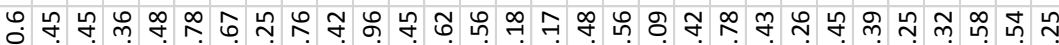
m

นกำ ํำ नं

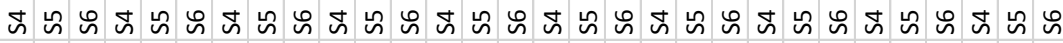

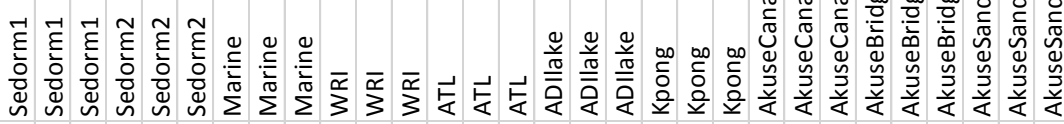

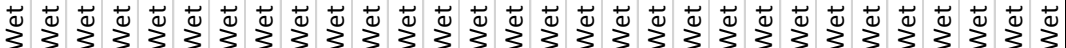

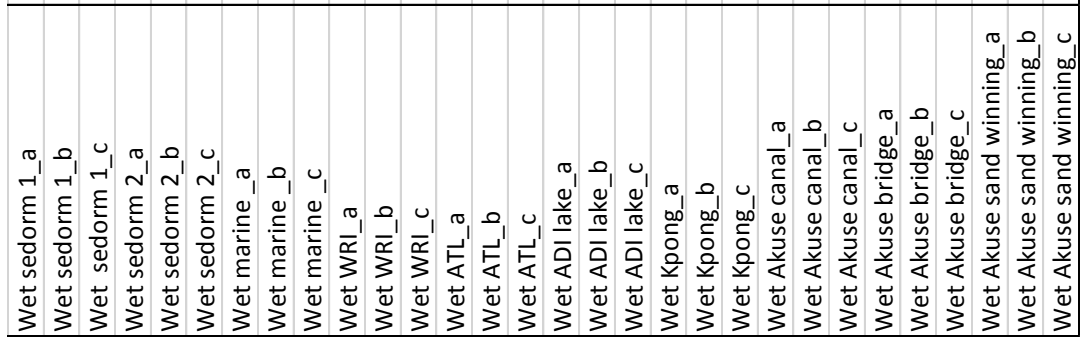




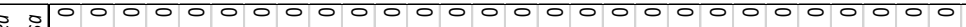

है

000000000000000000000000000000 站

000000000000000000000000000000 帘

穿

$0000000000000000000000000 n 000 n$

害

$000000000000000000000000000 \mathrm{ln}$

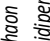

0000000000000000000000 Ln

000000000000000000100000000000 (⿱艹)

$2000000000000000 n$
200000000000000 ธั่

i 000000000000 L $00000000000 n N 0$ N

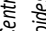

$000000000000 n 00000000000000000$

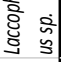

ह 0 N 0000000000000000000000000000000

S 000000000600000000000400000000 을

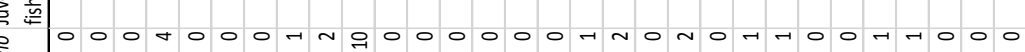
을

:

से है 000000 n 000000000000000000000 을

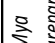

en 는

ㅎํㄴ

है

m 每

.

恚

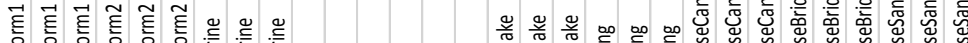

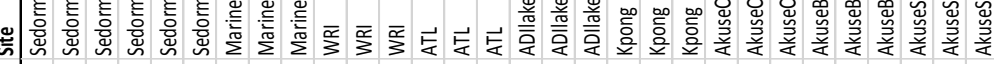

愈

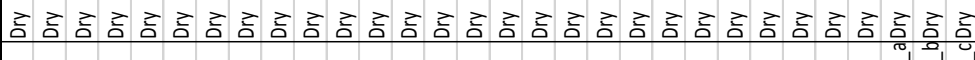

त.

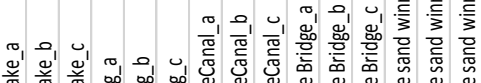

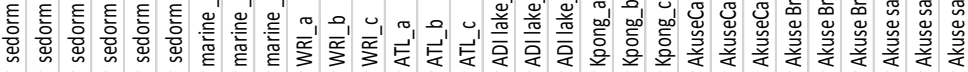

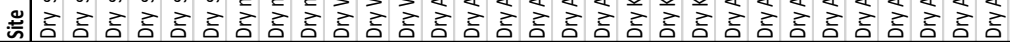




\section{Chapter 4}

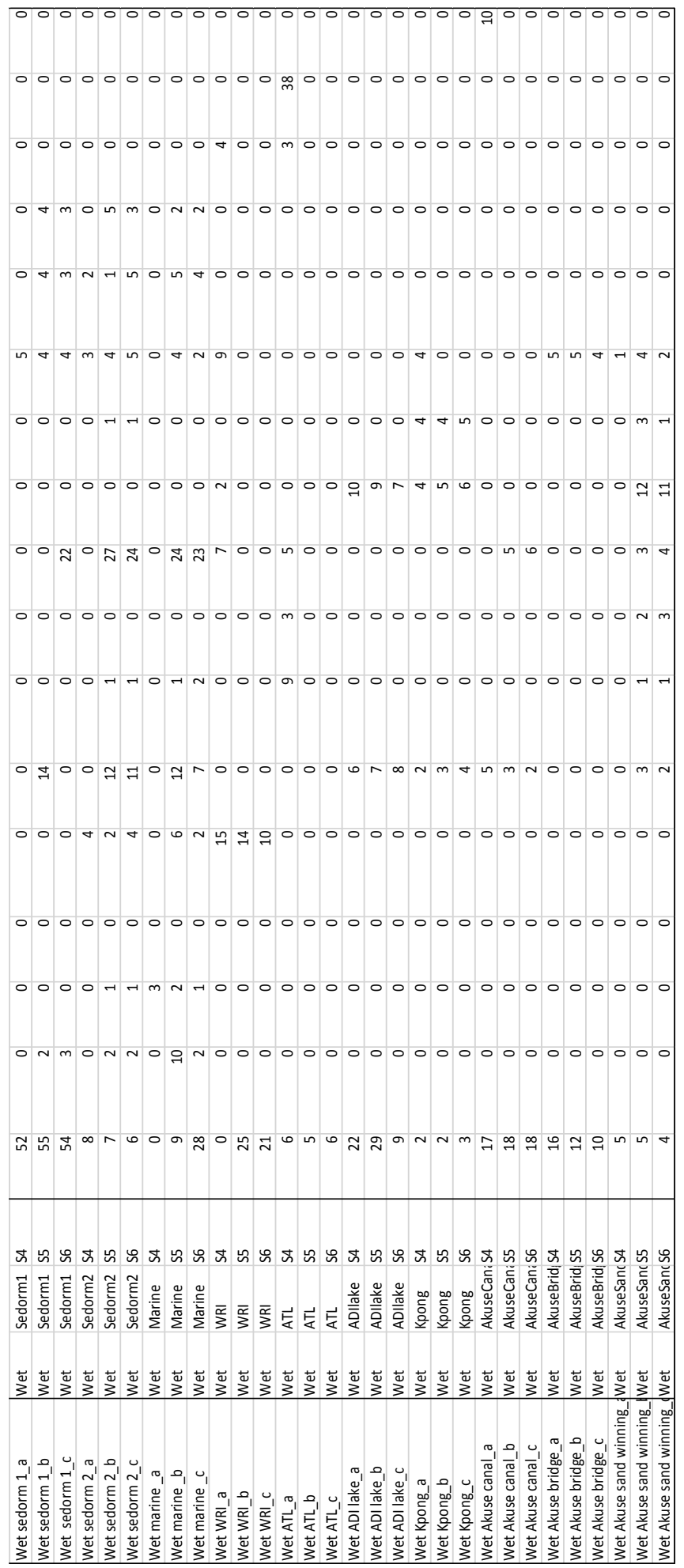


Linking macroinvertebrates and physico-chemical parameters for water quality assessment in the lower basin of the Volta River in Ghana

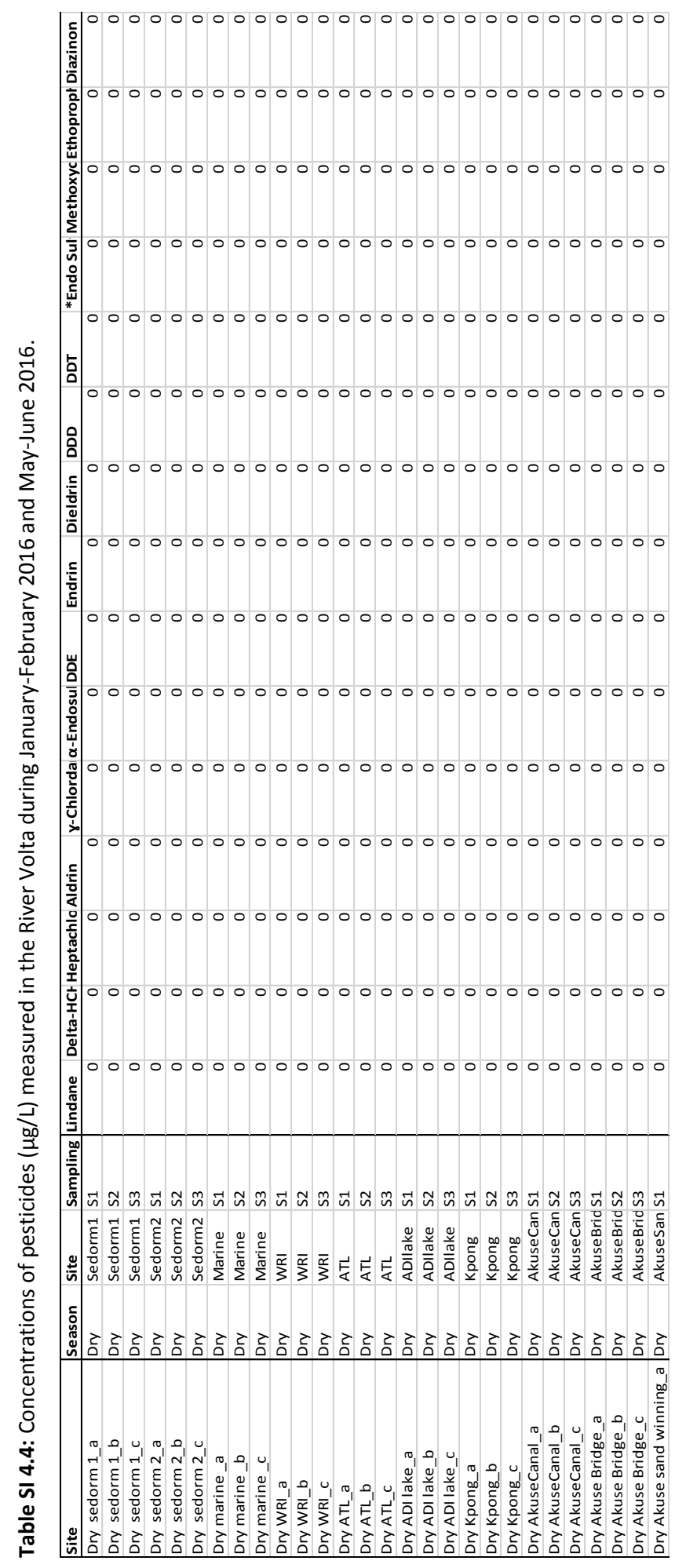




\section{Chapter 4}

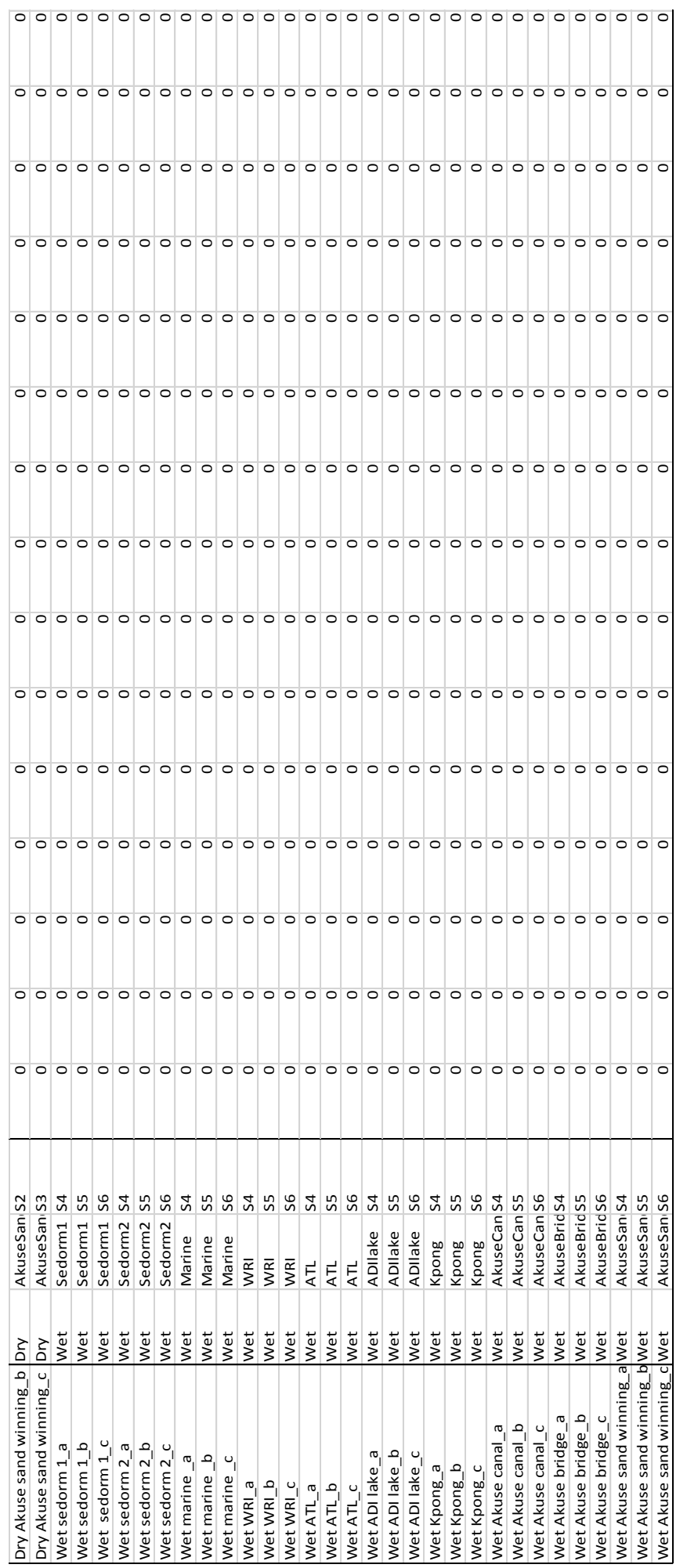




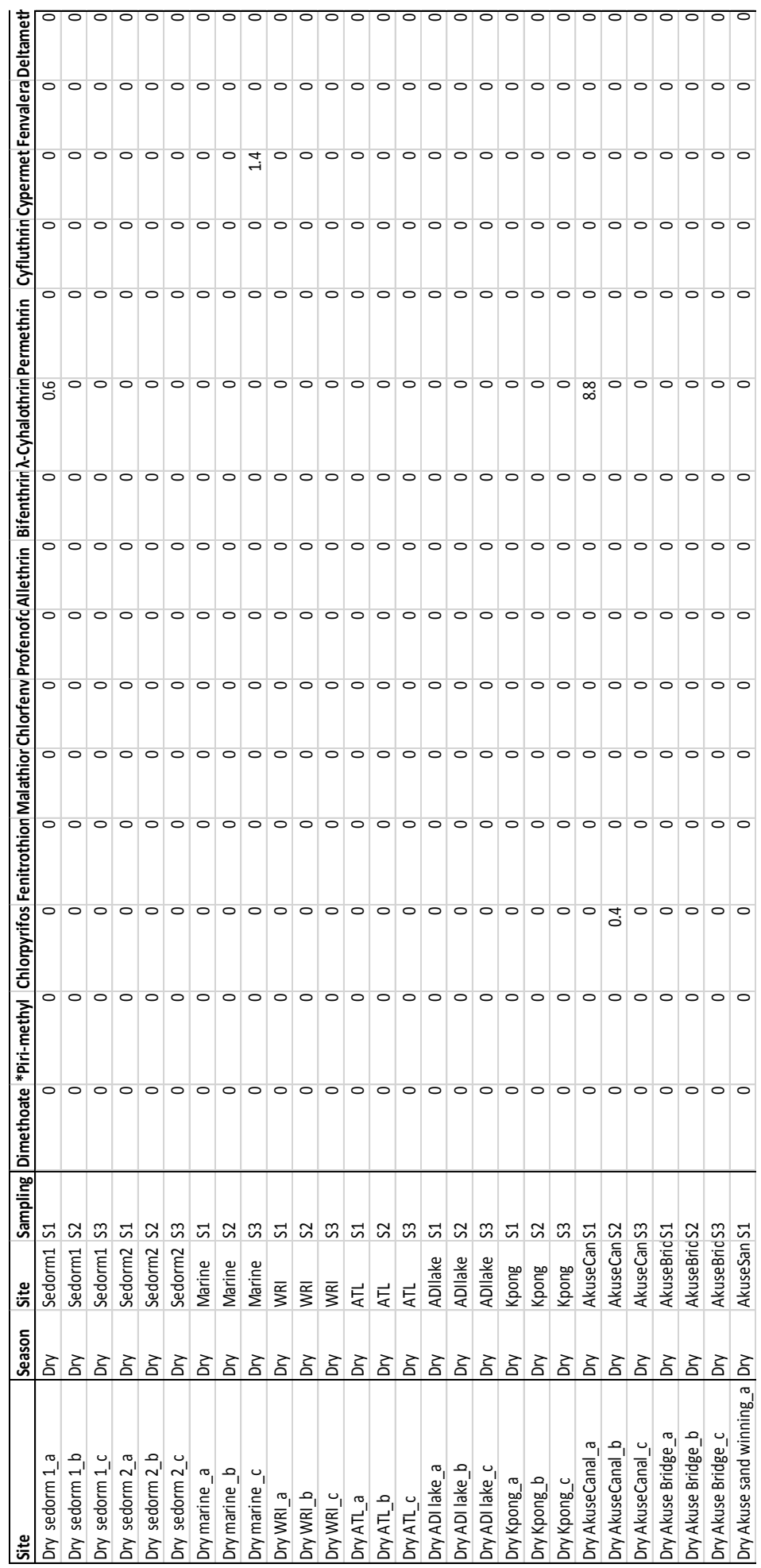




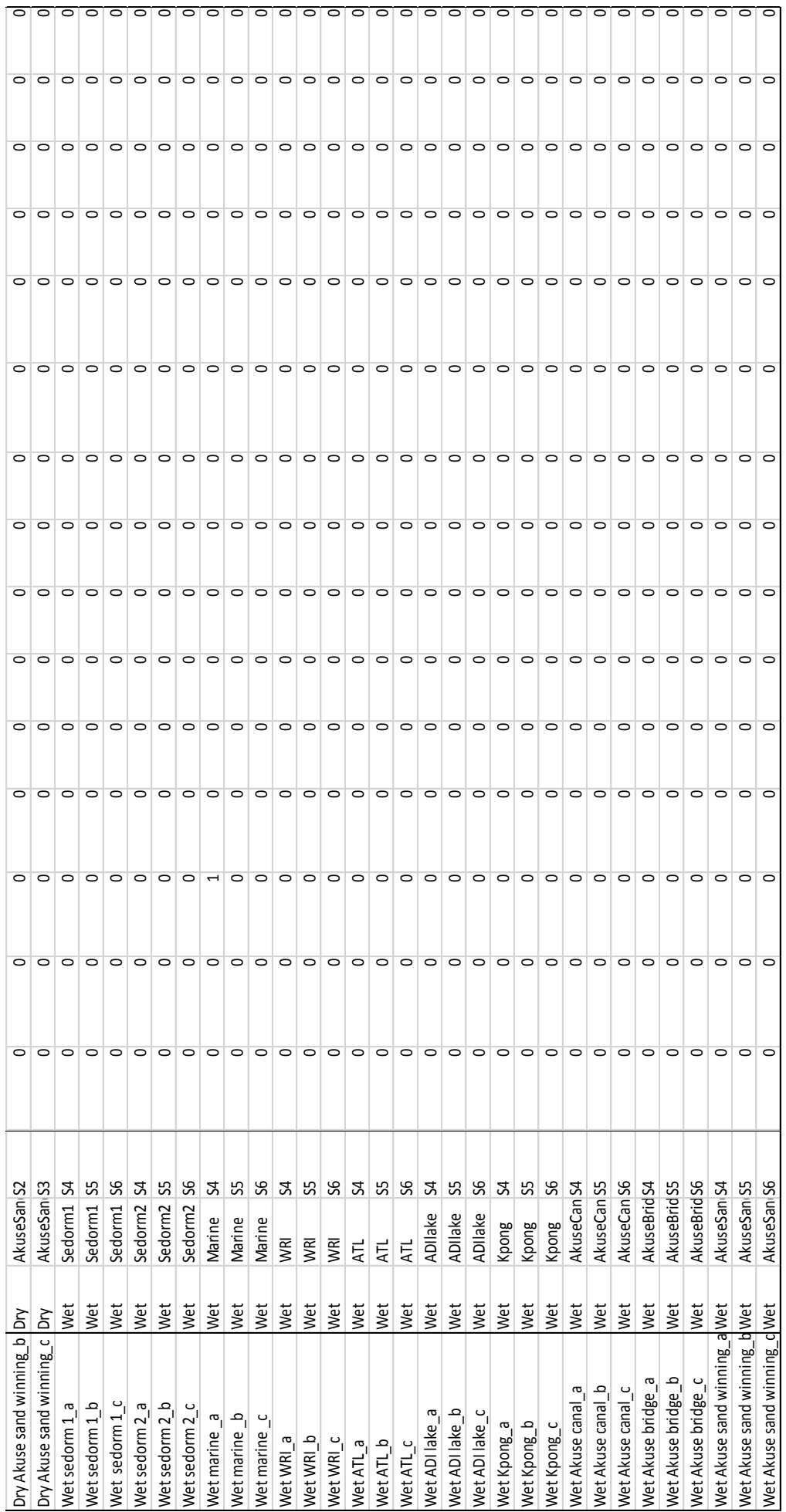


Linking macroinvertebrates and physico-chemical parameters for water quality assessment in the lower basin of the Volta River in Ghana 


\section{Chapter 5}

\section{Pesticides Decrease Bacterial Diversity and Abundance of Irrigated Rice Fields}

Michael Onwona Kwakye ${ }^{a, b}$, Kimberly Paris-Plants ${ }^{c}, K^{\text {Kadiatu Keita }}{ }^{c}$, Jessica Lee ${ }^{c}$, Paul J. Van den
Brink $^{a, d}$, Jonathan N. Hogarh ${ }^{*}{ }^{*}$ Charles Darkoh ${ }^{c, f}$

${ }^{a}$ Aquatic Ecology and Water Quality Management Group, Wageningen University, P.O. Box 47, 6700 AA, Wageningen, The Netherlands

${ }^{\mathrm{b}}$ Ghana Environmental Protection Agency, P. O. Box M326, Accra Ghana

' University of Texas Health Science Center, School of Public Health, Department of Epidemiology, Human Genetics, and Environmental Sciences, Center for Infectious Diseases, Houston, Texas 77030, USA.

${ }^{d}$ Wageningen Environmental Research, P.O. Box 47, 6700 AA, Wageningen, The Netherlands

e Department of Environmental Science, College of Science, Kwame Nkrumah University of Science and Technology, PMB University Post Office, Kumasi, Ghana

${ }^{f}$ MD Anderson Cancer Center UTHealth Graduate School of Biomedical Sciences, Microbiology and Infectious Diseases Program, Houston, Texas, USA.

This chapter has been published in Microorganisms (2020), 8: 318. 


\title{
Chapter 5
}

\begin{abstract}
Microbes play an important role in soil ecosystems and their activities are crucial in nutrient composition and recycling. Pesticides are extensively used in agriculture to control pests and improve yield. However, increased use of pesticides on agricultural lands will result in contamination of the soil, which could have adverse effect on its microbial communities. We investigated the effect of pesticides commonly used on irrigated rice fields on bacterial abundance and diversity. Irrigated soil samples were collected from unexposed, pesticideexposed, and residual exposure areas and cultured under aerobic and anaerobic conditions at $37^{\circ} \mathrm{C}$ in brain heart infusion medium to enable bacterial growth. DNA was extracted from the resulting culture and analysed by $16 \mathrm{~S}$ rRNA sequencing. The results showed overall decrease in bacterial abundance and diversity in areas exposed to pesticides. Operational taxonomic units of the genera Enterobacter, Aeromonas, Comamonas, Stenotrophomonas, Bordetella, and Staphylococcus decreased in areas exposed to pesticides impairing the degradation of organic compounds, plant growth promotion, microbial equilibrium and plant protection from microbes and insects. Conversely, Domibacillus, Acinetobacter, Pseudomonas, and Bacillus increased in abundance in pesticide-exposed areas. Simpson and Shannon diversity indices and the multivariate analysis technique Canonical Correspondence Analysis (CCA) demonstrated a decrease in both aerobic and anaerobic bacterial diversity and community composition in areas exposed to pesticides. These results suggest a need for alternative ways of improving agricultural productivity and to educate and encourage farmers to adopt innovative integrated pest management strategies to reduce deleterious impacts of pesticides on soil ecosystems.
\end{abstract}




\section{Introduction}

Microbes play an important role in soil ecosystems and their activities are critical in nutrient composition and recycling (DeLorenzo et al. 2001; Khan et al. 2007; Khan et al. 2010). The increasing global human population (expected to be approximately 9.7 billion by 2050) would dramatically increase the demand for food resources (UNDESA 2015; UNFAO 2009). The increase in demand for food throughout the world has prompted farmers to devise ways to increase productivity, including the use of pesticides. Increased use of pesticides on agricultural lands causes contamination of the soil ecosystem with toxic chemicals (MunozLeoze et al. 2013). Modern agriculture largely relies on extensive application of agrochemicals, including inorganic fertilizers and pesticides. Indiscriminate long-term pesticides use or overapplication of pesticides could have severe effects on soil ecosystems, which may lead to alteration and/or erosion of beneficial soil microflora (Prado and Airoldi, 2001). Annually, an estimated two million tons of pesticides are applied on agricultural lands worldwide (De et al. 2014). In 2012, herbicides accounted for $49 \%$ of chemicals used in agriculture and this was followed by fumigants (19\%), insecticides (18\%), and fungicides (14\%) (Atwood and PaiselyJones, 2007).

Pesticides may also affect non-target organisms and exert deleterious effects on the environment and farmland biodiversity (Geiger et al. 2010). Among the non-target populations, soil microorganisms are extremely important, since they play an essential role in nutrient turnover (Jacoby et al. 2017) and maintain the generative capacity of agroecosystems (Bohlen et al. 2002). The impact of pesticides on soil microbial populations could also be used as potential indicators of their toxicity and alteration of the environment (Kent and Triplett, 2002). The metabolites or the degraded products of pesticides can persist in the soil long-term. For example, trifloxystrobin typically has a half-life of 7 days in the soil, whereas its metabolite (E,E)-trifloxystrobin acid) has a half-life of up to 268 days (Kent and Triplett, 2002). Previous studies on terbuconazole and carbendazim indicated that these pesticides can affect soil microbial activity. Specifically, increasing concentrations of moderate to high doses of tebuconazole significantly inhibited soil respiration and enzymatic activities (Kent and Triplett, 2002). Further, moderate doses of carbendazim stimulated urease and invertase activities and significantly inhibited other soil microbial activities after 7 days (Kent and Triplett, 2002). Rice is a major source of food for more than half of the world's population 


\section{Chapter 5}

(Vito and Sreenivasulu, 2016). However, rice cultivation is usually vulnerable to a variety of pests and requires pesticides to help control them and improve yield. Although pesticides help increase economic gains from agriculture, they also impact microbial ecosystems in the soil. Due to the large amount of pesticides applied during rice cultivation, the rice field ecosystem is one of the major contributing agroecosystems from which pesticide residues contaminate the environment (Abdullah et al. 1997). Although pesticides are commonly used to improve agricultural yields, little is known about their effects on the soil microbiota in irrigated rice fields. The goal of this study was to investigate the effect of pesticides commonly used on irrigated rice fields on bacterial abundance and diversity. An irrigated rice field in Ghana was used as a case study since the majority of the rice farms in Ghana are irrigated and pesticides are often applied on these irrigated fields.

\section{Materials and Methods}

\section{Study Area}

The samples used in the study were collected from the Kpong irrigation project site at Akuse, Ghana, where rice is cultivated all year round under a well-managed irrigation scheme. Sample collection was limited to a 4-hectare irrigated rice field with known history of pesticides use during the growing season (Table 5.1). The climate is the savannah type, characterized by a bimodal rainfall pattern ranging from 900 to $1100 \mathrm{~mm}$ annually with a predominant wind speed of 1 and 2 knots (57.26\%) and the mean annual temperature is 28.6 ${ }^{\circ} \mathrm{C}$ (MoFA, 2019). The soil in this area is heavy dark clay with high water holding capacity of up to $220 \mathrm{~mm}$ per meter depth of soil and an average dry bulk density of about $1.0 \mathrm{~g} / \mathrm{cm}^{3}$ (Sally, 2001). Water is sourced from the Kpong dam upstream through canals and via laterals to cover the fields. Jasmine 85 is the variety of rice cultivated and takes $110-120$ days to mature, usually starting from June/July-October/November. The samples analysed in this study were collected in November 2016. 
Table 5.1: The list of pesticides, application rate per hectare, active ingredients formulations used on the irrigation field under study.

\begin{tabular}{|c|c|c|c|c|c|}
\hline Pesticide Name & $\begin{array}{l}\text { Active ingredient } \\
\text { conc. }\end{array}$ & $\begin{array}{l}\text { Application } \\
\text { rate/ha }\end{array}$ & Target pest & $\begin{array}{l}\text { Application } \\
\text { method }\end{array}$ & Frequency \\
\hline Condax & $\begin{array}{l}\text { Bensulfuron methyl } \\
(30 \%)\end{array}$ & $0.42 \mathrm{Kg}$ & $\begin{array}{l}\text { Selective } \\
\text { Herbicide }\end{array}$ & Spraying & 3 \\
\hline Kilsect $2.5 \mathrm{EC}$ & $\begin{array}{l}\text { Lambda Cyhalothrin } \\
(25 \mathrm{~g} / \mathrm{L})\end{array}$ & $1.0 \mathrm{~L}$ & $\begin{array}{l}\text { Grasshoppers, } \\
\text { Worms, Thrips }\end{array}$ & Spraying & 5 \\
\hline Bounty/Nakitse & $\begin{array}{l}\text { Bispyribac sodium } \\
\text { (400g/L) }\end{array}$ & $62.5-75 \mathrm{ml}$ & $\begin{array}{l}\text { Selective } \\
\text { Herbicide }\end{array}$ & Spraying & 3 \\
\hline \multirow[t]{2}{*}{ Nativo } & $\begin{array}{l}\text { Terbuconazole } \\
(200 \mathrm{~g} / \mathrm{L})+\end{array}$ & \multirow[t]{2}{*}{$1.0 \mathrm{~L}$} & \multirow[t]{2}{*}{ Blast } & \multirow[t]{2}{*}{ Spraying } & \multirow[t]{2}{*}{5} \\
\hline & $\begin{array}{l}\text { Trifloxystrobine } \\
(100 \mathrm{~g} / \mathrm{L})\end{array}$ & & & & \\
\hline \multirow[t]{2}{*}{ Orizo plus } & Propanil $(360 \mathrm{~g} / \mathrm{L})+$ & \multirow[t]{2}{*}{$2.0 \mathrm{~L}$} & \multirow{2}{*}{$\begin{array}{l}\text { Selective } \\
\text { Herbicide }\end{array}$} & \multirow[t]{2}{*}{ Spraying } & \multirow[t]{2}{*}{3} \\
\hline & $2,4 \mathrm{D}$ amine $(200 \mathrm{~g} / \mathrm{L})$ & & & & \\
\hline Dursban/Sunpyrifos & Chlorpyrifos(480g/L) & $1.0 \mathrm{~L}$ & $\begin{array}{l}\text { Grasshoppers, } \\
\text { Worms, Thrips }\end{array}$ & Spraying & 5 \\
\hline Alligator & $\begin{array}{l}\text { Pendimethalin } \\
(400 \mathrm{~g} / \mathrm{L})\end{array}$ & $3.0 \mathrm{~L}$ & $\begin{array}{l}\text { Selective } \\
\text { Herbicide }\end{array}$ & Spraying & 3 \\
\hline
\end{tabular}

\section{Sampling procedure for soil}

Wet soil samples (5-10 g) were collected from different locations along the irrigation canal from the water source upstream, the rice field itself (where the chemicals are applied), and areas downstream of the irrigation canal. The soil samples were collected using soil auger (5.1 cm in diameter and $122 \mathrm{~cm}$ in length) at depths between $15-30 \mathrm{~cm}$ and grouped as (i) water source upstream (unexposed); (ii) rice field where the chemicals were applied (exposed); (iii) areas downstream of the irrigation line (residual). Eleven (11) samples were collected at equal intervals of 25 meters at each depth: unexposed (samples 1-4; from water source upstream), exposed (samples 5-9; rice field where pesticides are applied), and residual zone (samples 10 and 11; areas downstream of the irrigation line). The soil samples were refrigerated and shipped on ice-packs for analysis at University of Texas Health Science Center, School of Public Health, Department of Epidemiology, Human Genetics, and Environmental Sciences, Center for Infectious Diseases, Houston, Texas, USA.

\section{Bacteria culture}

Anaerobic condition was maintained in a Bactron 600 anaerobic chamber (Sheldon Manufacturing, Cornelius, $\mathrm{OR}$ ) using $5 \% \mathrm{CO}_{2}, 10 \% \mathrm{H}_{2}$, and $85 \% \mathrm{~N}_{2}$. The soil samples (1 g each) were suspended in $20 \mathrm{~mL}$ of brain heart infusion (BHI) medium (Becton Dickinson, Franklin 
Lakes, NJ). To isolate both aerobic and anaerobic bacteria in the soil, the suspensions were divided into two in $50 \mathrm{~mL}$ culture tubes and one tube $(10 \mathrm{~mL})$ was incubated aerobically or anaerobically, respectively, at $37^{\circ} \mathrm{C}$ for 24 hours. Following the 24 hour incubation period, the culture was thoroughly mixed and freezer stock $(1 \mathrm{~mL})$ of each culture were made, allowed to stand for 30 seconds for the soil particles to settle, and decanted. Freezer stocks $(1 \mathrm{~mL})$ of each culture were made in $10 \%$ DMSO and stored at $-80^{\circ} \mathrm{C}$. The remaining culture was centrifuged for 10 minutes at $15,000 \mathrm{xg}$ and the pellets were stored at $-20^{\circ} \mathrm{C}$ for DNA isolation and PCR analysis.

\section{DNA extraction and 16S ribosomal RNA (rRNA) gene sequencing}

DNA was isolated from each of the bacterial pellets using the GenElute Bacterial Genomic DNA Kit (Sigma-Aldrich, St. Louis, MO, USA), according to the protocol provided by the manufacturer. The concentration and purity of the extracted DNA was determined using NanoDrop (ThermoScientific, Wilmington, DE, USA) and the DNA quality was assessed by agarose gel electrophoresis. The extracted DNA samples were normalized and equal amounts were analysed by $16 \mathrm{~S}$ ribosomal RNA (rRNA) gene sequencing. The V4 region of the bacterial 16S rRNA gene was PCR-amplified using bacteria/archaeal primers 515F (5'GTGCCAGCMGCCGCGGTAA3') and 806R (5'GGACTACHVGGGTWTCTAAT3') (Caporaso et al. 2012). The conditions for amplification were: 1 cycle of $94{ }^{\circ} \mathrm{C}$ for $3 \mathrm{~min}, 35$ cycles of $94{ }^{\circ} \mathrm{C}$ for $45 \mathrm{~s}, 50^{\circ} \mathrm{C}$ for $60 \mathrm{~s}$, and $72{ }^{\circ} \mathrm{C}$ for $90 \mathrm{~s}$, and $72{ }^{\circ} \mathrm{C}$ for $10 \mathrm{~min}$ (Caporaso et al. 2012). Sequencing was performed at the Alkek Center for Metagenomics and Microbiome Research (Baylor College of Medicine, Houston, Texas) on the Illumina MiSeq platform (Illumina, San Diego, CA, USA) using $2 \times 250 \mathrm{bp}$ paired-end protocol, which yielded pair-end reads that almost completely overlapped, targeting at least 15,000 reads per sample. DNA extracted under similar conditions, but without any bacterial pellet was used as control. The read pairs were demultiplexed based on unique molecular barcodes, and merged using USEARCH v7.0.1001 (Edgar, 2010). The data was analysed using the CMMR-16S (v4) analytic pipeline, as described previously (Caporaso et al. 2010; Caporaso et al. 2012; Hasegawa et al. 2016). The CMMR pipeline for $16 \mathrm{~S}$ analysis leverages the QIIME (Quantitative Insights Into Microbial Ecology) software package (Caporaso et al. 2010; Caporaso et al. 2012; Hasegawa et al. 2016) and custom analytic packages. The $16 \mathrm{~S}$ rRNA gene sequences were clustered into taxonomic operation units (OTUs) at a similarity cut-off value of $97 \%$ using the UPARSE algorithm in QIIME 
and the SILVA database (Quast et al. 2013). The OTUs were determined by mapping to the SILVA database containing only the 16S V4 region to determine taxonomies (Quast et al. 2013). An OTU table was constructed for taxonomic summaries and the alpha- and betadiversity calculated (Lozupone and Knight, 2005). The data from this study will be deposited in the U.S. National Center for Biotechnology Information and will be available through accession number PRJNA608009.

\section{Data Analysis}

Data were analyzed using STATA 15 for Windows (StataCorp LLC, College Station, TX) and R software (Quast et al. 2013). To visualize the frequency of genera across soil samples, heat maps derived from the relative abundance of the OTUs were generated using the Heatplus, gplots, and RcolorBrewer packages for $R$ (Quast et al. 2013). To assess the association between region of pesticide exposure and frequency of selected genera, the Kruskal-Wallis test was used. Statistical significance was defined as p-value $<0.05$.

The bacterial data was also analysed using multivariate ordination techniques to assess the effects of depth, culture under either aerobic or anaerobic conditions, and exposure on the composition of the bacterial community. Genus level data were $\log (x+1)$ transformed to down-weight the high abundances and approximate a normal distribution of the data. Since the data were compositional (relative), canonical correspondence analysis (CCA) was used (Meng et al. 2013; Braak and Smilauer, 2002). First, a CCA using sites as explanatory variables and depth and being aerobic or anaerobic were included as covariable in order to get an overview on the (dis)similarity in genera composition between the sites. This analysis was followed by a Monte Carlo permutation test, permuting the samples within the blocks defined by covariables. Three more Monte Carlo permutation tests were performed to test the significance of depth, being cultured under aerobic or anaerobic conditions and exposure. In each test, one factor was included as explanatory variable and the two others as covariable, which defined the blocks within which the samples were permuted. A second CCA analysis was performed using the interaction between exposure and culture under aerobic or anaerobic conditions as explanatory variables and depth as covariable, in order to show the (interactive) effects of the variables. All analysis were performed using the CANOCO Software package, version 5 (Ter Braak and Smilauer, 2002). 


\section{Chapter 5}

\section{Results}

The active ingredients, formulations, mode and frequency of application, and seasonal application rates of the pesticides used on the irrigation field are shown in Table 5.1. These pesticides are applied 3 to 5 times during the season and include herbicides ( 4 formulations), insecticides (2), and fungicides (1).

\section{Effect of pesticides on soil bacterial abundance and diversity}

The five most prevalent bacterial genera identified from the soil samples that were incubated under aerobic conditions were Bacillus, Domibacillus, Enterobacter, Acinetobacter, and Aeromonas (Fig. 5.1). Domibacillus, Enterobacter, and Aeromonas were the most predominant genera detected from the areas that were not exposed to pesticides. On the other hand, Bacillus, Domibacillus, and Enterobacter were the most frequent genera identified from the samples collected from the pesticide-exposed areas whereas Bacillus was the most frequent in the residual exposure areas. All of the five most prevalent aerobic bacterial genera identified contain species that are reported to play beneficial roles in the soil (Table 5.2). The five most prevalent genera detected in the samples cultured under anaerobic conditions were Enterobacter, Clostridiales (CsrSardi), Bacillus, Paraclostridium, and Clostridiales (Unc58672). Enterobacter, Clostridiales (CsrSardi), and Paraclostridium were the most frequent genera in the unexposed area. Clostridiales (CsrSardi), Clostridiales (Unc58672), and Enterobacter were the most frequent genera in the area exposed to pesticides whilst Paraclostridium and Bacillus were the most predominant genera in the residual exposure area (Fig. 5.1). 


\begin{tabular}{|c|c|c|c|c|c|c|c|c|c|c|c|c|}
\hline 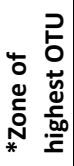 & 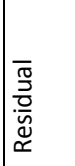 & 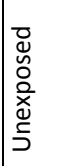 & \begin{tabular}{|l}
$\overline{\frac{\pi}{3}}$ \\
$\frac{\bar{y}}{\bar{y}}$ \\
$\stackrel{y}{x}$
\end{tabular} & 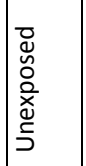 & 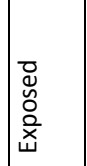 & 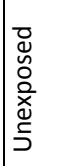 & 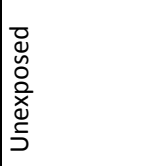 & 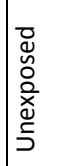 & 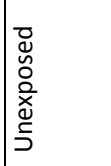 & 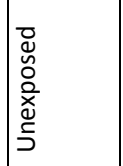 & 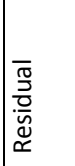 & 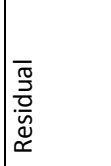 \\
\hline 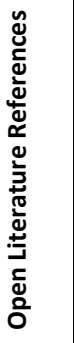 & 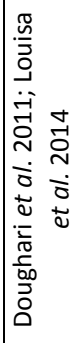 & 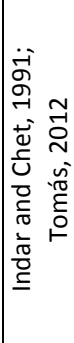 & 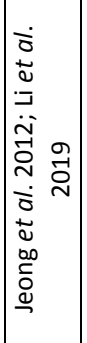 & 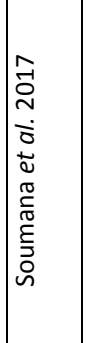 & 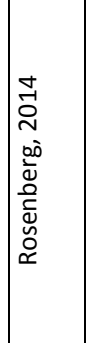 & 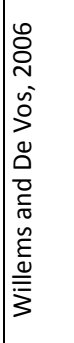 & 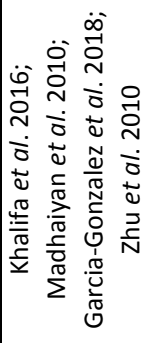 & 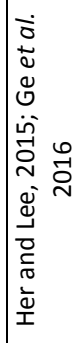 & 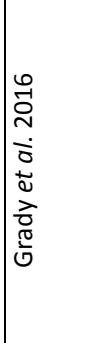 & 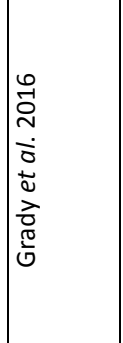 & 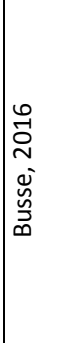 & 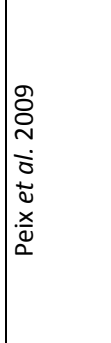 \\
\hline 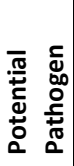 & 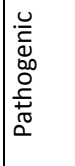 & 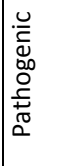 & 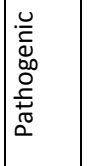 & 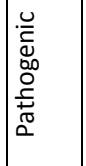 & 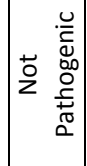 & 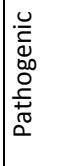 & 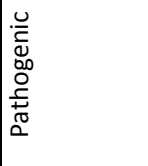 & 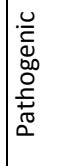 & 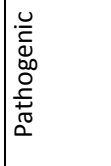 & 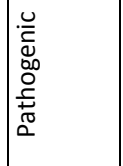 & 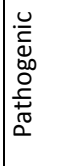 & 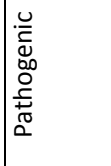 \\
\hline 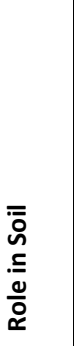 & 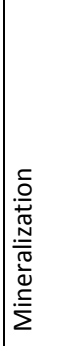 & 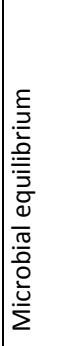 & 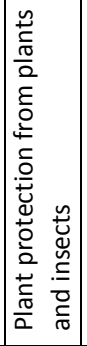 & 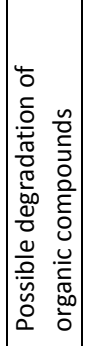 & 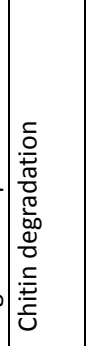 & 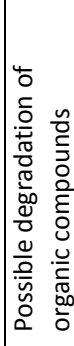 & 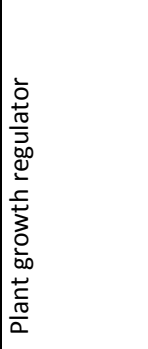 & 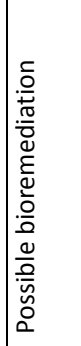 & 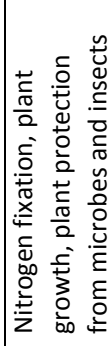 & 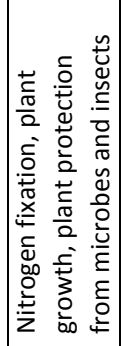 & 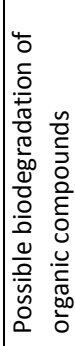 & 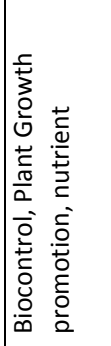 \\
\hline $\begin{array}{l}\frac{1}{5} \\
\frac{5}{0} \\
\frac{10}{10} \\
\frac{10}{1}\end{array}$ & 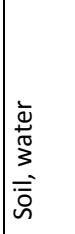 & 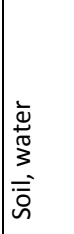 & $\begin{array}{l}\frac{n}{0} \\
\frac{0}{3} \\
\frac{0}{0} \\
\frac{0}{\partial}\end{array}$ & 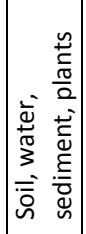 & $\overline{\overline{0}}$ & 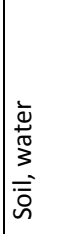 & $\begin{array}{l}\frac{n}{0} \\
\frac{0}{3} \\
\frac{.0}{2} \\
\frac{.0}{2} \\
\frac{1}{2}\end{array}$ & 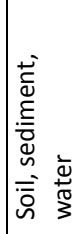 & 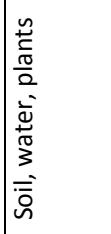 & 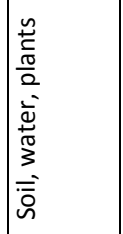 & $\overline{\overline{\bar{D}}}$ & 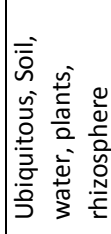 \\
\hline 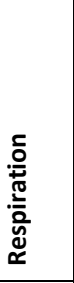 & 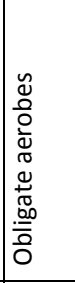 & 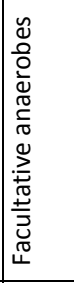 & 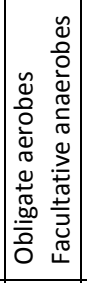 & 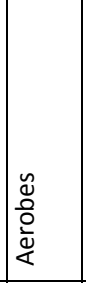 & 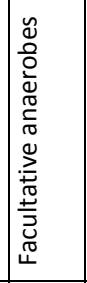 & 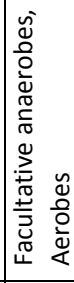 & 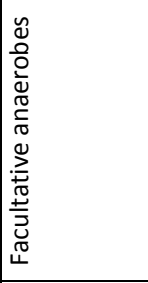 & 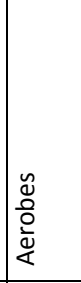 & 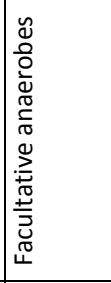 & 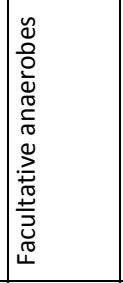 & 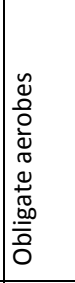 & 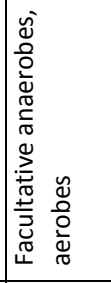 \\
\hline 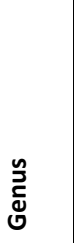 & 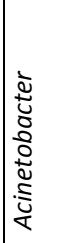 & 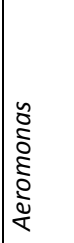 & 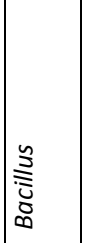 & $\begin{array}{l}\frac{0}{2} \\
\frac{0}{0} \\
\frac{0}{0} \\
\infty \\
\infty\end{array}$ & 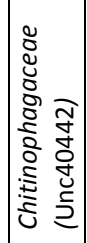 & 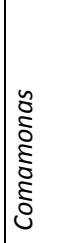 & 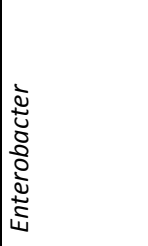 & 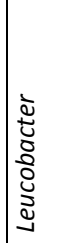 & 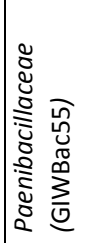 & 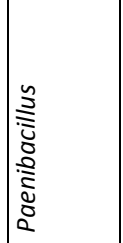 & 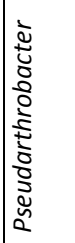 & 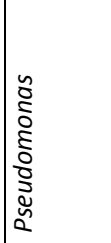 \\
\hline
\end{tabular}




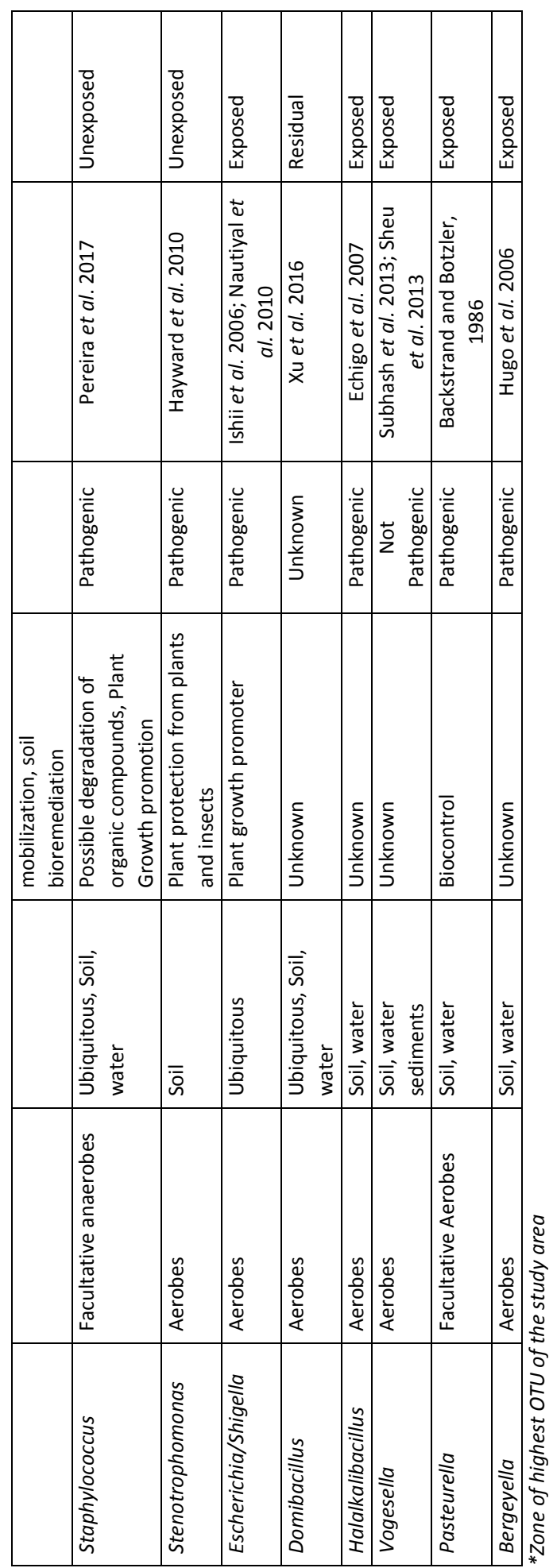



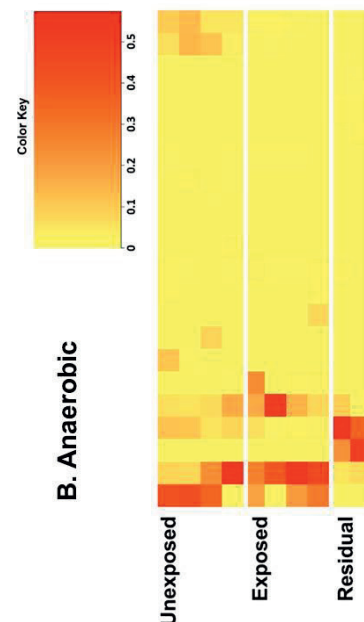

uo!̣6əy əגnsodx $\exists$

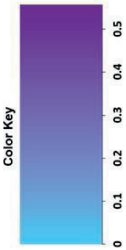

$\frac{0}{0}$
$\frac{2}{4}$
$<$

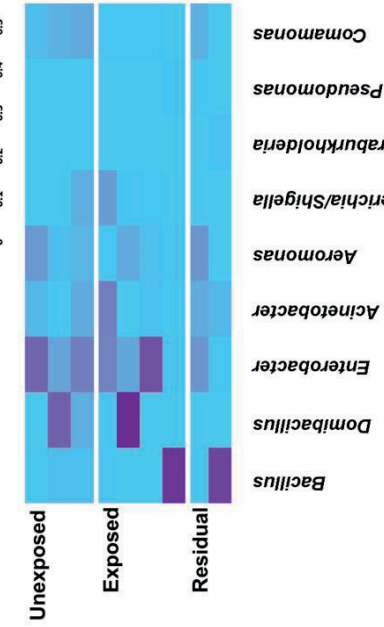

uo!̣6ay a.nsodx $\exists$

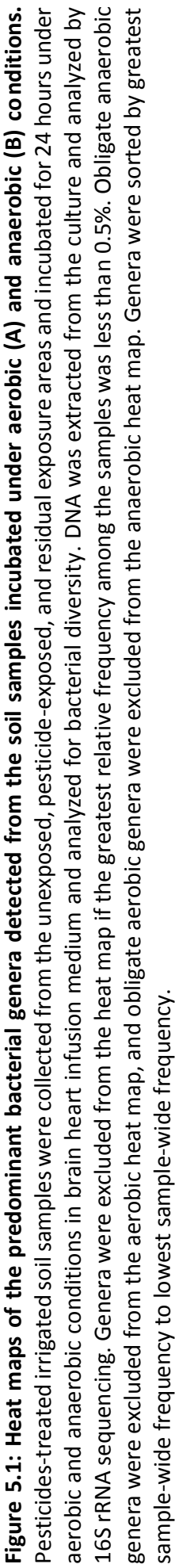


Both Simpson and Shannon diversity indices indicated a decrease in bacterial diversity in the pesticide-exposed area (Fig. 5.2). Simpson diversity index showed significant decrease in bacterial diversity in the exposed [ $p=0.011$ (aerobic), $p=0.002$ (anaerobic)] and the residual exposed areas [ $p=0.022$ (aerobic), $p=0.015$ (anaerobic)]. The Shannon diversity index also showed a similar degree of significant decrease in the areas exposed to pesticides compared to the unexposed areas.

A. Aerobic

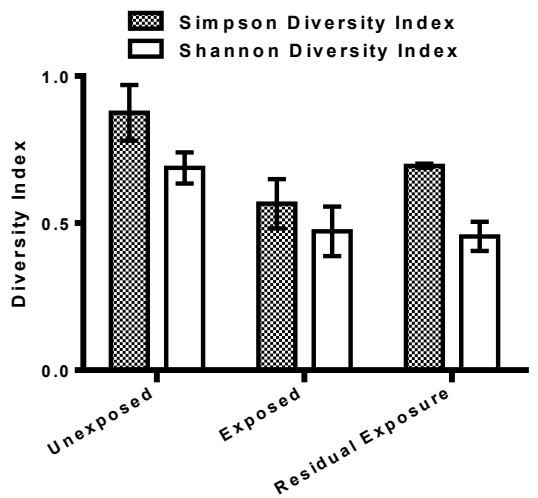

B. Anaerobic

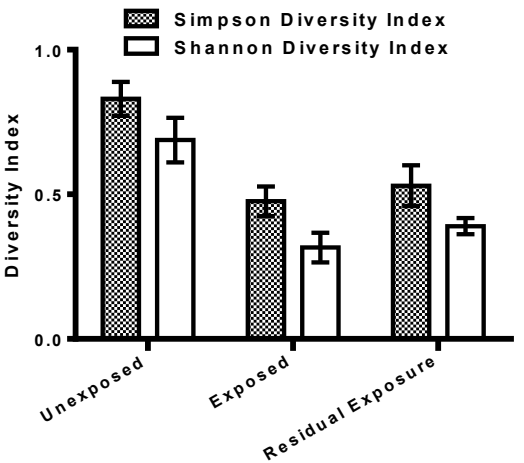

Figure 5.2: The Simpson and Shannon bacterial diversity indices of pesticide-treated irrigated soil samples. Pesticides-treated irrigated soil samples were collected from the unexposed, pesticideexposed, and residual exposure areas and incubated for $24 \mathrm{~h}$ under aerobic (A) and anaerobic (B) conditions. DNA was extracted and analyzed by $16 \mathrm{~S}$ rRNA sequencing. In the anaerobic samples, twosample t-test showed that the mean Simpson and Shannon diversity indices were significantly different between the pesticide-exposed and unexposed areas ( $p=0.00003$ and $p=0.00005$, respectively). In the aerobic samples, the mean Simpson and Shannon diversity indices were also significantly different between the pesticide-exposed and unexposed areas ( $p=0.001$ and $p=0.003$, respectively). The error bars represent the mean \pm S.D. of the indices of the replicate samples from each exposure group.

To investigate the effect of the pesticides on bacterial abundance, the twenty most frequent aerobic and anaerobic bacterial genera were examined based on their average operational taxonomic units (OTU). Enterobacter, Aeromonas, Comamonas, Stenotrophomonas, Bordetella, and Staphylococcus decreased in the area exposed to pesticides. The abundance of Aeromonas species decreased in the area exposed to pesticides but showed a slight increase in the residual exposure area (Fig. 5.3). Escherichia/Shigella had 
the greatest frequency in areas exposed directly to pesticides. The frequency of Bacillus was higher in the residual area than in areas that were either exposed or unexposed to pesticides. Other anaerobic genera that significantly decreased in abundance in the area exposed to pesticides but to a lesser extent than Enterobacter, Aeromonas, Comamonas, Stenotrophomonas, Bordetella, and Staphylococcus included Clostridiales (CsrThio4), Paeniclostridium, Clostridiales (CsrSardi), Paraclostridium, Clostridiales (Unc58672), Terrisporobacter, Clostridiales (CsrSp125), Clostridiales (CsrFrigi), Clostridiales (CsrSeneg), and Clostridiales (CsrSac30). For the aerobic bacteria, the genera whose abundance decreased in the pesticides-exposed area were Enterobacter and Comamonas. Both genera are ubiquitous and contain bacterial species that play beneficial roles in the soil. On the other hand, Domibacillus, Pseudomonas, and Bacillus were in higher abundance in the pesticide-exposed area but to a lesser extent than Aeromonas in the unexposed area.

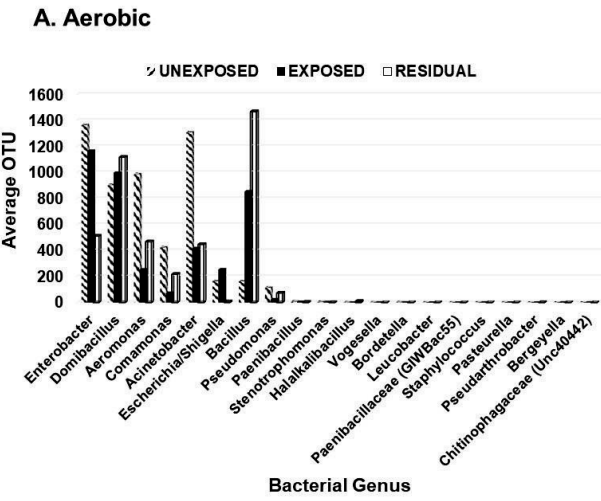

Figure 5.3: Distribution of the 20 most prevalent genera based on the region of pesticide exposure.

\section{Multivariate analyses}

The CCA showed a clear gradient (sites, $p=0.002$ ) from site 1 till 11 and different genera composition of the bacterial community was observed (Fig. 5.4). Sites 4, 6 and 7 had relatively low numbers, which also happens to be the exposed region. Of all variance, $38 \%$ was explained by the differences between sites, while the covariables explained $15 \%$ of the variation in genus composition. A reverse CCA using depth and being cultured under ae/anaerobic conditions as explanatory variables and site as covariable resulted in a biplot 


\section{Chapter 5}

showing a clear separation between depths and being cultured under ae/anaerobic conditions $(p=0.002$ ). Of all variance $32 \%$ was explained by the differences between sites, while the covariables explained $2 \%$ of the variation in genus composition (Fig. 5.5A). The results of the Monte Carlo permutation tests (Fig. 5.5B) demonstrated that exposure and either aerobic or anaerobic culture has significant effect on the bacterial community composition. These results also indicate that the bacterial community does not recover in the residual section, with a different composition than that of the areas directly exposed to pesticides.

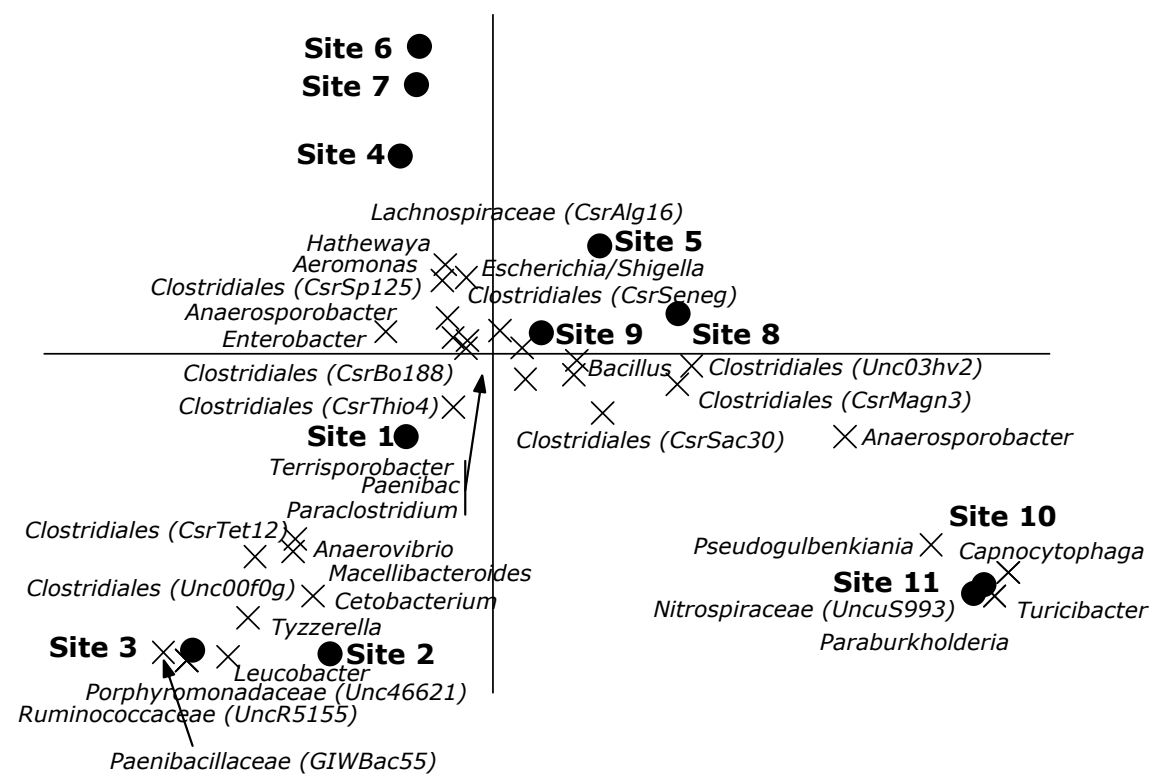

Figure 5.4: Canonical correspondence analysis biplot showing the results of the analysis using sites as explanatory variables and depth and being aerobic or anaerobic as covariables. Of all variance, $38 \%$ was explained by the differences between sites while the covariables explained $15 \%$ of the variation in genus composition. Of the variation explained by sites, $33 \%$ is displayed on the horizontal axis and an additional $18 \%$ on the vertical one. Only the 33 genera of which more than $15 \%$ of its variation is displayed by the axes are shown. 
A

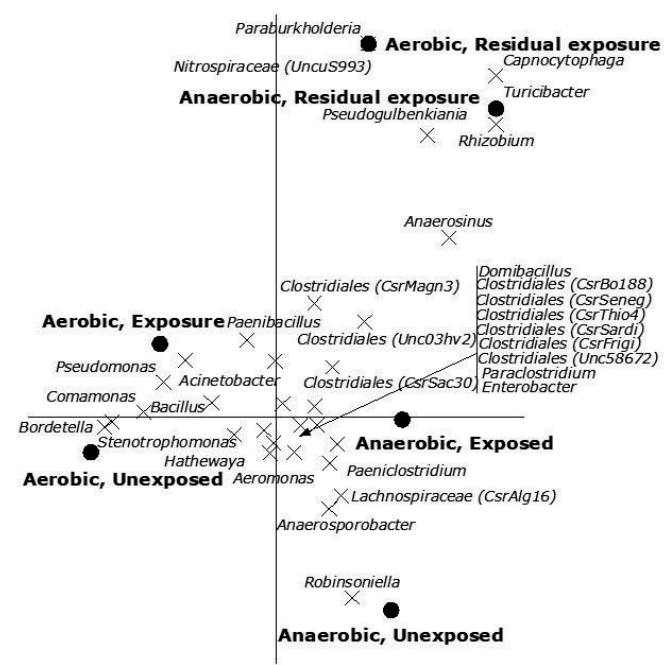

B

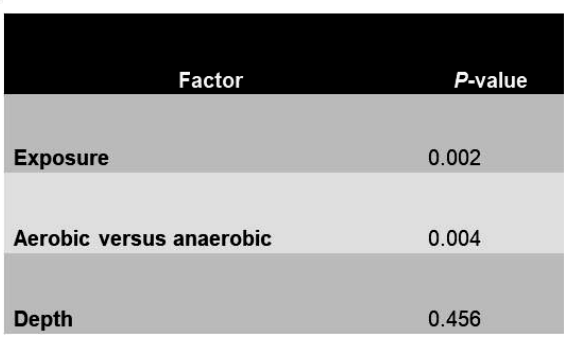

Figure 5.5: A. Canonical correspondence analysis biplot showing the results of the analysis using the interaction between exposure and being aerobic or anaerobic as explanatory variables and depth as covariable. Of all variance, $32 \%$ was explained by the differences between sites while the covariables explained $2 \%$ of the variation in genus composition. Of the variation explained by the explanatory variables, $41 \%$ is displayed on the horizontal axis and an additional $32 \%$ on the vertical one. Only the 32 genera of which more than $15 \%$ of its variation is displayed by the axes are shown. B. Significance of the effects of the different factors on the genus composition of the bacterial community as assessed by Monte Carlo permutation tests.

\section{Discussion}

In this study, we investigated the effect of pesticides commonly used in irrigated rice fields on bacterial abundance and diversity. The results showed that the use of pesticides decrease bacterial abundance and diversity of the soil. Soil samples collected from three locations (unexposed, exposed, residually-exposed areas) within an irrigated rice field with a history of pesticide use were examined for the presence of aerobic and anaerobic bacteria. The data demonstrated that aerobic bacteria exhibited a return to diversity in the residual pesticide exposure areas, but the anaerobic bacteria exhibited a continued decrease in diversity.

Among the top 20 most frequently identified aerobic genera (Fig. 5.3A), fourteen contain species that are known to be beneficial to the soil (Table 5.2), seventeen genera contain species that are potential pathogens, whereas fifteen contain species that are both 
beneficial to the soil and pathogenic (Table 5.2). Three of the genera (Domibacillus, Halalkalibacillus, Vogesella) contain novel soil bacteria with no established roles in the soil (Echigo et al. 2007; Subhash et al. 2013; Sheu et al. 2013; Xu et al. 2016). Domibacillus was one of the most frequent aerobic genera detected, but little is known about the species of this genera (Xu et al. 2016). Among the 20 most frequently detected anaerobic genera (Fig. 5.3B), Enterobacter, Aeromonas, and Bacillus contain species that are both pathogenic and beneficial to the soil (Inbar and Chet, 1991; Zhu et al. 2010; Madhaiyan et al. 2010; Jeong et al. 2012; Khalifa et al. 2016; Garcia-Gonzalez et al. 2018) whereas Paeniclostridium (Sasi Jyothsna et al. 2016), Hathewaya/Clostridium (Lawson and Rainy, 2016), Escherichia/Shigella (Ishii et al. 2006; Nautiyal et al. 2010), and Enterococcus contain notable pathogens with no established roles in the soil (Lebreton et al. 2014). Of the pathogenic genera, Escherichia/Shigella was the only genera that decreased in abundance in the exposed area. Aeromonas, Bacillus, and Pseudomonas are diverse genera that contain many beneficial soil bacteria in addition to potential human pathogens (Inbar and Chet, 1991; Peix et al. 2009).

The decrease in the abundance of Enterobacter, Aeromonas, Comamonas, Stenotrophomonas, Bordetella, and Staphylococcus in areas exposed to pesticides may impair degradation of organic compounds, plant growth, microbial homeostasis, and plant protection from microbes and insects (Inbar and Chet, 1991; Willems and De Vos, 2006; Madhaiyan et al. 2010; Hayward et al. 2010; Khalifa et al. 2016; Soumana et al. 2017; Pereira et al. 2017). Conversely, Domibacillus, Acinetobacter, Pseudomonas, and Bacillus abundance in pesticideexposed areas has the potential to promote bioremediation and biocontrol of the pesticidecontaminated field, improve mineralization, promote plant growth, and nutrient mobilization (Peix et al. 2009; Doughari et al. 2011; Jeong et al. 2012; Xu et al. 2016; Fira et al. 2018; Li et al. 2019).

Application of herbicides has been shown to induce stress conditions in nonphotosynthetic microorganisms. For instance, metabolism of the Gram-negative bacteria Stenotrophomonas maltophilia usually present in rice field irrigation channels (Reche et al. 2005) (also identified in this study), has been demonstrated to be negatively affected by herbicides (Lu et al. 2009). Also, a mixture of quinclorac and bensulfuron-methyl (BSM) (also applied in this study; Table 5.1) induced the activity of antioxidant enzymes superoxide dismutase and catalase of S. maltophilia strain WZ2, demonstrating the induced oxidative 
stress caused by the herbicides. The effect of BSM on soil microbial communities in a model paddy microcosm study showed that the nitrification potential was significantly suppressed (Saeki and Toyota, 2004). In a related study, bispyribac sodium application in an irrigated rice field had no effects on soil microbes (Alam 1977). Thus, we expect similar effects of the applied herbicides on the microbial ecosystem of our study site, which will be addressed in our ongoing study.

In the natural environment, microorganisms have access to an abundant and diverse array of carbon sources that may be more easily assimilated than complex organic compounds. Biodegradation of 2,4-D is important in determining its overall fate in the environment, which is used on the rice field studied (Table 5.1). Degradation of 2,4-D in the soil is a fundamental attenuation process, which is influenced by both abiotic and biological processes. Different soil constituents and interactions of microbial communities and 2,4-D in soil play a critical role in the degradation process. 2,4-D usually degrades after a few days of its application through both abiotic and biotic interactions (Boivin et al. 2005). Soil microorganisms also play vital roles in the degradation of pesticides and mineralization of their metabolites. Among these microorganisms are dominant species of endophyte Pseudomonas (40\%) and Enterobacter (18\%) (Gardner et al. 1982). Pseudomonas is a diversified genus possessing a series of catabolic pathways and enzymes involved in pesticide degradation. Pseudomonas putida MAS-1 is reported to be efficient in chlorpyrifos degradation by a rate 90\% higher than other species of Pseudomonas (Gilani et al. 2015). The chlorpyrifos degradation involve the metabolism and mineralization of 3, 5, 6-trichloro-2-pyridinol and 3,5,6-trichloro-2-methoxypyridine. Pseudomonas is the group of bacteria present in large amount in the soil and have a vital role in the mineralization of organic matter. They are metabolically adaptable and have capability to degrade most of the aromatic hydrocarbons, oil, petroleum products, and pesticides (Sarkar et al. 2009). Pseudomonas has the capability to mineralize phenolic compounds (Hughes and Cooper, 1996). A variety of low-molecular-weight compounds, including chlorinated aliphatic hydrocarbons can also be metabolized by Pseudomonas because of diversified range of catabolic pathways (Lynch and Hobbie, 1988). Our study also supports the ability of Pseudomonas to degrade pesticides, as there was no significant 


\section{Chapter 5}

difference in the abundance of Pseudomonas genus between the exposed and unexposed areas.

In order to reduce the effect of pesticides on bacterial diversity, it is important to monitor the response of soil bacterial communities and various enzymatic activities. Various bacterial genera were negatively impacted in the area exposed to pesticides and most of these genera are known to be involved in nutrient mobilization, plant growth promotion, mineralization, and metabolism of organic compounds. It remains to be seen whether the depletion of soil microbes would also affect the fertility of the soil and overall productivity of this rice field. The increase in abundance of the genera Domibacillus, Bacillus, and Clostridia suggest they were generally not constrained by the pesticides. It is possible that these bacteria can metabolize the pesticides or require a much higher concentration of the pesticides in order to be affected. Our research is on-going to identify the species among these genera present in the sample and to explore their potential as candidates for bioremediation. Our study shows that there is a need to educate and encourage farmers to adopt innovative integrated pest management strategies that promote the function of beneficial microbes with little to no deleterious impact on the soil bacterial ecosystem.

\section{Acknowledgement}

This work was supported by Ghana Education Trust Fund (GETFund), Environmental Protection Agency, Ghana, Scheme Managers of Kpong Irrigation Project, NIH R01 Grant number R01Al116914, the Molecular Basis of Infectious Diseases Training Grant from the NIH Institute of Allergy and Infectious Diseases (T32AI055449), and the Gillson-Longenbaugh Foundation. 
Pesticides decrease bacterial diversity and abundance of irrigated rice fields 


\section{Chapter 6}

General discussion and concluding remarks 
Increase in human population has resulted in the growth of agricultural activity with the use of chemicals in terms of artificial fertilizer and plant protection products required to satisfy and maintain the local and global demand for higher food production (Firbank et al. 2012). Hence, modern agriculture practices rely on the usage of synthetic pesticides (e.g. insecticides, herbicides, fungicides) in order to reduce crop losses due to pests and diseases to achieve higher crops yields. Pesticides applied to crops may enter water bodies adjacent to agricultural fields via different entry routes such as spray drift, agricultural run-off, leaching and/or drainage (Dabrowski et al. 2002; Brown et al. 2004). These contaminations may have undesirable impacts on the ecology of fresh water ecosystems (Liess et al. 2005; Holvoet et al. 2007; Van den Brink, 2008). In order to prevent unacceptable adverse effects, legal provisions are in place for the registration/procedures for pesticides in most jurisdictions globally. In Ghana, Part Il of the Ghana Environmental Protection Agency (EPA) Act, Act 490 of 1994 governs the whole pesticide life cycle, so the registration and procurement of pesticides, their import, distribution and retail to farmers, monitoring, quality control and waste management.

The present thesis aimed at analyzing to what extent the Ghana pesticide law and pesticide registration procedure has contributed to effectively protecting the environment and to establish the extent of risks associated with pesticides using tools such as PRIMET (Pesticides Risks in the Tropics to Man, Environment, and Trade), SSD (Species Sensitivity Distribution), DNA $16 \mathrm{~S}$ ribosomal RNA ( $\mathrm{rRNA}$ ) gene sequencing and the gathering of empirical data from the field to determine pesticide risks to aquatic and terrestrial organisms.

The thesis presents a comprehensive review on the Ghana pesticide law and registration procedure, including views of various actors in implementing the law in a conceptual framework based on the contextual interaction theory (CIT) (Fimyar, 2014; Sabatier, 1991; Van Horn and Van Meter, 1977). In this thesis, new information was added to the general knowledge on factors needed to enhance the implementation of the pesticide law in Ghana by both state and nonstate actors, such as developing well-targeted training programmes for pesticide retailers and farmers on pesticide use, personal PPE use, as well as pesticide law and management. A recommendation from this study (chapter 2 ) sets out the study for chapter 3 . Here the focus was on preliminary risk assessment of aquatic organisms in water bodies adjacent fields treated with 
pesticides, and the exposure of the pesticides to other terrestrial organisms. Empirical pesticide use data obtained from farmers and the aquatic scenario for the $1^{\text {st }}$ tier PRIMET (Pesticides RIsks in the Tropics to Man, Environment, and Trade) model were used to assess environmental risks of pesticides currently applied in Ghana. Pesticides that showed risks were further evaluated by the Species Sensitivity Distribution (SSD) model to determine $2^{\text {nd }}$ tier ecological threshold levels of the pesticides protective to aquatic communities. The $1^{\text {st }}$ tier and $2^{\text {nd }}$ tier thresholds could also be compared, evaluating the protectiveness of potential risks of pesticides for primary producers, invertebrates and vertebrates as set by the $1^{\text {st }}$ tier. The tools used could support environmental risk assessment decision-making for pesticide registration in Ghana. A part of this thesis also contributes to the application of benthic macroinvertebrates as indicators for monitoring the quality of water bodies in Ghana (Chapter 4). The effect of pesticides was also evaluated on microorganisms in soils of irrigated rice field regarding diversity and abundance (Chapter 5) informed by an observation in chapter $\mathbf{2}$ and the environmental risk assessment (Chapters3). Linking macroinvertebrates and physico-chemical parameters for water quality assessment in a river was achieved by surveys and measurements on site and in the laboratory in order to record the various anthropogenic activities and physico-chemical parameter values at the various sampling points indicative for the level of pollution. These were then compared to macroinvertebrate abundance values to statistically make inferences. The effect of commonly used pesticides on bacterial abundance and diversity was investigated on irrigated rice fields (Chapter 5). Irrigated soil samples were collected from unexposed, pesticide-exposed, and residual exposure areas and cultured under aerobic and anaerobic conditions at $37^{\circ} \mathrm{C}$. DNA extracted from the resulting culture were analysed by 165 rRNA sequencing.

In chapter $\mathbf{2}$ it was obvious that farmers spill pesticide mix during pouring and loading of spray equipment even though they had received a lot of training sessions on pesticide use and application. Most farmers admitted using recommended rate and frequency of pesticides for pesticides as directed by the by supplier, retailer or dealer or as shown on the packaging label, but this was found out not to be the exact practice as observed in the field, where most pesticide in use were overdosed (Chapter $\mathbf{3}$ ) at magnitudes of 1.3 to 13 times the recommended dose. It was anticipated that the use rate, may lead to problems of pest resistance, environmental 
pollution, and occupational exposure among others (Metcalf, 1980; Ngowi et al. 2007; Ramo et al. 2016). Subsequently, results from $1^{\text {st }}$ tier risk assessment conducted on pesticides used in the study area had indicated that many pesticides may pose acute risk to aquatic ecosystems adjacent treated fields while lambda cyhalothrin, chlorpyrifos, cypermethrin, dimethoate, mancozeb, carbendazim, sulphur, maneb, copper hydroxide and cuprous oxide may pose the highest chronic risks. Butachlor, dimethoate and carbendazim may pose acute risks to the terrestrial soil ecosystem, while glyphosate, chlorpyrifos, imidacloprid, dimethoate, mancozeb, carbendazim, maneb, copper hydroxide and cuprous oxide may pose the highest chronic risks to the terrestrial ecosystem. Paraquat, lambda cyhalothrin, chlorpyrifos, emamectin benzoate, imidacloprid, thiamethoxam, bifenthrin, cypermethrin, dimethoate, carbofuran, mancozeb and maneb may pose acute risks to bees and propanil, lambda cyhalothrin, chlorpyrifos imidacloprid, carbofuran, sulphur, copper hydroxide and cuprous oxide to the terrestrial non-target arthropods. A $2^{\text {nd }}$ tier acute aquatic risk assessment also had showed that the risks of pendimethalin, propanil, oxyfluorfen, lambda cyhalothrin, chlorpyrifos, cypermethrin, dimethoate carbofuran, mancozeb, carbendazim, maneb and copper hydroxide was possible for the aquatic ecosystem (Chapter 3).

The concentration of organochlorine pesticides were generally below the detection limit $(0.01 \mu \mathrm{g} / \mathrm{L})$ of the instrument used in all the sampling sites in the Volta river. A situation that could be attributed to the ban of e.g. DDT (GEPA, 2008) on the use of other such compounds in Ghana over time leading to possible degradation and dilution in the water body. There are, however, isolated cases of the detection of $\lambda$-cyhalothrin at Sedorm 1 and Akuse Canal in the dry season with concentrations of $0.6 \mu \mathrm{g} / \mathrm{L}$ and $8.8 \mu \mathrm{g} / \mathrm{L}$, respectively. Cypermethrin at a concentration of $1.4 \mu \mathrm{g} / \mathrm{L}$ was detected at Marine during the dry period which probably could have been due to recent application on farms adjacent to the river body or had come in through run offs (chapter 4 ). The many non-detection of pesticides in chapter 4 could be due to the fact that sampling was confined to a few meters from the river course $(\sim 4 \mathrm{~m})$ and not directly edgeof-field. However, large risks were indicated for chapter 3 where the focus was on the edge of treated fields and the scenario adopted was realistic for the irrigation fields. Besides, the sampling areas were different for both chapters 3 and 4 . 
This findings of chapter 3 on the effect of recently used pesticides on soil microorganisms in irrigated rice fields demonstrated a decrease in both aerobic and anaerobic bacterial diversity and community composition in areas exposed to pesticides (Chapter 5). Microbes play an important role in soil ecosystems and their activities are crucial in nutrient composition and recycling. Increased use of pesticides on agricultural lands result in contamination of the soil, which could have adverse effect on its microbial communities (DeLorenzo et al. 2001; Khan et al. 2007, Khan et al. 2010). It will therefore be prudent to find alternative ways of helping to reduce pesticide exposure to the environment. Even though a lot of papers had previously reported on the environmental risks of pesticide and recommended training of farmers and pesticide applicators especially in developing countries including Ghana (Metcalf, 1980; Clarke et al. 1997; Ecobichon, 2001; Ngowi et al. 2007; Wiratno et al. 2007; Fianko et al. 2011; Ramo et al. 2016), it appears the intervention is not yielding the desired results.

This is because in developing countries most of the farmers are not well educated (Wiratno et al. 2007; Mengistie et al. 2014; Onwona-Kwakye et al. 2019) and to understand the science and rudiments of pesticide use is often not practicable. It is also not possible for the farmers to sublet the pest control component of the farm operations to professional pest control bodies due to financial constraints. Therefore, it becomes difficult for these farmers to invest heavily in their farm operations, and in most cases these farmers also act as the pesticide applicators and the decisions concerning pesticide application is informed by what they want and not necessarily what they have been trained to practice. So even when they have been trained on specific farm routines regarding pesticide use, in reality they do not practice them (Chapter 3). It is obvious that the current situation requires alternative approaches to solving these pertinent problems. Most farmers in our study mentioned and assured us during the discussion that pesticides are necessary, but they were open and willing to use appropriate alternative methods of pest control if they became available, effective and affordable (Chapter 2).

Recognizing that education and training of farmers in the application of pesticides in developing countries is not helping the local environment is a first step toward developing more robust solutions to environmental risks. Enforcing existing pesticide laws and regulations should receive greater attention through surveillance and monitoring activities. For example, there 
should be a pesticide safety certification program for pesticide applicators and retailers to ensure that only those certified are allowed to sell, handle, or apply pesticides even at farm levels. From a regulatory perspective, addressing issues of pesticide regulation by identifying the jurisdictions that are struggling with these issues, identifying the pesticides that are most often being reported as negatively affecting the environment, and identifying the span and distributions of the dosages these pesticides are applied, are other efforts that could help control risks to the environment (Jennings and Li, 2014). The development and use of highly efficient, low toxic and low residual pesticides, particularly bio-pesticides has been proposed (Sanjaya et al. 2013; Darvishzadeh et al. 2014; Jafarbeigi et al. 2014; Sharifian and Darvishzadeh, 2015; Gupta et al. 2017). The use of mixture pesticides, as a resistance management strategy as well as a pollution reduction measure, can be explored. Furthermore, it is recognized that productive soil is a finite resource (as water) and, in order to ensure continued production of food, the agriculture must go side by side with soil and ecosystems preservation, restoration, and agronomic research on better yield cultivars. Therefore, it is urgent to achieve a generalized agreement on pesticide application and adoption of good agriculture practices, with consideration of Integrated Pest Management (IPM) techniques thus minimizing the use of chemical pesticides (Mardani et al. 2017), and protect natural enemies and biodiversity, and maximize the role of natural balance. Again, promote precision use of pesticides, reduce off-target phenomena and enhance utilization rate of pesticide use. It is also worth mentioning that pesticide product stewardship from the manufacturers and multi-national pesticide companies have failed to assist in preventing environmental pollution. In Ghana, for example, where the bulk of pesticide imports comes from China (Chapter 1 ), there is no pesticide product stewardship and follow up by manufactures like what takes place in developed countries (Reynolds, 2018). In Ghana, the multi-national pesticide producing companies appear not to be doing a good job in this regard as their products are not only used by their target groups but by other pesticide user sectors as well (e.g. Kocide, a registered cocoa fungicide in Ghana is also used on vegetables; Amoako et al. 2012; OnwonaKwakye et al. 2019). The stewardship approach in this regard should be made more holistic by involving other user categories. The development and introduction of extended producer responsibility (EPR) for pesticide bound for developing countries is proposed to support capacity 
building of pesticide users regarding safer pesticide use and other related interventions to prevent environmental risks.

\section{Conclusion and Outlook}

The study concludes that pesticides are registered in compliance with the law whilst nonstate actors were mostly non-compliant with pesticide handling and management which is likely to result in environmental risks. Significant association existed between educational level attained and knowledge on pesticide use. Likewise, work experience or duration of farming also significantly influenced the knowledge of respondents, as well as farm management practices and pesticide handling. State actors were not motivated and resourced (Chapter 2 ) to carry out their mandate in ensuring the smooth implementation of the pesticide policy. Resources in terms of vehicles, and other forms of motivation are required to generate the needed interest.

The ecological risk assessment models estimated that pesticides used in the study area were likely to pose the highest risks to aquatic ecosystems adjacent to the treated fields and to the terrestrial ecosystem. Ecological models have been heavily advertised due to their extrapolative power and could be used in comparing alternative scenarios for risk management in the field (Wiratno et al. 2007; Peeters et al. 2008; Ansara-Ross et al. 2008) and in this study it has been recommended that the PRIMET and SSD models are incorporated into the pesticide registration processes in Ghana. It was established that actual pesticide use was higher than the recommended rates (Chapter $\mathbf{3}$ ) and likely to impact negatively on the environment (Chapter $\mathbf{2}$, 3) thus requiring intervention (Chapter 2). Our research identified species among the Domibacillus, Bacillus, and Clostridia genera present in the samples (Chapter 5) which survived in the pesticide exposed sites, and it is recommended that further work is carried out to explore their potential for use in bioremediation. 


\section{References}

Abban T, Johnson FA, Dash J, Padmadas SS. 2018. Spatiotemporal variations in rainfall and temperature in Ghana over the twentieth century, 1900 - 2014. Earth and Space Science 5: 120-132.

Abdullah AR, Bajet CM, Matin MA, Nhan DD, Sulaiman AH. 1997. Ecotoxicology of pesticides in the tropical paddy field ecosystem. Environmental Toxicology and Chemistry 16: 59-70.

Acquaah SO. 1997. "Lindane and Endosulfan Residues in Water and Fish in the Ashanti Region of Ghana," Proceedings of Symposium on Environmental Behaviour of Crop Protection Chemicals by the IAEA/FAO, IAEA, Vienna, 1-5 July.

Aktar MW, Sengupta D, Chowdhury A. 2009. Impact of pesticides use in agriculture: their benefits and hazards. Interdisciplinary toxicology 2(1): 1-12.

Alam S. 1977. "Checklist of rice insect pests of Bangladesh," in Literature Review of Insect Pests and Diseases of Rice in Bangladesh, pp. 79-90, Bangladesh Rice Research Institute (BRRI), Dhaka, Bangladesh.

Aldenberg T, Jaworska JS. 2000. Uncertainty of the hazardous concentration and fraction affected for normal species sensitivity distributions. Ecotoxicol Environ Saf 46:1-18.

Amoako PK, Kumah P, Appiah F. 2012. Pesticides usage in Cabbage (Brassica oleracea) Cultivation in the Ejisu-Juaben Municipality of the Ashanti Region of Ghana. International Journal of Research in Chemistry and Environment 2(3): 26-31.

Amoah C, Koranteng SS. 2006. Volta Basin Research Project (VBRP). University of Ghana, Legon, Accra, Ghana.

Ampomah B. 2017. 60\% of Ghana's water bodies polluted-Water Resources Commission. Executive Secretary of the Commission at a workshop in Ho, Source: Ghana News Agency (GNA), May 13, 2017.

Andah WE, van de Giesen N, Biney CA. 2003. Water, climate, food, and environment in the Volta Basin. Contribution to the project ADAPT, Adaptation strategies to changing environments. ADAPT, Accra, Ghana.

Ansara-Ross TM, Wepener V, Van Den Brink PJ, Ross MJ. 2008. Probabilistic risk assessment of the environmental impacts of pesticides in the Crocodile (west) Marico catchment, North-West Province. Water SA 34 (5): 637-644.

Anyadike RNC. 1993. Seasonal and annual rainfall variations over Nigeria. International Journal of Climatology 13: 567-580.

APHA (American Public Health Association). 1998. Standard Methods for the Examination of Water and Wastewater, 20th edn. Washington, D.C., USA.

Asantewaa Owusu P, Asumadu-Sarkodie S, Ameyo P. 2016. A review of Ghana's water resource management and the future prospect. Cogent Engineering 3: 1164275.

Atwood D, Paisley-Jones C. 2017. Pesticides industry sales and usage 2008-2012 market estimates: US Environmental Protection Agency. Washington, D.C., USA.

Baa-Poku J, Asante F, Amakye JS. 2013. Impact of Urban Effluents on the Macroinvertebrates of a Creek in Accra, Ghana. West African Journal of Applied Ecology 21 (1): 97-109. 
Backstrand JM, Botzler, RG. 1986. Survival of Pasteurella multocida in soil and water in an area where avian cholera is enzootic. Journal of wildlife diseases 22(2): 257-9.

Barbour MT, Gerritsen J, Snyder BD, Stribling JB. 1999. Rapid Bioassessment Protocol for Use in Streams and Wadable Rivers: Periphyton, Benthic Macroinvertebrates and Fish, Second Edition. EPA 841-B99-002. U.S. Environmental Protection Agency: Office of Water; Washington, D.C., USA.

Barry B, Obuobie E, Andreini M, Andah W, Pluquet M. 2005. The Volta river basin. Comparative study of river basin development and management. Rapport, IWMI, CAWMA, Colombo, Sri Lanka.

Bakhtiar JNH, Ahmad Sa'ad FN, Mat Amin AR, Othman MF, Mohd Yusoff MZ. 2019. Relationship Between Electrical Conductivity and Total Dissolved Solids as Water Quality Parameter in Teluk Lipat by Using Regression Analysis. In: Abu Bakar M., Mohamad Sidik M., Öchsner A. (eds) Progress in Engineering Technology. Advanced Structured Materials, vol 119. Springer, Cham.

Bekoe EO, Logah FY. 2013. The Impact of Droughts and Climate Change on Electricity Generation in Ghana. Environmental Sciences 1: 13-24.

Begon M, Townsend CR, Harper JL. 2009. Ecology: from individuals to ecosystems, John Wiley \& Sons, $4^{\text {th }}$ ed., New Jersey, USA.

Berg H. 2001. Pesticide use in rice and rice-fish farms in the Mekong Delta, Vietnam. Crop Protection 20: 897-905.

Belden JB, Gilliom RJ, Martin JD, Lydy MJ. 2007. Relative toxicity and occurrence patterns of pesticide mixtures in streams draining agricultural watersheds dominated by corn and soybean production. Integr Environ Assess Manag 3(1): 90-100.

Biesmeijer JC, Roberts SPM, Reemer M, Ohlemuller R, Edwards M. et al. 2006. Parallel declines in pollinators and insect-pollinated plants in Britain and the Netherlands. Science 313: 351-354.

Braak CJF, Smilauer P. 2002. CANOCO Reference manual and CanoDraw for Windows User's guide: Software for Canonical Community Ordination (version 4.5). Microcomputer Power.

Bohlen PJE CA, Zhang Q, Parmelee RW, Allen M. 2002. Indirect effects of earthworms on microbial assimilation of labile carbon. Applied Soil Ecology 20: 255-261.

Boivin A, Amellal S, Schiavon M, Van Genuchten MT. 2005. 2,4-Dichlorophenoxyacetic acid (2,4-D) sorption and degradation dynamics in three agricultural soils. Environ Pollut 138: 92-99.

Bonmatin, JM, Giorio C, Girolami V, Goulson D, Kreutzweiser DP, Krupke C, Tapparo A. 2015. Environmental fate and exposure; neonicotinoids and fipronil. Environmental science and pollution research international, 22(1): 35-67.

Bressers H. 2007. Contextual interaction theory and the issue of boundary definition: governance and the motivation, cognitions and resources of actors contribution to theoretical framework [online]. CSTM series studies and reports. Enschede, The Netherlands: University of Twente, Institute for Governance Studies.

Brock TCM, Alix A, Brown CD, Capri E, Gottesbüren BFF, Heimbach F, Lythgo CM, Schulz R, Streloke $M$, eds. 2010. Linking Aquatic Exposure to Effects: Risk Assessment of Pesticides. CRC, Boca Raton, FL, USA.

Brock TCM, Lahr J, Van Den Brink PJ. 2000a. Ecological Risk Assessment of Pesticides in Freshwater Ecosystems Part 1: Herbicides. Alterra-Report 088. Wageningen, the Netherlands. 
Brock TCM, Van Wijngaarden RPA, Van Geest G. 2000b. Ecological Risk Assessment of Pesticides in Freshwater Ecosystems Part 2: Insecticides. Alterra-Report 089. Wageningen, the Netherlands, $p$. 143.

Brock TCM, Van Wijngaarden RPA, 2012. Acute toxicity tests with Daphnia magna, Americamysis bahia, Chironomus riparius and Gammarus pulex and implications of new EU requirements for the aquatic effect assessment of insecticides. Environ Sci Pollut Res 19: 3610-3618.

Brock TCM, Bhatta R, van Wijngaarden RPA, Rico A. 2016. Is the chronic tier-1 effect assessment approach for insecticides protective for aquatic ecosystems? Integrated Environmental Assessment and Management 12: 747-758.

Brock TCM, Arts GHP, Maltby L, Van den Brink PJ. 2006. Aquatic risks of pesticides, ecological protection goals and common aims in EU legislation. Integr Environ Assess Manage 2: e20-e46.

Brown CD, Dubus IG, Fogg P, Spirlet M, Gustin C. 2004. Exposure to sulfosulfuron in agricultural drainage ditches: Field monitoring and scenario-based modelling. Pest Manage Sci 60: 765776.

Busse HJ. 2016. Review of the taxonomy of the genus Arthrobacter, emendation of the genus Arthrobacter sensu lato, proposal to reclassify selected species of the genus Arthrobacter in the novel genera Glutamicibacter gen. nov., Paeniglutamicibacter gen. nov., Pseudoglutamicibacter gen. nov., Paenarthrobacter gen. nov. and Pseudarthrobacter gen. nov., and emended description of Arthrobacter roseus. International journal of systematic and evolutionary microbiology 66(1): 9-37.

Cai DW. 2008. Understand the role of chemical pesticides and prevent misuses of pesticides. Bulletin of Agricultural Science and Technology 1: 36-38.

Carvalho FP. 2017. Pesticides, environment, and food safety. Food and Energy Security 6(2): 48-60.

Caporaso JG, Kuczynski J, Stombaugh J, Bittinger K, Bushman FD, Costello EK, Fierer N, Pena AG, Goodrich JK, Gordon JI, Huttley GA, Kelley ST, Knights D, Koenig JE, Ley RE, Lozupone CA, McDonald D, Muegge BD, Pirrung M, Reeder J, Sevinsky JR, Turnbaugh PJ, Walters WA, Widmann J, Yatsunenko T, Zaneveld J, Knight R. 2010. QIIME allows analysis of high-throughput community sequencing data. Nat Methods 7: 335-6.

Caporaso JG, Lauber CL, Walters WA, Berg-Lyons D, Huntley J, Fierer N, Owens SM, Betley J, Fraser L, Bauer M, Gormley N, Gilbert JA, Smith G, Knight R. 2012. Ultra-high-throughput microbial community analysis on the Illumina HiSeq and MiSeq platforms. The ISME Journal 6: 1621-1624.

Carlisle DM, Meador MR, Moulton SR, Ruhl PM. 2007. Estimation and application of indicator values for common macroinvertebrate. Ecol Indicators 7: 22-33.

Carlsson B. 2006. 'The role of public policy in emerging clusters', in P. Braunerhjelm and M. P. Fieldman (eds.) Cluster Genesis: Technology based Industrial Development, Oxford University Press, New York, USA.

Chapman PM. 2000. The Sediment Quality Triad: Then, now and tomorrow. Int J Environ Pollut 13: 351356.

Chen C, Wang Y, Zhao X, Wang Q, Qian Y. 2014. Comparative and combined acute toxicity of butachlor, imidacloprid and chlorpyrifos on earthworm, Eisenia fetida. Chemosphere 100: 111-115.

Clarke EEK, Levy LS, Spurgeon A. Calvert IA. 1997. The problems associated with pesticide use by irrigation workers in Ghana. Occup Med 47: 301-308. 
Corcoran E, Nellemann C, Baker E, Bos R, Osborn D, Savelli H. 2010. Sick Water? The Central Role of Wastewater Management in Sustainable Development. A Rapid Response Assessment. UNHabitat/UNEP/GRID-Arendal, www.grida.no.

Daam MA, Van den Brink PJ. 2010. Implications of differences between temperate and tropical freshwater ecosystems for the ecological risk assessment of pesticides. Ecotoxicology 19: $24-37$.

Daam MA, Crum SJ, Van den Brink PJ, Nogueira AJ. 2008a. Fate and effects of the insecticide chlorpyrifos in outdoor plankton-dominated microcosms in Thailand. Environ Toxicol Chem 27: 2530-2538.

Daam MA, Van den Brink PJ, Nogueira AJ. 2008b. Impact of single and repeated applications of the insecticide chlorpyrifos on tropical freshwater plankton communities. Ecotoxicology 17: 756-771.

Dabrowski JM, Peall SKC, Reinecke AJ, Liess M, Schulz R. 2002. Runoff-related pesticide input into the lourens river, South Africa: Basic data for exposure assessment and risk mitigation at the catchment scale. Water Air Soil Poll 135: 265-283.

Damalas CA, Eleftherohorinos IG. 2011. Pesticide Exposure, Safety Issues, and Risk Assessment Indicators. Int J Environ Res Public Health 8: 1402-1419.

Darvishzadeh A, Salimian-Rizi S, Katoulinezhad AA. 2014. Effect of Biolep ${ }^{\circledR}$, Permethrin and Hexaflumuron on mortality of cotton bollworm, Helicoverpa armigera (Noctuidae: Lepidoptera). Arthropods 3(4): 161-165.

Davis SN, Dewiest RJM. 1966. Hydrogeology. John Wiley and Sons, Inc., Hoboken, USA, 463 p.

De Bruijn JA, Hufen HAM. 1998. 'The Traditional Approach to Policy Instruments'. In B. G. Pters and F. K. M. V. Nispen (eds), Public Policy Instrument: Evaluating the Tools of Public Administration (pp, 1132). New York: Edward Elgars.

De ABR, Kumar A, Mozumdar S. 2014. Worldwide Pesticide Use. In Science SBiM (ed), Targeted Delivery of Pesticides Using Biodegradable Polymeric Nanoparticles. Springer India, New Delhi.

DeLorenzo ME, Scott GI, Ross PE. 2001. Toxicity of pesticides to aquatic microorganisms: a review. Environmental toxicology and chemistry 20: 84-98.

De Zwart D. 2002. Observed regularities in species sensitivity distributions for aquatic species. In: Posthuma L, Suter G, Traas T, editors. Species Sensitivity Distributions in Ecotoxicology. Boca Raton, FL: Lewis. (pp. 133-154).

Dickson KB, Benneh G. 1977. A New Geography of Ghana. UK: Longman, London, UK.

Dinham B. 2003. Growing vegetables in developing countries for local urban populations and export markets: problems confronting small-scale producers. Pest Manag Sci 59: 575-582.

Doughari HJ et al. 2011. The ecology, biology and pathogenesis of Acinetobacter spp.: an overview. Microbes and environments 26(2): 101-12.

DWAF (Department of Water Affairs and Forestry). 1998. Quality of domestic water supplies assessment guide, 2nd edn. Department of Water Affairs of Forestry, Department of Health and Water Research Commission, Pretoria, South Africa.

Echigo A et al. 2007. Halalkalibacillus halophilus gen. nov., sp. nov., a novel moderately halophilic and alkaliphilic bacterium isolated from a non-saline soil sample in Japan. International journal of systematic and evolutionary microbiology 57(5): 1081-5.

Ecobichon D. 2001. Pesticide use in developing countries. Toxicology 160: 27-33. 
Edgar RC. 2013. UPARSE: highly accurate OTU sequences from microbial amplicon reads. Nat Methods 10: 996-8.

Edwards CA, Bohlen PJ. 1996. Biology and ecology of earthworms, 3rd edn. Chapman \& Hall, London.

EPA (Ireland Environmental Protection Agency). 2001. "Parameters of water quality: Interpretations and standards". Relevant European Union Directives, Published by EPA, Ireland.

EC (European Commission). 2009. Regulation No. 1107/2009 of the European Parliament and of the Council of 21 October 2009 concerning the placing of plant protection products on the market and repealing Council Directives 79/117/EEC and 91/414/EEC. Off J Eur Comm L 309: 1-50.

EU (European Union). 1997. Council Directive 97/57/EC of September 21, 1997; Establishing annex VI to Directive $91 / 414 /$ EEC concerning the placing of plant protection products on the market. J Eur Commun L 265: 87-109.

EFSA (European Food Safety Authority). 2013a. EFSA Guidance Document on the risk assessment of plant protection products on bees (Apis mellifera, Bombus spp. and solitary bees). EFSA Journal 11(7): 3295.

EFSA (European Food Safety Authority). 2013b. Guidance on tiered risk assessment for plant protection products for aquatic organisms in the edge-of-field surface waters. EFSA Journal 11(7): 3290.

EFSA (European Food Safety Authority). 2018. Conclusions on the peer reviewof the pesticide risk assessment for bees for the active substance thiamethoxam considering the uses as seed treatments and granules. EFSA Journal 16(2): 5179.

Franson MA. 1989. Standard Methods for the Examination of Water and Wastewater, 17th ed. American Public Health Association, Washington D.C., USA.

FAO/WHO (Food and Agriculture Organization/World Health Organization). 2013. International code of conduct on the distribution and use of pesticides. Guidelines on data requirements for the registration of pesticides. Office of Knowledge Exchange, Research and Extension, FAO. Rome, Italy.

FIBI (Forschungsinstitut für biologischen Landbau). 2012. Organic agriculture promotes biodiversity. Available at: http://www.fibl.org/en/fibl/themes/biodiversity.html.

Fimyar 0. 2014. What is policy? In search of frameworks and definitions for non-Western contexts. Educate 14(3): 6-21.

Firbank LG, Petit S, Smart S, Blain A, Fuller RJ. 2012. Assessing the impacts of agricultural intensification on biodiversity: a British perspective. Phil Trans $R$ Soc 363: 777-787.

Fira D, Dimkic I, Beric T, Lozo J, Stankovic S. 2018. Biological control of plant pathogens by Bacillus species. J Biotechnol 285: 44-55.

Forbes VE, Hommen U, Grimm V, Thorbek P, Heimbach F, Van den Brink PJ, Wogram J, Thulke H. 2009. Ecological models in support of regulatory risk assessment of pesticides: Developing a strategy for the future. Integr Environ Assess Manage 5: 167-172.

Fragoso C, Brown GG, Patron JC, Blanchart E, Lavelle P, Pashanasi B, Senapati B, Kumar T. 1997. Agricultural intensification, soil biodiversity and agroecosystem function in the tropics: the role of earthworms. Appl Soil Ecol 6: 17-35.

Friberg-Jensen U, Wendt-Rasch L, Woin P, Christoffersen K. 2003. Effects of the pyrethroid insecticide, cypermethrin, on a freshwater community studied under field conditions. I. Direct and indirect 
effects on abundance measures of organisms at different trophic levels (Amsterdam, Netherlands). Aquatic toxicology 63: 357-71.

Fianko JR, Donkor A, Lowor ST, Yeboah PO. 2011. Agrochemicals and the Ghanaian Environment, A Review, Journal of Environmental Protection 2: 221-230.

Fondriest Environmental. 2013. "pH of Water." Fundamentals of Environmental Measurements. Available at: https://www.fondriest.com/environmentalmeasurements/parameters/water-quality/ph/.

Gardner JM, Feldman AW, Zablotowicz RM. 1982. Identity and behavior of xylem-residing bacteria in rough lemon roots of Florida citrus trees. J Appl Environ Microbiol 43: 1335 1342.

García-González T, Sáenz-Hidalgo HK, Silva-Rojas HV, Morales-Nieto C, Vancheva T, Koebnik R, ÁvilaQuezada GD. 2018 Enterobacter cloacae, an Emerging Plant-Pathogenic Bacterium Affecting Chili Pepper Seedlings. The plant pathology journal 34(1): 1-10.

Gampson EK, Nartey VK, Golow AA, Akiti TT. 2014. Hydrochemical study of water collected at a section of the Lower Volta River (Akuse to Sogakope area), Ghana. Appl Water Sci 4: 129-143.

Ge S, Ai W, Dong X. 2016. High-Quality Draft Genome Sequence of Leucobacter sp. Strain G161, a Distinct and Effective Chromium Reducer. Genome announcements 4(1).

Geiger F, Bengtsson J, Berendse F, Weisser WW, Emmerson M, Morales MB, Ceryngier P, Liira J, Tscharntke T, Winqvist C, Eggers S, Bommarco R, Pärt T, Bretagnolle V, Plantegenest $M$, Clement LW, Dennis C, Palmer C, Oñate JJ, Guerrero I, Hawro V, Aavik T, Thies C, Flohre A, Hänke S, Fischer C, Goedhart PW, Inchausti P. 2010. Persistent negative effects of pesticides on biodiversity and biological control potential on European farmland. Basic and Applied Ecology 11: 97-105.

Gerken A, Suglo JV, Braun M. 2001. Pesticides use and policies in Ghana: An economic and institutional analysis of current practice and factors influencing pesticide use. Hannover, Germany. Pesticide Policy Project Publication Series No. 10, Institut für Gartenbauökonomie, Universität Hannover.

GEPA (Ghana Environmental Protection Agency). 2014. Ghana. Annual Report, Accra Ghana

GEPA (Ghana Environmental Protection Agency). 2008. Register of pesticides as at $31^{\text {st }}$ December 2008 under Part 11 of the environmental protection agency act, 1994 (Act 490). Accra, Ghana

GEPA (Ghana Environmental Protection Agency). 2011. Ghana's Second National Communication (GSNC) to the UNFCCC; United Nations Development Programme: New York, NY, USA.

GEPA (Ghana Environmental Protection Agency). 2012. Pesticide Registration Manual (PRM), Chemicals Control and Management Center (CCMC), Accra, Ghana.

GSS (Ghana Statistical Service). 2014. Ghana Living Standards Survey Round 6. Accra, Ghana.

GSS (Ghana Statistical Service). 2015. Revised 2014 Annual Gross Domestic Product. Accra, Ghana.

GNA (Ghana News Agency). 2012. September 4, Accra, Ghana.

Giddings JM, Williams WM, Solomon KR, Giesy JP. 2014. Risks to Aquatic Organisms from Use of Chlorpyrifos in the United States. In: Giesy J., Solomon, K. (eds). Ecological Risk Assessment for Chlorpyrifos in Terrestrial and Aquatic Systems in the United States. Reviews of Environmental Contamination and Toxicology 231: 119-162.

Giesy JP, Solomon KR, Coates JR, Dixon KR, Giddings JM, Kenaga EE. 1999. Chlorpyrifos: ecological risk assessment in North American aquatic environments. Rev Environ Contam Toxicol 160: 1-129. 
Gill HK, Garg H. 2014. Pesticides: Environmental Impacts and Management Strategies. In M. L. Larramendy \& S. Soloneski (Eds.), Pesticides - Toxic Aspects (pp. 187-230). Croatia: Intech.

Gobi M, Gunasekaran P. 2009. "Effect of Butachlor Herbicide on Earthworm Eisenia fetida-Its Histological Perspicuity", Applied and Environmental Soil Science vol. 2010, Article ID 850758, 4 pages.

Goh KM. 2011. Greater mitigation of climate change by organic than conventional agriculture: A review. Biol Agric Hortic: Int J Sustainable Prod Syst 27: 205-229.

Gordon C, Nukpezah D, Tweneboah-Lawson E, Ofori BD, Yirenya-Tawiah D, Pabi O, Ayivor JS, Koranteng S, Darko D, Mensah AM. 2013. West Africa - Water resources vulnerability using a multidimensional approach: Case study of Volta Basin. In: Climate vulnerability: Understanding and addressing threats to essential resources, ed., Pielke, R.A. Sr. Elsevier Inc., Academic Press, Amsterdam, the Netherlands: pp. 283-309.

Grady EN, MacDonald J, Liu L, Richman A, Ze-Chun Y. 2016. Current knowledge and perspectives of Paenibacillus: a review. Microbial cell factories 15(1): p. 203.

Grizzetti B, Lanzanova D, Liquete C, Reynaud A, Cardoso AC. 2016. Assessing water ecosystem services for water resource management. Environmental Science \& Policy 61: 194-203.

Gupta S, Chauhan NS, Bhushan S, et al. 2017. Insecticidal, food utilisation and biochemical effect of essential oils extracted from seeds of Brassica juncea (Czern.) against Spodoptera litura (Lepidoptera: Noctuidae) (Fabricius). Arthropods 6(3): 93-106.

Hansen L, Noe E, Hojring K. 2006. Nature and nature values in organic agriculture. An analysis of contested concepts and value among different actors in organic farming. J Agric Environ Ethics 19: 147-168.

Harris J. 2000. Chemical Markets, Health Risks and Residues. New York, USA: Biopesticides Series 1. CABI.

Harder M. 2008. How Do Rewards and Management Styles Influence the Motivation to Share Knowledge? Centre for Strategic Management and globalization (SMG) Working Paper No. 6.

Hasegawa K, Mansbach JM, Ajami NJ, Espinola JA, Henke DM, Petrosino JF, Piedra PA, Shaw CA, Sullivan AF, Camargo CA Jr. 2016. Association of nasopharyngeal microbiota profiles with bronchiolitis severity in infants hospitalised for bronchiolitis. Eur Respir J 48: 1329-1339.

Hayward AC, Fegan N, Stirling GR. 2010. Stenotrophomonas and Lysobacter: ubiquitous plant-associated gamma-proteobacteria of developing significance in applied microbiology. Journal of applied microbiology 108(3): 756-70.

He, LM, Troiano, J, Wang A, Goh K. 2008. Environmental chemistry, ecotoxicity, and fate of lambdacyhalothrin. Rev Environ Contam Toxicol 195: 71-91.

Her J, Lee SS. 2015. Leucobacter humi sp. nov., Isolated from Forest Soil. Current microbiology 71(2): 23542.

Hole DG, Perkins AJ, Wilson JD, Alexander IH, Grice PV, Evans AD. 2005. Does organic farming benefit biodiversity? Biol Conserv 122: 113-130.

Holvoet K, Seuntjens P, Mannaerts R, De Scepper V, Vanrolleghem PA. 2007. The dynamic watersediment system: results from an intensive pesticide monitoring campaign. Water Sci Technol 55: 177-182.

Hooda PS, Edwards AC, Anderson HA, Miller A. 2000. A review of water quality concerns in livestock farming areas. Sci Total Environ 250: 143-167. 
Horna D, Smale M, Al-Hassan R, Falck-Zepeda J, Timpo SE. 2008. “Insecticides use on vegetables in Ghana: would GM seed benefit farmers?" IFPRI Discussion Paper 007855.

Hooper DU, Chapin III FS, Ewel JJ, Hector A, Inchausti P, Lavorel S, Lawton JH, Lodge DM, Loreau M, Naeem S, Schmid B, Setälä H, Symstad AJ, Vandermeer J, Wardle DA 2005. Effects of biodiversity on ecosystem functioning: A consensus of current knowledge. Ecol Monogr 75: 3-35.

Hughes S, Cooper D. 1996. Biodegradation of phenolusing the self-cycling fermentation (SCF) process. J Biotechnol Bioeng 51: $112-119$.

Hugo CJ, Bruun B, Jooste PJ. 2006. The Genera Bergeyella and Weeksella, in The Prokaryotes, M. Dworkin, Falkow, S., Rosenberg, E., Schleifer, KH., Stackebrandt, E., Springer: New York.

Hynes JD. 1975a. Annual cycles of macroinvertebrates of a river in Southern Ghana. Fresh Water Biology 5: 71-83.

Hynes JD. 1975b. Down stream drift of invertebrates in a river in Southern Ghana. Fresh Water Biology 5: 515-532.

leromina O, Musters CJ, Bodegom PM, Peijnenburg WJ, Vijver MG. 2016. Trait modality distribution of aquatic macrofauna communities as explained by pesticides and water chemistry. Ecotoxicology 25(6): 1170-1180.

Imoro ZA, Larbi J, Duwiejuah AB. 2019. Pesticide Availability and Usage by Farmers in the Northern Region of Ghana. J Health Pollution 23: (190906).

Inbar J, Chet I. 1991. Evidence that chitinase produced by Aeromonas caviae is involved in the biological control of soil-borne plant pathogens by this bacterium. Soil Biology and Biochemistry 23(10): 973978.

Ishii S et al. 2006. Presence and growth of naturalized Escherichia coli in temperate soils from Lake Superior watersheds. Applied and environmental microbiology 72(1): 612-21.

Jacoby R, Peukert M, Succurro A, Koprivova A, Kopriva S. 2017. The Role of Soil Microorganisms in Plant Mineral Nutrition-Current Knowledge and Future Directions. Frontiers in plant science 8: 1617.

Jafarbeigi F, Samih MA, Zarabi M et al. 2014. Sublethal effects of some botanical and chemical insecticides on the cotton whitefly, Bemisia tabaci (Hem: Aleyrodidae). Arthropods 3(3): 127-137.

Jänsch S, Frampton GK, Römbke J, Van den Brink PJ, Scott-Fordsmand JJ. 2006. Effects of pesticides on soil invertebrates in model ecosystem and field studies: a review and comparison with laboratory toxicity data. Environmental Toxicology and Chemistry 25: 2490-2501.

Jennings AA, Li Z. 2014. Scope of the worldwide effort to regulate pesticide contamination in surface soils. J Environ Manag 146: 420-443.

Jeong $\mathrm{H}$ et al. 2012. Draft genome sequence of the plant growth-promoting bacterium Bacillus siamensis KCTC 13613T. Journal of bacteriology 194(15): 4148-9.

Johnson RM, Wen Z, Schuler MA, Berenbaum MR. 2006. Mediation of Pyrethroid Insecticide Toxicity to Honey Bees (Hymenoptera: Apidae) by Cytochrome P450 Monooxygenases. Journal of Economic Entomology 99 (4): 1046-1050.

Kariathi V, Kassim N, Kimanya M, Yildiz F. 2016. Pesticide exposure from fresh tomatoes and its relationship with pesticide application practices in Meru district. Cogent Food \& Agriculture 2:1. 
Karikari AY, Ansa-Asare OD. 2006. Physico-Chemical and Microbial Water Quality Assessment of the Densu River of Ghana. West African Journal of Applied Ecology 10: 87-100.

Karikari AY, Bernasco JK, Bosque-Hamilton EKA. 2007. "An Assessment of Water Quality of Augaw River in South-Eastern Coastal Plain of Ghana". Unpublished paper, CSIR-Water Research Institute, Accra, Ghana.

Kent AD, Triplett EW. 2002. Microbial communities and their interactions in soil and rhizosphere ecosystems. Annual review of microbiology 56: 211-36.

Khalifa AY, Alsyeeh AM, Almalki MA, Saleh FA. 2016. Characterization of the plant growth promoting bacterium, Enterobacter cloacae MSR1, isolated from roots of non-nodulating Medicago sativa. Saudi journal of biological sciences 23(1): 79-86.

Khan S, Cao Q, Hesham AB, Xia Y, He J. 2007. Soil enzymatic activities and microbial community structure with different application rates of $\mathrm{Cd}$ and Pb. Journal of Environmental Sciences 19: 834-840.

Khan S, Hesham AL, Qiao M, Rehman S, He JZ. 2010. Effects of Cd and Pb on soil microbial community structure and activities. Environmental science and pollution research international 17: 288-96.

Kidd H, James DR, Eds. 1991. The Agrochemicals Handbook, Third Edition. Royal Society of Chemistry Information Services, Cambridge, UK.

Kishi M, Hirschhorn N, Djajadisastra M, Satterlee LN, Strowman S, Dilts R. 1995. Relationship of pesticide spraying to signs and symptoms in Indonesian farmers. Scan J Work Environ Health 21: 124-133.

Kleijn D, Berendse F, Smit R, Gilissen N. 2001. Agrienvironment schemes do not effectively protect biodiversity in Dutch agricultural landscapes. Nature 413: 723-725.

Knacker T, Van Gestel CAM, Jones SE, Soares AMVM, Schallnaß H-J, Förster B, Edwards CA. 2004. Ringtesting and field-validation of a terrestrial model ecosystem (TME)-An instrument for testing potentially harmful substances: Conceptual approach and study design. Ecotoxicology 13: 5-23.

Koh D, Jeyaratnam J. 1996. Pesticides hazards in developing countries. The science of the total environment 188 (1): S78-S85.

Konradsen F, van der Hoek W, Cole DC, Hutchinson G, Daisley H, Singh S, Eddleston M. 2003. Reducing acute poisoning in developing countries - options for restricting the availability of pesticides. Toxicology 192: 249-261.

Kimani VN, Mwanthi AM. 1995. Agrochemical exposure and health implications in Githunguri location Kenya. East Afr Med J 72(8): 531-535.

Kwok KWH, Leung KMY, Lui GSG, Chu VKH, Lam PKS, Morritt II D, Maltby L, Brock TCM, Van Den Brink PJ, Warne MSJ, Crane M. 2007. Comparison of tropical and temperate freshwater animal species' acute sensitivities to chemicals: Implications for deriving safe extrapolation factors. Integr Environ Assess Manage 3 (1): 49-67.

Lavelle P, Spain AV. 2001. Soil ecology. Kluwer Scientific, Amsterdam, The Nethrlands.

Lavelle P, Decaëns T, Aubert M, Barot S, Blouin M, Bureau F, Margerie P, Mora P, Rossi J-P. 2006. Soil invertebrates and ecosystem services. Eur J Soil Biol 42:S3-S15.

Lawson PA, Rainey FA. 2016. Proposal to restrict the genus Clostridium Prazmowski to Clostridium butyricum and related species. International journal of systematic and evolutionary microbiology 66(2): 1009-1016. 
Lebreton F, Willems RJL, Gilmore MS. 2014. Enterococcus Diversity, Origins in Nature, and Gut Colonization, in Enterococci: From Commensals to Leading Causes of Drug Resistant Infection C.D. Gilmore MS, Ike Y, et al. Editor, Massachusetts Eye and Ear Infirmary: Boston, USA.

Leprieur F, Beauchard O, Blanchet S, Oberdorff T, Brosse S. 2008. Fish invasions in the world's river systems: when natural processes are blurred by human activities. PLoS biology 6: e28.

Leistra M, Zweers AJ, Warinton JS, Crum SJH, Hand LH, Beltman WHJ, Maund S.J. 2003. Fate of the insecticide lambda-cyhalothrin in ditch enclosures differing in vegetation and nutrient level. Pest Manage Sci 60: 75-84.

Liess M, Brown C, Dohmen P, Duquesne S, Heimbach F, Kreuger L, Lagadic L, Maund S, Reinert W, Streloke M, Tarazona JV. 2005. Effects of Pesticides in the Field-EPIF (October 2003), European Union and SETAC Europe. SETAC, Le Croisic, France Brussels, Belgium.

Li QR, Liao ST, Zhi HY, Xing DX, Xiao Y, Yang Q. 2019. Characterization and sequence analysis of potential biofertilizer and biocontrol agent Bacillus subtilis strain SEM-9 from silkworm excrement. Can J Microbiol 65: 45-58.

Locke EA, Letham GP. 2004. What Should We Do About Motivation Theory? Six Recommendations for the Twenty-First Century, Academy of Management Review 29(3): 388-403.

Logan D. 2010. What is Information Governance? And Why is it So Hard? Available at: http://blogs.gartner.com/debra_logan/2010/01/11/what-is-information-governance-and-why-is-itso-hard/.

López-Mancisidor P, Carbonell G, Fernandez C, Tarazona JV. 2008a. Ecological impact of repeated applications of chlorpyrifos on zooplankton community in mesocosms under Mediterranean conditions. Ecotoxicology 17: 811-825.

López-Mancisidor P, Carbonell G, Marina A, Fernandez C, Tarazona JV. 2008b. Zooplankton community responses to chlorpyrifos in mesocosms under Mediterranean conditions. Ecotoxicol Environ Saf 71: $16-25$.

Lovelle ST, Sullivan WC. 2006. Environmental Benefits of Conservation buffers in the United states: evidence, promise, and questions. Agr Ecosyst Environ 112: 249-260.

Lozupone C, Knight R. 2005. UniFrac: a new phylogenetic method for comparing microbial communities. Applied and environmental microbiology 71: 8228-8235.

Lü Z, Sang L, Li Z, Min H. 2009. Catalase and superoxide dismutase activities in a Stenotrophomonas maltophilia WZ2 resistant to herbicide pollution. Ecotoxicology and Environmental Safety 72(1): 136143.

Luísa CS, Antunes PV, Towner KJ. 2014. Acinetobacter baumannii: evolution of a global pathogen. Pathogens and Disease 71(3): 292-301.

Lynch JM, Hobbie JE. 1988. Micro-Organisms in Action: Concepts and Applications in Microbial Ecology, Blackwell Scientific Publications, Oxford, UK.

Mackereth FIF, Heron J, Talling JF. 1978. Water analysis: some revised methods for limnologist. Freshwater Biological Association London, UK. 121 p.

Madhaiyan M, Poonguzhali S, Lee JS, Saravanan VS, Lee KC, Santhanakrishnan P. 2010. Enterobacter arachidis sp. nov., a plant-growth-promoting diazotrophic bacterium isolated from rhizosphere soil of groundnut. International journal of systematic and evolutionary microbiology 60(7): 1559-64. 
Malherbe W, Van Vuren JHJ, Wepener V. 2013. Preliminary risk assessment of common-use pesticides using PRIMET and PERPEST pesticide risk models in a semi-arid subtropical region. Water SA 39(5): 599-610.

Maltby L, Blake N, Brock TCM, Van den Brink PJ. 2005. Insecticide species sensitivity distributions: importance of test species selection and relevance to aquatic ecosystems. Environ Toxicol Chem 24: 379-388.

Maltby L, Brock TCM, Van den Brink PJ. 2009. Fungicide Risk Assessment for Aquatic Ecosystems: Importance of Interspecific Variation, Toxic Mode of Action, and Exposure Regime. Environ Sci Technol 43: 7556-7563.

Maltby L, Van den Brink PJ, Faber JH, Marshall S. 2017. Advantages and challenges associated with implementing an ecosystem services approach to ecological risk assessment for chemicals. Science of the Total Environment 621: 1342-1351.

Mardani A, Almasi A, Hashemi SM et al. 2017. Side effects of thiacloprid+deltamethrin, pirimicarb and pymetrozine on the black bean aphid parasitoid, Lysiphlebus fabarum Marshall (Hymenoptera: Aphidiidae). Arthropods 6(2): 67-77.

Matthews G, Wiles T, Baleguel P. 2003. A survey of pesticide application in Cameroon. Crop Prot 22: 707714.

Maund SJ, Hamer MJ, Warinton JS, Kedwards TJ. 1998. Aquatic ecotoxicology of the pyrethroid insecticide lambda-cyhalothrin: Considerations for higher-tier aquatic risk assessment. Pestic Sci 54: 408-417.

MEA (Millenium Ecosysten Assessment). 2005. Ecosystems and Human Well-Being: Synthesis. Island Press, Washington, DC., USA., ISBN-13: 9781597260404, Pages: 160.

Mengistie BT, Mol PJ, Oosterveer P, Simane B. 2014. Information, motivation and resources: the missing elements in agricultural pesticide policy implementation in Ethiopia. International Journal of Agricultural Sustainability 13(3): 240-256.

Mensah E, Amoah P, Abaidoo RC, Drechsel P. 2002. Environmental concerns of (peri-) urban vegetable production - case studies from Kumasi and Accra. In P. Drechsel \& D. Kunze (Eds.), Waste Composting for Urban and Peri-urban Agriculture - Closing the Rural-Urban Nutrient Cycle in Sub-Saharan Africa (pp. 55-68). Wallingford, IWMI/FAO/CABI.

Metacalf RL. 1980. Changing role of insecticides in crop protection. Annu Rev Entomol 25: 119-256.

Morrissey CA, Mineau P, Devries JH, Sanchez-Bayo F, Liess M, Cavallaro MC, Liber K. 2015. Neonicotinoid contamination of global surface waters and associated risk to aquatic invertebrates: a review. Environ Int 74: 291-303.

MOFA (Ministry of Food and Agriculture). 2003. Agriculture in Ghana: Facts and Figures. Accra, Ghana: Statistics, Research and Information Directorate, Accra, Ghana.

MOFA (Ministry of Food and Agriculture). 2010. Agriculture in Ghana, Facts and Figures. Accra, Ghana: Statistics Research and Information Directorate, Accra, Ghana.

MOFA (Ministry of Food and Agriculture). 2011. Agriculture in Ghana: Facts and Figures. Accra, Ghana: Statistics, Research and Information Directorate, Accra, Ghana.

MOFA (Ministry of Food and Agriculture). 2018. Kpong Irrigation Scheme. Ministry of Food and Agriculture (MoFA), Accra, Ghana. 
MOFA (Ministry of Food and Agriculture). 2019. Ghana Commercial Agriculture Project (GCAP): Environmental and Social Impact Assessment (ESIA) of the rehabilitation and modernization of the Kpong Irrigation Scheme (KIS) report, Accra, Ghana.

Morrison G, Fatoki OS, Ekberg A. 2001. Assessment of the impact of point source pollution from Keiskammahoek sewage treatment plant on the Keiskamma River- $\mathrm{pH}$, electrical conductivity, oxygen-demanding substances (COD) and nutrients. Water SA 27: 475-480.

Mul M, Obuobie E, Appoh R, Kankam-Yeboah K, Bekoe-Obeng E, Amisigo B, Logah FY, Ghansah B, McCartney M. 2015. Water resources assessment of the Volta River Basin. Colombo, Sri Lanka: IWMI Working Paper 166, International Water Management Institute (IWMI) Colombo, pp 78.

Munoz-Leoz B, Garbisu C, Charcosset JY, Sanchez-Perez JM, Antiguedad I, Ruiz-Romera E. 2013. Nontarget effects of three formulated pesticides on microbially-mediated processes in a clay-loam soil. The Science of the total environment 449: 345-54.

Murphy HH, Hoan NP, Matteson P, Abubakar AL. 2002. Farmers' self-surveillance of pesticide poisoning: a 12-month pilot in northern Vietnam. Int J Occup Environ Health 8(3): 201-211.

Nautiyal CS, Rehman A, Chauhan PS. 2010. Environmental Escherichia coli occur as natural plant growthpromoting soil bacterium. Arch Microbiol 192(3): 185-93.

Ngowi AV, Maeda D, Wesseling C, Partanen TJ, Sanga MP, Mbise G. 2001. Pesticide handling practices in agriculture in Tanzania: observational data from 27 coffee and cotton farms. Int J Occup Environ Health 7: 326-332.

Ngowi AVF, London L. 2006. Action on pesticides under the programme on Work and Health in Southern Africa (WAHSA). Afr. Newslett. Occup Health Saf 16(1): 15-19.

Norris RH, Thoms MC. 1999. What is river health? Freshwater Biology 41: 197-209.

NPASP (Northern Presbyterian Agricultural Services and Partners). 2012. Ghana's Pesticide Crisis: The need for further Government action, NPASP, Ghana.

Nkansah MA, Boadi MO, Badu M. 2010. "Assessment of the Quality of Water from Hand-Dug Wells in Ghana". Environmental Health Insights 4: 7-12.

Ntow WJ. 2001. Organochlorine pesticides in water, sediment, crops, and human fluids in a farming community in Ghana. Arch Environ Contam Toxicol 40: 557-563.

Ntow WJ. 2005. Pesticide residues in Volta Lake, Ghana. Lakes \& Reservoirs: Research and Management 10: 243-248.

Ntow WJ. 1998. Pesticide misuse at Akumadan to be tackled. NARP Newslett 3: 3.

Ntow WJ, Gijzen HJ, Kelderman P, Drechsel P. 2006. Farmer perceptions and pesticide use practices in vegetable production in Ghana. Pest Manage Sci 62: 356-365.

OECD-FAO (Organisation of Economic Co-operation and Development and Food and Agriculture Organization). 2012. Agricultural Outlook: United Nations, Paris, France.

Onwona Kwakye M, Mengistie B, Ofosu-Anim J, Tetteh Nuer, AK, Van den Brink, PJ. 2019. "Pesticide registration, distribution and use practices in Ghana". Environ Dev Sustain 21: 2667-2691.

Ogren SA. 2014. Using indicators of biotic integrity for assessment of stream condition. Michigan Tech 7: 10-19. 
Okoffo ED, Mensah M. Fosu-Mensah BY. 2016. Pesticides exposure and the use of personal protective equipment by cocoa farmers in Ghana. Environ Syst Res 5: 17.

Pandey J. Singh A. 2012. Opportunities and constraints in organic farming: An Indian perspective. J Sci Res 56: 47-72.

Peeters FM, Van den Brink PJ, Vlaming J, Groenwold JG, Beltman WHJ, Boesten JJTI. 2008. PRIMET version 2.0 manual and technical description. A decision support system for assessing Pesticides Risk in the tropics to Man, Environment and Trade. Wageningen, Alterra, Alterra-rapport 1648. 77 blz.; 29 figs.; 2 tables.; 22 refs.

Pereira EJ, Fonseca S, Meena RM, Ramaiah N. 2017. Improved Sprouting and Growth of Mung Plants in Chromate Contaminated Soils Treated with Marine Strains of Staphylococcus species. Indian journal of microbiology 57(4): 400-408.

Peix A, Ramirez-Bahena MH, Velazquez E. 2009. Historical evolution and current status of the taxonomy of genus Pseudomonas. Infection, genetics and evolution: journal of molecular epidemiology and evolutionary genetics in infectious diseases 9(6): 1132-47.

Pérez-Lucas G, Nuria V, Abderrazak El Aatik, Navarro S. 2018. Environmental Risk of Groundwater Pollution by Pesticide Leaching through the Soil Profile, Pesticides - Use and Misuse and Their Impact in the Environment, Marcelo Larramendy and Sonia Soloneski, IntechOpen.

Perry MJ, Marbella A, Layde PM. 2002. Compliance with required pesticide-specific protective equipment use. Am J Ind Med 41(1): 70-73.

Pham DA, Le QP, Le NP. 2015. Linking Benthic Macroinvertebrates and Physicochemical Variables for Water Quality Assessment in Lower Dongnai River System, Vietnam. International Journal of Environmental Science and Development, Vol. 6, No. 2.

Pimentel D. 2009. Environmental and Economic Costs of the Application of Pesticides Primarily in the United States. Integrated Pest Management: innovation-Development Process (eds R. Peshin \& A. k. Dhawan), pp 89-111.

PPDB (Pesticide Properties Database). 2018. "Butachlor" University of Hertfordshire Available at: https://sitem.herts.ac.uk/aeru/ppdb/en/Reports/101.htm.

PPDB (Pesticide Properties Database). 2020. Pesticide Properties Database (PPDB). University of Hertfordshire, UK. Available at: https://sitem.herts.ac.uk/aeru/ppdb/en/index.htm.

Prado AG, Airoldi C. 2001. Toxic effect caused on microflora of soil by pesticide picloram application. Journal of environmental monitoring: JEM 3: 394-7.

Quast C, Pruesse E, Yilmaz P, Gerken J, Schweer T, Yarza P, Peplies J, Glockner FO. 2013. The SILVA ribosomal RNA gene database project: improved data processing and web-based tools. Nucleic Acids Res 41: D590-6.

Gilani RA, Rafique M, Rehman A, Munis MFH, Chaudhary SRHJ. 2015 Biodegradation of chlorpyrifos by bacterial genus Pseudomonas. J Basic Microbiol 55: 1-15.

Ramo RA, van den Brink PJ, Ruepert C, Castillo LE, Gunnarsson JS. 2016. Environmental risk assessment of pesticides in the River Madre de Dios, Costa Rica using PERPEST, SSD, and mSPAF models. Environ Sci Pollut Res 25(14):13254-13269.

Reche MHLR, Fiuza LM. 2005. Bacterial diversity in rice-field water in Rio Grande do Sul. Brazilian Journal of Microbiology 36(3): 253-257. 
Reynolds JD. 2018. "International Pesticide Trade: Is There Any Hope for the Effective Regulation of Controlled Substances?, "Florida State University Journal of Land Use and Environmental Law 13 : No. 1 , Article 2.

Rico A, Van den Brink PJ. 2015. Evaluating aquatic invertebrate vulnerability to insecticides based on intrinsic sensitivity, biological traits, and toxic mode of action. Environ Toxicol Chem 34: 1907-1917.

Roessink I, Merga LB, Zweers HJ, Van den Brink PJ. 2013. The neonicotinoid imidacloprid shows high chronic toxicity to mayfly nymphs. Environ Toxicol Chem 32: $1096-1100$.

Rosenberg E. 2014. The family Chitinophagaceae. In: Rosenberg E, DeLong EF, Lory S, Stackebrandt E, Thompson F (eds) The prokaryotes. Springer, Berlin, pp 493-495.

Rosenberg D, Resh V. 1993. Freshwater Biomonitoring and Benthic macroinvertebrates. Chapman hall publ., New York, USA.

Rupa I, Victor G, Stepanov BI. 2013. Isolation and molecular characterization of a novel pseudomonas putida strain capable of degrading organophosphate and aromatic compounds. Advances in Biological Chemistry 3: 564-578.

Sabatier P, Mazmania D. 1980. The Implementation of Regulatory Policy: A Framework of Analysis. Policy Studies Journal 8(4): 538-560.

Sabatier P. 1991. Towards better theories of the policy process. Political science and politics 24: 147-156.

Saeki M, Toyota K. 2004. Effect of bensulfuron-methyl (a sulfonylurea herbicide) on the soil bacterial community of a paddy soil microcosm. Biology and Fertility of Soils 40(2): 110-118.

Saha, N.C., Giri, SK., Chatterjee, N., Biswas, S.J., Bej, S., 2016. Acute toxic effects of Mancozeb to fish Oreochromis mossambicus (W. K. H. Peters, 1852) and their behavior. Int J Adv Res Biol Sci 3: 40-44.

Sally HA. 2001. C. L. Private irrigation in Sub-Saharan Africa: Regional Seminar on Private Sector Participation and Irrigation Expansion in Sub-Saharan Africa, Accra, Ghana, 22-26 October 2001. Colombo, Sri Lanka: International Water Management Institute (IWMI); Rome, Italy: FAO; Wageningen, Netherlands: Technical Centre for Agricultural and Rural Cooperation ACP-EU (CTA). p. In Sally HA, C. L. (ed).

Sally HA. 2002. C. L. Private irrigation in Sub-Saharan Africa: Regional Seminar on Private Sector Participation and Irrigation Expansion in Sub-Saharan Africa, Accra, Ghana, 22-26 October 2001. Colombo, Sri Lanka: International Water Management Institute (IWMI); Rome, Italy: FAO; Wageningen, Netherlands: Technical Centre for Agricultural and Rural Cooperation ACP-EU (CTA).

Samson-Robert O, Labrie G, Chagnon M, Fournier V. 2014. Neonicotinoid-contaminated puddles of water represent a risk of intoxication for honey bees. PLoS One 9(12): e108443.

Sanjaya Y, Ocampo VR, Caoili BL. 2013. Selection of entomopathogenic fungi against the red spider mite Tetranychus kanzawai (Kishida) (Tetranychidae: Acarina). Arthropods 2(4): 208-215.

Sarkar S, Seenivasan S, Premkumar R. 2009. Biodegra-dation of propiconazole by Pseudomonas putida isolated from tea rhizosphere. Plant Soil Environ 55: 196 -201.

Sasi Jyothsna TS. et al. 2016. Paraclostridium benzoelyticum gen. nov., sp. nov., isolated from marine sediment and reclassification of Clostridium bifermentans as Paraclostridium bifermentans comb. nov. Proposal of a new genus Paeniclostridium gen. nov. to accommodate Clostridium sordellii and Clostridium ghonii. International journal of systematic and evolutionary microbiology 66(3): 12681274. 
Schäfer RB, Van den Brink PJ, Liess M. 2010. Impacts of pesticides on freshwater ecosystems. In: Sánchez-Bayo F, Van den Brink PJ, Mann RM. (Eds.) Ecological impacts of toxic chemicals. Bentham Science Publishers Ltd. Bussum, The Netherlands. pp: 139-173.

Schafer Al, Rossiter HMA, Owusu PA, Richard BS, Awuah E. 2010. “Developing country water supplies: physico-chemical water quality in Ghana". Desalination 251: 193-203.

Schmaranzer S. 2000. Thermoregulation of water collecting honey bees (Apis mellifera). J Ins Physiol 46(8): 1187-94.

Schmitt-Jansen M, Veitb MU, Dudelc G, Altenburgera R. 2008. An ecological perspective in aquatic ecotoxicology: approaches and challenges. Basic Appl Ecol 9: 337-345.

Schroer AFW, Belgers D, Brock TCM, Matser A, Maund SJ, Van den Brink PJ. 2004. Comparison of laboratory single species and field population-level effects of the pyrethroid insecticide lambda cyhalothrin on freshwater invertebrates. Arch Environ Contam Toxicol 46: 324-335.

Sharifian I, Darvishzadeh A. 2015. Chemical composition and insecticidal efficacy of essential oil of Echinophora platiloba DC (Apiaceae) from Zagros foothills, Iran. Arthropods 4(2): 38-45.

Sheu SY, et al. 2013. Vogesella fluminis sp. nov., isolated from a freshwater river, and emended description of the genus Vogesella. International journal of systematic and evolutionary microbiology 63(8): 3043-9.

Shield K, Tippler C, Renshaw A, Wright IA. 2014. The invasive freshwater gastropods, Physa acuta and Potamopyrgus antipodarum: distribution in urban streams in the Georges River Catchment, in Vietz, G; Rutherfurd, I.D, and Hughes, R. (editors), Proceedings of the 7th Australian Stream Management Conference. Townsville, Queensland, Australia. pp 542-548.

Sims RW, Gerard BM. 1999. Earthworms. FSC Publications, London, UK.

Snelder DJ, Masipiquena MD, de Snoo GR. 2008. Risk assessment of pesticide usage by smallholder farmers in the Cagayan Valley (Philippines). Crop Prot 27(3-5): 747-762.

Solomon KR, Brock TCM, De Zwart D, Dyer SD, Posthuma L, Richards SM, Sanderson H, Sibley PK, Van den Brink PJ, eds. 2008. Extrapolation practice for ecotoxicological effect characterization of chemicals. CRC, Boca Raton, FL, USA.

Soumana IH, Linz B, Harvill ET. 2017. Environmental Origin of the Genus Bordetella. Frontiers in Microbiology 8(28).

Šporka F, Vlek HE, Bulánková E, Krno I. 2006. Influence of seasonal variation on bioassessment of streams using macroinvertebrates. In: The ecological status of European rivers: evaluation and intercalibration of assessment methods. Developments in hydrobiology 188: 543-555.

Subhash Y, et al. 2013. Vogesella alkaliphila sp. nov., isolated from an alkaline soil, and emended description of the genus Vogesella. International journal of systematic and evolutionary microbiology 63(6): 2338-43.

Suter GW, Cormier SM. 2015. Why care about aquatic insects: uses, benefits, and services. Integr Environ Assess Manage 11: 188-194.

Sumon K, Khanam Ritika A, Peeters E, Rashid H, Bosma R, Shahidur R M, Fatema M, Van den Brink P. 2018. Effects of imidacloprid on the ecology of sub-tropical freshwater microcosms (Barking, Essex: 1987). Environmental pollution 236: 432-441. 
Tapparo A, Giorio C, Marzaro M, Marton D, Solda L, Girolami V. 2011. Rapid analysis of neonicotinoid insecticides in guttation drops of corn seedlings obtained from coated seeds. J Environ Monit 13(6): 1564-8.

Teklu BM, Hailu A, Wiegant DA, Scholten BS, Van den Brink PJ. 2016. Impacts of nutrients and pesticides from small- and large-scale agriculture on the water quality of Lake Ziway, Ethiopia. Env Sci Pollut Res 25: 13207-13216.

Ter Braak CJ, Šmilauer P. 2018. Canoco Reference Manual and User's Guide: Software for Ordination (Version 5.1). Microcomputer Power, Ithaca, USA. pp 536 pp.

Thorne RSJ, Williams PW, Gordon C. 2000. The Macroinvertebrates of a Polluted Stream in Ghana. Journal of Freshwater Ecology 15(2): 209-217.

Thorne RSJ, Williams WP. 1997. The response of benthic macroinvertebrates to pollution in developing countries: a multimetric system of bioassessment. Freshwater Biology 37: 671-686.

Tomás JM. 2012. “The Main Aeromonas Pathogenic Factors.” Microbiology Article ID 256261, 22 pages.

Tomlin CDS. 2000. The Pesticide Manual (12 ${ }^{\text {th }}$ edn.) British Crop Protection Council, Farnham, UK.

Tscharntke T, Klein AM, Kruess A, Steffan-Dewenter I, Thies C. 2005. Landscape perspectives on agricultural intensification and biodiversity-ecosystem service management. Ecol Lett 8: 857-874.

UNDESA (United Nations Department of Economic and Social Affairs). 2017. World Population Prospects: The 2017 Revision, published by the UN Department of Economic and Social Affairs, New York, USA.

UNDESA (United Nations Department of Economic and Social Affairs). 2015. World Population Prospects, New York, USA.

UNFAO (United Nations Food and Agriculture Organisation). 2009. How to Feed the World in 2050, Rome, Italy.

USEPA (United States Environmental Protection Agency). 2018. ECOTOX User Guide: ECOTOXicology Knowledgebase System; U.S. EPA: Washington, DC, USA.

USEPA (United States Environmental Protection Agency). 2013. Aquatic Life Ambient Water Quality Criteria for Ammonia -Freshwater. EPA 822-R-13-001, United States Environmental Protection Agency, Washington, DC, USA.

USEPA/PFS (United States Environmental Protection Agency/Pesticide Facts Sheet). 1987. Mancozeb. Registration Standard. Office of Pesticides and Toxic Substances. Office of Pesticide Programs. Washington DC, USA.

USEPA (United States Environmental Protection Agency). 2020a. ECOTOX User Guide: ECOTOXicology Knowledgebase System; U.S. EPA: Washington DC, USA.

USEPA (United States Environmental Protection Agency). 2020b. CADDIS Volume 4 SSD Generator V1; U.S. EPA: Washington DC, USA.

USEPA (United States Environmental Protection Agency). 2012. Definition and Procedure for the Determination of the Method Detection Limit - Revision 1.11.Code for Federal Regulations, Title 40, Appendix B to Part 136. United States Environmental Protection Agency, Washington DC, USA.

USGS (United States Geological Survey). 2013. Water Properties: pH. In The USGS Water Science School, Colorado, USA. 
Van den Brink PJ. 2008. Ecological risk assessment: from book-keeping to chemical stress ecology. Environ Sci Technol 42: 8999 - 9004.

Van den Bosch H, Chaowen L, Pham Van Hoi, Ter Horst MMS, Van den Brink PJ, Yunliang P, Groenwold JG, Yibing C, Van Dung N, Van Wijk MS, Vlaming J. 2006. Environmental risks of pesticide use in intensive vegetable farming systems in periurban Hanoi (Dong Anh) and Chengdu (Pengzhou). Wageningen, The Netherlands: Alterra report 1285, $166 \mathrm{p}$.

Van den Brink PJ. 2008. Ecological risk assessment: From book-keeping to chemical stress ecology. Environ Sci Technol 42: 8999-9004.

Van den Brink PJ, Ter Horst MMS, Beltman WHJ, Vlaming J, Van den Bosch H. 2005. PRIMET version 1.0, manual and technical description. A decision support system for assessing pesticide risks in the tropics to man, environment and trade. Wageningen, The Netherlands: Alterra report 1185, $60 \mathrm{p}$.

Van den Brink PJ, Van Smeden JM, Bekele RS, Dierick W, De Gelder DM, Noteboom M Roessink I. 2016. Acute and chronic toxicity of neonicotinoids to nymphs of a mayfly species and some notes on seasonal differences. Environ Toxicol Chem 35: 128-133.

Van den Brink PJ, Blake N, Brock TCM, Maltby L. 2006. Predictive value of species sensitivity distributions for effects of herbicides in freshwater ecosystems. Human Ecol Risk Assess 12: 645-674.

Van den Brink PJ, Hattink J, Bransen F, Van Donk E, Brock TCM. 2000. Impact of the fungicide carbendazim in freshwater microcosms. II. Zooplankton, primary producers and final conclusions. Aquatic Toxicology 48: 251-264.

Van Horn E, Van Meter D. 1977. The implementation of intergovernmental policy. Policy studies review annual 1: 97-120.

Van Vlaardingen P, Traas TP, Aldenberg T. 2003. Normal distribution based hazardous concentration and potentially affected fraction. ETX-2000. Rijksinstituut voor Volksgezondheid en Milieu, Bilthoven, The Netherlands.

Van Wijngaarden RPA, Arts GHP. 2018. Is the Tier-1 Effect assessment for herbicides protective for aquatic algae and vascular plant communities? Environ Toxicol Chem 37: 175-183.

Van Wijngaarden RPA, Cuppen JGM, Arts GHP, Crum SJH, van den Hoorn MW, Van den Brink PJ, Brock TCM. 2004. Aquatic risk assessment of a realistic exposure to pesticides used in bulb crops: a microcosm study. Environ Toxicol Chem 23: 1479-1498.

Van Wijngaarden RP, Brock TC, Douglas MT. 2005a. Effects of chlorpyrifos in freshwater model ecosystems: the influence of experimental conditions on ecotoxicological thresholds. Pest Manag Sci 61: 923-935.

Van Wijngaarden RPA, Brock TCM, Van den Brink PJ. 2005b. Threshold levels for effects of insecticides in freshwater ecosystems: a review. Ecotoxicology 14: 355-380.

Van Wijngaarden PA, Maltby L, Brock TCM. 2015. Acute tier-1 and tier-2 effect assessment in the new EFSA Aquatic Guifdance Document. Pest Manag Sci 71: 1059-1067.

Vijver MG, Hunting ER, Nederstigt TAP, Tamis WLM, van den Brink PJ, van Bodegom PM. 2017. Postregistration monitoring of pesticides is urgently required to protect ecosystems. Environ Toxicol Chem 36: 860-865. 
Vito M. Butardo Jr. Sreenivasulu N. 2016. Chapter Two - Tailoring Grain Storage Reserves for a Healthier Rice Diet and its Comparative Status with Other Cereals. Int Rev of Cell and Molecular Biology 323: 31-70.

Wang HT, Wang T, Zhang BR, Li FT, Brahima T, Omosa IB, Chiramba T, Abdel-Monem M, Pradhan M. 2013. Water and wastewater treatment in Africa: current practices and challenges. Clean Soil Air Water 42: 1029-1035.

WAAPP (West Africa Agricultural Productivity Programme). 2014. Annual Report. Accra, Ghana, p. 129.

WHO (World Health Organization). 2004. The Impact of Pesticides on Health: Preventing Intentional and Unintentional Deaths from Pesticide Poisoning. Pesticides and Health. Facts

WHO/UNEP (World Health Organization/United Nations Environment Programme). 1990. Public Health impacts of pesticides used in agriculture. Geneva: WHO, 1990. Pp 85-86.

WHO (World Health Organization). 2004a. Guidelines for drinking-water quality vol 1: Recommendations, 3rd edn. World Health Organization, Geneva.

WHO (World Health Organization). 2004b. Water, sanitation and hygyiene links to health: factsand figures, updated November 2004. WHO, Geneva, 2004. WHO - World Health Organization, 2008. Guidelines for drinking-water quality, Vol.1, Recommendations (3rd Ed). Geneva. ISBN 978924154761 1. p. 668.

Willems A, De Vos P. 2006. Comamonas. In: Dworkin M., Falkow S., Rosenberg E., Schleifer KH., Stackebrandt E. (eds) The Prokaryotes. Springer, New York, NY.

Williamson S, Ball A, Pretty J. 2008. Trends in pesticide use and drivers for safer pest management in four African countries. Crop Protection 27: 1327- 1334.

Wilson C, Tisdell C. 2001. Why farmers continue to use pesticides despite environmental, health and sustainability costs. Ecol Econ 39: 449.

Wiratno W, Taniwiryono D, Van den Brink PJ, Rietjens I, Murk A. 2007. A case study on Bangka Island, Indonesia on the habits and consequences of pesticide use in pepper plantations. Environmental toxicology 22: 405-14.

Wisconsin Department of Natural Resources, 1996. Analytical Detection Limit Guidance \& Laboratory Guide for Determining Method Detection Limits. Laboratory Certification Program. Wisconsin Department of Natural Resources, Wisconsin, USA.

Xu D, Wang L, Wang G, Zheng S. 2016. Domibacillus antri sp. nov., isolated from the soil of a cave. International Journal of Systematic and Evolutionary Microbiology 66(1): 2502-2508.

Zafar MI, Van Wijngaarden RP, Roessink I, Van den Brink, PJ. 2011. Effects of time-variable exposure regimes of the insecticide chlorpyrifos on freshwater invertebrate communities in microcosms. Environ Toxicol Chem 30: 1383-1394.

Zámečník R. 2014. The measurement of employee motivation by using multi-factor statistical analysis. Procedia - Social and Behavioral Sciences 109: 851 - 857.

Zhang W, Ricketts TH, Kremen C, Carney K, Swinton SM. 2007. Ecosystem services and dis-services to agriculture. Ecol Econ 64: 253-260.

Zhang W. 2018. Global pesticide use: profile, trend, cost/benefit and more. Proc Int Acad Ecol Environ Sci 8(1): 1-27. 
Zhang WJ, Jiang FB, Ou JF. 2011. Global pesticide consumption and pollution: with China as a focus. Proceedings of the International Academy of Ecology and Environmental Sciences 1(2): 125-144.

Zhu B, Wang G, Xie G, Zhou Q, Zhao M, Praphat K, Li B, Tian W. 2010. Enterobacter spp.: A new evidence causing bacterial wilt on mulberry Sci China Life Sci 53: 292.

Zhu YC, Yao J, Adamczyk J, Luttrell R. 2017. Synergistic toxicity and physiological impact of imidacloprid alone and binary mixtures with seven representative pesticides on honey bee (Apis mellifera). PLoS One 12(5): e0176837. 


\section{Summary}

Pesticides are broadly applied in current agriculture practices globally and may end up in interconnected water bodies i.e. ditches, ponds, and lakes via numerous routes such as spray drift, runoff and leaching. Given the fact that they are inherently designed to harm biota, pesticides may pose risks to a range of aquatic and terrestrial organisms. Non-target organisms may be exposed to pesticide contaminants. In Ghana, the legal procedure for pesticide registration is prescribed by Part II (Pesticides Control and Management) of Environmental Protection Agency Act, 1994 (Act 490), however the registration is based on international data and prospective risk assessment. This thesis aimed to evaluate whether registered pesticide use in Ghana harms the environment (aquatic and terrestrial).

In Chapter 1, a general introduction to the thesis is presented, taking into consideration contemporary issues of pesticides globally and narrowing it down to Ghana. An overview of the pesticide law in Ghana is presented as well as a brief description of the evaluation procedure as well as reported environmental impacts, occupational health effects and the populations at risk. The overall aim of the thesis is presented including the research objectives. It concludes with the outline of the thesis.

Chapter 2, reviews Ghana's pesticide policy by providing an overview of the pesticide regulatory policy framework (pesticide law) and the pesticide registration and licensing procedure and presents a theoretical framework (evaluation model) for the study. The main part of the study deals with how the policy has performed overtime. First, the farmers' pesticide use in day-to-day farm practices and distribution of pesticides in the country were discussed, in relation to the policy and also the interactions of state and non-state actors. The results indicated that pesticides were registered in compliance with the law. Non-state actors scored low with respect to their mandate which likely resultes in environmental and human health risks. Significant association existed between educational level attained and knowledge on pesticide use. Work experience or duration of farming also significantly influenced the knowledge of respondents $(P<0.001)$, as well as attitude $(P<0.05)$, while state actors were not motivated and resourced. It was recommended that a preliminary risk assessment be performed to the aquatic 
environment, to derive threshold levels which are protective of communities, to screen farmers for pesticide exposure and poisoning, to develop well-targeted training programmes for pesticide retailers and farmers on pesticide use, personal protective device use, as well as pesticide management and law. Additionally, pesticide policy implementers were to be motivated and resourced to carry out their mandate i.e. to execute the pesticide legislation.

In Chapter 3 we used the PRIMET model ( $1^{\text {st }}$ Tier) to assess the risk of pesticides to the aquatic and terrestrial environment using empirically gathered field data on pesticide use. Results from $1^{\text {st }}$ tier showing risk were then further refined using the SSD model $\left(2^{\text {nd }}\right.$ tier) to estimate pesticide concentration levels protective of the aquatic environment. Results of PRIMET indicated that in the investigated regions in south Ghana, lambda cyhalothrin, chlorpyrifos, mancozeb and maneb may pose the highest risks to aquatic ecosystems adjacent to the treated fields, butachlor and carbendazim to the terrestrial soil ecosystem, lambda cyhalothrin, chlorpyrifos, emamectin benzoate, imidacloprid, thiamethoxam, dimethoate and cypermethrin to bees and propanil, oxyfluorfen, lambda cyhalothrin, imidacloprid and copper hydroxide to terrestrial non-target arthropods. Actual pesticide use was 1.3 to 13 times higher than the recommended label instructions, indicating a general practice of overdosing. For protectiveness, the $1^{\text {st }}$ tier PNEC was protective in all cases of insecticides for invertebrates and vertebrates compared to $2^{\text {nd }}$ tier HC5. The case study showed that the PRIMET model in combination with the SSD concept may offer pesticide registration authorities in Ghana a means to assess environmental risks associated with pesticide usage in a user-friendly and cost-effective manner.

Chapter 4 describes the approach to using a variety of techniques in determining the exposure of water bodies to pollutants including fertilizers, pesticides and other waste. This involved the sampling and analysis of water samples from locations with known human activity and testing for the presence or otherwise of the probable pollutants envisaged in the areas from an earlier survey. This is linked to the physico-chemical characteristics of the samples from various locations as well as the identified macroinvertebrates. Generally, the water was not polluted per the physico-chemical characteristics except isolated cases of low pH level and pesticide concentrations ( $\lambda$-cyhalothrin and cypermethrin). The results from the pesticides were 
however not included in the analysis due to the low level of detections. The presence of the few detected could be from agricultural pollution mainly from recent application and run offs though it may likely affect other organisms. The results showed that the environmental variables can potentially be analysed to monitor the ecological status of aquatic ecosystems in ecological assessment practices and may also be used to develop new practices for biodiversity conservation that aims at preserving both the taxonomic and functional diversity in Ghana.

The goal of chapter $\mathbf{5}$ was to investigate the potential effects of pesticides on the abundance and diversity of soil bacteria in irrigated rice field and to isolate bacteria capable of degrading diverse classes of pesticides used in these fields. The results showed an overall decrease in bacterial abundance and diversity in areas exposed to pesticides. Operational taxonomic units of the genera Enterobacter, Aeromonas, Comamonas, Stenotrophomonas, Bordetella, and Staphylococcus decreased in areas exposed to pesticides, which may impair degradation of organic compounds, plant growth, and plant protection from microbes and insects. Conversely, Domibacillus, Acinetobacter, Pseudomonas, and Bacillus increased in abundance in pesticide-exposed areas. Simpson and Shannon diversity indices and canonical correspondence analysis demonstrated a decrease in both aerobic and anaerobic bacterial diversity and community composition in areas exposed to pesticides. Concluding, a need for alternative ways in improving agricultural productivity and to educate and encourage farmers to adopt innovative integrated pest management strategies to reduce deleterious impacts of pesticides on soil ecosystems has been proposed.

Chapter 6 is the general discussion and conclusion of the overall thesis. It looked at the pesticide law as it pertains now and its implementation challenges, and related to the ecological risks identified in this thesis. Solutions to these challenges are prescribed through published open literature and suggestions from the field surveys and observations and conclusions are drawn for all the results presented in this thesis. 


\section{Acknowledgements}

Opportunity, they say come but once! This is indeed true when it comes to my academic carrier. Clearly, I had nurtured the desire to do a PhD but would not have made it without help and support of many people. First of all, I would like to express my heart felt gratitude to Prof. dr ir Paul van den Brink for his effort, valuable and constructive suggestions and for supporting me whole heartedly from the beginning until the end. Paul, thank you for giving me this rare opportunity. You introduced me generously to your wide network and your supervising approach fostered independent research and creativity. Thank you for listening to my oral presentation when I had the opportunity of meeting up with you albeit short notice and the enthusiasm you showed deserves commendation. I am indebted to Huub Stoetzer who introduced me to the Aquatic Ecology and Water Quality Management department and Floor Peeters who linked me to Paul. I had only come to Wageningen for 3 weeks for a short course on Integrated Pest Management and Food Safety but in addition I left with the assurance of doing a PhD.

To my co-promoter: Dr. Jonathan Hogarh, thank you for all your comments and suggestions. They always helped me to look at issues from another perspective. I would also like to extend my gratitude to different people who made this journey better. Mengistie, thank you for coming and helping me with social science aspects of the study. It was great to have such an insightful and supportive assistance from you. Alex, I am so happy you were here and helped me get that social science work moving! Isaac and Joan, thank you for assisting me in the various surveys, sampling and data collection and taking interest in my work back in Ghana. Prof. OfosuAnim, thank you for your interest, encouragement and invaluable contributions.

To my stress group, I am grateful our fates coincided and that we got to spend all this time together. Mazhar, thank you for being there, thank you for receiving me and taking me round Wageningen to get settled. Berhan, you supported me with statistical analysis. I enjoyed spending time with you: Noel, Darya, Jacqui, Concillia, Andreu, Jugk, Zhang, Fengjiao - thanks for the fun memories, I am happy to have spent time with you all. 
It cannot go without mentioning the support of Prince, Ansah, Bright (Ecological Laboratory) and Bashara (Centre for Remote Sensing and Geographic Information Services) of the the University of Ghana, Legon for their assistance with the laboratory work, analysis and sampling site maps. Similarly, my gratitude goes to Paul of Ghana Standards Authority in assisting with the analysis of pesticides.

I would also like to extend my gratitude to Dr. Charles Darkoh, Kim, Kadiatu and Jessica of University of Texas Health Science Center at Houston, School of Public Health Department of Epidemiology, Human Genetics, and Environmental Sciences. My stay in Houston was really fulfilling considering your interest in my work on bacterial abundance and diversity. Thank you for your valuable insight and contributions.

To my colleagues at work (Ghana EPA): Ebenezer, Sam, Emmanuel, Joseph, Hasford, Edmund, Lovelace, Abena, Baaba and Kafui I say thank you for your interest and support!

Finally, the biggest casualty of living with a PhD sandwich student must be the partner, in my case my dear wife Nana Domtie. Nana, forgive me for making you endure endless PhD rants about issues, which, to a non-PhD, may seem not necessary and minor. You have always had the patience to listen to my complaints, and have always supported and helped me put things in order, and not allowing me to dwell on minor issues for too long. Thank you for taking care of our daughters when am out in the fields, or out of the country and house during all those long days I was busy with my official work or PhD. I am excited to see where life takes us next!

\section{Michael Onwona-Kwakye}

Wageningen University

June, 2020 
Addendum 


\section{Curriculum Vitae}

Michael Onwona-Kwakye was born (1970) and raised in Accra, Ghana. I obtained my primary and secondary education with a strong emphasis in science. I studied Agricultural Science at the University of Ghana-Legon from 1994 to 1998. I majored in crop science focusing my dissertation on, Identification and Partial Characterization of Cassava Mosaic Virus Prevalent in Ghana. After obtaining my BSc in 1998, I worked with the Ministry of Food and Agriculture of the Accra Metropolitan Assembly as a field staff. A year later I enrolled at the University of GhanaLegon to study Master degree (MPhil) in Environmental Science. During the studies my thesis was on environmental impact assessment, investigating and monitoring the effect of effluent from Barima fuel service center (Mallam - Accra) on a swampy land and auditing of some fuel service stations in Accra - Tema metropolitan areas of Ghana. I was employed by the Ghana Environmental Protection Agency, the same year that I completed my Master's degree (2002).

I was subsequently attached to the Chemicals Control and Management Center (CCMC) of the agency from where I was trained at Pesticide Safety Directorate in the United Kingdom to manage chemicals and register pesticides. After exploring the life of pesticide registration and chemicals management for over 10 years I enrolled as a sandwich student to do my PhD project in the Aquatic Ecology and Water Quality Management group at Wageningen University under the supervision of Paul van den Brink. This thesis is the product of more than 6 years' worth of research on environmental risks associated with pesticide use in Ghana. I will continue doing research on pesticide impacts on global ecosystems and hopes to develop mitigation and management actions that ensure the sustainability of natural resources. I also work at the National Pzone Unit (NOU) of Ghana, as part of a team implementing Ghana's obligation under the Montreal Protocol). My free time is usually spent on walks with the family, watching movies with my daughters, travelling to the village where my kinsmen are, as well as reading and attending to the family business. 


\section{Publications}

\section{Refereed Scientific Publications}

Onwona Kwakye M, Hogarh JN, Van den Brink PJ. 2020. Environmental risk assessment of pesticides currently applied in Ghana. Chemosphere 254, 126845.

https://doi.org/10.1016/j.chemosphere.2020.126845

Onwona Kwakye M, Paris-Plants K, Keita K, Lee J, Van den Brink PJ, Hogarh JN, Darkoh C. 2020. Pesticides Decrease Bacterial Diversity and Abundance of Irrigated Rice Fields. Microorganisms 8, 318. https://doi.org/10.3390/microorganisms8030318

Onwona Kwakye M, Mengistie B, Ofosu-Anim J, Tetteh Nuer, AK, Van den Brink, PJ. 2019. Pesticide registration, distribution and use practices in Ghana. Environment, Development and Sustainability 21, 2667-2691. https://doi.org/10.1007/s10668-018-0154-7

\section{To be submitted/Ready}

Onwona Kwakye M, Feng-Jiao P, Hogarh JN, Van den Brink PJ. Linking macroinvertebrates and physico- chemical parameters for water quality assessment in the lower basin of the Volta River in Ghana. 
List of publications 


\section{Colophon}

Thesis and cover layout: Michael Onwona-Kwakye

Printing: ProefschriftMaken.nl

Financial support from Aquatic Ecology and Water Quality Management for printing this thesis is gratefully acknowledged. 